\title{
FIELD INVESTIGATION OF STREAM-AQUIFER INTERACTIONS: A CASE STUDY IN COASTAL CALIFORNIA
}

\author{
A Thesis \\ presented to \\ the Faculty of California Polytechnic State University, \\ San Luis Obispo
}

In Partial Fulfillment

of the Requirements for the Degree

Master of Science in Forestry Sciences

by

Devin Pritchard-Peterson

June 15, 2018 
(C) 2018

Devin Pritchard-Peterson

ALL RIGHTS RESERVED 
COMMITTEE MEMBERSHIP

TITLE: Field Investigation of Stream-Aquifer Interactions:

A Case Study in Coastal California

AUTHOR: Devin Pritchard-Peterson

DATE SUBMITTED: June 2018

COMMITTEE CHAIR: Dr. Bwalya Malama, Ph.D.

Professor of Groundwater and Soil Physics

COMmittee Member: Dr. Christopher Surfleet, Ph.D.

Professor of Hydrology and Watershed Management

COMMITTEE MEMBER: Dr. Brian Dietterick, Ph.D.

Director, Swanton Pacific Ranch 


\section{ABSTRACT}

Field Investigation of Stream-Aquifer Interactions: A Case Study in Coastal California

\section{Devin Pritchard-Peterson}

This study is a detailed investigation of the dynamic interaction between a stream and an alluvial aquifer at Swanton Pacific Ranch in the Scotts Creek watershed in Santa Cruz County, California. The aquifer is an important source of groundwater for cropland irrigation and for aquatic ecosystem support. The potential for groundwater pumping to deplete Scotts Creek stream flows is a source of serious concern for land managers, fisheries biologists, and regulatory agencies due to the presence of federally protected steelhead trout (Oncorhynchus mykiss) and coho salmon (Oncorhynchus kisutch). An understanding of the interaction between the stream and pumped aquifer will allow for assessment of the impacts of groundwater extraction on stream flows and is essential to establishing minimum instream flow requirements. This will aid in the development of sustainable groundwater pumping practices that meet agricultural and ecological needs. Based on findings from studies conducted in similar hydrogeologic settings and Scotts Creek stream survey reports filed by the California Department of Fish and Wildlife, we hypothesized that the stream is directly connected to the aquifer and that abstraction of groundwater from agricultural wells has a measurable impact on Scotts Creek stream flows, particularly during the summer low-flow period. We tested this hypothesis by employing a multi-scale approach combining multiple measurement techniques. Results of field investigations, including extensive direct push subsurface sampling, constant rate pumping tests, dye tracer tests, electrical resistivity interrogation of the subsurface, and long-term passive monitoring of aquifer hydraulic heads and stream stage, are reported. Additionally, results of laboratory falling-head permeameter tests and particle size analyses of aquifer sediments, and numerical groundwater flow modeling (MODFLOW) are presented. Findings indicate that the permeable subsurface formation tapped by irrigation wells is a leaky semi-confined aquifer, overlain by a thin and laterally discontinuous very low-permeability aquitard of silt and clay above which lies Scotts Creek. The aquitard reduces the hydraulic connection between the stream and pumped aquifer resulting in a low and steady streamflow depletion rate over the short term. These results are particularly useful to land managers responsible for sustainable groundwater abstraction from wells that tap into the aquifer. Calculations of stream depletion rate based on aquifer hydraulic 
parameters and well pumping rates are included to allow land managers to conveniently modify groundwater abstraction practices, minimizing concerns of streamflow depletion. The conclusions presented herein are based on the results of a two year study. Stresses imposed by changes in climate and water resource needs should be examined with rigorous science to determine appropriate management strategies. Additional research, including improvement of the numerical groundwater flow model's representation of the natural system, supplementary subsurface investigations, and continued long-term measurement of groundwater levels, is needed to further quantify the degree of streamaquifer connectivity and to ensure continued sustainable groundwater management. 


\section{ACKNOWLEDGMENTS}

This research project was a collaborative effort between Cal Poly students and faculty, and Swanton Pacific Ranch staff. Funding for the research was provided by the California State University Agricultural Research Initiative (ARI). I would first like to thank my advisor, Dr. Bwalya Malama, for his great sense of humor, relaxed and positive attitude, and above all, his guidance and support throughout the process of conducting this research. I feel incredibly fortunate to have been mentored by an individual with such a high level of expertise in groundwater hydrology. I would especially like to thank Dr. Christopher Surfleet for contacting me about this master's thesis opportunity and for his assistance with data collection and analysis. Dr. Brian Dietterick also deserves recognition for initiating the project and for his efforts to ensure the sustainable use and management of water resources in the Scotts Creek watershed. Special thanks to Dr. John Jasbinsek for his time and assistance with the geophysical data collection and analysis. Finally, thank you to all of the individuals who contributed to the project in one way or another and made it possible including Grant Williams, Steve Auten, Cortney Newby, Ian Kapostins, Ben Cook, James Solum, Mary Hillis, Dr. Ronald Taskey, Craig Stubler, Jeff Reimer, Lisa Wallravin, Espie Wilkinson, and Sue Tonik. 


\section{TABLE OF CONTENTS}

Page

LIST OF TABLES ...................... ix

LIST OF FIGURES . . . . . . . . . . . . . . . . . xi CHAPTERS

1 INTRODUCTION . . . . . . . . . . . . . . . . . . . . 1

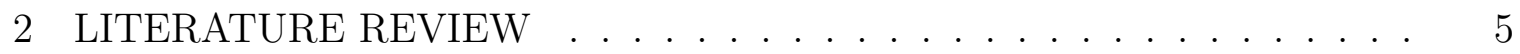

2.1 Overview . . . . . . . . . . . . . . . . . 5

2.2 Fundamentals of Groundwater-Surface Water Interactions . . . . . . . 5

2.2.1 Exchanges Between Groundwater and Surface Water . . . . 5

2.2.2 Effects of Groundwater Abstraction on Streamflow . . . . . 7

2.2.3 Hydraulic Properties of the Subsurface and Streambed . . . 10

2.2.3.1 Storage Parameters . . . . . . . . . . . . . . . 11

2.2.3.2 Transmission Parameters . . . . . . . . . . . 12

2.2.3.3 Additional Parameters . . . . . . . . . . . . . . . 15

2.3 Methods for Measuring Streamflow Depletion . . . . . . . . . . . 16

2.3.1 Direct Measurement of Water Flux . . . . . . . . . . . . 16

2.3.2 Heat Tracer Methods . . . . . . . . . . . . . . . . . . . . 17

2.3.3 Particle Size Analysis and Hydraulic Tests . . . . . . . . . 18

2.3.4 Mass Balance Approaches . . . . . . . . . . . . . . . 20

2.4 Modeling Groundwater-Surface Water Interactions . . . . . . . . . . 21

2.4.1 Analytical Models . . . . . . . . . . . . . . . . . . . . . 22

2.4.1.1 Confined Aquifer Models . . . . . . . . . . . . . . 22

2.4.1.2 Unconfined Aquifer Models . . . . . . . . . . . . . 23

2.4.1.3 Limitations of Analytical Models . . . . . . . . . . 24

2.4 .2 Numerical Models . . . . . . . . . . . . . . . . . . . . . . . 24

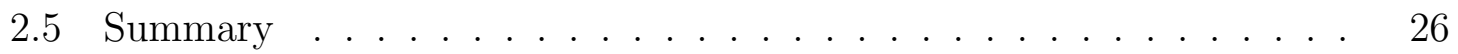

3 DESCRIPTION OF STUDY AREA . . . . . . . . . . . . . . . 28

3.1 Location and Biophysical Environment . . . . . . . . . . . 28

3.2 Development of Lower Scotts Creek Groundwater

Resources . . . . . . . . . . . . . . . . . . . 31

3.3 The Lower Scotts Creek Instream Flow Controversy . . . . . . . . . . 34

4 EXPERIMENTAL APPROACH AND MODELING . . . . . . . . . 37

4.1 Field Investigations $\ldots \ldots \ldots \ldots$ 
4.1 .1 Exploratory Borehole Drilling . . . . . . . . . . . . . . . 37

4.1 .2 Piezometer Installation . . . . . . . . . . . . . . . . . . . . . 42

4.1 .3 Pumping Tests . . . . . . . . . . . . . . . . . . . 47

4.1 .4 Dye Tracing . . . . . . . . . . . . . . . . . . . . . 57

4.1 .5 Geophysical Surveys . . . . . . . . . . . . . . . . . 63

4.2 Laboratory Measurement of Hydraulic Conductivity . . . . . . . . . 67

4.2 .1 Permeameter Tests . . . . . . . . . . . . . . . . . . . 67

4.2.2 Particle Size Analysis . . . . . . . . . . . . . . . . . . . . 75

4.3 Analysis of Pumping Tests . . . . . . . . . . . . . . . . . 83

4.3.1 Estimation of Aquifer Hydraulic Properties . . . . . . . . . . . 83

4.3.2 Calculation of Streamflow Depletion _. . . . . . . . . . 95

4.4 Groundwater Flow Modeling . . . . . . . . . . . . . . . . . . . . . . . 99

4.4 .1 Model Construction . . . . . . . . . . . . . . . . . . . . . . . 101

4.4 .2 Model Calibration . . . . . . . . . . . . . . . . . . 107

5 RESULTS AND DISCUSSION . . . . . . . . . . . . . . . . 111

5.1 Aquifer Characterization . . . . . . . . . . . . . . . . . . 111

5.1 .1 Geometry and Lithology . . . . . . . . . . . . . . . 111

$5.1 .2 \quad$ Hydraulic Properties . . . . . . . . . . . . . . . . . . . 113

5.2 Quantification of Stream-Aquifer Connectivity . . . . . . . . . 116

5.2 .1 Groundwater Flow Modeling . . . . . . . . . . . . . . . 116

5.2.2 Long-term Groundwater Monitoring . . . . . . . . . . . . . 120

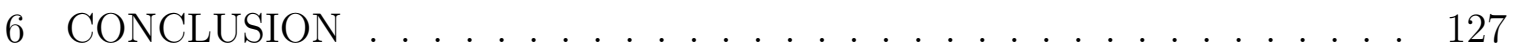

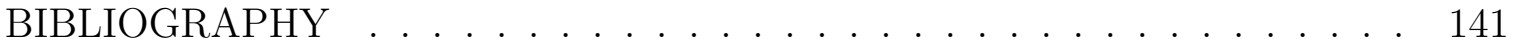

APPENDICES

A Well Completion Reports . . . . . . . . . . . . . . . . . . . . . . 142

B Exploratory Borehole Drilling Logs . . . . . . . . . . . . . . . . . 147

C Piezometer Installation . . . . . . . . . . . . . . . . . . . . 157

D Pumping Tests . . . . . . . . . . . . . . . . . . . . 158

E Dye Tracing . . . . . . . . . . . . . . . . . . . . . . . 161

F Permeameter Tests . . . . . . . . . . . . . . . . . . . . 163

G Particle Size Analysis . . . . . . . . . . . . . . . . . . . . . . . 170

H Calculation of Streamflow Depletion . . . . . . . . . . . . . 184

I Groundwater Flow Modeling . . . . . . . . . . . . . . . . . 186 


\section{LIST OF TABLES}

4.1 Elevation (feet AMSL), depth to water, total depth, and height of the riser (above ground surface) of each piezometer and each irrigation well. Static water levels in riparian piezometers and irrigation wells were measured August 16, 2017. Static water levels in instream piezometers were measured August 6, 2016. All measurements in feet from top of PVC/steel casing. Dash (-) indicates data are either not available or not applicable. . . . . . . . . . . . . . . . .

4.2 Summary of maximum drawdown and lag time measured in piezometers and observation wells during pumping tests, as well as the linear distance from the pumping well to each piezometer and each observation well. . . . . . . . . . . . . . . . . . . . .

4.3 Location, length, and orientation of each ERT survey. . . . . . . . . 65

4.4 Typical values of saturated hydraulic conductivity $(K)$ for unconsolidated geologic materials of different texture (adapted from Hillel, 2003). . . . . . . . . . . . . . . . . . .

4.5 Summary of saturated hydraulic conductivity $(K)$ values for sediments from EB-1 -4 determined using falling-head permeameter method. . .

4.6 Summary of results of the particle size analysis for sediments from EB-1 -4. The particle size parameters included in the table were determined from individual particle size distribution curves. The $d_{10}, d_{50}$, and $d_{60}$ values are in mm. . . . . . . . . . . . . . . . . . . .

4.7 Summary of hydraulic conductivity $(K)$ values in $\mathrm{m} / \mathrm{s}$ for sediments from EB-1 -4 estimated using the empirical methods of Hazen and Kozeny-Carman. . . . . . . . . . . . . . . . . .

4.8 Summary of hydraulic parameter estimates produced by curvematching the Theis (1935) and Cooper and Jacob (1946) solutions to time-drawdown data in AQTESOLV. . . . . . . . . . . . . .

4.9 Summary of hydraulic parameter estimates produced by curve-matching the Hantush and Jacob (1955) solution to time-drawdown data in AQTESOLV. . . . . . . . . . . . . . . . .

4.10 Estimated rate of stream depletion expressed as a fraction of the well discharge rate $\left(Q_{r} / Q\right)$ at various times $(t)$ since pumping began for

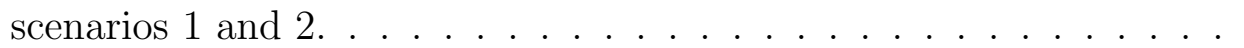


4.11 Head-stage and bottom elevation in meters of nodes along the boundaries of the MODFLOW model. Dash (-) indicates data are not applicable. . . . . . . . . . . . . . . . . . 106

5.1 Comparison of hydraulic conductivity $(K)$ values in $\mathrm{m} / \mathrm{s}$ for each alluvial layer estimated using sediment particle size distributions, falling-head permeameter tests, and constant rate pumping tests. Dash $(-)$ indicates data are not available. . . . . . . . . . . . . . . . . . 114

5.2 Flow budget data in $\mathrm{m}^{3} / \mathrm{d}$ for all grid cells for time step 10 summarized by simulation. . . . . . . . . . . . . . . . . . . . . . . 117 


\section{LIST OF FIGURES}

2.1 Common flow regimes between groundwater and surface water (excerpted from Brunner et al., 2011) . . . . . . . . . . . . . .

2.2 Schematic of the dynamics of the hyporheic zone at a riffle-pool-sequence (excerpted from Kalbus et al., 2006). . . . . . . . . . . . . . .

2.3 Relationship between sources of pumped groundwater for a hypothetical well. As pumping time increases, streamflow becomes the dominant source of water discharged from the well (excerpted from Barlow and Leake, 2012).

2.4 Hydraulic conductivity of selected consolidated and unconsolidated geologic materials (excerpted from Heath, 1983). . . . . . . . . . . .

3.1 The study location at Swanton Pacific Ranch in the Scotts Creek watershed, Santa Cruz County, California. . . . . . . . . . . . .

3.2 Head $(\mathrm{m})$ in VFD Well under normal pumping conditions (July 18-24, 2016).

3.3 Head $(\mathrm{m})$ in Pump House Well under normal pumping conditions (August 15-21, 2016).

3.4 Head ( $\mathrm{m}$ ) in Archibald Well under normal pumping conditions (July 11-17, 2016).

4.1 The locations where exploratory boreholes were drilled on lower Scotts Creek.

4.2 (a): The AMS PowerProbe 9120-RAP used to drill exploratory boreholes and to install piezometers, and; (b): EB-1 sediments collected from 0 (top) to 24 (bottom) feet.

$4.3 \log$ of boring EB-1. . . . . . . . . . . . . . . .

4.4 The locations of irrigation wells, riparian piezometers, and instream piezometers on lower Scotts Creek. . . . . . . . . . . . . .

4.5 (a): Riparian piezometer equipped with an INW PT2X Smart Sensor for continuous monitoring of groundwater levels, and; (b): Instream piezometer equipped with a HOBO U20L Water Level Logger for continuous measurement of stream stage. . . . . . . . . . . 
4.6 Head (cm) in PHP-1 over one week period (August 30-September 6, 2016). The data clearly shows the diurnal fluctuations in groundwater levels as a result of evapotranspiration by phreatophytes. . . . . . . 45

4.7 VFD Well pumping test flow rate (gpm). . . . . . . . . . . . . . 48

4.8 Head $(\mathrm{m})$ in VFD Well during pumping test. . . . . . . . . . . . . . 48

4.9 Pump House Well pumping test flow rate (gpm). . . . . . . . . . . . 49

4.10 Head (m) in Pump House Well during pumping test. . . . . . . . . . 50

4.11 Drawdown $(\mathrm{cm})$ in VFDP-1 during VFD Well pumping test. . . . . 52

4.12 Drawdown $(\mathrm{cm})$ in VFDP-2 during VFD Well pumping test. . . . . 52

4.13 Drawdown $(\mathrm{cm})$ in VFDP-4 during VFD Well pumping test. . . . . 53

4.14 Drawdown (cm) in PHP-1 during Pump House Well pumping test. . 53

4.15 Drawdown $(\mathrm{cm})$ in PHP-2 during VFD Well pumping test. . . . . . 54

4.16 Drawdown (cm) in PHP-4 during Pump House Well pumping test. . 54

4.17 Normalized stream stage (cm) recorded 29 July-11 August, 2016.

Rectangle indicates time period during which pumping tests occurred. 55

4.18 Drawdown $(\mathrm{m})$ in Archibald Well during Pump House Well pumping test. . . . . . . . . . . . . . . . . . 55

4.19 Drawdown (m) in Pump House Well during VFD Well pumping test. 56

4.20 Drawdown (m) in VFD Well during Pump House Well pumping test. 56

4.21 Drawdown $(\mathrm{m})$ in Queseria Well during VFD Well pumping test. . . 57

4.22 Concentration of Rhodamine dye (ppb) in Scotts Creek prior to and during the VFD Well pumping test. Rectangle indicates time period during which pumping occurred. Gaps in the data are a result of dye injection issues encountered during the test. . . . . . . . . . . . . 59

4.23 Comparison of typical (smooth line) and atypical (dashed line) time-concentration curves of slug dye injections. . . . . . . . . . 62

4.24 Stream discharge (cfs) calculated from slug dye injection timeconcentration curves. Rectangle indicates time period during which pumping occurred and dashed line shows data trend. . . . . . . . . . 62

4.25 The locations where ERT surveys were performed on lower Scotts Creek. 64

4.26 The two-dimensional (2D) resistivity models for the subsurface for data obtained from the ERT surveys completed on lower Scotts Creek. Survey S2E (top) was performed near the VFD Well and parallel to the stream channel while surveys S3E (middle) and S4E (bottom) were performed between Scotts Creek and Swanton Road, and perpendicular and parallel to the stream channel, respectively. . . . . . . . . . . 65

4.27 Typical ranges of resistivities of consolidated and unconsolidated geologic materials (excerpted from Palacky, 1988). . . . . . . . . 66

4.28 Flow test data showing change in head (psi) over time (minutes) for a single experimental run on sediments from 12-14 foot interval of EB-1. 69

4.29 Falling-head permeameter setup. . . . . . . . . . . . . . 70

4.30 Schematic of falling-head permeameter setup. . . . . . . . . . . 71 
4.31 Plot of flow test data with linear fit for a single experimental run on sediments from 12-14 foot interval of EB-1. . . . . . . . . . . . . .

4.32 Saturated hydraulic conductivity $(K)$ in $\mathrm{m} / \mathrm{s}$ at depth $(\mathrm{ft})$ for sediments from EB-1 determined using falling-head method. . . . . . . . . . . .

4.33 Common conventional schemes for the classification of inorganic solid particle fractions of unconsolidated geologic materials on the basis of particle diameter ranges (excerpted from Hillel, 2003). . . . . . . . .

4.34 Schematic of typical particle size distribution curves for various types of unconsolidated geologic materials (excerpted from Hillel, 2003).

4.35 Particle size distribution for sediments from the 4-8 foot interval (surficial aquifer) of EB-1.

4.36 Particle size distribution for sediments from the 16-20 foot interval (semipervious layer) of EB-1.

4.37 Particle size distribution for sediments from the 20-24 foot interval (deep aquifer) of EB-1.

4.38 Estimation of aquifer properties by matching the Theis (1935) curve to time-drawdown data collected in Pump House Well during VFD Well pumping test.

4.39 Estimation of aquifer properties by matching the Theis (1935) curve to time-drawdown data collected in Queseria Well during VFD Well

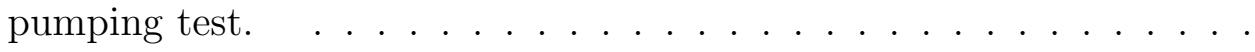

4.40 Estimation of aquifer properties by matching the Theis (1935) curve to time-drawdown data collected in VFD Well during Pump House Well pumping test.

4.41 Estimation of aquifer properties by matching the Cooper and Jacob (1946) straight-line solution to time-drawdown data collected in Pump House Well during VFD Well pumping test. . . . . . . . . . . . . . .

4.42 Estimation of aquifer properties by matching the Cooper and Jacob (1946) straight-line solution to time-drawdown data collected in Queseria Well during VFD Well pumping test. . . . . . . . . . . .

4.43 Estimation of aquifer properties by matching the Cooper and Jacob (1946) straight-line solution to time-drawdown data collected in VFD Well during Pump House Well pumping test. . . . . . . . . . . . . .

4.44 Estimation of aquifer properties by matching the Hantush and Jacob (1955) curve to time-drawdown data (log-log axes) collected in Pump House Well during VFD Well pumping test. . . . . . . . . . . . . . .

4.45 Estimation of aquifer properties by matching the Hantush and Jacob (1955) curve to time-drawdown data (log-log axes) collected in Queseria Well during VFD Well pumping test. . . . . . . . . . . . . . .

4.46 Estimation of aquifer properties by matching the Hantush and Jacob (1955) curve to time-drawdown data (log-log axes) collected in VFD Well during Pump House Well pumping test. 
4.47 Estimation of aquifer properties by matching the Hantush and Jacob (1955) curve to time-drawdown data (semi-log axes) collected in Pump House Well during VFD Well pumping test. . . . . . . . . . . . . . .

4.48 Estimation of aquifer properties by matching the Hantush and Jacob (1955) curve to time-drawdown data (semi-log axes) collected in Queseria Well during VFD Well pumping test. . . . . . . . . . . .

4.49 Estimation of aquifer properties by matching the Hantush and Jacob (1955) curve to time-drawdown data (semi-log axes) collected in VFD Well during Pump House Well pumping test. . . . . . . . . . . . . .

4.50 Scenario 1 estimated rates of stream depletion $\left(Q_{r}\right)$ at various times since pumping began $(t)$ and at different well discharge rates $(Q)$ obtained using the Hantush (1965) solution for flow to wells near streams with semipervious beds. . . . . . . . . . . . . .

4.51 Scenario 2 estimated rates of stream depletion $\left(Q_{r}\right)$ at various times since pumping began $(t)$ and at different well discharge rates $(Q)$ obtained using the Hantush (1965) solution for flow to wells near streams with semipervious beds. . . . . . . . . . . . .

4.52 Plan view of the three-dimensional (3D) finite-difference groundwater flow model (MODFLOW 2000) grid of lower Scotts Creek showing the boundary and initial conditions (starting head contours $(\mathrm{m})$ ) of the model. . . . . . . . . . . . . . . . . . .

4.53 Schematic of conceptual model of the groundwater system on lower Scotts Creek. . . . . . . . . . . . . . . . . 103

4.54 Schematic of general-head boundary (excerpted from the online user-supported help database for XMS software). . . . . . . . . . .

4.55 Schematic of river boundary streambed conductance components for an individual cell (excerpted from McDonald and Harbaugh, 1988). . 104

4.56 Plan view of the calibrated MODFLOW model showing layer 3 drawdown contours $(\mathrm{m})$ for the last time step (time step 10) when the VFD Well is pumped. . . . . . . . . . . . . . . . .

4.57 Drawdown data measured in the Pump House Well (observation well) during the VFD Well pumping test plotted against uncalibrated and calibrated model generated drawdown values. . . . . . . . . . . .

4.58 Drawdown data measured in the VFD Well (observation well) during the Pump House Well pumping test plotted against uncalibrated and calibrated model generated drawdown values.

5.1 Plot showing flow $\left(\mathrm{m}^{3} / \mathrm{d}\right)$ vs. time $(\mathrm{d})$ of river leakage for simulation of groundwater withdrawal from the Pump House Well. . . . . . . . . . 119

5.2 Plot showing flow $\left(\mathrm{m}^{3} / \mathrm{d}\right)$ vs. time $(\mathrm{d})$ of river leakage for simulation of groundwater withdrawal from the VFD Well. . . . . . . . . . . . . 119

5.3 Head (cm) in PHP-1 July 2016 to November 2017. . . . . . . . . . . 121

5.4 Head (m) in the Pump House Well August 2016 to November 2017. 121 
5.5 Comparison of timing and magnitude of water level fluctuations $(\mathrm{m})$ in a piezometer (PHP-1) and an irrigation well (Pump House Well) over a 7 month period from October 2016 to May 2017. . . . . . . . . . .

5.6 Head $(\mathrm{m})$ in Pump House Well and head $(\mathrm{cm})$ in PHP-1 AugustOctober 2016. The data show pumping events in the Pump House Well and the drawdown response in PHP-1 superimposed on the diurnal fluctuations in groundwater levels in PHP-1 indicative of evapotranspiration by phreatophytes. . . . . . . . . . . . . . 124

5.7 Head (cm) in PHP-1 June-November 2017. The data show fluctuations in groundwater levels as a result of phreatophytic consumption and groundwater abstraction. . . . . . . . . . . . . . 125

5.8 Head (m) in the Queseria Well August 2015 to December 2017. . . . 125 


\section{CHAPTER 1: INTRODUCTION}

The sustainable use and management of water resources has become a serious global challenge due to a changing climate, population growth, and the attendant increase in consumption. Groundwater is an important source of water for many societal needs, but has historically been more or less unregulated (Anderson and Woosley, 2005; Kløve et al., 2014). As a result, a myriad of undesirable consequences of groundwater overdraft are becoming ever more apparent including: 1) chronic lowering of groundwater levels, 2) reduction of groundwater storage, 3) seawater intrusion, 4) degraded water quality, 5) land subsidence, and 6) surface water depletion (Baron et al., 2002; Brunke and Gonser, 1997; Hancock, 2002; Zektser et al., 2005; Sophocleous, 2002). Groundwater and surface water are commonly hydraulically connected (Hayashi and Rosenberry, 2002; Sophocleous, 2002; Woessner, 2000), and consequently streamflow depletion (defined as pumping-induced increased inflow to and decreased outflow from an aquifer) can occur as a result of groundwater abstraction (Barlow and Leake, 2012; Nyholm et al., 2002; Rugel et al., 2012; Sophocleous, 2002). Adverse effects of streamflow depletion range from diminished water supplies for agricultural and municipal uses to aquatic ecosystem destruction (Sophocleous, 2002). In coastal California streams with rare, threatened, and/or endangered anadromous salmonids, the diminishment of instream flows during dry periods is of particular concern (Deitch and Dolman, 2017; Marston, 1992; Snider et al., 1995; Smith, 1994). Because coastal California experiences low summer rainfall and significant inter-annual variability in precipitation, 
groundwater inputs are critical to maintaining instream flows through the dry season (Deitch and Dolman, 2017; Ronayne et al., 2017).

Over the past 70 years, extensive research has improved scientific understanding of the factors and processes that affect how groundwater pumping near a stream impacts streamflow (Barlow and Leake, 2012, and references therein). Several studies have investigated the spatial and temporal response of instream flows to groundwater pumping in coastal California watersheds. For example, McGlochlin (1984) examined the degree of stream-aquifer interaction in the lower Carmel Valley in Monterey County, California, and discovered through groundwater monitoring and stream discharge measurements that the aquifer is in intimate contact with flow in the Carmel River, contrary to widespread belief that a confining layer separates the stream from the pumped aquifer. Similarly, Kondolf et al. (1987) described how groundwater withdrawal locally decreased base flows and inhibited steelhead trout migration in the Carmel River using streamflow and well-level measurements. Fleckenstein et al. (2004) evaluated groundwater management strategies to restore fall flows, critical for supporting Chinook salmon runs, in the Cosumnes River in Sacramento County, California. Their numerical modeling results suggested that extensive pumping reductions could improve long-term river conditions by reconnecting the river with the regional aquifer (Fleckenstein et al., 2004).

These case studies and others have led to an increased knowledge of streamaquifer exchange processes in coastal California watersheds, yet additional research in these environments is needed. Furthermore, geologic materials in fluvial settings are inherently heterogeneous with hydraulic conductivities that vary randomly by orders of magnitude over short distances (Bradbury and Muldoon, 1990). Understanding such complex systems and developing sustainable groundwater pumping practices is thus best accomplished through detailed investigation at the catchment or stream 
reach scale using a wide range of measurement techniques that integrate many spatial and temporal scales (Kalbus et al., 2006; Sophocleous, 2002).

In this study, we conducted field and laboratory experiments as well as numerical groundwater flow modeling to investigate the dynamic interaction between Scotts Creek and the underlying alluvial aquifer at Swanton Pacific Ranch in Santa Cruz County, California. Several high capacity agricultural wells (pumping capacities of 300 gallons per minute (gpm) each) are used to irrigate cropland on lower Scotts Creek. The potential for groundwater pumping to deplete Scotts Creek stream flows is a source of serious concern for land managers, fisheries biologists, and regulatory agencies due to the presence of federally protected steelhead trout (Oncorhynchus mykiss) and coho salmon (Oncorhynchus kisutch). The main objective of this research is to test a hypothesis, the results of which will inform resource policy and fill critical knowledge gaps that currently limit the effective management of water resources in the Scotts Creek watershed. These results may be extended to other watersheds in coastal California allowing for the sustainable use and management of water resources for human supply and ecological conservation.

The specific study objectives were to: 1) characterize the lower Scotts Creek alluvial aquifer (geometry, lithology, and hydraulic properties), 2) quantify the degree of hydraulic connectivity between the stream and the aquifer, and 3) provide sustainable groundwater pumping recommendations. Based on findings from studies conducted in similar hydrogeologic settings and Scotts Creek stream survey reports filed by the California Department of Fish and Wildlife (CDFW), we hypothesized that the stream is directly connected to the aquifer and that abstraction of groundwater from agricultural wells has a measurable impact on Scotts Creek stream flows, particularly during the summer low-flow period. To test this hypothesis and to achieve the objectives of this research a multi-scale approach combining multiple measurement techniques was 
employed. Eighteen boreholes were drilled for sediment core collection and piezometer installation. Long-term passive monitoring of aquifer hydraulic heads and stream stage, constant rate pumping tests, dye tracer tests, falling-head permeameter tests and particle size analyses of aquifer sediments, electrical resistivity interrogation of the subsurface, and numerical simulation of groundwater flow (MODFLOW) were performed to characterize the aquifer and to quantify the degree of stream-aquifer hydraulic connectivity. Lastly, rates of streamflow depletion during a series of pumping tests conducted at the site were estimated using the Hantush (1965) method. Results of all methodologies were then used to make sustainable groundwater pumping recommendations.

In the following chapters we review pertinent literature, discuss the methodology used to test the hypothesis, report results from field and laboratory tests, present groundwater flow modeling results, offer sustainable groundwater pumping recommendations, and advise of future research needs. 


\section{CHAPTER 2: LITERATURE REVIEW}

\subsection{Overview}

The quantification of the effects of groundwater pumping on streamflow allows water resource managers to make informed management decisions that meet ecological and societal needs (Sophocleous, 2002; Kalbus et al., 2006). This literature review covers the fundamental concepts of groundwater-surface water interactions and how groundwater abstraction affects streamflow, provides an overview of common methods for quantifying groundwater-surface water interactions, summarizes the development of modeling methods, and identifies the main limitations of existing solutions.

\subsection{Fundamentals of Groundwater-Surface Water Interactions}

\subsubsection{Exchanges Between Groundwater and Surface Water}

Groundwater and surface water systems are intimately connected hydrologically (Hayashi and Rosenberry, 2002). The hydrologic exchange between streams and aquifers occurs at the sediment/water interface by subsurface lateral flow through the unsaturated zone and by flow into or out of the saturated zones. Water also percolates vertically from streams through unconsolidated sediments. Thus, exchanges between streams and aquifers are inherently three-dimensional (Boulton et al., 1998; Hayashi and Rosenberry, 2002; Sophocleous, 2002). These flow processes occur over many spatial and temporal scales and often vary dramatically between and within stream 
reaches (Boulton et al., 1998; Hancock, 2002). In general, streams may be classified as either gaining, losing and connected, or losing and disconnected as illustrated in Figure 2.1 (Brunner et al., 2011). However, some combination of these commonly exist in natural systems.

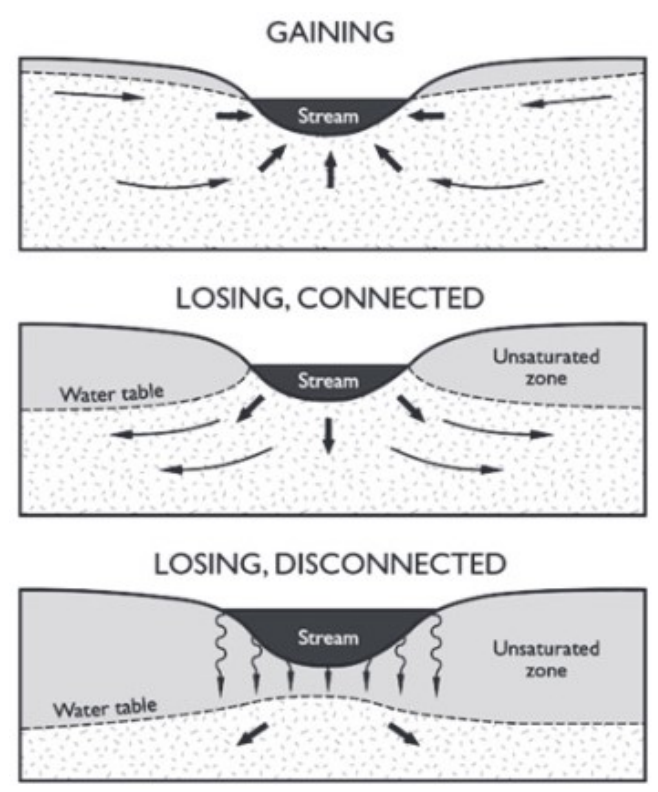

Figure 2.1: Common flow regimes between groundwater and surface water (excerpted from Brunner et al., 2011).

Exchanges between groundwater and surface water are controlled by several factors including stream discharge and stage, the magnitude and distribution of hydraulic conductivities $(K)$ of the streambed and aquifer sediments, streambed thickness and its variation, the hydraulic gradient $(\nabla h)$ between the stream and the aquifer, and the geometric/morphological characteristics of the stream channel (Boulton et al., 1998; Hancock, 2002; Sophocleous, 2002).

The transitional ecotone directly beneath the streambed where these exchanges take place is called the hyporheic zone, which is a region of increased biogeochemical activity, is an integral part of the fluvial ecosystem (Brunke and Gonser, 1997; Hayashi and Rosenberry, 2002; Sophocleous, 2002). As a transition region, the hyporheic 
zone exhibits characteristics of both surface water and groundwater (Boulton et al., 1998; Brunke and Gonser, 1997; Hancock, 2002; Sophocleous, 2002). In many streams, it contains unique invertebrate fauna as well as fungi and microbes that contribute substantially to nutrient cycles of aquatic ecosystems (Hancock, 2002). Streams receive important nutrient inputs from groundwater and similarly the biologically active upper layers of aquifers obtain dissolved and particulate organic matter from streams (Boulton et al., 1998). The hydrologic exchange processes within the hyporheic zone vary spatially and temporally (Brunke and Gonser, 1997; Sophocleous, 2002). The hyporheic zone extends both vertically below the stream and laterally into the streambank sediments and floodplain (Brunke and Gonser, 1997). Fluvial geomorphological features such as pool-riffle sequences and discontinuities in slope and depth drive local upwelling and downwelling processes along the streambed (Figure 2.2) (Boulton et al., 1998; Sophocleous, 2002). At the downstream end of pools decreasing stream depth causes a high pressure zone where water downwells into the sediments. Conversely, at the end of riffles increasing stream depth creates a low-pressure zone where subsurface water upwells and reenters the stream. Instream features, such as logs and boulders, often create complex flow paths that also contribute to the degree of upwelling and downwelling along stream reaches (Boulton et al., 1998; Hancock, 2002).

In summary, a thorough understanding of the dynamic relationship between groundwater and surface water systems, as well as the importance of the hyporheic zone, are key to quantifying stream-aquifer connectivity, and to identifying and managing the effects of groundwater abstraction on streamflow.

\subsubsection{Effects of Groundwater Abstraction on Streamflow}

When water is extracted from a well, groundwater levels around the well decline creating a cone of depression. The cone of depression is deepest at the well and extends 


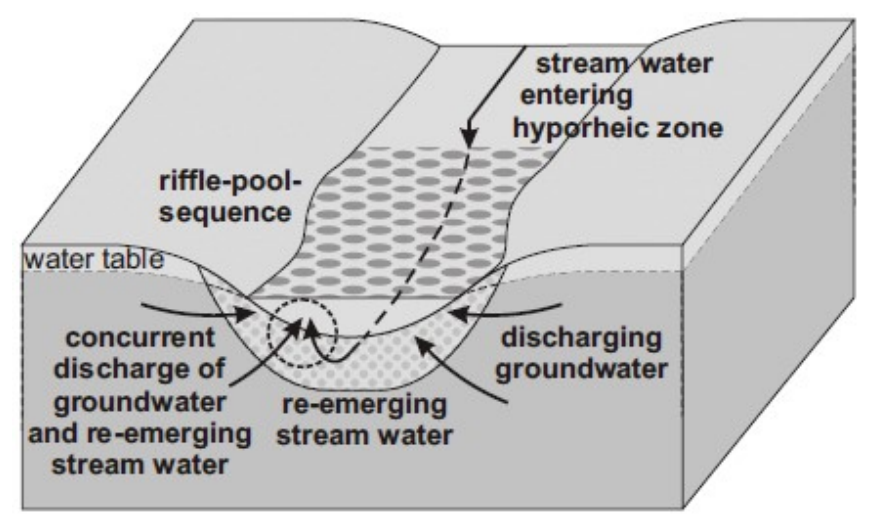

Figure 2.2: Schematic of the dynamics of the hyporheic zone at a riffle-pool-sequence (excerpted from Kalbus et al., 2006).

radially to a distance away from the well where water-level decline (or drawdown) is effectively zero. The cone of depression is associated with steep hydraulic gradients in the vicinity of the well that draw water from the aquifer into the well. The water that is drawn into the well and discharged comes from one or a combination of several potential sources including aquifer storage, leakage from an underlying or overlying aquitard, induced infiltration from a nearby stream, or from the natural flow that would have discharged into the stream if the well had not been pumped (Barlow and Leake, 2012). In small streams where discharge is low, pumping-induced increased inflow to an aquifer will inevitably cause changes in stream stage, velocity, and temperature (Hunt et al., 2001; Hunt, 2003; Nyholm et al., 2002). Groundwater abstraction will eventually result in reduced baseflow to the stream, which can be harmful to aquatic life (Figure 2.3) (Nyholm et al., 2003).

A mass balance study conducted by Nyholm et al. (2003) in Denmark used stream discharge measurements to estimate streamflow depletion in a small alluvial stream. The study revealed that abstraction of groundwater from a well 60 meters from the stream caused a reduction in stream discharge in approximately one day and within one week stream depletion stabilized at about $40 \%$ of the pumping rate $(\mathrm{Q}=14.7$ 


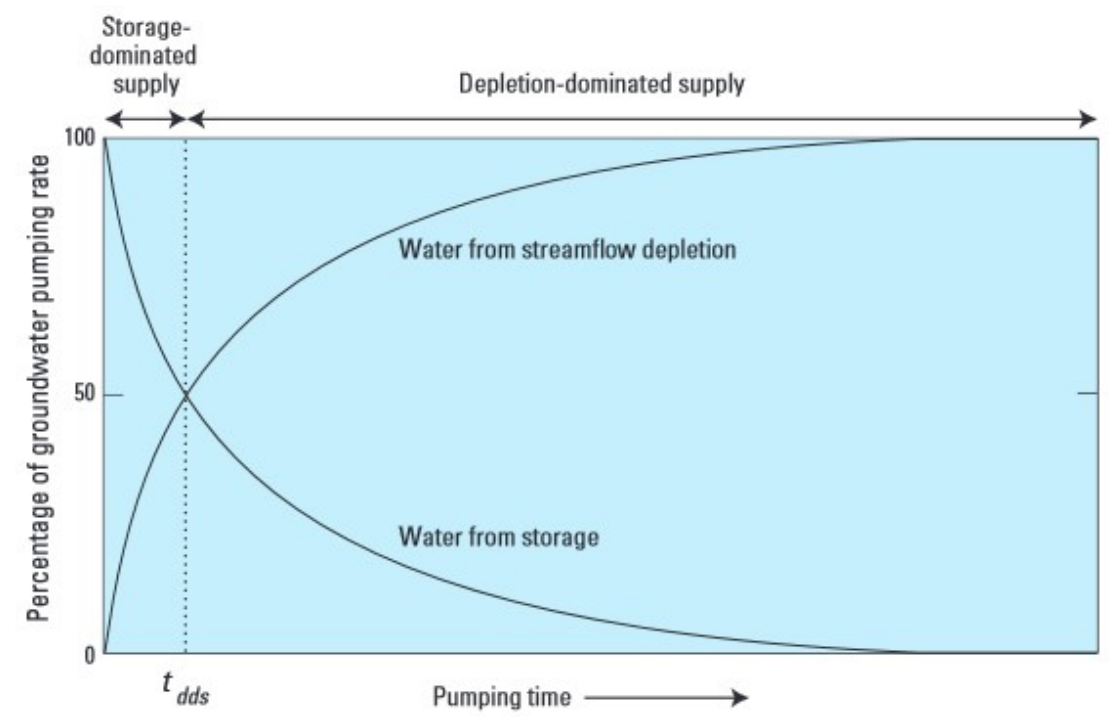

Figure 2.3: Relationship between sources of pumped groundwater for a hypothetical well. As pumping time increases, streamflow becomes the dominant source of water discharged from the well (excerpted from Barlow and Leake, 2012).

$\mathrm{l} / \mathrm{s}$ ). More commonly however, streamflow depletion from a single or group of wells is difficult to detect because stream flows are inherently dynamic and large compared to streamflow depletion. Furthermore, the accuracy of stream discharge measurements is often low and does not exceed the streamflow depletion rate, and depletion is frequently delayed due to aquifer and streambed heterogeneities and variabilities in pumping schedules (Barlow and Leake, 2012; Kollet and Zlotnik, 2003; Nyholm et al., 2003). The residual effects of pumping can be much greater than those during pumping, and for some stream-aquifer systems, base-flow reduction can account for more than $90 \%$ of the total depletion (Chen and Shu, 2002). Because streamflow depletion can be delayed, the effects of groundwater abstraction often go unnoticed for several years. Additionally, when a well near a stream is pumped, streamflow depletion consistently follows a seasonal trend with the greatest levels of depletion occurring during the growing season or shortly thereafter when irrigation demands are highest and streams are in their critical low flow period. However, as the distance between the 
stream and well increases, pumping results in constant streamflow depletion with little seasonal fluctuation (Barlow and Leake, 2012; Bredehoeft and Kendy, 2008; Rugel et al., 2012). Streamflow depletion also tends to follow a diurnal cycle with the greatest depletion occurring in the afternoon when stream temperature and evapotranspiration by phreatophytes are at their highest (Anderson, 2005). For both fixed and cyclical pumping, stream depletion approaches the annual rate of pumping asymptotically over time (Barlow and Leake, 2012). Although irrigation depletes streamflow in the summer, it can generate return flow overland and through the aquifer, and provide base flow to streams in the fall and winter (Bredehoeft and Kendy, 2008).

After pumping ceases, groundwater levels begin to recover and return to prepumping equilibrium. However, the timing and rates of recovery vary substantially between systems (Bredehoeft, 2011). Many aquifers take decades or centuries to recover and some never reach pre-abstraction levels (Barlow and Leake, 2012; Bredehoeft, 2011). The rates and timing of aquifer recovery and streamflow depletion depend on a number of factors including the number of wells and distance of each from the stream, the hydrologic conditions along the boundaries of the groundwater system, and the geologic structure, dimensions, and hydraulic properties of the aquifer and streambed (Barlow and Leake, 2012).

\subsubsection{Hydraulic Properties of the Subsurface and Streambed}

The hydraulic properties of subsurface and streambed sediments control the interactions between surface water and groundwater (Woessner, 2000; Sophocleous, 2002). The storage and fluid transmission properties of a porous medium together influence the timing and rates of streamflow depletion (Heath, 1983; Barlow and Leake, 2012). 


\subsubsection{Storage Parameters}

Porosity is a measure of the void spaces of a porous medium and is commonly expressed as a percentage of the total volume (Heath, 1983). It is the most fundamental storage parameter. Other storage properties of aquifers include specific storage $\left(S_{s}\right)$, storativity $(S)$, and specific yield $\left(S_{y}\right)$.

Specific storage (elastic storage) is defined as the volume of water that flows into or out of a unit volume of saturated porous medium per unit change in head. Specific storage is usually a small number $\left(6.2 \times 10^{-3}\right.$ to $\left.<1 \times 10^{-6} \mathrm{ft}^{-1}\right)$, but translates to large volumes of water (Domenico and Mifflin, 1965). It is related to the compressibilities of the aquifer sediment and water by the equation (Freeze and Cherry, 1979)

$$
S_{s}=\rho g\left(\beta_{b}+n \beta_{w}\right)
$$

where $\rho$ is the fluid density $\left[\mathrm{M} / \mathrm{L}^{2}\right], g$ is gravitational acceleration $\left[\mathrm{L} / \mathrm{T}^{2}\right], \beta_{b}$ is compressibility of the solid matrix $\left[\mathrm{T}^{2} \mathrm{~L} / \mathrm{M}\right], n$ is effective porosity [dimensionless], and $\beta_{w}$ is compressibility of water $\left[\mathrm{T}^{2} \mathrm{~L} / \mathrm{M}\right]$. Specific storage has dimensions of $L^{-1}$, where $\mathrm{L}$ is length, and is commonly expressed as $\mathrm{m}^{-1}$ or $\mathrm{ft}^{-1}$ (Barlow and Leake, 2012).

Storativity (storage coefficient) is a dimensionless property defined as the volume of water released from storage per unit surface area of aquifer per unit change in head and is related to specific storage (confined aquifers) by the equation

$$
S=S_{s} b
$$

where $b$ is aquifer thickness. Storativity is simply the vertical depth average of specific storage. Typical values of storativity of confined aquifers range from $5 \times 10^{-5}$ to $5 \times 10^{-3}$ (Barlow and Leake, 2012). 
Specific yield (effective porosity) is an additional storage term for unconfined aquifers. It is defined as the ratio of the volume of water drainable by gravity to the total volume of the aquifer and is commonly expressed as a percentage. Common values of specific yield are between 10 and 30 percent (Heath, 1983). Estimation of specific yield from drawdown data is difficult and has been found to be sensitive to modeling techniques (Poulsen et al., 2011).

\subsubsection{Transmission Parameters}

Darcy's Law states that flux is proportional to hydraulic gradient and is commonly written as

$$
q=-K \frac{\Delta h}{\Delta x},
$$

where $q$ is Darcy velocity or flux (volume flow rate per unit area normal to flow) and $(\Delta h / \Delta x)$ is the hydraulic gradient (change in total head divided by the distance over which the change occurs). Hydraulic conductivity is then the constant of proportionality between the flux and the potential gradient. Hydraulic conductivity describes the rate of flow of a volume of water per unit time under a unit hydraulic gradient through a unit area of aquifer or streambed. It depends on the size and arrangement of the pores of a medium, as well as the density and viscosity of water and is defined by the equation

$$
K=k \frac{\rho g}{\eta},
$$

where $k$ is the intrinsic permeability of the porous medium (a measure of the ability of a porous medium to allow fluids to pass through it, commonly expressed in units of $\mathrm{m}^{2}, \mathrm{ft}^{2}$, or Darcies (1 darcy is equivalent to $\left.9.869233 \times 10^{-13} \mathrm{~m}^{2}\right)$ ) and $\eta$ is the 
dynamic viscosity of the fluid. Hydraulic conductivity has dimensions of $\mathrm{L} / \mathrm{T}$ and is commonly expressed in units of $\mathrm{m} / \mathrm{s}, \mathrm{m} / \mathrm{d}$, or $\mathrm{ft} / \mathrm{d}$. Hydraulic conductivity values have a range of 12 to 13 orders of magnitude and are typically relatively small for clays and silts $\left(1 \times 10^{-8}\right.$ to $\left.0.1 \mathrm{ft} / \mathrm{d}\right)$ and large for sands and gravels ( 1 to $\left.10,000 \mathrm{ft} / \mathrm{d}\right)$ (Figure 2.4) (Barlow and Leake, 2012; Heath, 1983).

The distribution and magnitude of hydraulic conductivities, within both the aquifer and streambed, control exchanges between surface water and groundwater. Streams commonly have a streambed with a lower hydraulic conductivity (one to three orders of magnitude lower) than the alluvial aquifer, in which case the streambed is referred to as the clogging layer (Brunner et al., 2010; Fox, 2004). In general, as the distance between a stream and well increases, the influence of the streambed properties decreases (Butler et al., 2001). Determining streambed hydraulic conductivity and streambed vertical extent are often challenging and unknown (Brunner et al., 2010). Aquifers that have spatially constant hydraulic conductivities are considered homogenous, whereas ones with spatially varying hydraulic conductivities are heterogeneous (Barlow and Leake, 2012).

An additional transmission parameter is transmissivity, which is vertically integrated hydraulic conductivity, defined by the equation

$$
T=K b .
$$

Transmissivity has dimensions of $\mathrm{L}^{2} / \mathrm{T}$ and is commonly expressed in units of $\mathrm{m}^{2} / \mathrm{s}$ or $\mathrm{ft}^{2} / \mathrm{s}$. Transmissivity values vary at different locations in an aquifer due to subsurface heterogeneity and, in unconfined aquifers, change in response to fluctuations in the water table (Barlow and Leake, 2012). 


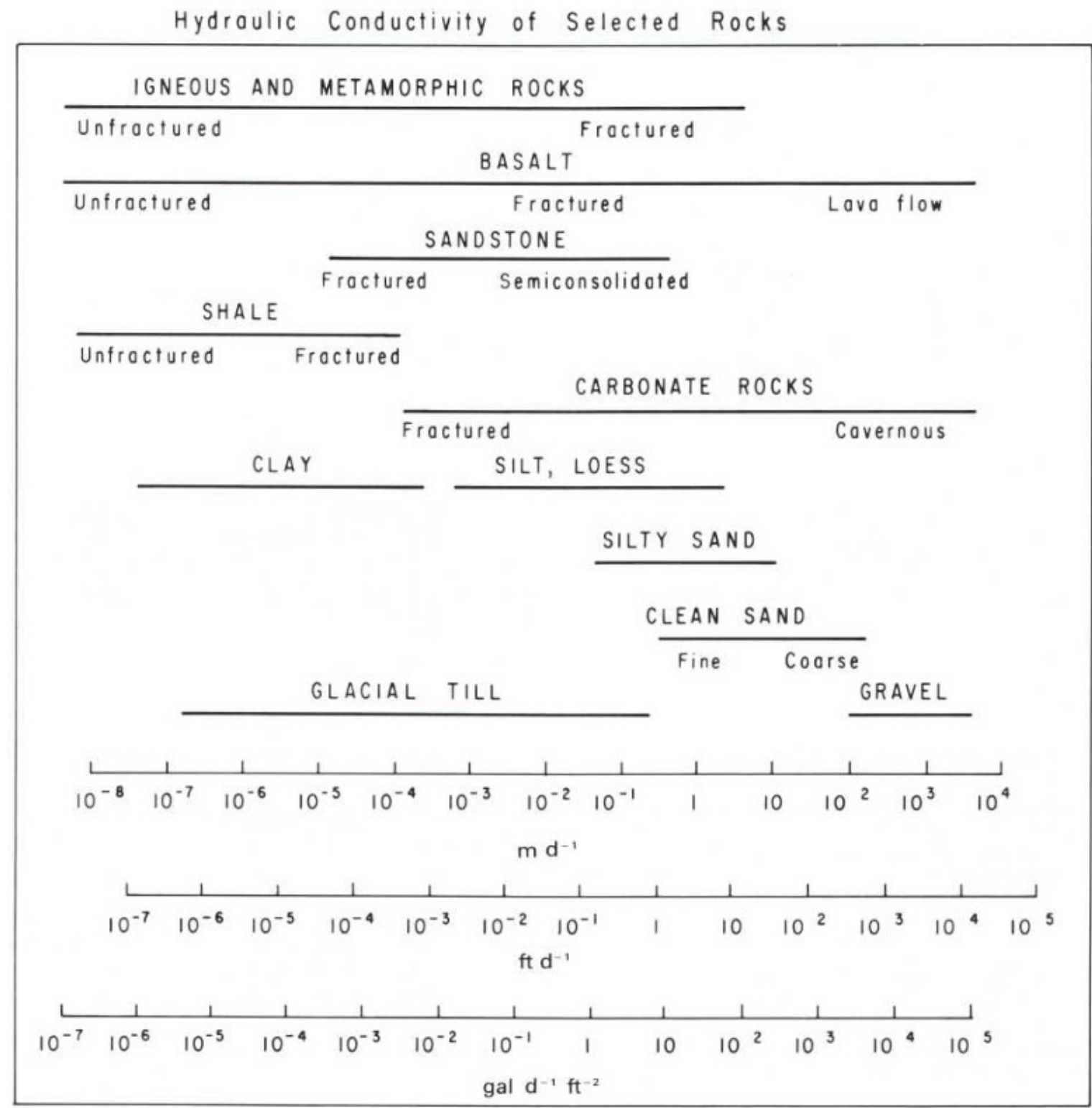

Figure 2.4: Hydraulic conductivity of selected consolidated and unconsolidated geologic materials (excerpted from Heath, 1983). 


\subsubsection{Additional Parameters}

Hydraulic diffusivity is another hydraulic property that has relevance to streamflow depletion. Hydraulic diffusivity is defined as

$$
D=\frac{T}{S}=\frac{K}{S_{s}} .
$$

Hydraulic diffusivity has dimensions of $\mathrm{L}^{2} / \mathrm{T}$ and is commonly expressed in units of $\mathrm{m}^{2} / \mathrm{d}$ or $\mathrm{ft}^{2} / \mathrm{d}$. Rapid streamflow depletion by groundwater pumping is correlated with high values of aquifer hydraulic diffusivity. The distance of a pumping well to a stream and the hydraulic diffusivity of the associated aquifer are two of the most important factors that control the behavior of streamflow depletion (Barlow and Leake, 2012).

The "stream depletion factor (SDF) method" was introduced by Jenkins (1968) and is defined by the equation

$$
S D F=\frac{d^{2}}{D},
$$

where $d$ is the distance between the stream and well. It is a measure of how quickly a wells effect reaches the stream. Values of SDF have units of time. Wells close to a stream have low SDF values, which result in high rates of streamflow depletion. Conversely, wells farther from a stream have high SDF values, which correspond with low rates of streamflow depletion (Bredehoeft and Kendy, 2008; Barlow and Leake, 2012).

Estimation of the hydraulic properties defined above allows for quantitative prediction of system response to groundwater pumping. Several techniques have been developed to acquire such estimates, the most common method involving performing pumping tests in a well and fitting an analytical model to drawdown data (Neuman, 
1972; Neuman and Witherspoon, 1972). However, due to the spatial and temporal variability of groundwater and surface water interactions, a broad range of measurement and analysis methods performed at various scales are recommended to fully understand stream-aquifer interactions (Kalbus et al., 2006).

\subsection{Methods for Measuring Streamflow Depletion}

A wide range of techniques have been developed to quantify groundwater-surface water interactions. The methods can be grouped into the following five categories: 1) direct measurements of water flux, 2) heat tracer methods, 3) methods based on Darcy's Law, 4) mass balance approaches, and 5) modeling approaches. To achieve the best representation of local and/or regional stream-aquifer interactions, a combination of small- and large-scale methods is recommended (Brodie et al., 2007; Kalbus et al., 2006; Menció et al., 2014; Rosenberry and LaBaugh, 2008).

\subsubsection{Direct Measurement of Water Flux}

Direct measurement of water flux across the stream-aquifer interface can be accomplished using seepage meters or similar devices. Bag-type seepage meters are most common and consist of a bottomless cylinder vented to an expandable plastic bag (Kalbus et al., 2006). The cylinder is inserted into the streambed and seepage rate is measured by calculating the change in water volume in the bag over a measured time interval. Although seepage meters are an inexpensive technique for assessing water flux, the bag-type method can lead to inaccuracies in measured flux when water flowing over the bag causes it to become distorted (Brodie et al., 2007). Therefore, numerous types of automated seepage meters have been developed to overcome issues related to the collection bags including heat pulse, ultra-sonic, dye-dilution, and electromagnetic meters (Kalbus et al., 2006). While seepage meters 
are useful for identifying groundwater recharge and discharge zones, the applicability of such instruments in streams is low because of challenges encountered in obtaining representative average seepage fluxes due to the inherent variability in stream discharge and hyporheic exchange flow. Additionally, numerous measurements are required to effectively characterize flux along a given stream reach (Menció et al., 2014).

\subsubsection{Heat Tracer Methods}

Heat tracer methods can be used to quantify water fluxes at the stream-aquifer interface and to delineate groundwater recharge or discharge zones (Menció et al., 2014). Heat tracer methods are appealing because they necessitate little to no alteration of the environment (Somers et al., 2016). Such methods utilize fiber-optic cables or node-like temperature loggers installed in the water column to record stream temperature (Somers et al., 2016). Stream temperatures vary on a daily and seasonal basis, whereas the temperature of groundwater remains relatively constant throughout the year if there is limited groundwater pumping and evapotranspiration (Anderson, 2005; Kalbus et al., 2006). Temperature monitoring in the stream and surrounding sediments can therefore indicate gaining and losing stream reaches (groundwater discharge and recharge zones, respectively). Furthermore, when combined with an analytical or numerical solution for the heat transport equation, heat tracer methods can be used to quantify seepage fluxes through streambed sediments (Brodie et al., 2007; Somers et al., 2016). Information on the movement of heat also helps to constrain the calibration of a groundwater flow model by providing additional data (Anderson, 2005). The use of temperature measurements in groundwater research has been sporadic, but with improved temperature sensors and numerical codes, its usefulness in hydrogeological settings is beginning to be revealed. For example, Su et al. (2004) estimated streambed hydraulic conductivities and water fluxes using heat as an 
environmental tracer in the Russian River, Sonoma County, California. Somers et al. (2016) used heat tracer methods and a deterministic numerical stream temperature model (HFLUX) to quantify the groundwater contributions to the Quilcay River, and to understand the interaction between groundwater and surface water in a proglacial valley of the Cordillera Blanca, Peru.

\subsubsection{Particle Size Analysis and Hydraulic Tests}

Methods based on Darcy's Law are the most commonly used to investigate groundwater movement in terrestrial aquifers (Kalbus et al., 2006; Menció et al., 2014). These methods require point measurements of the components of the Darcy equation (Eq.2.3) including the hydraulic conductivity of the aquifer and the hydraulic gradient between the stream and the aquifer (Menció et al., 2014; Rosenberry and LaBaugh, 2008).

Determining the hydraulic conductivity of aquifer material can be accomplished in a laboratory setting by performing grain-size analyses of sediment samples. Hydraulic conductivity can be derived from the grain-size distribution of a sediment sample using empirical relations between grain size and permeability such as the Hazen (1892) or Kozeny (1927) and Carman (1956) (Kozeny-Carman) equations. However, empirical methods have been found to produce poor estimates when compared to measured values for several reasons the primary being that each equation is most applicable for

the type of sediment used to derive it (Bradbury and Muldoon, 1990; Rosas et al., 2014; Sahu and Saha, 2016).

Hydraulic conductivity can also be estimated from measurements of flow rate and head in a permeameter filled with aquifer sediments under steady-state (constant head) or transient (falling head) conditions (Kalbus et al., 2006). Although permeameter tests are effective at determining relative differences in hydraulic conductivity between sediment types, such methods often underestimate hydraulic conductivity values 
when compared to values measured in situ. This is likely because sediment grains are rearranged when packed into the permeameter and large-scale features such as fractures and bedding are not captured at the scale of the permeameter sample (Bradbury and Muldoon, 1990).

Alternatively, hydraulic conductivity can be determined by performing pumping, slug, or bail tests in a well. During a pumping test, water is abstracted from a well at a constant rate and drawdown (the change in hydraulic head from some initial state in an aquifer) is measured as a function of time. During a slug or bail test, a known volume of water is displaced or removed from the well, and as the water level recovers, hydraulic head is measured as a function of time (Kalbus et al., 2006). Several researchers (Cardiff et al., 2011; Fox, 2004; Hunt et al., 2001; Hunt, 2003; Kollet and Zlotnik, 2003; Lough and Hunt, 2006; Nyholm et al., 2002, 2003; Poulsen et al., 2011) have used such techniques in a range of hydrogeological settings to estimate aquifer hydraulic conductivity and to determine degree of stream-aquifer connectivity. Several of these authors have made significant contributions to our understanding of groundwatersurface water interactions by improving the applicability of established analytical models and by highlighting some important findings future researchers should consider. For example, Poulsen et al. (2011) found that an important component in parameter estimation by pumping test analysis for unconfined aquifers when the drainage process is delayed is the use of a model that accounts for time-varying drainage from the vadose zone (such as the models of Mishra and Neuman (2010) and Malama et al. (2011)). Kollet and Zlotnik (2003) discovered that streambed and aquifer heterogeneity is the major cause for the inconsistencies in parameter and stream depletion estimates. Lough and Hunt (2006) found that pumping tests must be carried out for a sufficiently long period of time to allow leakage from the stream to have a significant influence on the measured drawdown curve. 
The other component of Darcy's Law required for the determination of water flux in the subsurface is the hydraulic gradient between the stream and the aquifer. Determining the hydraulic gradient is usually accomplished by measuring and comparing the water level in wells and piezometers installed in the fluvial plain to those installed in the stream. Piezometers, with pressure transducers installed in them, provide point measurements of hydraulic head and have become a standard method to determine hydraulic head. The vertical and horizontal components of groundwater flow can be determined from differences in hydraulic head between individual piezometers installed in clusters and at various depths (Kalbus et al., 2006). It has been shown that more than one piezometer or piezometer cluster is needed for parameter estimation and for evaluating stream depletion rate (Kalbus et al., 2006; Kollet and Zlotnik, 2003; Menció et al., 2014). Baxter et al. (2003) proposed a new method for installing numerous mini-piezometers in gravel and cobble streambeds to measure hydraulic head and to estimate streambed hydraulic conductivity. Hydraulic potentiomanometer measurements provide an additional technique for measuring the vertical hydraulic-head gradient beneath a surface water body and for estimating hydraulic conductivities (Rosenberry and LaBaugh, 2008). Lamontagne et al. (2014) successfully used a drive point and manometer system to measure pressure gradients and estimate infiltration through a riverbed in a semi-arid river basin in southeastern Australia.

\subsubsection{Mass Balance Approaches}

Mass balance methodologies have been developed based on the assumption that any change in the properties of surface water, or any gain or loss of surface water, can be related to a water source, and, thus, the groundwater component can be identified (Kalbus et al., 2006; Menció et al., 2014; Rosenberry and LaBaugh, 2008). Methodologies include incremental streamflow, hydrograph separation, and environmental 
and solute tracer techniques. The incremental streamflow method involves measuring streamflow discharge at successive cross-sections during low flow conditions, and associating any change in streamflow to groundwater recharge or discharge (Kalbus et al., 2006). The hydrograph separation technique has been the most widely used of the mass balance approaches due to the accessibility of data and involves separating a stream hydrograph into its distinct runoff components, and then assuming that baseflow signifies groundwater discharge into the stream. Several researchers (Nyholm et al., 2003; Rugel et al., 2012; Weber and Perry, 2006) have successfully used hydrograph separation to estimate streamflow depletion in vastly different hydrogeological environments. Hydrological tracers can be used to characterize water dynamics within a watershed or stream reach by determining mixing and flow paths, residence time, and inputs and outputs within a system (Rosenberry and LaBaugh, 2008). Environmental tracer techniques utilize concentrations of isotopic and geochemical tracers, whereas solute tracer methods involve injecting a known amount of a conservative tracer into a stream or well. It has been noted that a combination of hydrologic data and tracer tests produce the most reliable results (Kalbus et al., 2006; Menció et al., 2014).

\subsection{Modeling Groundwater-Surface Water Interactions}

Direct measurements of stream depletion are difficult to obtain due to the inherent variability of runoff and the often low accuracy of streamflow measurements (Zlotnik, 2004). Therefore, analytical and numerical modeling approaches are commonly used to overcome such uncertainties and predict streamflow depletion rates. Both approaches require solution of the partial differential equation of groundwater flow and have been widely used by researchers to estimate stream depletion caused by groundwater pumping (Menció et al., 2014). Analytical models require less site-specific data than numerical models and can account for multi-layered systems with anisotropy, but 
rely on idealized conditions in which many of the complexities of natural systems are either approximated or ignored completely. Thus, analytical models are often oneor two-dimensional, rely on idealized boundary geometries, and assume the aquifer material is homogeneous (Kollet and Zlotnik, 2003). In general, analytical models are the simplest and quickest way to estimate average aquifer scale hydraulic properties and to improve understanding of the effects of groundwater abstraction on streamflow. They provide generalized results transferable to other hydrologic settings. Numerical models, in contrast, can simulate flow as three-dimensional and account for complex boundary geometries and conditions, and heterogeneous aquifer materials (Barlow and Leake, 2012). Numerical models handle the complexities of natural systems and are useful for large-scale catchment modeling, but describe a specific hydrologic setting making results difficult to generalize (Bredehoeft and Kendy, 2008). Furthermore, obtaining enough accurate data to setup, calibrate, and verify numerical models can be relatively expensive and time consuming (Hunt, 2012).

\subsubsection{Analytical Models}

\subsubsection{Confined Aquifer Models}

Several analytical models have been developed to determine rates of streamflow depletion by groundwater pumping in confined aquifers. Theis (1941) used the method of images to obtain the first transient analytical solution, and the most widely applied, for a well in the neighborhood of a straight and fully penetrating stream with perfect hydraulic connection to an semiinfinite aquifer. Later, Glover and Balmer (1954) obtained the same solution but expressed it more compactly using the "complementary error function", allowing the solution to be evaluated using well-known series approximations. Jenkins (1968) introduced an alternative input to the stream depletion equation of Theis (1941) called the "stream depletion 
factor" (SDF), and provided data tables for evaluating the complementary error function. Subsequently, Hantush (1965) introduced a solution that accounts for an imperfect hydraulic connection produced by a stream with a semipervious bed that partially penetrates a horizontal nonleaky water-table aquifer. Around the same time, in the former Soviet Union, Grigoryev (1957) and Bochever (1966) developed a steady-state model for the design of wellfields in alluvial aquifers that incorporates a simplified representation of a partially penetrating stream where the stream and the aquifer are separated by a thin zone of relatively low hydraulic conductivity (Butler et al., 2001). More recently, Zlotnik and Huang (1999) extended the steady-state Grigoryev-Bochever solution to model transient drawdown and stream depletion from a partially-penetrating, finite-width stream with a semipermeable streambed. Hunt (1999) obtained a solution for a partially penetrating stream with a semipermeable streambed bisecting an infinite, homogenous aquifer. Shortly thereafter, Butler et al. (2001) realized the impact of lateral boundaries on stream-depletion calculations and extended the Zlotnik-Huang solution to account for the case where the stream and pumped aquifer both have finite widths. Additionally, Butler et al. (2007) obtained a solution for drawdown and stream depletion in a stream-leaky aquifer system. The pumped aquifer is underlain by a leaky aquitard that sits above a constant-head aquifer. Only horizontal flow in the pumped aquifer and pumping-induced vertical flow in the aquitard are considered.

\subsubsection{Unconfined Aquifer Models}

Until recently, most analytical models for stream depletion focused on the confined aquifer case. Hunt (2003) was the first to develop an analytical solution that simulates drawdown and stream depletion in a water-table or unconfined aquifer. The hydrogeology described by the analytical solution of Boulton (1963) for delayed-yield drawdown 
response is used in the formulation of the solution. Later, Hunt (2009) obtained a stream depletion solution for a well abstracting water near a partially penetrating stream in a multi-layered, leaky-aquifer system.

\subsubsection{Limitations of Analytical Models}

All of the analytical solutions described above that have been developed to estimate stream depletion by groundwater pumping rely on a series of idealized assumptions. The assumptions of these models, such as fixed stream stage, no vertical flow in aquifer interacting with stream, stream stage same as initial aquifer head, streambed leakage modeled using classical conductance/leakance approach which neglects streambed storage, isotropic aquifer, and homogenous streambed, have limited applicability in natural systems. Thus, there is opportunity to develop a solution that can be used to assess drawdown and stream depletion in more realistic stream-aquifer systems than those previously considered.

\subsubsection{Numerical Models}

Numerical groundwater models were first developed in the 1970s and 1980s to overcome some of the simplifying assumptions on which analytical models are based (Hunt, 2012). Numerical modeling approaches allow for solution of groundwater flow problem in inherently complex natural systems with irregular stream and aquifer geometries and heterogeneous hydraulic properties. They are often used to consider more complex boundary geometries in one-dimensional problems and to study basinscale flow in two and three dimensions (Barlow and Leake, 2012; Bredehoeft and Kendy, 2008). According to Barlow and Leake (2012), numerical groundwater models are the most powerful tools for estimating streamflow depletion from groundwater pumping. Several categories of numerical groundwater models exist: 1) finite difference, 
2) finite element, 3) finite volume, and 4) analytic element models, all of which require user construction and calibration prior to model simulation of system behavior (Faust et al., 1980). The most commonly used to simulate groundwater-surface water interactions are the finite difference and finite element models, in particular the USGS finite-difference groundwater-model program, MODFLOW (Brunner et al., 2010; Harbaugh, 2005; McDonald and Harbaugh, 1988). For example, Nyholm et al. (2002) used MODLOW to estimate stream depletion caused by well drawdown in a watershed in Denmark. Rodríguez et al. (2006) used MODFLOW to analyze streamaquifer interactions in a shallow aquifer on Choele Choel Island, Patagonia, Argentina. Fleckenstein et al. (2006) performed numerical simulations using MODFLOW to assess how the heterogeneity of alluvial sediments influences river seepage and low flows in the Cosumnes River, California. Although MODFLOW is the most commonly used numerical groundwater model, various authors have opted to use lesser-known numerical groundwater models to accomplish their research objectives. For example, Foster and Allen (2015) conducted numerical modeling using the MIKE SHE finitedifference modeling interface to explore the seasonally and spatially dynamic nature of groundwater-surface water interactions in a mountain-to-coast watershed on Vancouver Island, British Columbia, Canada. Su et al. (2007) used TOUGH2, a multiphase, three-dimensional numerical model to analyze pumping-induced unsaturated regions beneath a reach of the Russian River, California. Although numerical models are advantageous in that they account for the complexities of natural systems, such models will produce biased predictions of stream depletion if not calibrated correctly. Brunner et al. (2010) provide some conceptual considerations often unseen during MODFLOW calibration that future researchers should review prior to simulation. 


\subsection{Summary}

Groundwater and surface water systems are interconnected. Exchanges between groundwater and surface water occur at various scales so any alteration to one directly or indirectly affects the other. Groundwater abstraction can cause streamflow depletion in hydraulically connected stream-aquifer systems, but the rates, timing, and location of depletion are highly variable. The factors that influence the rates and timing of streamflow depletion include the number of wells and distance of each from the stream, the hydrologic conditions along the boundaries of the groundwater system, and the geologic structure, dimensions, and hydraulic properties of the aquifer and the streambed. A wide range of methods exist to measure groundwater-surface water interactions, but there are limitations and uncertainties associated with all techniques. Thus, a multi-scale approach combining multiple measurement techniques is recommended to constrain estimates of water fluxes between streams and aquifers. Scientific research since the early 1940s has improved understanding of the causes and behavior of streamflow depletion, but under changing climatic conditions and population growth the need for continued scientific research remains.

As indicated by this literature review, groundwater-surface water interactions are inherently complex and dynamic in nature. For this reason, it is imperative to have a thorough understanding of subsurface conditions and knowledge of the degree of stream-aquifer connectivity in a particular area for appropriate water resource policy and management decisions to be made. Recently, concerns have arisen regarding the abstraction of groundwater from agricultural wells for crop irrigation on lower Scotts Creek and the potential impacts these activities may have on stream flows during the summer low-flow period. The following chapters of this thesis provide a description of the study site, the basis of the streamflow depletion concerns, the methodologies used 
to test the hypothesis and to achieve the objectives of the research, a presentation of results of the tests performed, and a discussion of study findings accompanied by sustainable groundwater pumping recommendations. 


\section{CHAPTER 3: DESCRIPTION OF STUDY AREA}

\subsection{Location and Biophysical Environment}

Scotts Creek is a $78 \mathrm{~km}^{2}$ coastal watershed located approximately $100 \mathrm{~km}$ south of San Francisco in Santa Cruz County, California. It originates in the Santa Cruz Mountains within the Coast Range and meanders southwest for $19 \mathrm{~km}$ before emptying into the Pacific Ocean. The creek is fed by three perennial tributaries (Mill, Big, and Little creeks), three intermittent tributaries (Winter, Archibald, and Queseria creeks), and several small ephemeral drainages (Figure 3.1). An estuary at the outlet of the Scotts Creek watershed becomes a freshwater lagoon during the summer low flow period when a sandbar builds up at the creek mouth (Marston, 1992, Snider et al., 1995). The focus of this study was on lower Scotts Creek, specifically the stream reach between Archibald and Queseria creeks and the underlying alluvial aquifer. Groundwater pumping is most prevalent in this region of the watershed.

The climate of the Santa Cruz Mountains is of the Mediterranean type with cool wet winters and warm dry summers. Most of the annual precipitation occurs as rain between October and April averaging $1270 \mathrm{~mm}$ (50 in). During summer months, a fog bank forms along the coast bringing cool moist air to lower elevation, fog-dependent ecosystems. Stream flows in Scotts Creek during summer months are very low $(\leq 0.1$ $\mathrm{m}^{3} / \mathrm{s}$ or $\leq 4$ cubic feet per second ( $\left.\mathrm{cfs}\right)$ ) and reach chronically dry levels until the first rain event in the fall. In the winter, Scotts Creek exhibits peak flows ranging from 20 to $70 \mathrm{~m}^{3} / \mathrm{s}$ (700-2500 cfs), as measured at the Scotts Creek streamgage below 


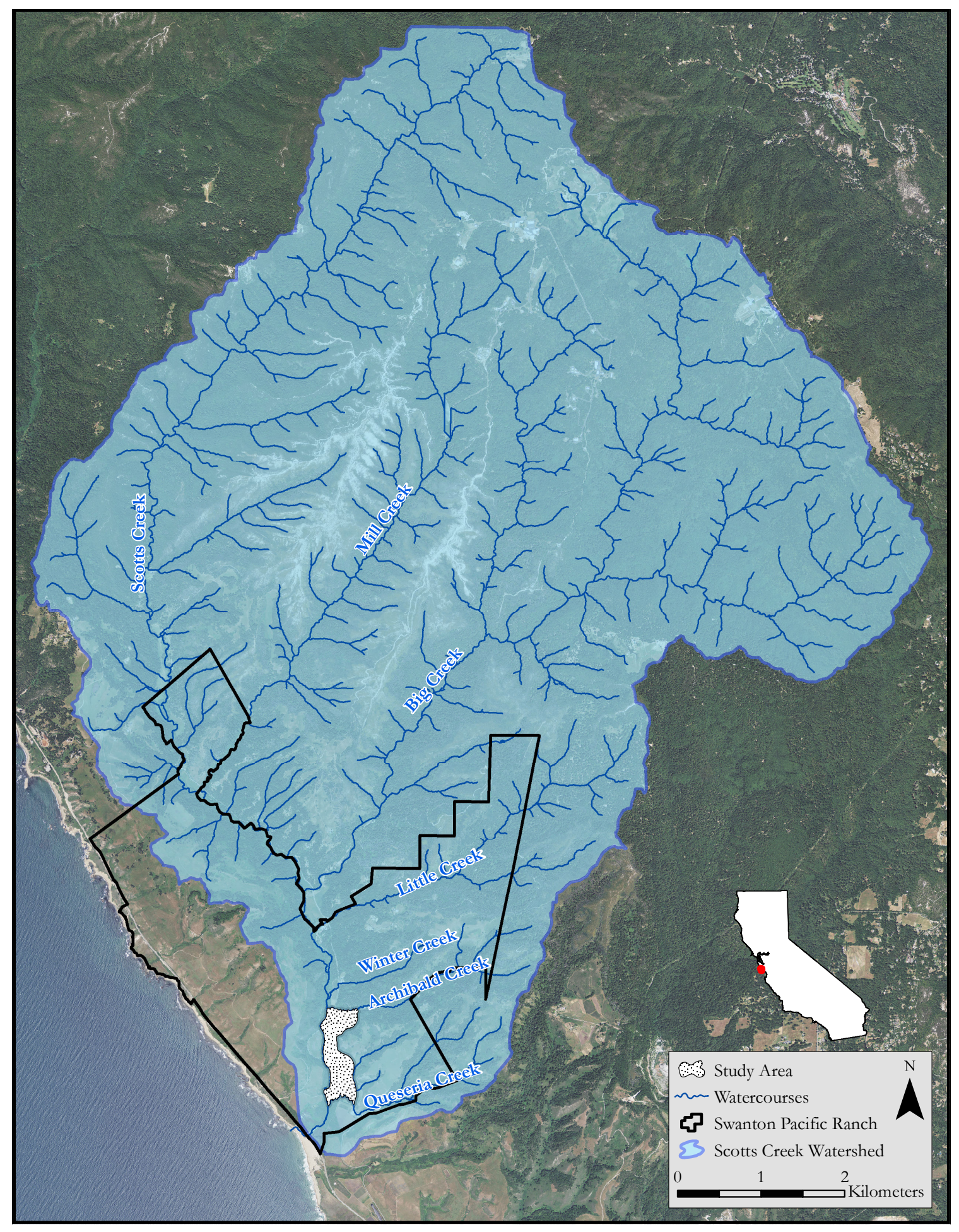

Figure 3.1: The study location at Swanton Pacific Ranch in the Scotts Creek watershed, Santa Cruz County, California. 
Archibald Creek.

The Scotts Creek watershed lies in the tectonically active central California Coast Ranges between the San Gregorio and San Andreas fault zones. The watershed rests on the Salinian block, which is comprised of dominately quartz diorite (Cretaceous), Santa Margarita Sandstone (Miocene), and Santa Cruz Mudstone (Late Miocene). The sedimentary rocks (Santa Margarita Sandstone and Santa Cruz Mudstone) dominate the surface geology of the Scotts Creek watershed, but the granitic basement is evident in the upper reaches of the main stem and tributaries. The lower portion of the watershed consists of alluvium from mixed rock sources overlying Santa Cruz Mudstone bedrock (Taskey, 2017).

The Scotts Creek watershed supports a diverse community of over 600 native plant species (West, 2014). The upper portion of the watershed is high gradient and dominated by mixed conifer stands of coast redwoods (Sequoia sempervirens) and Douglas fir (Pseudotsuga menziesii), and mixed hardwood stands of Douglas fir, tanoak (Notholithocarpus densiflorus), pacific madrone (Arbutus menziesii), California bay laurel (Umbellularia californica), and coast live oak (Quercus agrifolia). The ridgelines are dominated by knobcone pine (Pinus attenuata) and various chaparral species including manzanita (Arctostaphylos spp.) and chamise (Adenostoma fasciculatum). The lower portion of the watershed is low gradient and supports a thick riparian plant community of red alder (Alnus rubra), arroyo willow (Salix lasiolepis), yellow willow (Salix lutea), and big leaf maple (Acer macrophyllum).

Scotts Creek is unique in that it supports the southernmost extant population of coho salmon in North America, which is listed as a federally-endangered species under the U.S. Endangered Species Act (ESA). Scotts Creek also provides habitat for several other sensitive species including the steelhead trout, tidewater goby (Eucyclogobius newberyi), and red-legged frog (Rana aurora) (Marston, 1992; Snider et al., 1995). A 
variety of factors including overfishing, changes in climatic and oceanic conditions, reduction in water quality, and habitat degradation have contributed to declines in the natural population of coho salmon. In Scotts Creek, the native coho salmon population has survived despite natural and anthropogenic stresses.

\subsection{Development of Lower Scotts Creek Groundwater Resources}

Swanton Pacific Ranch (SPR), a $13 \mathrm{~km}^{2}$ (3,200-acre) educational and research facility owned by Cal Poly Corporation and managed by the College of Agriculture, Food, and Environmental Sciences (CAFES), currently leases approximately $0.25 \mathrm{~km}^{2}$ (65 acres) of prime agricultural cropland on lower Scotts Creek to Jacobs Farm/Del Cabo. Three high-capacity irrigation wells (Archibald, Pump House, and VFD wells) provide groundwater for agricultural purposes including irrigation. A fourth well (Queseria Well) located downstream of the VFD Well is used primarily as a monitoring well. Well completion reports requested from the California Department of Water Resources (CDWR) indicate that two irrigation wells were established on lower Scotts Creek in 1964. A third irrigation well was installed in 1984. The well completion reports provide valuable information pertaining to well construction and the types of sediments removed during installation (see Appendix A for well completion reports). However, the reports lack a detailed description of drilling location making it difficult to match each report to its respective well. That said, based on well completion reports, field inspection of the wells, and information provided by Swanton Pacific Ranch staff, it is believed that the Archibald and VFD wells were completed in 1964 and that the Pump House Well was installed later in 1984. On this basis, it is inferred that the Archibald Well is 12 inches in diameter, 110 feet deep, and perforated from 15 to 105 feet (report No. 67476). An additional report indicates that the Archibald 
Well was cleaned in 1984, although there is no indication as to why a cleaning was needed (report No. 056712). The existing 12-inch casing was cleaned out to 70 feet and 60 feet of 8-inch pipe with 10 feet of blank casing was installed. The VFD Well is 12 inches in diameter, 110 feet deep, and perforated from 50 to 110 feet (report No. 67477). The Pump House Well is 8 inches in diameter, 110 feet deep, and perforated from 60 to 110 feet (report No. 056730). All three wells are steel cased. The well completion reports indicate depth to bedrock ranges from 105-108 feet. The Queseria Well is 6 inches in diameter and made of plastic (likely polyvinyl chloride (PVC)), but the total depth and screened interval is unknown.

Currently, the VFD and Pump House wells are the two wells primarily used by Jacobs Farm to irrigate crops. Flowmeter and pressure transducer data indicate that the wells are pumped at an average rate of $200 \mathrm{gpm}$ for a duration of 4-10 hours six times a week from May through October. Figures 3.2 and 3.3 show pressure transducer data, with head in meters relative to the installation point of the pressure transducer (all subsequent graphs with "head" on y-axis have same aforementioned datum/reference point), recorded in the VFD and Pump House wells, respectively. The Archibald Well, which is mainly used to fill a Jacobs Farm water tank, is pumped for a duration of 2-8 hours five times a week May through October (Figure 3.4). The greatest groundwater withdrawals from all three wells occur during the midto late-summer period (July through September) when crop irrigation demands are highest. During this time, both the duration and frequency at which the wells are pumped reaches a maximum level. Even so, the heads in all of the irrigation wells on lower Scotts Creek rebound to pre-pumping static levels when no water is being abstracted, indicating a stable groundwater supply (no significant/discernible chronic drops in groundwater levels). Cumulatively, the volume of groundwater abstracted on lower Scotts Creek is approximately 40 acre-feet $(\mathrm{AF})$ a year. 


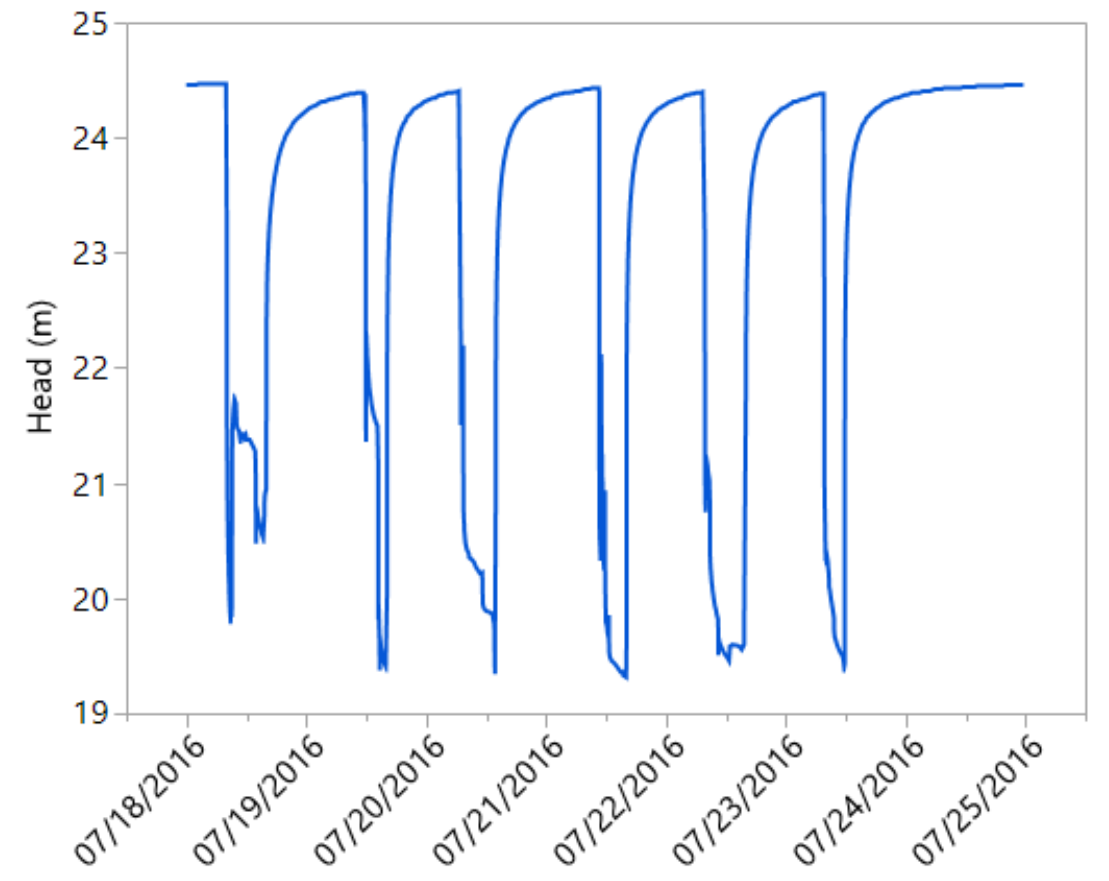

Figure 3.2: Head (m) in VFD Well under normal pumping conditions (July 18-24, 2016).

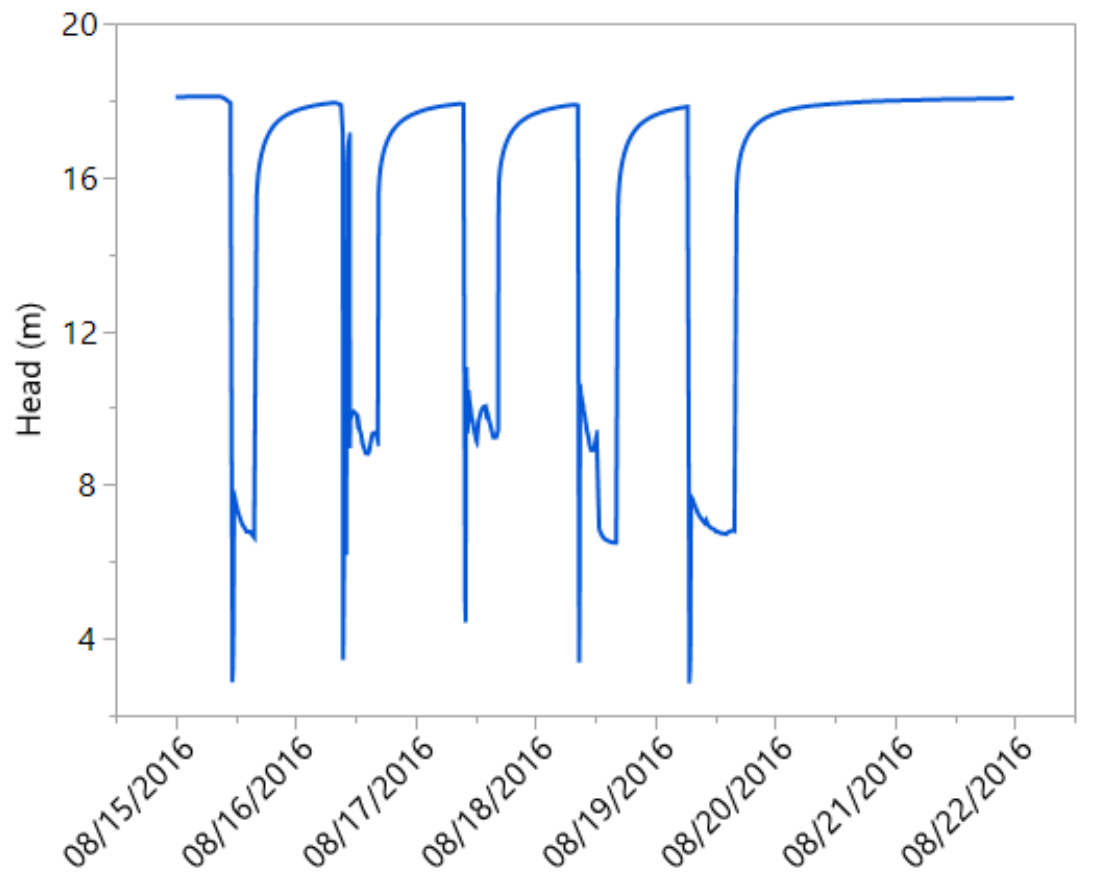

Figure 3.3: Head (m) in Pump House Well under normal pumping conditions (August 15-21, 2016). 


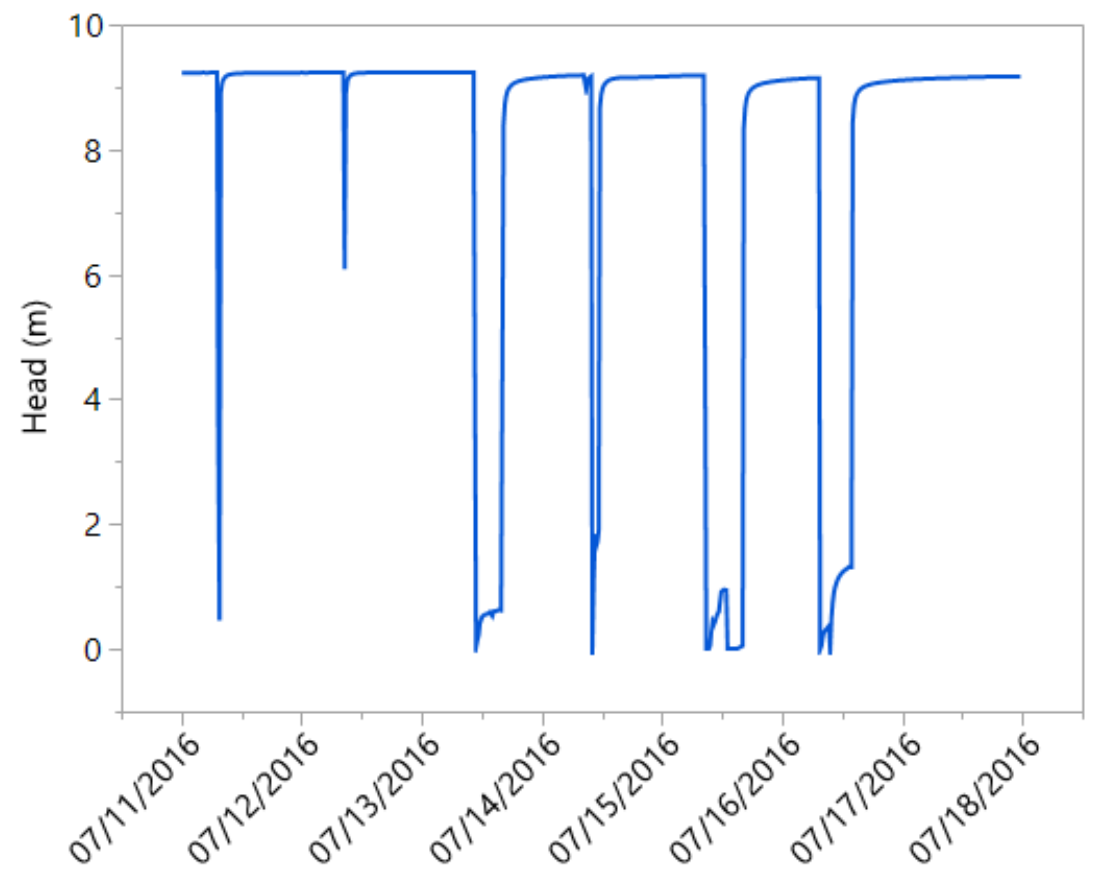

Figure 3.4: Head (m) in Archibald Well under normal pumping conditions (July 11-17, 2016).

\subsection{The Lower Scotts Creek Instream Flow Controversy}

Historically, lower Scotts Creek has been greatly modified by agricultural development and the construction of Highway 1 . In the early 1900s, the lower approximately 1 $\mathrm{km}$ of the Scotts Creek stream channel was artificially leveed on both sides to maximize the amount of arable land and to prevent flooding of agricultural crops. In 1939, the Highway 1 bridge was constructed at the outlet of Scotts Creek. These modifications to the stream channel significantly degraded aquatic habitat quality on lower Scotts Creek adversely affecting coho salmon and steelhead trout populations (Marston, 1992). In 2015, a stream restoration project designed to improve salmonid habitat on lower Scotts Creek by restoring floodplain and instream habitat for winter refugia and summer rearing was completed. The artificial levees were breached in several locations to improve floodplain connectivity and large instream wood complexes were installed to 
increase channel complexity (Cook, 2016). Although salmonid habitat on lower Scotts Creek has been improved in recent times, it has long been speculated that surface water diversions by private landowners for domestic uses and groundwater pumping by Swanton Pacific Ranch for crop irrigation adversely affect salmonid populations in Scotts Creek by depleting stream flows, particularly during the summer low-flow period (Marston, 1992; Snider et al., 1995).

The California Department of Fish and Wildlife (previously California Department of Fish and Game) stream survey records, which date back to 1934, state that the lower reach of Scotts Creek was often chronically dry during summer/fall months and that on several occasions the stream channel dried up completely resulting in degraded water quality in the lagoon and mass die-offs of juvenile coho salmon and steelhead trout (Marston, 1992). In recent years, critically low flows ( $\leq 2 \mathrm{cfs}$ ) occur regularly from late August to early October (Snider et al., 1995). In 2012, CDFW developed a draft set of instream flow recommendations for lower Scotts Creek (stream mile 0.3 upstream to stream mile 0.9) for transmittal to the California State Water Resources Control Board (SWRCB) to ensure that adequate stream flows for fish and wildlife resources are maintained. Scotts Creek was selected for development of recommended minimum instream flow levels because it is a significant watercourse with high resource value (CDFG, 2012). The recommended monthly instream flow conditions were based on an analysis of the relationship between the percentage of available habitat using a 1dimensional Physical Habitat Simulation System (PHABSIM) model, flow availability, and salmonid life stage (CDFG, 2012). However, the recommended minimum instream flow levels proposed for steelhead and coho salmon fry and juvenile rearing ( $\geq 6$ cfs June-October) were found to be higher than current measured flows indicating that minimum suggested flows are rarely achievable. The recommended flows produced by PHABSIM are primarily based upon flow levels predicted to maximize habitat for each 
life stage of steelhead and coho salmon. That said, PHABSIM does have limitations, the major one being that the existence of adequate physical habitat is necessary but does not guarantee a species' survival. There are countless interactions between species and the environment that influence the state of the ecosystem that PHABSIM is not capable of modeling (Milhous, 1999). Consequently, the methodology used to establish minimum instream flow levels has been scrutinized and is currently being reviewed. The implication of the review is that domestic surface water diversions and agricultural groundwater pumping may be restricted to ensure that adequate instream flow levels are maintained during low flow periods to protect the aquatic environment.

Currently, minimum instream flow requirements in Scotts Creek continue to be of environmental and economic concern. The need for sufficient instream flow levels to sustain salmonid populations during low flow periods, and, simultaneously, continued water availability for agricultural and domestic uses creates a critical management issue. This study aims to address concerns related to groundwater pumping by conducting a detailed investigation of stream-aquifer interactions on lower Scotts Creek. 


\section{CHAPTER 4: EXPERIMENTAL APPROACH AND MODELING}

In this chapter, the field and laboratory methods used to characterize the lower Scotts Creek alluvial aquifer and to quantify the degree of hydraulic connectivity between the stream and the aquifer are described. The field methods include exploratory borehole drilling, installation of piezometers, pumping tests, instream dye tracer tests, and electrical resistivity surveys. Next, laboratory measurements of hydraulic conductivity including falling-head permeameter tests and particle size analyses of aquifer sediments are discussed. Rate of stream depletion is then calculated using the hydraulic properties of the aquifer and aquitard as determined by field and laboratory methods. Finally, data from the previously stated field and laboratory methods are used to construct a numerical groundwater flow model (MODFLOW) and simulations are performed.

\subsection{Field Investigations}

\subsubsection{Exploratory Borehole Drilling}

Eighteen exploratory boreholes (Figure 4.1) were drilled on the lower Scotts Creek floodplain using a direct push hydraulic probe (AMS PowerProbe 9120-RAP) (Figure $4.2 \mathrm{a}$ ) to obtain sediment cores (Figure 4.2b) for stratigraphic and structural characterization of the subsurface, laboratory testing, and to install piezometers for

monitoring of groundwater levels. Fourteen exploratory boreholes were drilled during the summer of 2016 and an additional four boreholes were drilled during the summer of 
2017. The fourteen boreholes completed in the summer of 2016 were drilled to depths not exceeding 32 feet (all depths are below ground surface), with the majority of the boreholes drilled to about 16 feet depth (first groundwater was intercepted at shallow depths of a few feet below ground surface so 16 feet was considered an adequate depth for piezometer installation/monitoring of groundwater levels). The four boreholes completed during the summer of 2017 were drilled to depths not exceeding 40 feet. Drilling depth was limited to 40 feet by drilling equipment and tooling capabilities.

In all boreholes, first groundwater was intercepted at shallow depths not exceeding 10 feet, and in some locations, depths to the water table were as shallow as 2 feet. Undisturbed sediment cores were collected from all boreholes. A 4-foot long by 1.5-inch diameter plastic sediment collection sleeve was mounted inside the leading section of 2.25-inch diameter drilling tooling and slowly pressed into the sediment. As boreholes were drilled, sediment cores were retrieved, visually inspected to note composition and other physical characteristics, and stored for laboratory testing. Visual inspection revealed a mixture of sediment units and a range of textures, including gravels, sands, silts, and clays. A wide variation in layer thickness, grain size, and sorting of grains was observed. In boreholes drilled to 20 feet depth, samples generally consisted of unconsolidated sediment comprised of brown sandy loam from land surface to a depth of about 4 feet, brown to red micaceous silty sand and gravel from about 4 feet to approximately 16 feet depth, and a dark gray to black silt and clay zone from around 16 to 20 feet depth. The apparent silt and clay layer was encountered in all drilling locations, but depth to first indication and vertical extent varied. Additionally, the lithology of the layer varied from fine-grained silty sand to clay. Figure 4.3 is the log of boring exploratory borehole 1 (EB-1) and provides a description of the subsurface conditions encountered during drilling and the sediments retrieved (see Appendix B for the other exploratory borehole drilling logs). Seven of the eighteen boreholes were 


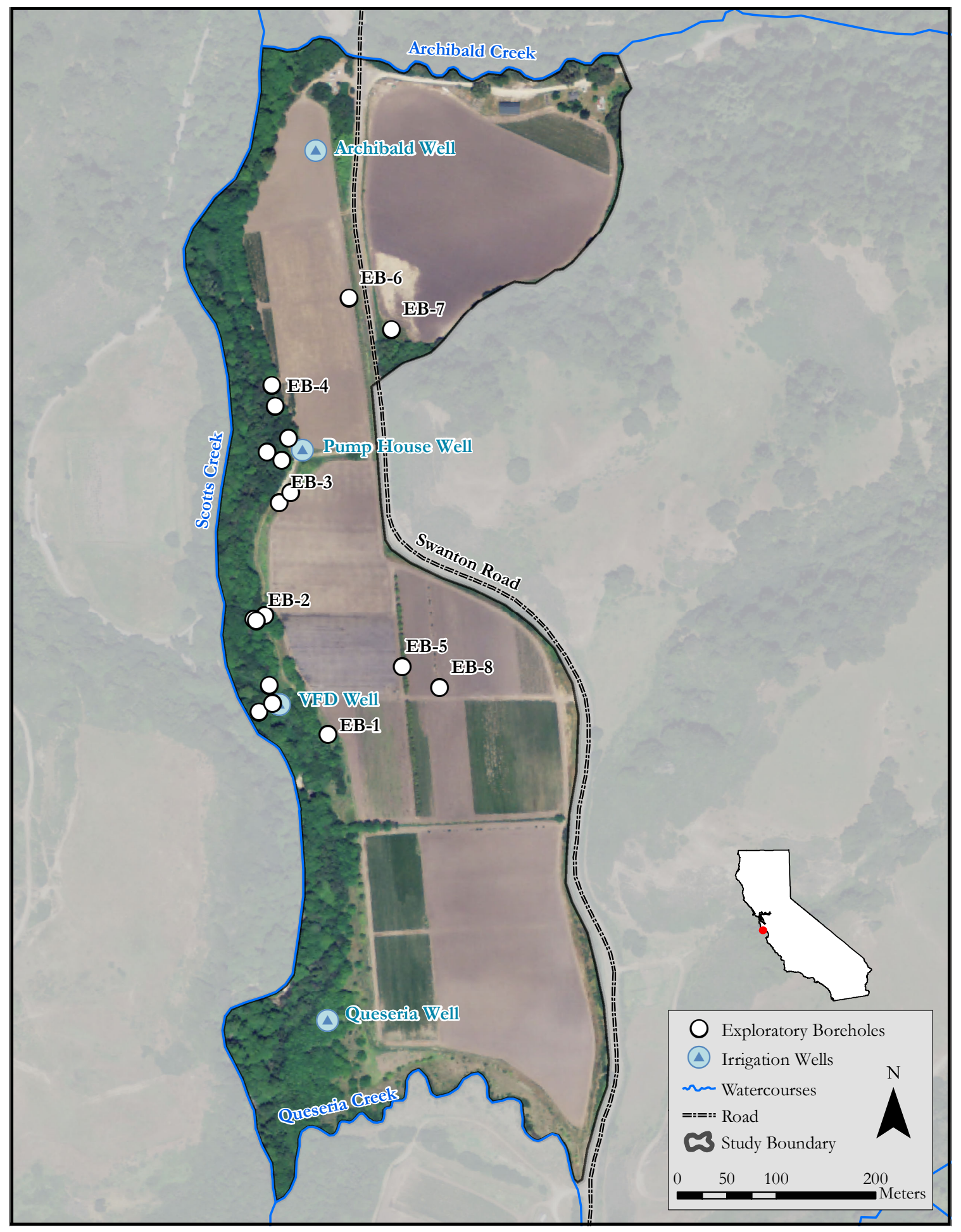

Figure 4.1: The locations where exploratory boreholes were drilled on lower Scotts Creek. 


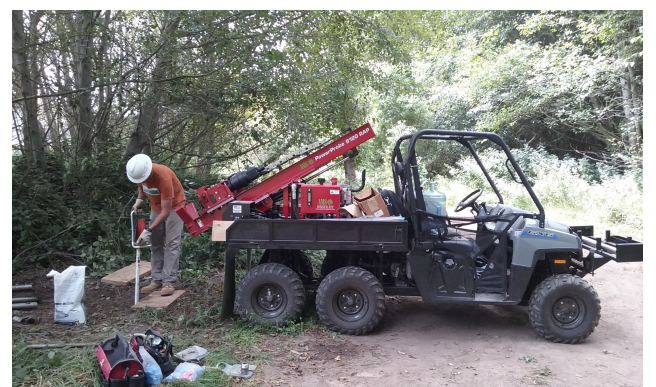

(a)

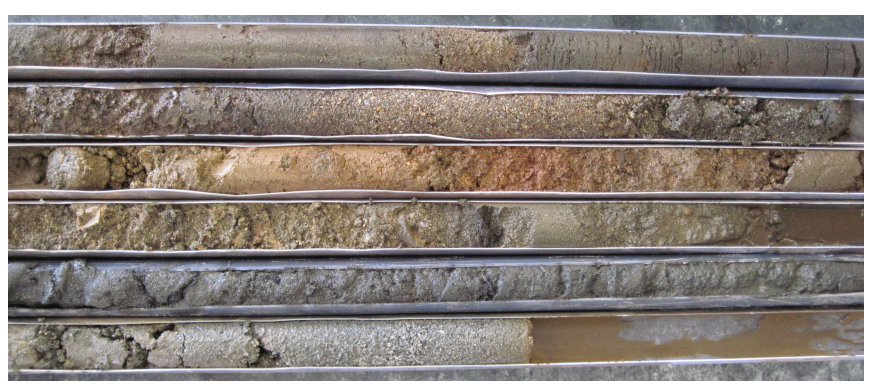

(b)

Figure 4.2: (a): The AMS PowerProbe 9120-RAP used to drill exploratory boreholes and to install piezometers, and; (b): EB-1 sediments collected from 0 (top) to 24 (bottom) feet.

drilled to depths exceeding 20 feet, and four of the seven boreholes were drilled to depths exceeding 24 feet. Beyond 20 feet depth, sediments generally consisted of sand and gravel interbedded with deposits of silt and clay. In the deep boreholes $(>24$ feet depth), heaving of sediments occurred around 30-40 feet depth when the drilling tooling breached through a semi-confining unit into a fully saturated sand and gravel layer. The heaved sediments comprised moderately well sorted clean (low in fines) sand and gravel.

The complex interbedding of fine- and coarse-grained sediments observed in all eighteen boreholes indicates a varied depositional environment. The fine silt and clay sediments appear to form a thin and laterally discontinuous semi-confining lowpermeability layer (aquitard) of variable thickness and spatial extent overlying a relatively homogeneous sand and gravel aquifer as indicated by the heaving (due to a different and higher pressure) of sands and gravels between 30 and 40 feet depth. In some locations, the aquitard appears to form a single continuous unit, but in general is is discontinuous, forming a semi-confining layer that is a heterogeneous unit of low-permeability material layered with thin permeable zones.

Although first water was encountered at shallow depths of a few feet below land 


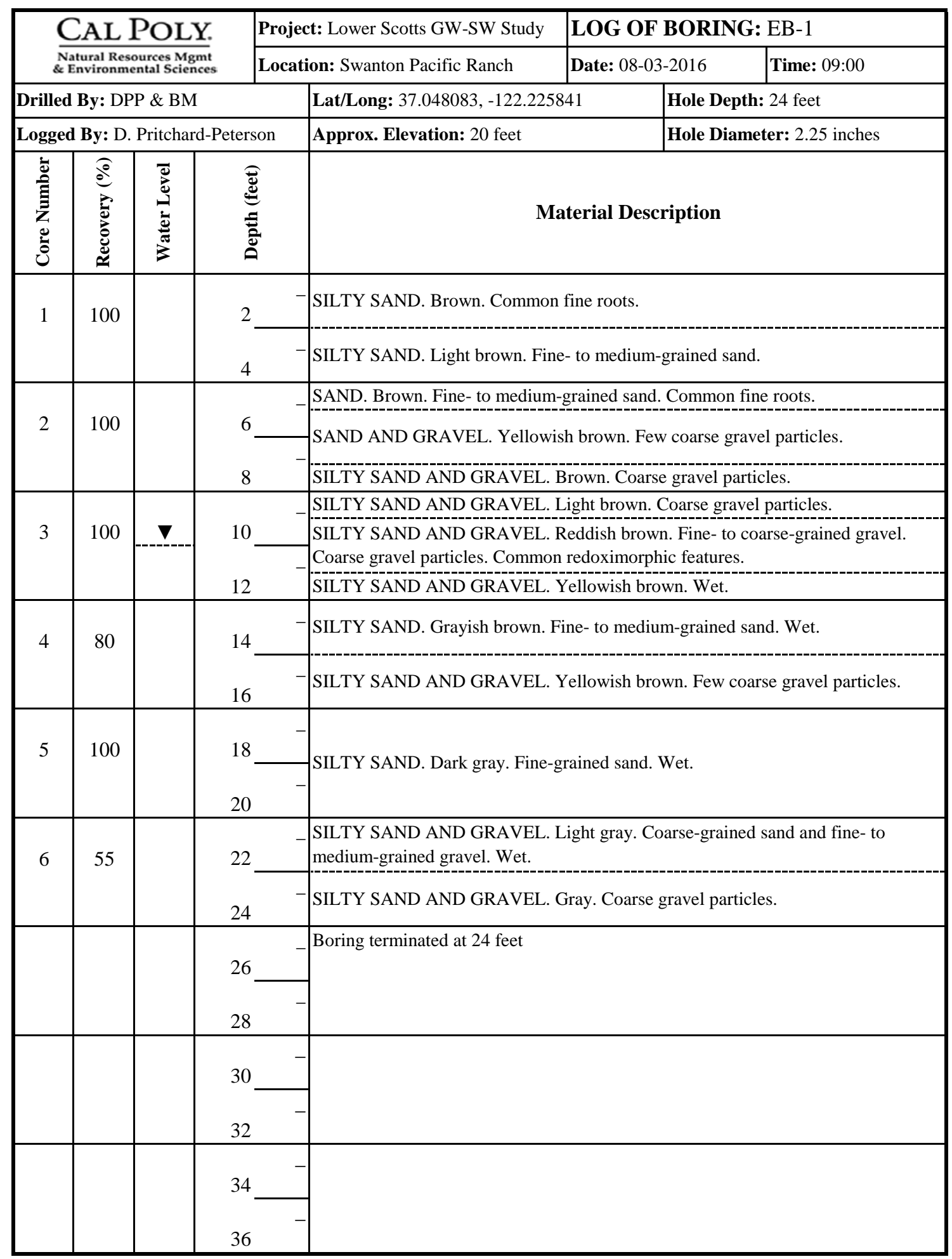

Figure 4.3: Log of boring EB-1. 
surface, the more significant water-bearing formation appears to be the sand and gravel aquifer located at depths of 30 feet and greater. Exploratory borehole drilling results suggest that Scotts Creek is hydraulically connected to the upper unconfined aquifer (layer 1) where first water was encountered, but is separated, by a thin silt and clay aquitard (layer 2), from the lower semi-confined sand and gravel aquifer (layer 3) where the irrigation wells are completed.

\subsubsection{Piezometer Installation}

Two sets of piezometers were installed on lower Scotts Creek: 1) riparian and 2) instream. During exploratory borehole drilling operations, riparian piezometers were installed to monitor groundwater levels. Nine piezometers were installed in June 2016 between the Pump House and VFD wells, and between the wells and stream channel. A cluster of five piezometers (PHP-1 -5) were installed near the Pump House Well, and a cluster of four piezometers (VFDP-1 -4) were installed near the VFD Well. Four additional piezometers were installed in May and June 2017 between the irrigation wells and Swanton Road (JFP-1 -3), and just east of Swanton Road (AP-1) (Figure 4.4). Piezometers were installed using the AMS direct push hydraulic probe by drilling 2.25-inch diameter boreholes. Each piezometer consisted of a 1-inch diameter PVC casing with the bottom 1 foot perforated to act as a screen (Figure 4.5a). The annulus around each piezometer was filled with coarse sand. Upon completion, piezometers were equipped with vented pressure transducers (INW PT2X Smart Sensor with $\pm 0.05 \%$ full scale output (FSO) typical error and \pm 0.1\% FSO maximum error) for continuous monitoring of groundwater levels. Pressure transducer logging intervals were set to 15 minutes for long-term data collection and were adjusted to shorter logging intervals during pumping tests. Figure 4.6 is an example of long-term groundwater level data recorded in Pump House Piezometer 
1 (PHP-1) over a one week period in summer of 2016. The data show the diurnal fluctuations in groundwater levels $(\sim 1 \mathrm{~cm})$ in response to evapotranspiration by riparian vegetation (phreatophytes). The depth to water, total depth, and height of the riser (above ground surface) of each piezometer measured on August 16, 2017 are provided in Table 4.1 .

Five instream piezometers were installed in June 2016 in Scotts Creek to measure stream stage. Instream piezometers were installed by driving a fence post into the streambed and securing to the post using hose clamps an approximately 5 -foot length of 1.5-inch diameter PVC casing with the bottom 1 foot perforated and the end capped (Figure 4.5b). One instream piezometer was installed approximately $100 \mathrm{~m}$ upstream of the Scotts Creek/Archibald Creek confluence (Arch-up) as a control while the additional four piezometers were installed near the VFD (VFD-up and -down) and Pump House (PH-up and -down) wells (Figure 4.4). Instream piezometers were equipped with non-vented absolute pressure transducers (HOBO U20L Water Level Logger with $\pm 0.1 \%$ FSO typical error and $\pm 0.2 \%$ FSO maximum error) for continuous monitoring of stream stage. A HOBO U20L Water Level Logger was deployed above the water in the shade to compensate for barometric pressure changes. Pressure transducer logging intervals were set to 5 minutes. Instream piezometers were removed August 11, 2016, five days after pumping tests were completed. The depth to water in each instream piezometer measured on August 6, 2016 are provided in Table 4.1.

Following piezometer installation, the geographic location and elevation of piezometers and irrigation wells were determined using electronic survey equipment (Topcon total station) (Table 4.1; see Appendix $\mathrm{C}$ for geographic locations). Permanent survey control points established during a recent stream restoration project on lower Scotts Creek were used to survey the top of each piezometer and each irrigation 


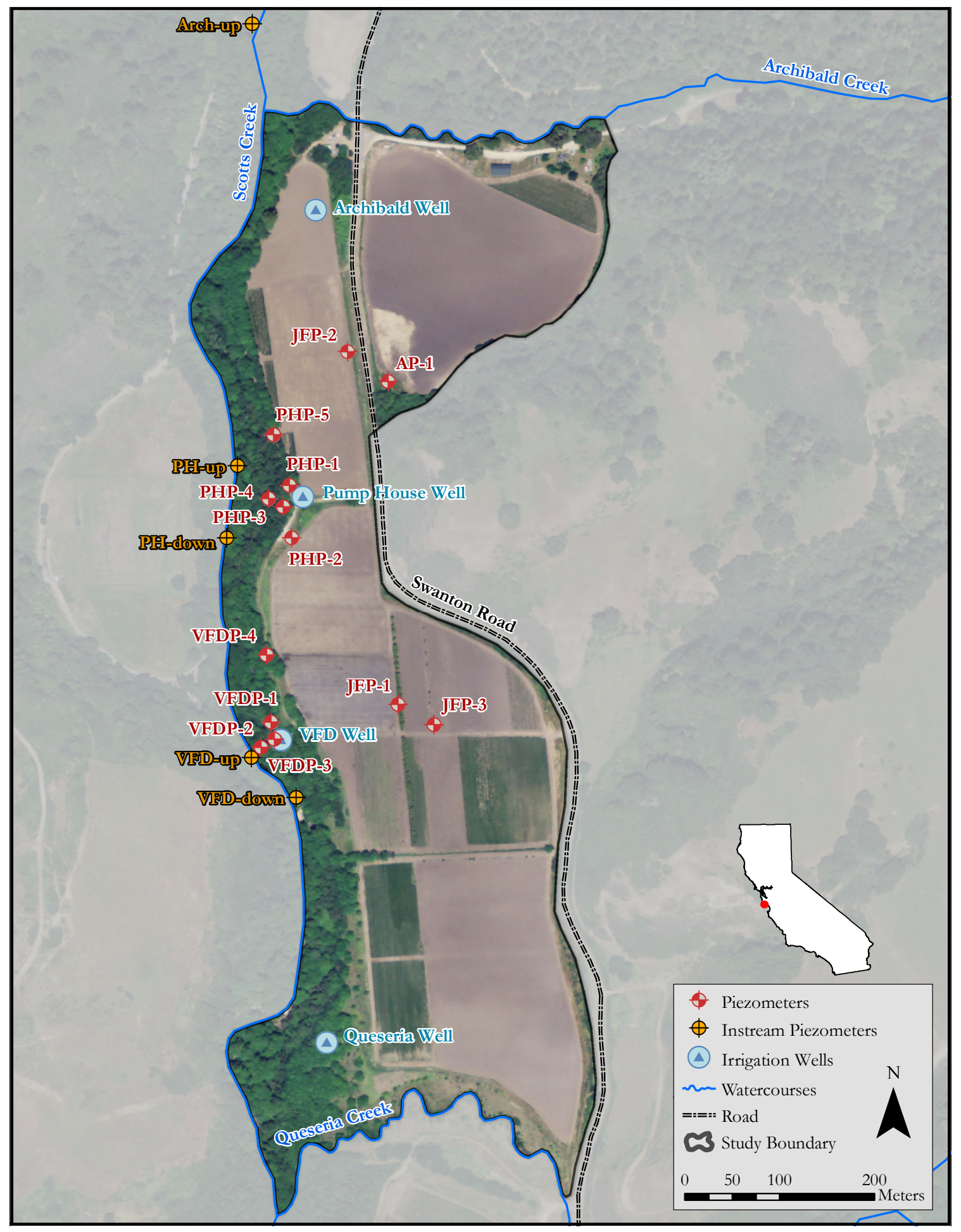

Figure 4.4: The locations of irrigation wells, riparian piezometers, and instream piezometers on lower Scotts Creek. 


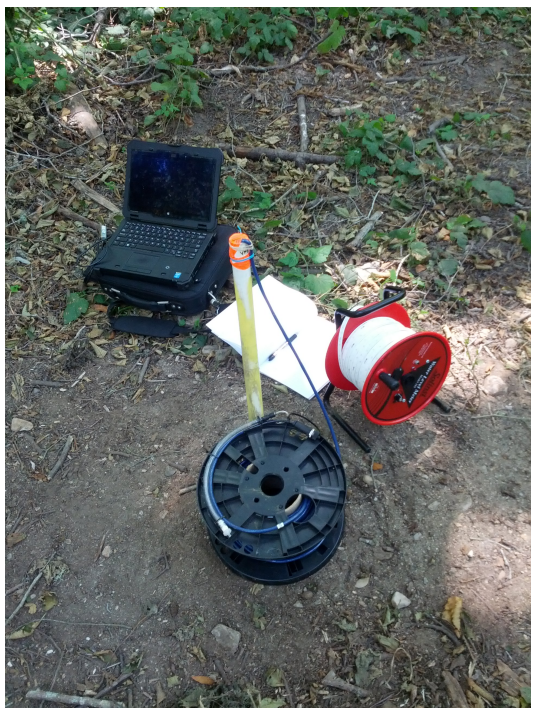

(a)

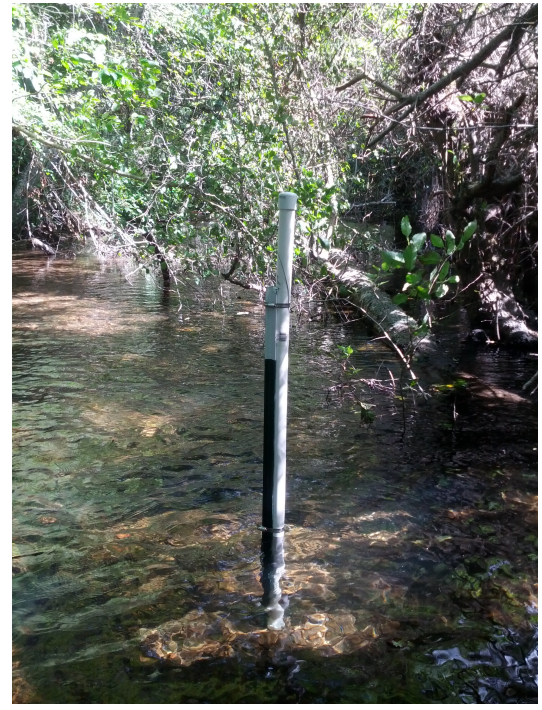

(b)

Figure 4.5: (a): Riparian piezometer equipped with an INW PT2X Smart Sensor for continuous monitoring of groundwater levels, and; (b): Instream piezometer equipped with a HOBO U20L Water Level Logger for continuous measurement of stream stage.

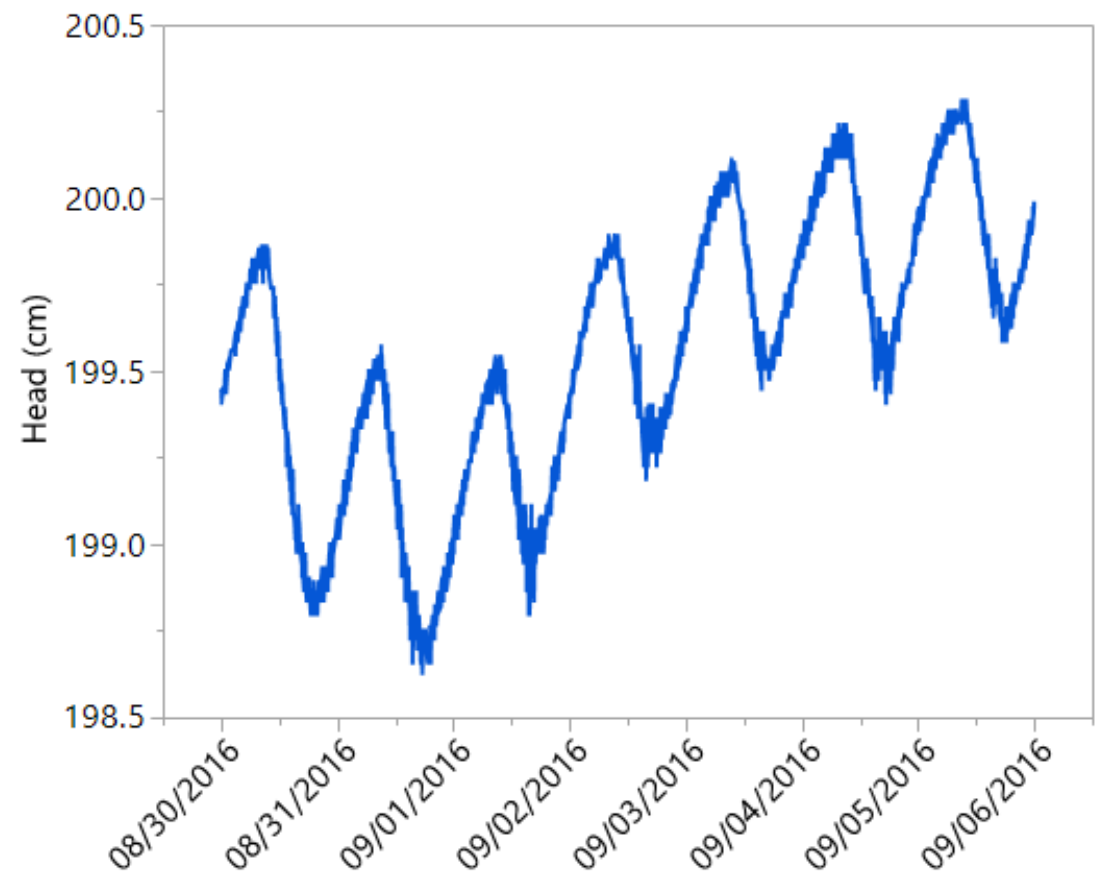

Figure 4.6: Head (cm) in PHP-1 over one week period (August 30-September 6, 2016). The data clearly shows the diurnal fluctuations in groundwater levels as a result of evapotranspiration by phreatophytes. 
well casing. The survey was performed using the North American Datum (NAD) 1983 California State Plane Zone III FIPS 0403 Feet projected coordinate system. Latitude and longitude were recorded in decimal degrees and elevations (above mean sea level (AMSL)) were recorded in feet. The elevation of the upstream-most instream piezometer (Arch-up) was not measured due to a lack of survey control in that location. Table 4.1: Elevation (feet AMSL), depth to water, total depth, and height of the riser (above ground surface) of each piezometer and each irrigation well. Static water levels in riparian piezometers and irrigation wells were measured August 16, 2017. Static water levels in instream piezometers were measured August 6, 2016. All measurements in feet from top of PVC/steel casing. Dash (-) indicates data are either not available or not applicable.

\begin{tabular}{lcccc}
\hline Piezometer/Well ID & Elevation & Depth to Water & Total Depth & Riser Height \\
\hline PHP-1 & 25.15 & 8.66 & 17.10 & 1.90 \\
PHP-2 & 24.03 & 8.27 & 17.45 & 2.03 \\
PHP-3 & 24.13 & 8.16 & 17.00 & 3.03 \\
PHP-4 & 23.57 & 7.50 & 16.65 & 2.14 \\
PHP-5 & 24.54 & 5.60 & 9.86 & 2.57 \\
VFDP-1 & 18.98 & 5.76 & 14.75 & 1.77 \\
VFDP-2 & 19.88 & 6.87 & 11.17 & 1.60 \\
VFDP-3 & 20.81 & 7.91 & 12.94 & 2.04 \\
VFDP-4 & 19.92 & 7.18 & 16.10 & 2.10 \\
JFP-1 & 22.78 & 10.55 & 26.95 & 1.55 \\
JFP-2 & 25.53 & 6.84 & 19.20 & 2.35 \\
JFP-3 & 23.60 & 10.32 & 22.67 & 1.84 \\
AP-1 & 30.90 & 5.02 & 13.41 & 3.57 \\
Arch-up & - & 3.16 & - & - \\
PH-up & 21.24 & 3.57 & - & - \\
PH-down & 19.03 & 2.94 & - & - \\
VFD-up & 18.25 & 3.74 & - & - \\
VFD-down & 16.52 & 2.99 & - & - \\
Archibald & 31.96 & 8.11 & 110.00 & 1.95 \\
Pump House & 28.43 & - & 110.00 & 2.50 \\
VFD & 20.12 & - & 110.00 & 0.40 \\
Queseria & 17.40 & - & - & - \\
\hline
\end{tabular}




\subsubsection{Pumping Tests}

A pumping test is an aquifer test that indicates how the hydraulic head in a water-bearing formation responds to groundwater withdrawals and is the most reliable method to determine aquifer hydraulic parameters and to investigate stream-aquifer connectivity (Bradbury and Muldoon, 1990; Heath, 1983; Kalbus et al., 2006). Two constant rate pumping tests were conducted in August 2016 to investigate the streamaquifer relationship on lower Scotts Creek and to estimate the hydraulic properties of the aquifer. The pumping wells were the VFD and Pump House wells. The pumping rate was recorded every 15 minutes in gallons per minute using an electronic water flowmeter installed on the discharge pipe at the well head. Abstracted groundwater was pumped approximately $500 \mathrm{~m}$ through a pipeline and discharged onto the Queseria Creek floodplain downstream and outside of the study area. The drawdown and recovery were monitored in the pumping well, six piezometers, and the irrigation wells that served as observation wells when not being pumped. Stream stage was measured in the five instream piezometers.

The first pumping test was conducted at the downstream-most irrigation well, the VFD Well, and was initiated on August 1, 2016 at 15:00 after a three day quiescent period of no pumping. Water was abstracted from the VFD Well at an average rate of $268 \mathrm{gpm}$ (see Appendix D for flowmeter data) for 24 hours (Figure 4.7). The response in the VFD Well is shown in Figure 4.8. Pumping test duration was limited to 24 hours due to limitations imposed by Jacobs Farm/Del Cabo irrigation needs. Groundwater levels were monitored in the Queseria, Pump House, and Archibald wells, VFD piezometers 1-4, and Pump House Piezometer 2. Additionally, stream stage was measured in the five instream piezometers. The VFD Well was shut off after 24 hours of constant pumping and groundwater level recovery was monitored for two 
days before the next pumping test was initiated.

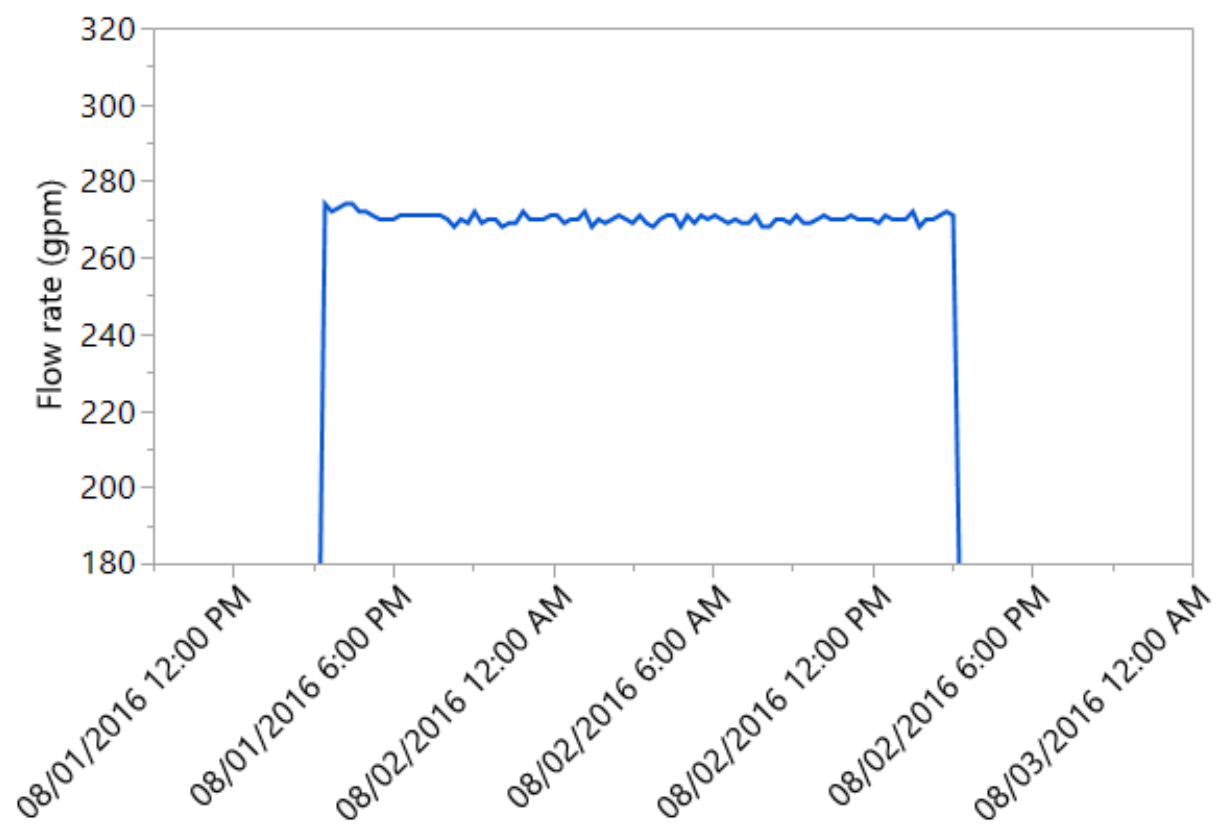

Figure 4.7: VFD Well pumping test flow rate (gpm).

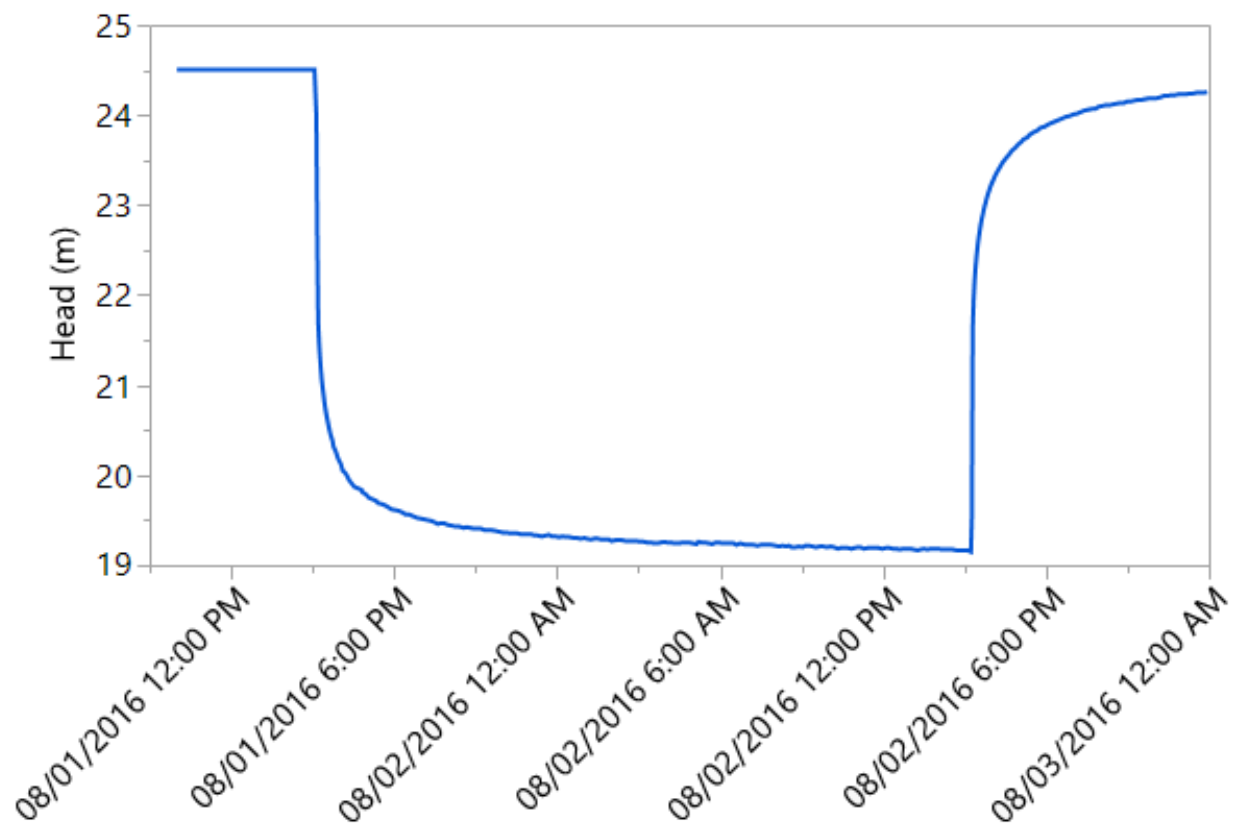

Figure 4.8: Head (m) in VFD Well during pumping test.

The second pumping test was initiated on August 5, 2016 at 14:00 after two days 
of groundwater recovery following the VFD Well pumping test. Water was abstracted from the Pump House Well at an average rate of $254 \mathrm{gpm}$ for 24 hours (Figure 4.9). The response in the Pump House Well is shown in Figure 4.10. Groundwater levels were monitored in the Queseria, VFD, and Archibald wells, Pump House piezometers 1, 3, 4, and 5, and VFD Piezometer 4. Stream stage was measured in the five instream piezometers. The Pump House Well was shut off after 24 hours and groundwater level recovery was monitored for two days before normal pumping operations by Jacobs Farm resumed.

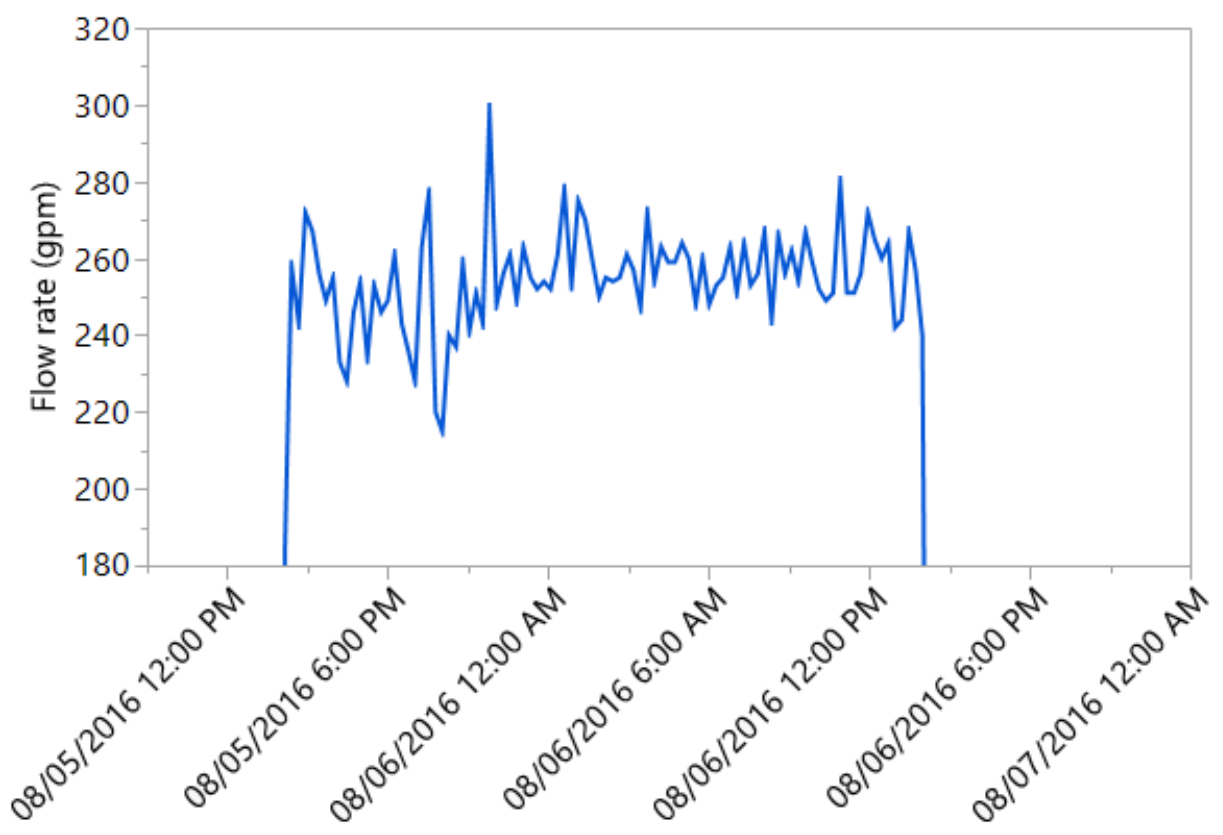

Figure 4.9: Pump House Well pumping test flow rate (gpm).

Water-level data measured in observation wells and piezometers during the pumping tests were analyzed to determine spatial and temporal variations in water flow in the aquifer and stream in response to pumping. An attenuated and delayed response to pumping was observed in almost all piezometers (Figures 4.11, 4.12, 4.13, 4.14, 4.15, 4.16, and 4.17). Several piezometers (VFDP-1, VFDP-2, VFDP-4, and PHP-2) were recovering from installation during the pumping tests making it difficult to 


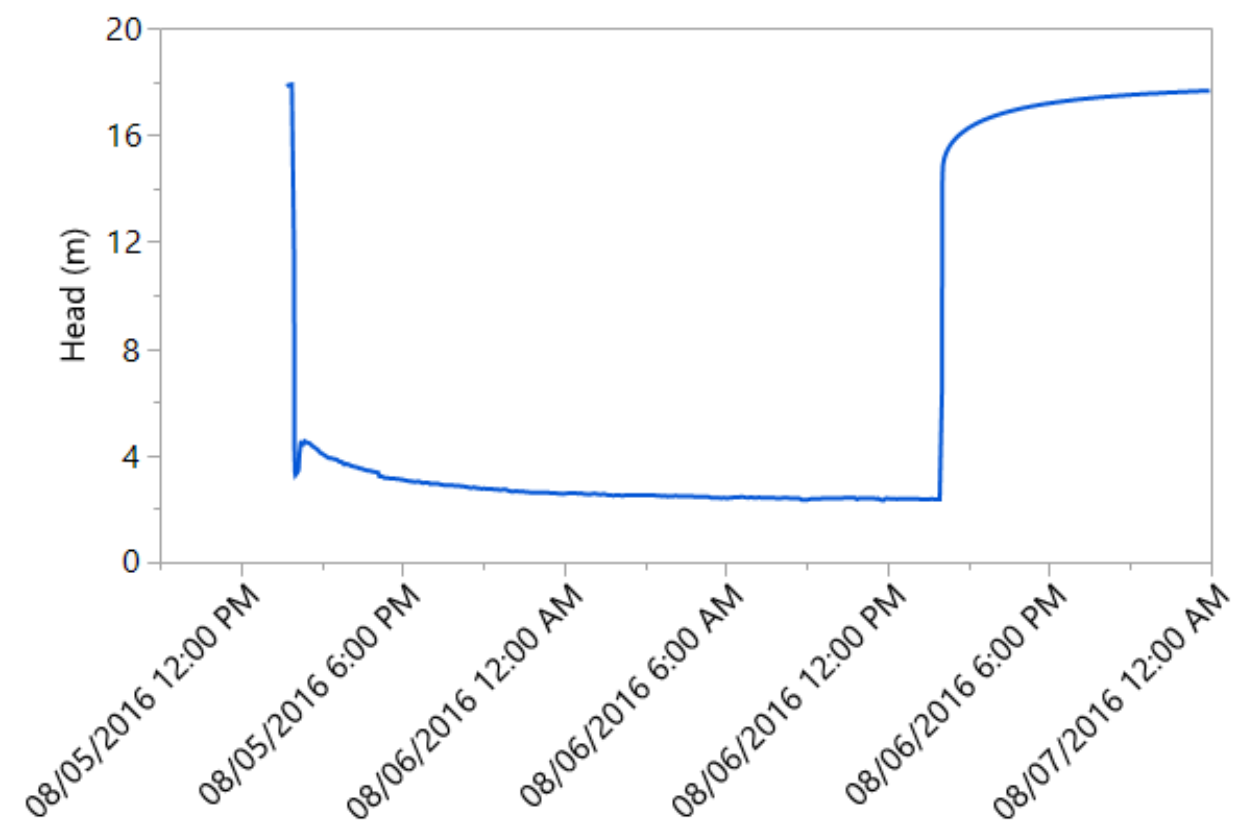

Figure 4.10: Head (m) in Pump House Well during pumping test.

differentiate between the effects of pumping and those from piezometer installation. Nevertheless, exceedingly small yet distinguishable drawdown was observed in the aforementioned piezometers. No response to pumping was observed in Pump House piezometers 3 and 5, or VFD Piezometer 3, because these piezometers were installed in the low-permeability layer encountered during direct push sampling and piezometer installation. Average drawdown measured in piezometers was approximately $2.5 \mathrm{~cm}$ with a maximum drawdown of $5 \mathrm{~cm}$ measured in PHP-1 (located at a distance of 18 $\mathrm{m}$ from the pumping well) during the Pump House Well pumping test (Figure 4.14). Similarly, no response to pumping was observed in the instream piezometers during the VFD Well pumping test, but a small decrease in stream stage of approximately $1 \mathrm{~cm}$ was measured in the instream piezometers adjacent to the Pump House Well (PH-up and PH-down) following the Pump House Well pumping test (Figure 4.17). However, it is uncertain whether the small decrease in stream stage was caused by groundwater pumping or if it can be attributed to natural factors given that the observed response 
was well within the limits of the water-level accuracy $(1-2 \mathrm{~cm})$ of the transducers used. Conversely, water levels measured in observation wells (Figures 4.18, 4.19, 4.20, and 4.21) showed a direct and unambiguous response to pumping with a maximum drawdown of approximately $0.9 \mathrm{~m}$ measured in the VFD Well (located at a distance of $260 \mathrm{~m}$ from the pumping well) during the Pump House Well pumping test (Figure 4.20). Drawdown measured in the pumping wells themselves was approximately 5.5 $\mathrm{m}$ in the VFD Well and $15.5 \mathrm{~m}$ in the Pump House Well (Figures 4.8 and 4.10, respectively). Table 4.2 provides a summary of maximum drawdown and lag time (elapsed time between when pumping began and peak drawdown occured) measured in piezometers and observation wells during the pumping tests, as well as the linear distance from the pumping well (VFD Well or Pump House Well) to each piezometer and each observation well.

Table 4.2: Summary of maximum drawdown and lag time measured in piezometers and observation wells during pumping tests, as well as the linear distance from the pumping well to each piezometer and each observation well.

\begin{tabular}{lccc}
\hline Piezometer/Well ID & Drawdown $(\mathrm{cm})$ & Lag Time $(\mathrm{hrs})$ & Dist. From Well $(\mathrm{m})$ \\
\hline VFDP-1 & 0.8 & 66 & 22 \\
VFDP-2 & 1.2 & 66 & 7 \\
VFDP-4 & 2.1 & 57 & 92 \\
PHP-1 & 5.0 & 27 & 18 \\
PHP-2 & 2.7 & 66 & 214 \\
PHP-4 & 3.8 & 27 & 36 \\
PH-up/PH-down & 1.0 & 140 & $77 / 91$ \\
Archibald & 6.0 & 24 & 305 \\
Pump House & 65.0 & 24 & 260 \\
VFD & 90.0 & 24 & 260 \\
Queseria & 45.0 & 24 & 325 \\
\hline
\end{tabular}




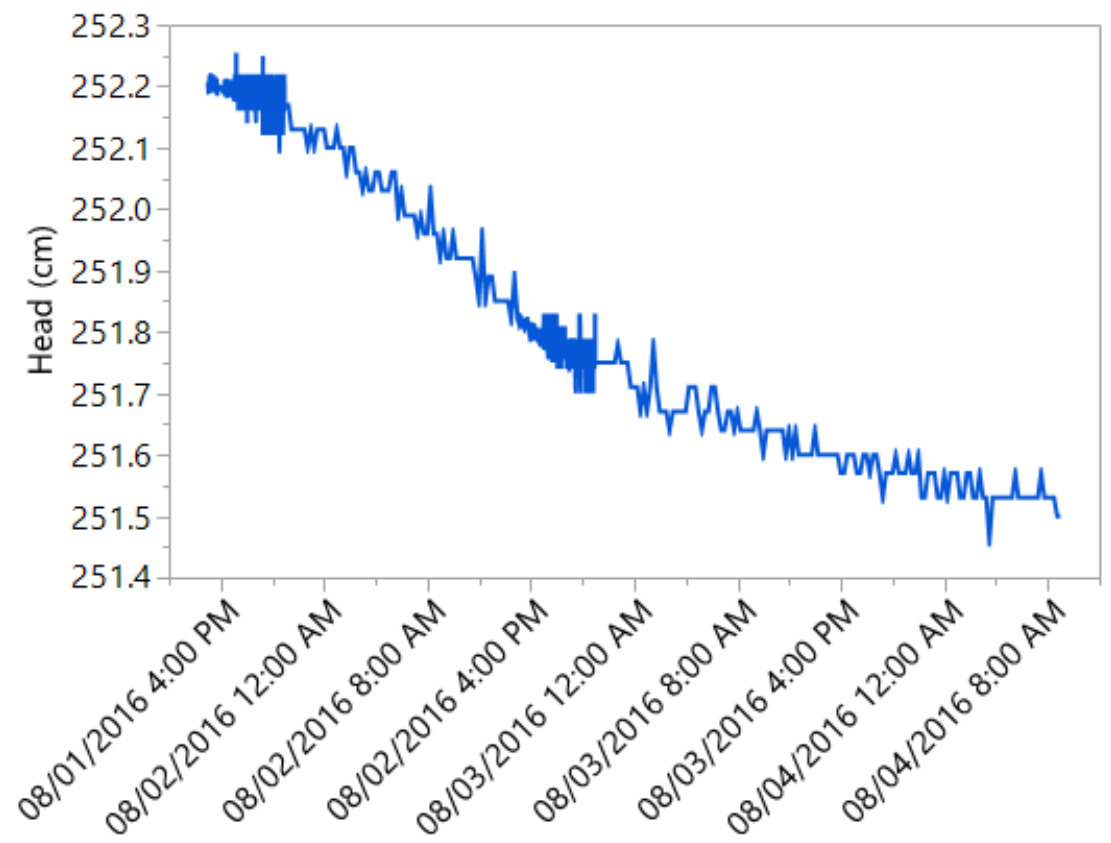

Figure 4.11: Drawdown $(\mathrm{cm})$ in VFDP-1 during VFD Well pumping test.

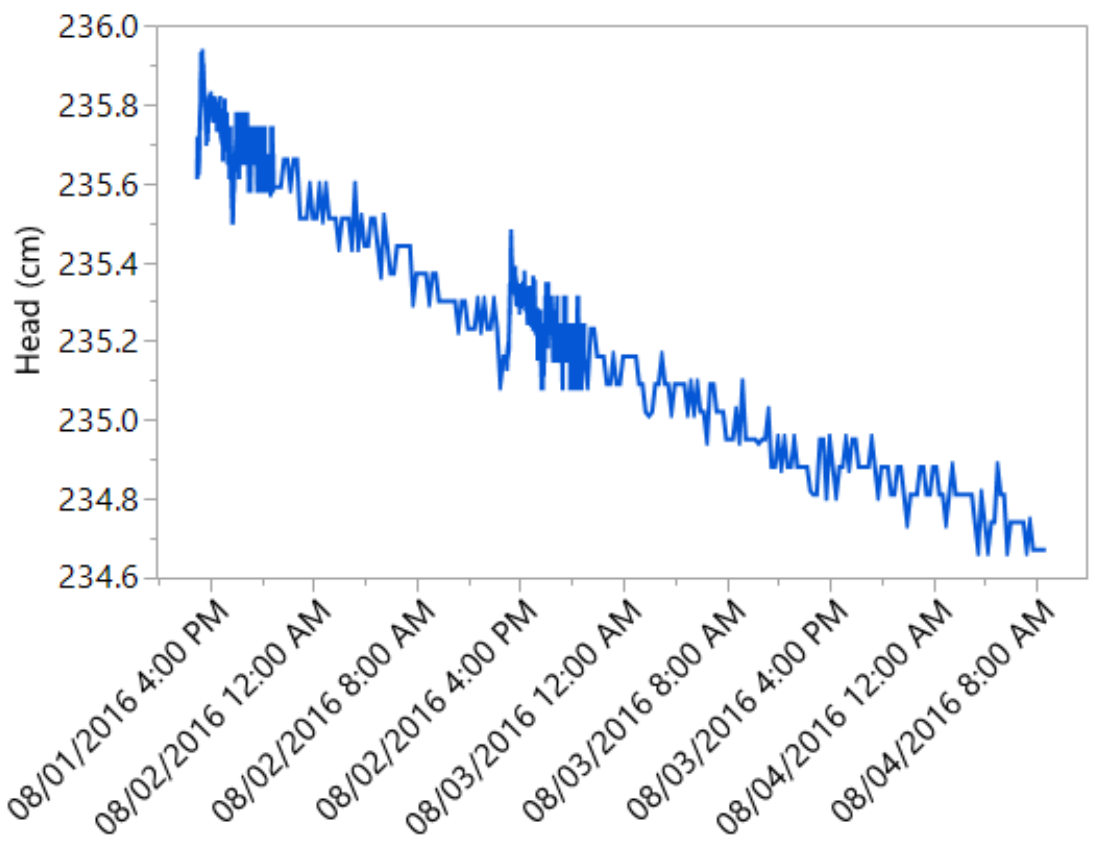

Figure 4.12: Drawdown $(\mathrm{cm})$ in VFDP-2 during VFD Well pumping test. 


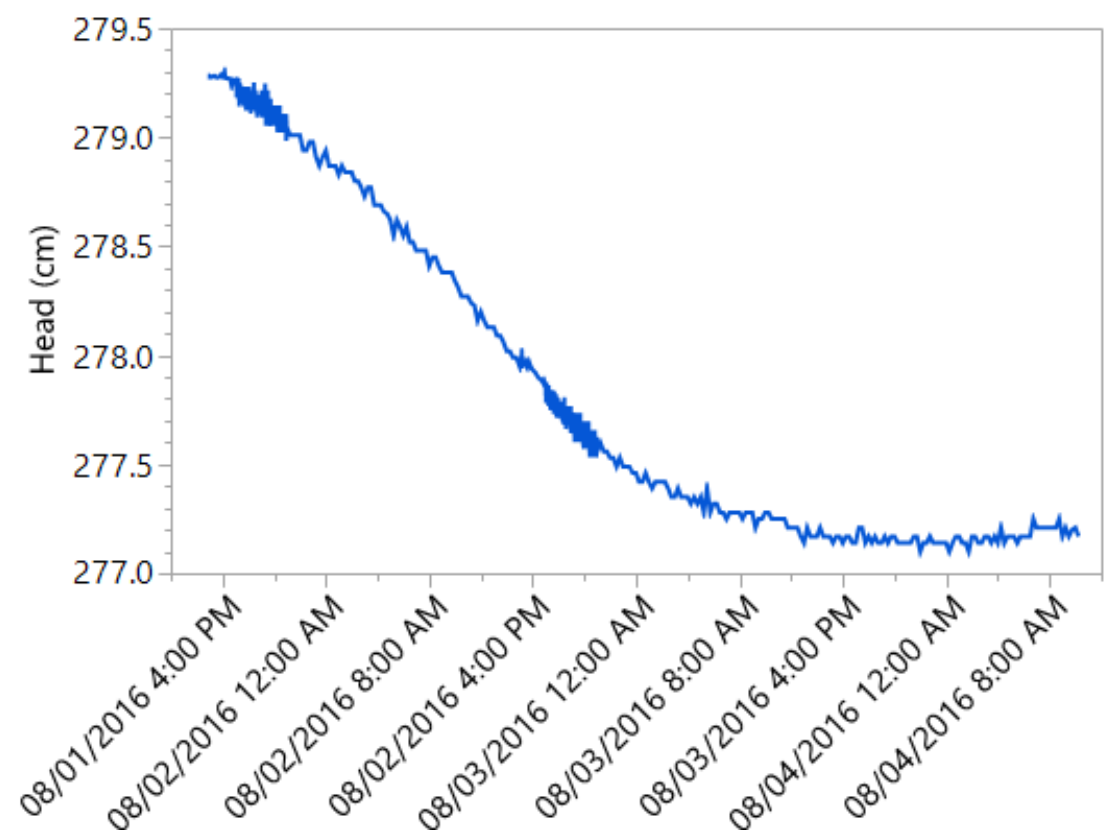

Figure 4.13: Drawdown $(\mathrm{cm})$ in VFDP-4 during VFD Well pumping test.

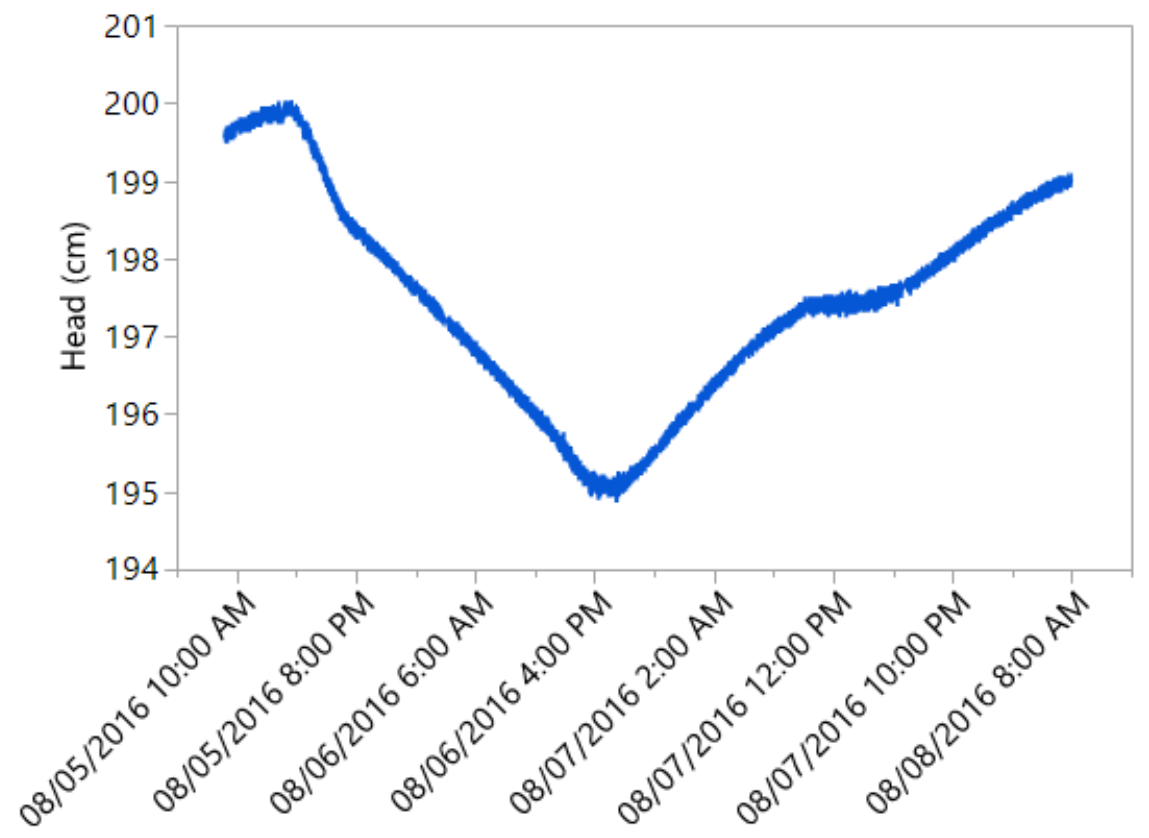

Figure 4.14: Drawdown $(\mathrm{cm})$ in PHP-1 during Pump House Well pumping test. 


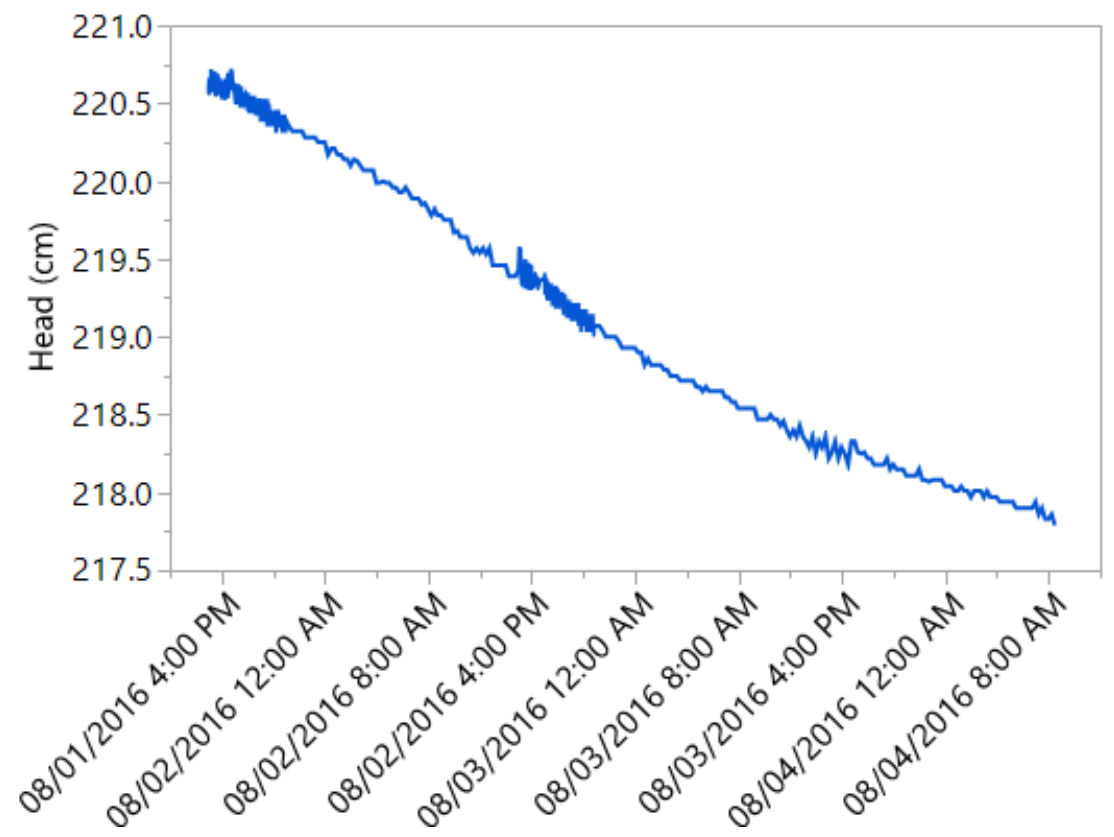

Figure 4.15: Drawdown (cm) in PHP-2 during VFD Well pumping test.

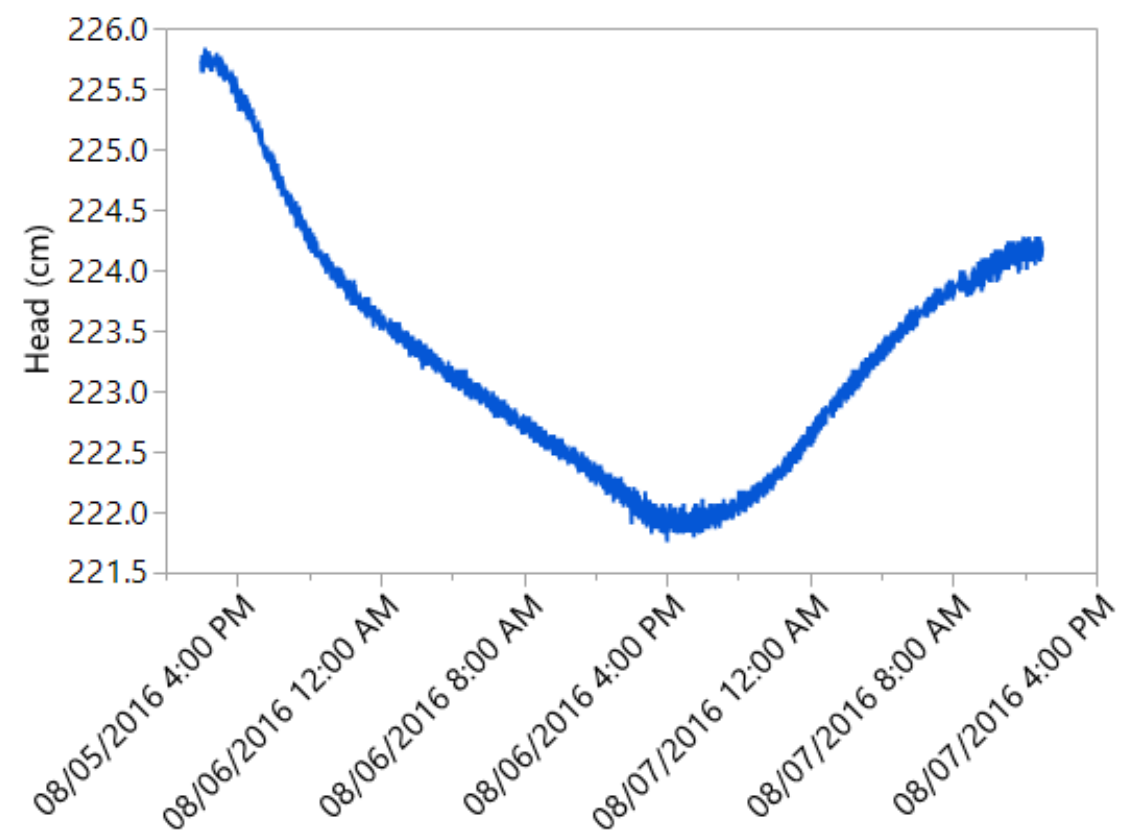

Figure 4.16: Drawdown $(\mathrm{cm})$ in PHP-4 during Pump House Well pumping test. 


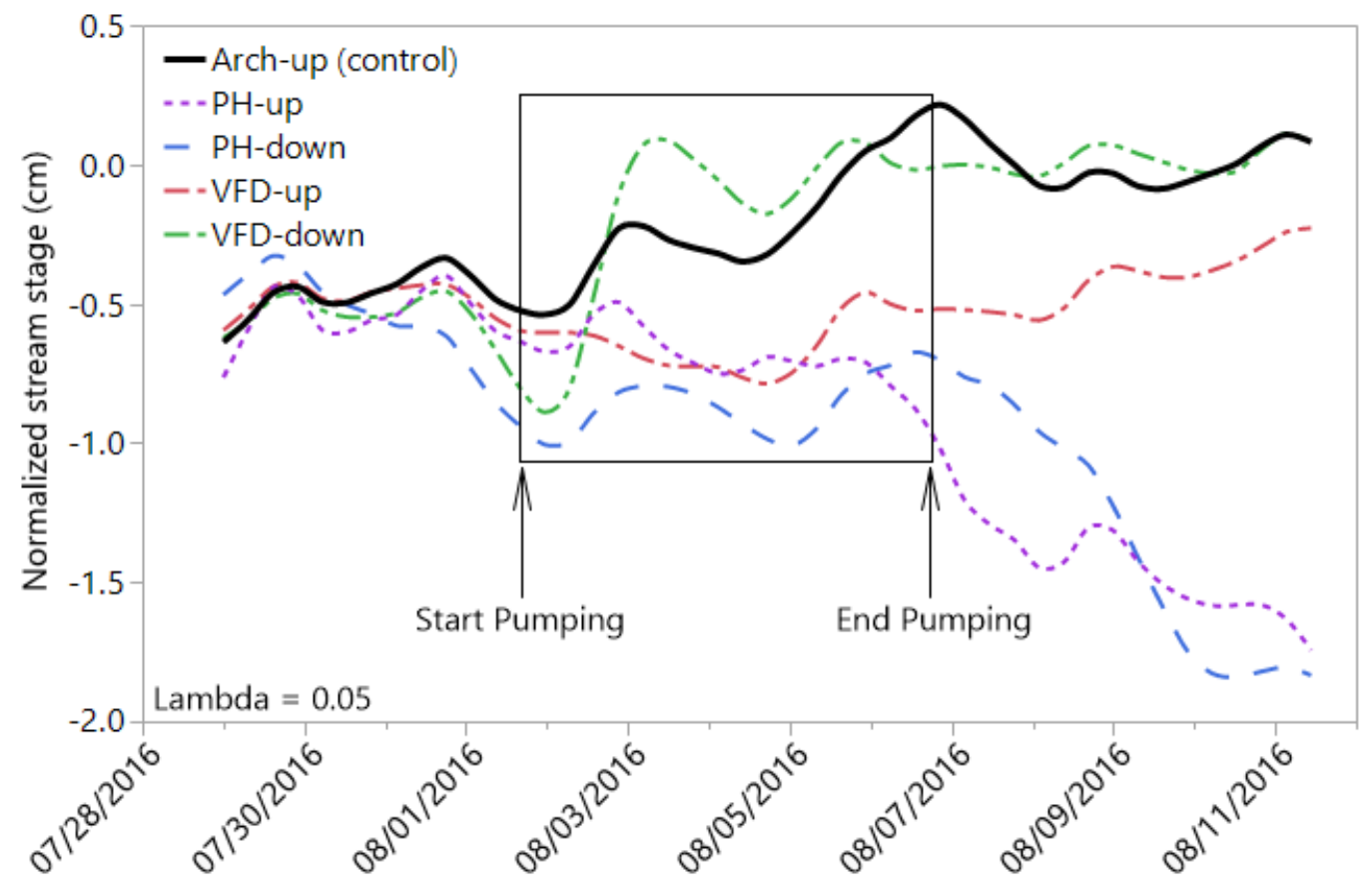

Figure 4.17: Normalized stream stage $(\mathrm{cm})$ recorded 29 July-11 August, 2016. Rectangle indicates time period during which pumping tests occurred.

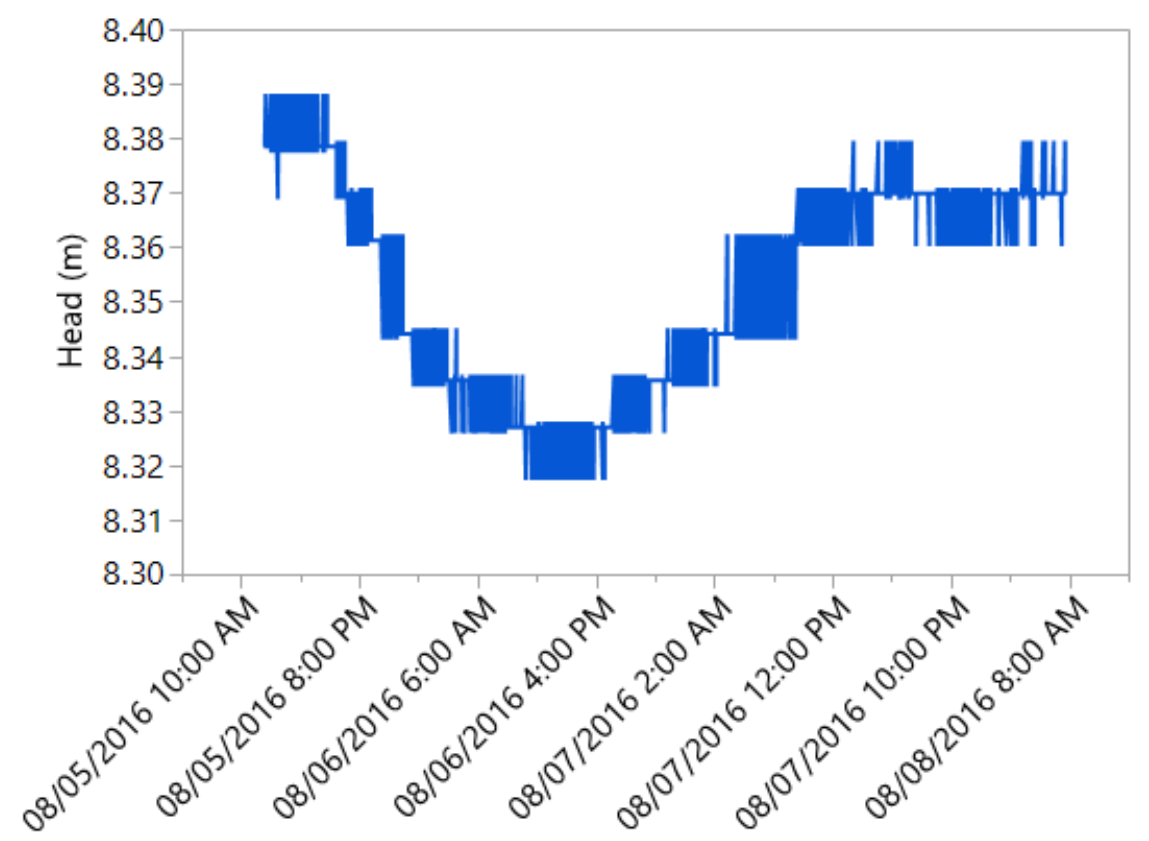

Figure 4.18: Drawdown (m) in Archibald Well during Pump House Well pumping test. 


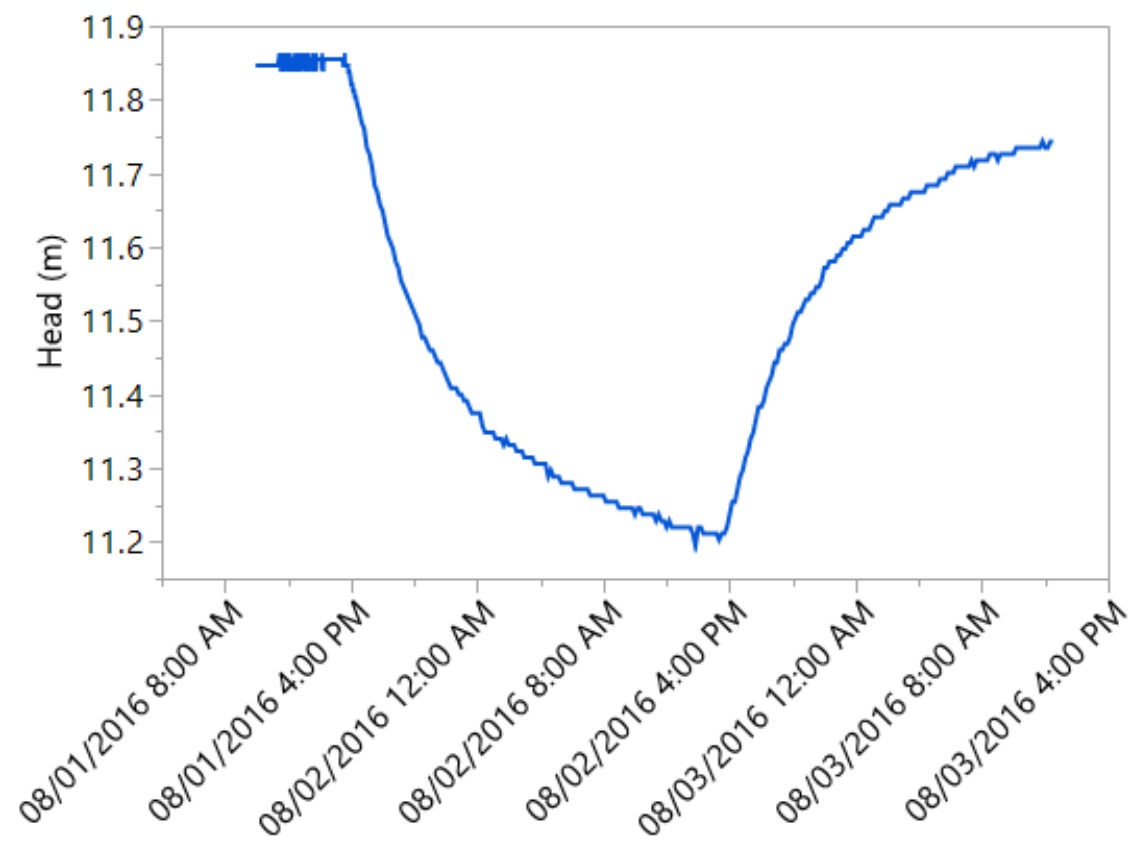

Figure 4.19: Drawdown (m) in Pump House Well during VFD Well pumping test.

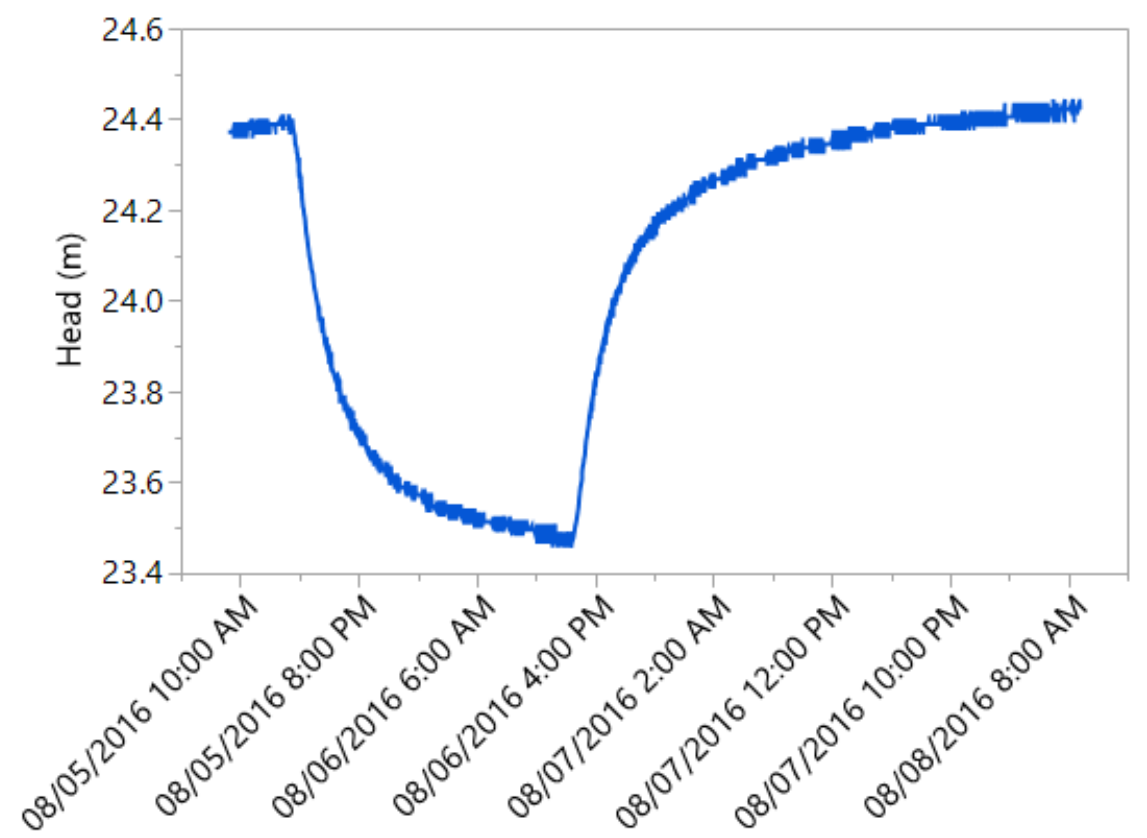

Figure 4.20: Drawdown (m) in VFD Well during Pump House Well pumping test. 


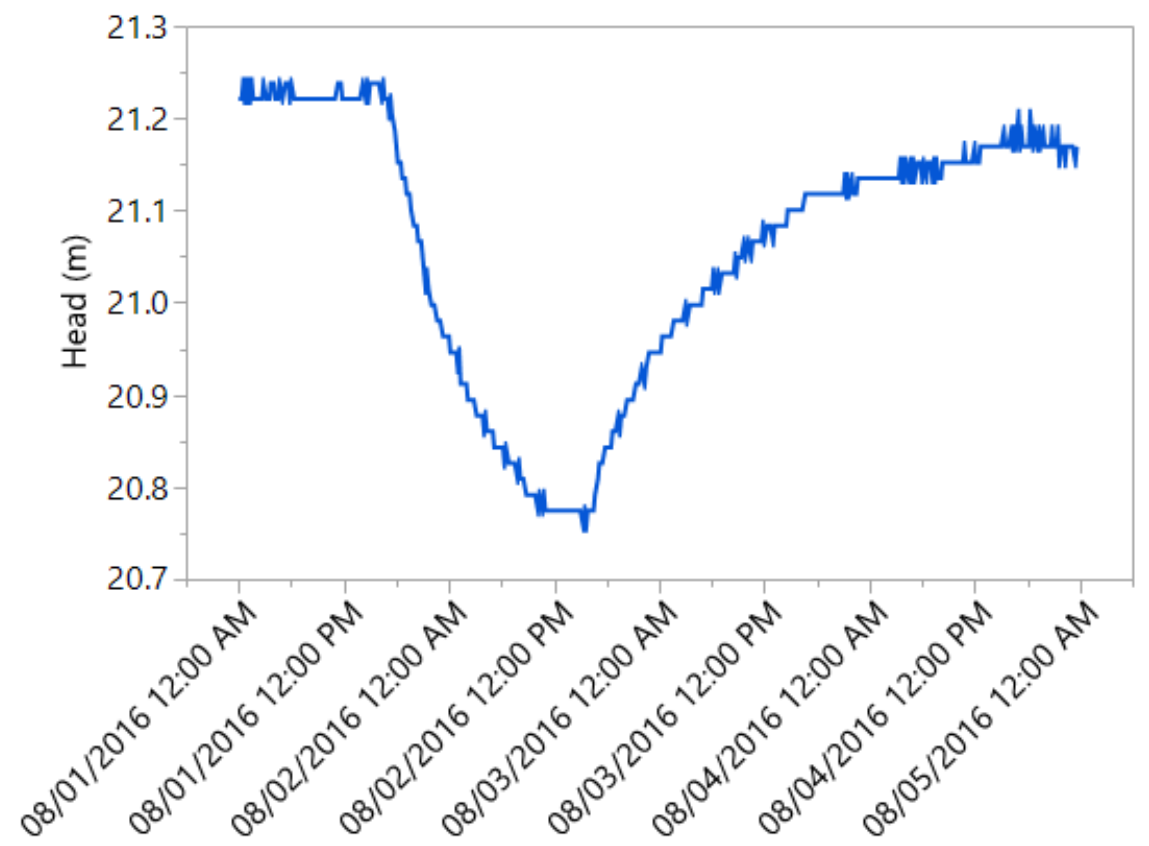

Figure 4.21: Drawdown (m) in Queseria Well during VFD Well pumping test.

\subsubsection{Dye Tracing}

Dye tracer studies provide a cost-effective method that poses little environmental risk for measuring the exchange of water between streams and aquifers (Rosenberry and LaBaugh, 2008; Kilpatrick and Cobb, 1985). Prior to, during, and after the pumping tests, a constant rate injection method, using a fluorescent dye tracer $(20 \%$ Rhodamine WT), was used to estimate surface-subsurface water exchange along lower Scotts Creek. Each injection location was carefully selected approximately $100 \mathrm{~m}$ upstream of the pumping well. During each injection, nine gallons of Rhodamine dye were mixed with an equivalent amount of water yielding a total of 18 gallons in a 35 gallon plastic container. The concentration of Rhodamine dye was $12.5 \mathrm{~mL} / \mathrm{L}$ during both injections. A small medical grade peristaltic pump (Solinst Canada Ltd.) was used to continuously inject the dye solution into the stream through a single injection tube placed in the middle of the stream channel at a rate of $10 \mathrm{~mL} / \mathrm{min}$. 
Tracer concentration (parts per billion (ppb)) and temperature $\left({ }^{\circ} \mathrm{C}\right)$ were measured in the stream every 5 minutes with a fluorometer (Precision Measurement Engineering Cyclops-7 Logger) placed in the middle of the stream channel flow on the streambed at a point approximately $200 \mathrm{~m}$ downstream from the injection point. A steady state concentration of approximately $24 \mathrm{ppb}$ Rhodamine was achieved in the stream prior to the initiation of each well pumping test. Well effluent was sampled every 30 minutes for the first 2 hours of each pumping test to test for traces of Rhodamine in abstracted groundwater by collecting a $250 \mathrm{~mL}$ grab sample at the well head. Samples were labeled and stored in a cardboard box to reduce photocatalytic degradation of the Rhodamine. The concentration of Rhodamine in grab samples was measured in the laboratory two days after collection using a fluorometer, calibrated using dilution from a sample of the injectate solution. After each well pumping test, data were downloaded from the fluorometer to a computer and time-concentration data were plotted as shown in Figure 4.22.

Visual analysis of the time-concentration data shown in Figure 4.22 suggests that the VFD Well pumping test had an insignificant effect on the concentration of Rhodamine dye tracer in the stream. The data show considerable fluctuation in dye concentration in the stream prior to, during, and after the pumping test, likely due to natural streamflow variations and changes in the dye injection rate caused by unexpected clogging of the peristaltic pump tubing. There is a modest increase in dye concentration near the end of the pumping test, followed by a modest lagged decrease in concentration (indicating an increase in streamflow) after cessation pumping, which could be interpreted as impacts of pumping. However, the data generally indicate a weak hydraulic connection exists between the stream and pumped aquifer with no significant change in dye concentration observed as a result of groundwater abstraction. Well effluent samples did not contain detectable levels of Rhodamine dye indicating 


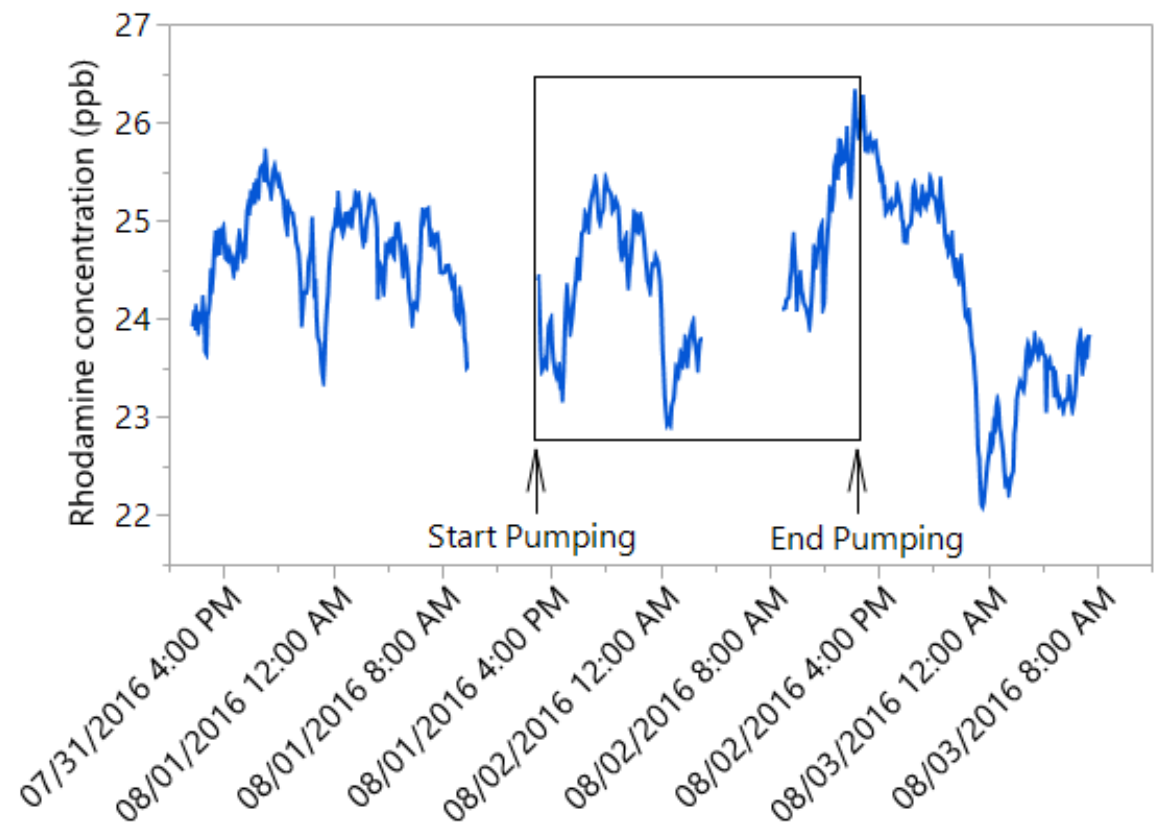

Figure 4.22: Concentration of Rhodamine dye (ppb) in Scotts Creek prior to and during the VFD Well pumping test. Rectangle indicates time period during which pumping occurred. Gaps in the data are a result of dye injection issues encountered during the test.

surface water from the stream was not abstracted during the pumping tests, or at least not during the first 2 hours of each test. Dye losses via dye adsorption to particle surfaces could have also occurred.

Unforeseen complications with the peristaltic pump during the Pump House Well pumping test dye injection resulted in poor quality data and consequently the injection was abandoned. In an attempt to examine water fluxes between the stream and the aquifer when groundwater is abstracted from the Pump House Well, slug dye injections were conducted to estimate stream discharge under normal pumping conditions. Thirty six slug dye injections were completed in September 2016 on a $30 \mathrm{~m}$ reach of lower Scotts Creek adjacent to the Pump House Well over the course of nine days (two weekends and one workweek). Four slug dye injections were performed each day at intervals of approximately four hours starting at 08:00 hours and ending at 20:00 
hours. Each slug injection lasted about 20 minutes and consisted of emptying a 250 $\mathrm{mL}$ bottle of dye solution with a concentration of $2.5 \mathrm{~mL} / \mathrm{L}$ Rhodamine into the stream in the middle of the stream channel flow at the upstream end of a riffle. Tracer concentration was measured in the stream every 5 seconds with a fluorometer at a point $30 \mathrm{~m}$ downstream from the injection point. The injection and measurement locations were the same for all thirty six injections. Data were downloaded from the fluorometer to a computer and dye concentrations measured during each slug injection were used to calculate stream discharge. The equation for computing stream discharge as measured by the slug injection method is

$$
Q=\frac{V_{1} C_{1}}{\int_{0}^{\infty}\left(C-C_{b}\right) d t}
$$

where $Q$ is the discharge of the stream, $V_{1}$ is the volume of the tracer solution injected into the stream, $C_{1}$ is the concentration of the tracer solution injected into the stream, $C$ is the measured tracer concentration at a given time at the downstream sampling site, $C_{b}$ is the background concentration of the stream, and $t$ is time. The term $\int_{0}^{\infty}\left(C-C_{b}\right) d t$ is the area under the time-concentration curve and can be approximated by

$$
\sum_{i=1}^{n}\left(C_{i}-C_{b}\right)\left(t_{i+1}-t_{i-1}\right) / 2,
$$

where $i$ is the sequence number of a sample, $N$ is the total number of samples, and $t_{i}$ is the time when a sample, $C_{i}$, is obtained (Kilpatrick and Cobb, 1985).

Twenty eight of the thirty six slug dye injections produced typical time-concentration curves and reasonable estimates of stream discharge; eight of the injections produced atypical time-concentration curves and unreasonable estimates of stream discharge and were excluded from data analyses (see Appendix E for slug dye injection data). Figure 
4.23 compares a typical time-concentration curve (smooth line), recorded during the first slug dye injection on September 10, 2016 at 08:00 hours, to an atypical curve (dashed line), recorded during the tenth slug dye injection on September 12, 2016 at 12:47 hours. Possible reasons for the atypical time-concentration curves include depression or enhancement of fluorescence and dye losses. Dye losses occur when there is adsorption of dye to particle surfaces, when dye gets trapped in storage areas (e.g., eddy), when chemicals like chlorine oxidize or quench dye, and when dye is exposed to direct sunlight (Kilpatrick and Cobb, 1985).

The twenty eight slug dye injections that produced reasonable estimates of stream discharge were plotted and visually analyzed (Figure 4.24). Calculated stream flows ranged from 2.2 to $2.9 \mathrm{cfs}$ for an average discharge of $2.6 \mathrm{cfs}$. The travel time of the peak concentration from the injection location to the fluorometer was about 3 minutes. There is an overall downward trend in stream discharge over the course of the nine days. Stream discharge during the first five days averaged about $0.5 \mathrm{cfs}$ higher than during the last four days. However, no significant changes in stream discharge as a result of groundwater abstraction from the Pump House Well under normal pumping conditions were observed. Short-term fluctuations in stream discharge and stage during rainless periods can be induced by several natural and anthropogenic factors (e.g., diurnal cycle of water uptake by vegetation, changes in streambed hydraulic conductivity triggered by temperature variations, and time-varying rates of groundwater extraction) making it difficult to attribute changes observed to any one phenomena without high resolution data (Gribovszki et al., 2010). 


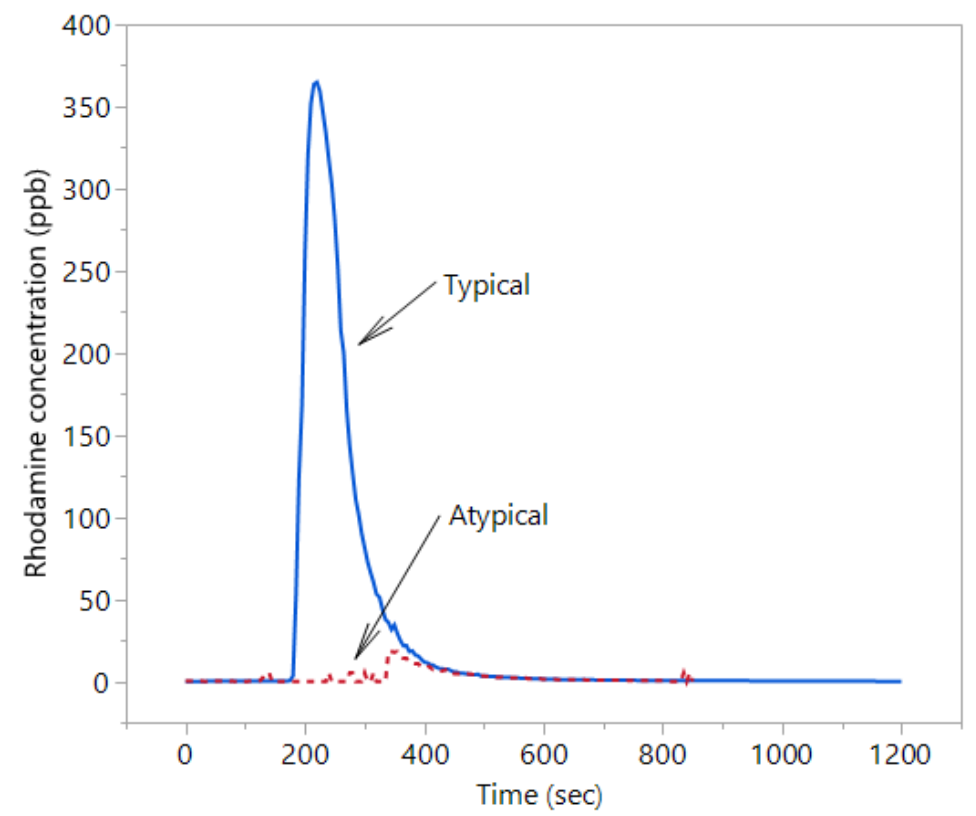

Figure 4.23: Comparison of typical (smooth line) and atypical (dashed line) timeconcentration curves of slug dye injections.

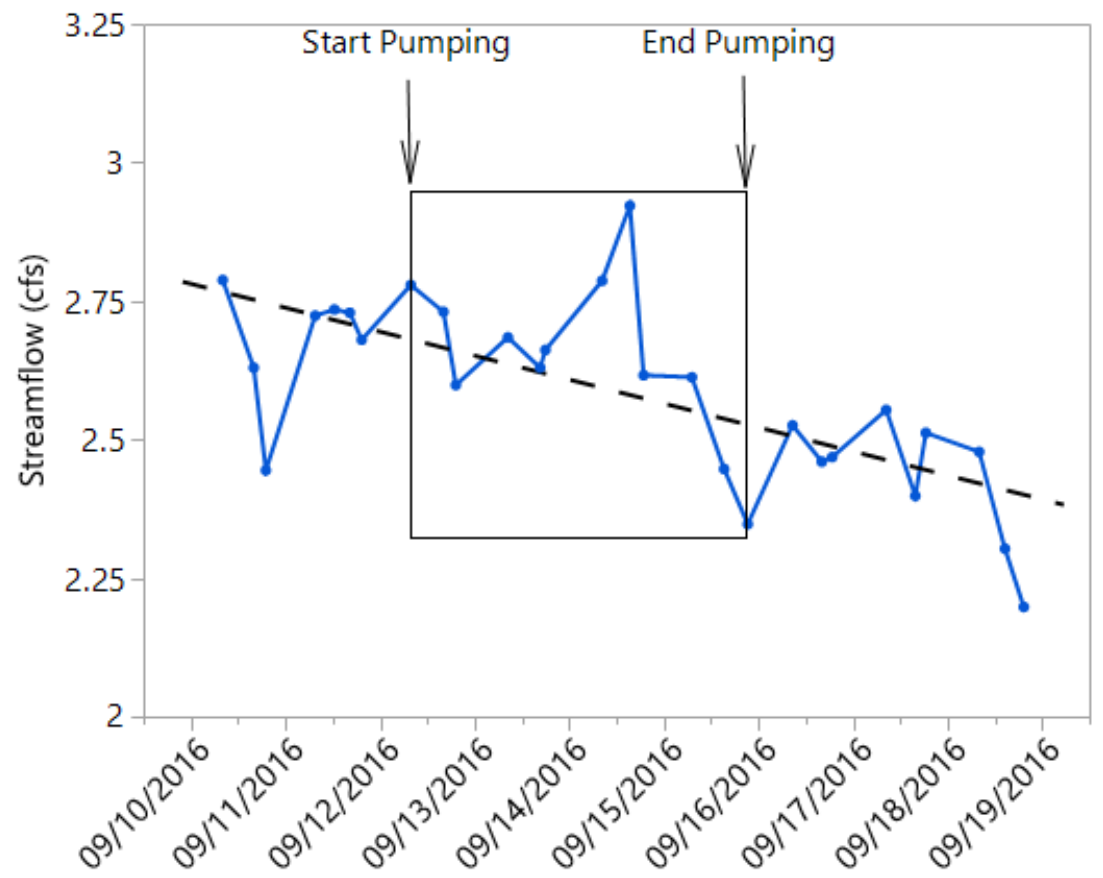

Figure 4.24: Stream discharge (cfs) calculated from slug dye injection timeconcentration curves. Rectangle indicates time period during which pumping occurred and dashed line shows data trend. 


\subsubsection{Geophysical Surveys}

Geophysical methods are commonly used to acquire information regarding the structural and hydraulic properties of aquifers, and are particularly useful for improving understanding of aquifer spatial heterogeneity (Goebel et al., 2017; Goldman and Kafri, 2006). Electrical resistivity tomography (ERT) surveys were conducted in October 2016 following the initial exploratory borehole drilling operations and pumping tests to delineate aquifer geometry, identify hydrogeologic boundaries, and establish the spatial continuity of the aquitard on lower Scotts Creek. An automatic resistivity meter (SYSCAL Kid Switch) with a 24-electrode string manufactured by IRIS Instruments was used to conduct the surveys. Resistivity measurements were collected using the Wenner PRF Switch array. Field data were downloaded from the resistivity meter to a computer using PROSYSII software where the data were converted to RES2DINV format and a two-dimensional (2D) resistivity model for the subsurface was generated using a linear depth axis and a common resistivity scale. RES2DINV uses a least-squares inversion scheme involving the finite-difference method to produce both measured and calculated apparent resistivity pseudosections for data obtained from ERT surveys, as well as an interpretation model for the subsurface.

Three ERT surveys were performed - one approximately $10 \mathrm{~m}$ north of the VFD Well and roughly parallel to Scotts Creek (S2E) and the other two approximately 100 $\mathrm{m}$ east of the VFD Well (one perpendicular (S3E) and one parallel (S4E) to Scotts Creek) (see Figure 4.25). For survey S2E a $2.5 \mathrm{~m}$ electrode spacing was used along a $57.5 \mathrm{~m}$ profile and yielded an imaging depth of approximately $10 \mathrm{~m}$. For surveys S3E and S4E a $5 \mathrm{~m}$ electrode spacing was used along a $175 \mathrm{~m}$ profile (one roll-along each) and yielded an imaging depth of approximately $20 \mathrm{~m}$ (Figure 4.26). Table 4.3 provides a summary of the ERT surveys. 


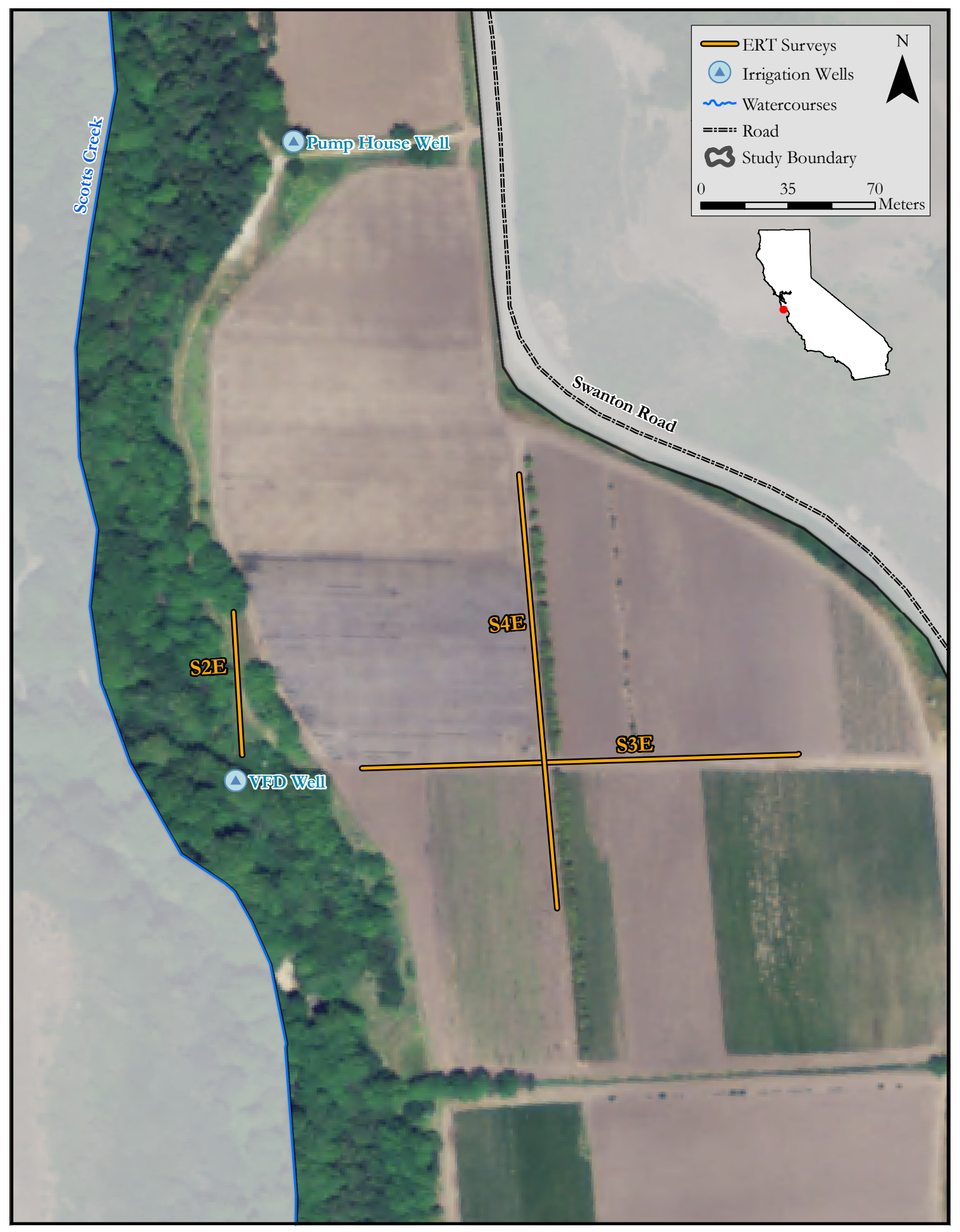

Figure 4.25: The locations where ERT surveys were performed on lower Scotts Creek. 
Table 4.3: Location, length, and orientation of each ERT survey.

\begin{tabular}{cccc}
\hline Survey ID & Location (Lat/Long) & Length $(\mathrm{m})$ & Orientation $\left(^{\circ}\right)$ \\
\hline S2E & $37.0487,-122.2264$ & 57.5 & 354 \\
S3E & $37.0484,-122.2248$ & 175 & 87 \\
S4E & $37.0487,-122.2251$ & 175 & 177 \\
\hline
\end{tabular}
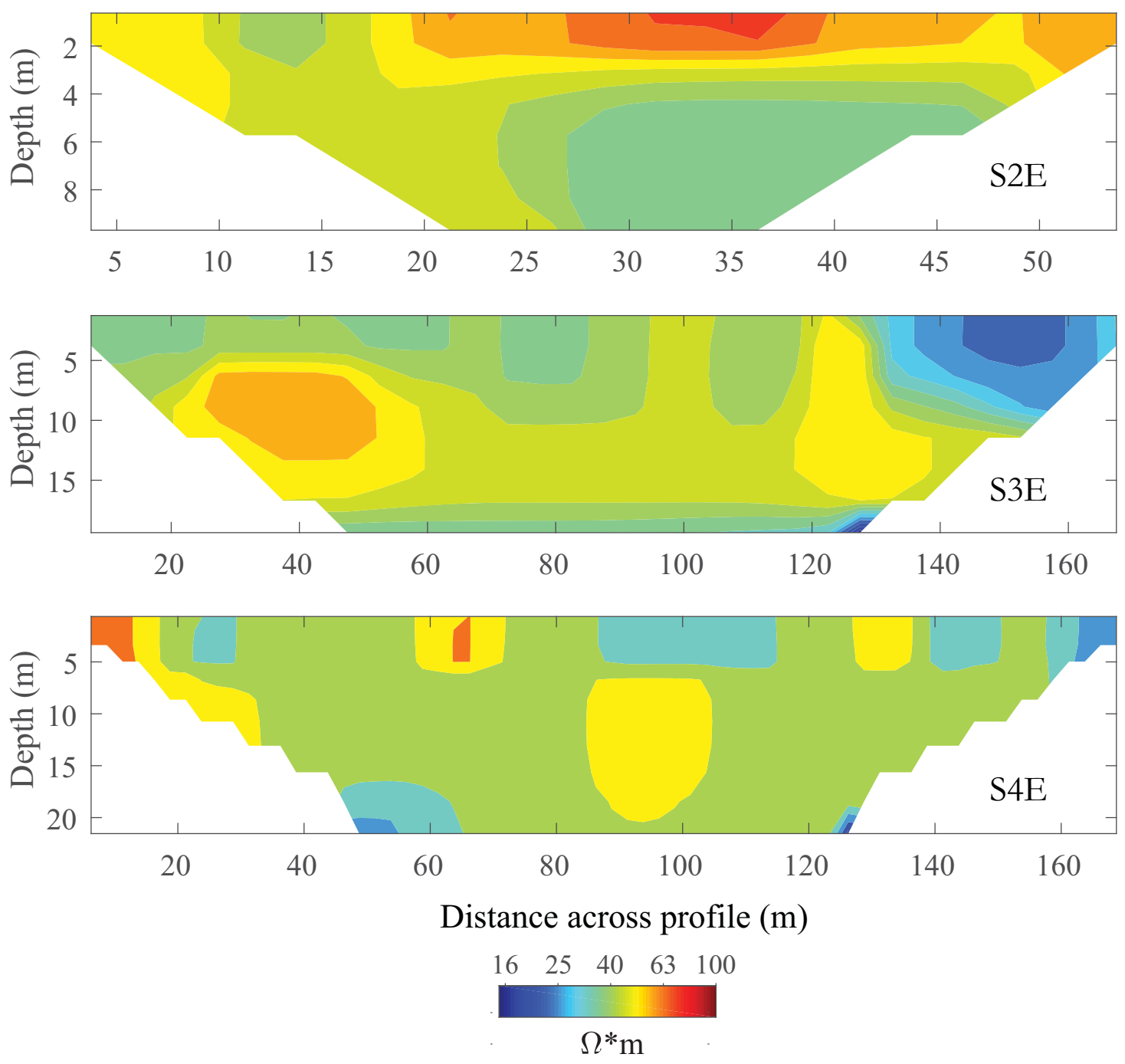

Figure 4.26: The two-dimensional (2D) resistivity models for the subsurface for data obtained from the ERT surveys completed on lower Scotts Creek. Survey S2E (top) was performed near the VFD Well and parallel to the stream channel while surveys S3E (middle) and S4E (bottom) were performed between Scotts Creek and Swanton Road, and perpendicular and parallel to the stream channel, respectively. 
Figure 4.26 shows detailed views of each of the three inverted resistivity sections. All three ERT profiles contain a range of resistivity values from approximately $20-70$ ohm-m. These variations in subsurface resistivity are a result of differences in pore fluid between layers and changes in lithology. To guide interpretation of the inverted resistivity sections, profiles were compared with data from exploratory borehole logs and well completion reports to identify commonalities in lithologic sequences and to make inferences about the composition and structure of the shallow subsurface on lower Scotts Creek. Figure 4.27 shows typical ranges of resistivities of geologic materials. However, comparison between the typical resistivity values for unconsolidated geologic materials, such as clay, and gravel and sand, and the resistivities observed in all three ERT profiles, it is clear that the resistivity values for the lower Scotts Creek subsurface are generally low and that Figure 4.27 should simply be used to guide interpretation.

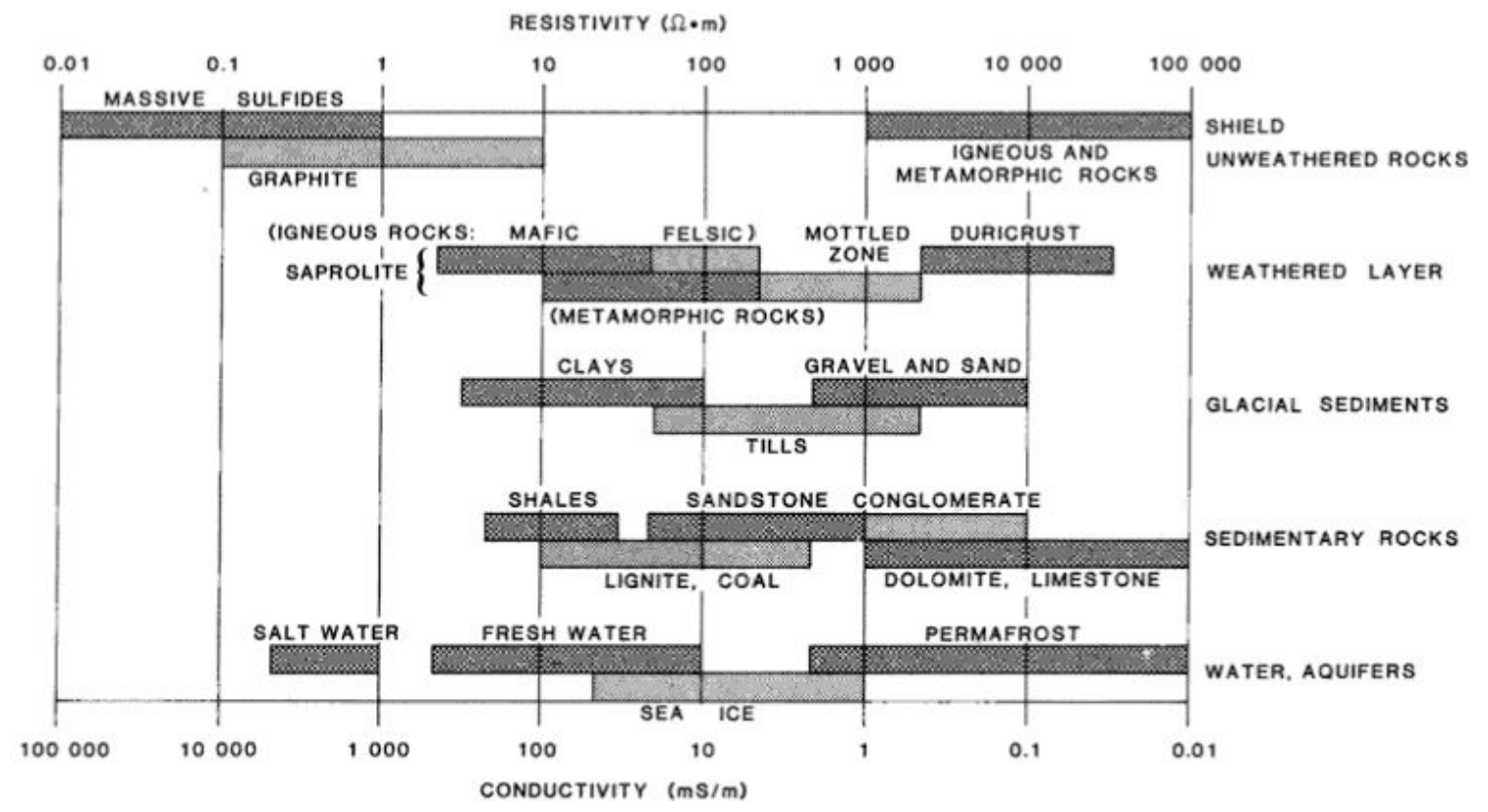

Figure 4.27: Typical ranges of resistivities of consolidated and unconsolidated geologic materials (excerpted from Palacky, 1988).

Survey S2E shown in Figure 4.26 (top image) suggests a heterogeneous layer exists from land surface to a depth of approximately $3 \mathrm{~m}$. The pocket of high resistivity 
$(\sim 66 \mathrm{ohm}-\mathrm{m})$ material located in the middle of the survey profile near the surface is interpreted to be unsaturated coarse sand and gravel deposited by a historic stream channel based on nearby borehole data. Below the heterogeneous surface zone, a mostly laterally continuous homogeneous layer of relatively high resistivity $(\sim 50$ ohm-m) that slowly grades to lower resistivity ( $\sim 40 \mathrm{ohm}-\mathrm{m})$ material starts at a depth of approximately $3 \mathrm{~m}$ and extends to $10 \mathrm{~m}$ (maximum imaging depth). Based on nearby exploratory borehole logs and well completion reports, this low resistivity layer is believed to be a silt and clay aquitard that acts a vertical flow boundary separating the upper and lower aquifer units.

Surveys S3E and S4E shown in Figure 4.26 (middle and bottom images, respectively), show complex resistivity distributions suggesting that significant subsurface heterogeneity exists in the surficial aquifer and aquitard at greater distances from the stream channel. The pockets of high resistivity $(\sim 60 \mathrm{ohm}-\mathrm{m})$ material are believed to be coarse sand and gravel deposits low in fines, while the areas of lower resistivity ( $\sim 40 \mathrm{ohm}-\mathrm{m})$ material are interpreted to be fine-grained sand deposits interlayered with silt and clay. The imaging depths of all three ERT profiles proved inadequate to capture the deep (pumped) aquifer's location and extent suggesting that it is located at depths greater than $10 \mathrm{~m}$ near the stream channel (S2E) and depths exceeding 20 $\mathrm{m}$ away from the stream channel (S3E and S4E).

\subsection{Laboratory Measurement of Hydraulic Conductivity}

\subsubsection{Permeameter Tests}

Laboratory permeameter tests are the standard procedure performed to measure the saturated hydraulic conductivity, $K$, of sediments taken from the field (Bradbury and Muldoon, 1990; Hillel, 2003). Saturated hydraulic conductivities of sediment 
samples collected during exploratory borehole drilling operations were determined in a laboratory setting using the falling-head permeameter method to acquire data on the spatial variability of hydraulic conductivity in the alluvial aquifer system. The falling-head permeameter method gives the hydraulic head $h(t)$ in the falling-head tube of diameter $d_{t}$ at time $t$ of flow through a soil sample of diameter $d_{s}$ and length $L$, as

$$
h(t)=h_{0} e^{-t / \tau_{0}},
$$

where $h_{0}$ is the initial head (head at $t=0$ ), and

$$
\tau_{0}=\frac{d_{t}^{2} L}{d_{s}^{2} K},
$$

and $K$ is the saturated hydraulic conductivity of the soil sample. From equation 4.3 it can be shown that

$$
\ln \left[\frac{h(t)}{h_{0}}\right]=-\frac{t}{\tau_{0}} .
$$

Therefore, plotting $\ln \left[h(t) / h_{0}\right]$ vs $t$ gives a straight line with a slope of $-1 / \tau_{0}$ from which $K$ can be determined.

Initially, a flow cell (permeameter) with an inner diameter of $7.82 \mathrm{~cm}$ and a fallinghead tube with an inner diameter of $5.08 \mathrm{~cm}$ were used. Unconsolidated sediment samples were transferred from the plastic collection tubes to the permeameter in 3 to 4 foot sections and packed under saturated conditions. Great care was taken to avoid boundary flow along the walls of the flow cell and to remove trapped air from the sediment before measurements were recorded. Experimental runs were preceded by several flushes of the flow cell to remove trapped air before measurements were made. A WIKA pressure transmitter $(0-5 \mathrm{psi} / 4-20 \mathrm{~mA})$ was attached to the 
permeameter inflow tubing and connected to a Campbell Scientific CR 300 Datalogger to measure the change in pressure (psi) over time (minutes) as a dilute solution of sodium chloride $(0.01 \mathrm{M} \mathrm{NaCl})$ was allowed to discharge through the sample (Figure 4.28). The temperature $\left({ }^{\circ} \mathrm{C}\right)$ of the water was also measured during each test. Flow tests were performed in triplicate on each sediment sample to obtain three independent measurements, which were averaged for a single estimate of hydraulic conductivity.

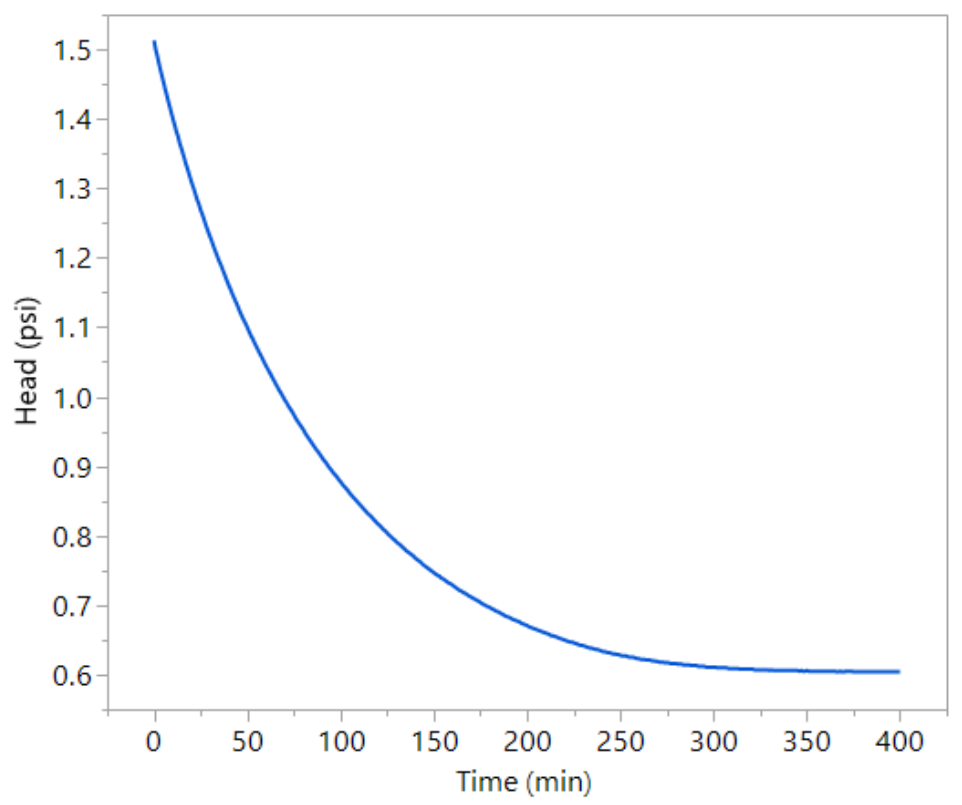

Figure 4.28: Flow test data showing change in head (psi) over time (minutes) for a single experimental run on sediments from 12-14 foot interval of EB-1.

After several measurements, the setup was modified by switching to a smaller permeameter with a diameter of $3.81 \mathrm{~cm}$ and length of $15 \mathrm{~cm}$. This allowed for the testing of smaller sections of sediment ( $\sim 2$ foot), thereby increasing the number of data points per borehole. However, because of the generally low-permeability of the sediments, the falling-head permeameter method with the $5.08 \mathrm{~cm}$ falling-head tube and $3.81 \mathrm{~cm}$ permeameter was excruciatingly slow, at times taking more than a week to complete one flow test. For that reason, the constant-head permeameter 
method was tested with the goal of speeding up the flow tests. The setup included an adjustable peristaltic pump and two pressure transducers, one on both the inflow and the outflow tube of the permeameter. However, it was found that the constant-head method produced poor quality data and was consequently abandoned. Finally, the falling-head method with a $1.5 \mathrm{~cm}$ diameter falling-head tube (100 mL burette) was tested and proved to be the ideal setup. For the majority of the permeameter tests, two permeameters of diameters $3.81 \mathrm{~cm}$ and $4.50 \mathrm{~cm}$, and both $15 \mathrm{~cm}$ in length, equipped with pressure transducers and $1.5 \mathrm{~cm}$ falling-head tubes were used (Figures 4.29 and 4.30). The $3.81 \mathrm{~cm}$ flow cell assembly included fine filter paper screens and was primarily used to test the permeability of fine sediments. Conversely, the $4.50 \mathrm{~cm}$ flow cell assembly included coarse stainless steel mesh screens and was primarily used to test the permeability of coarse sediments.

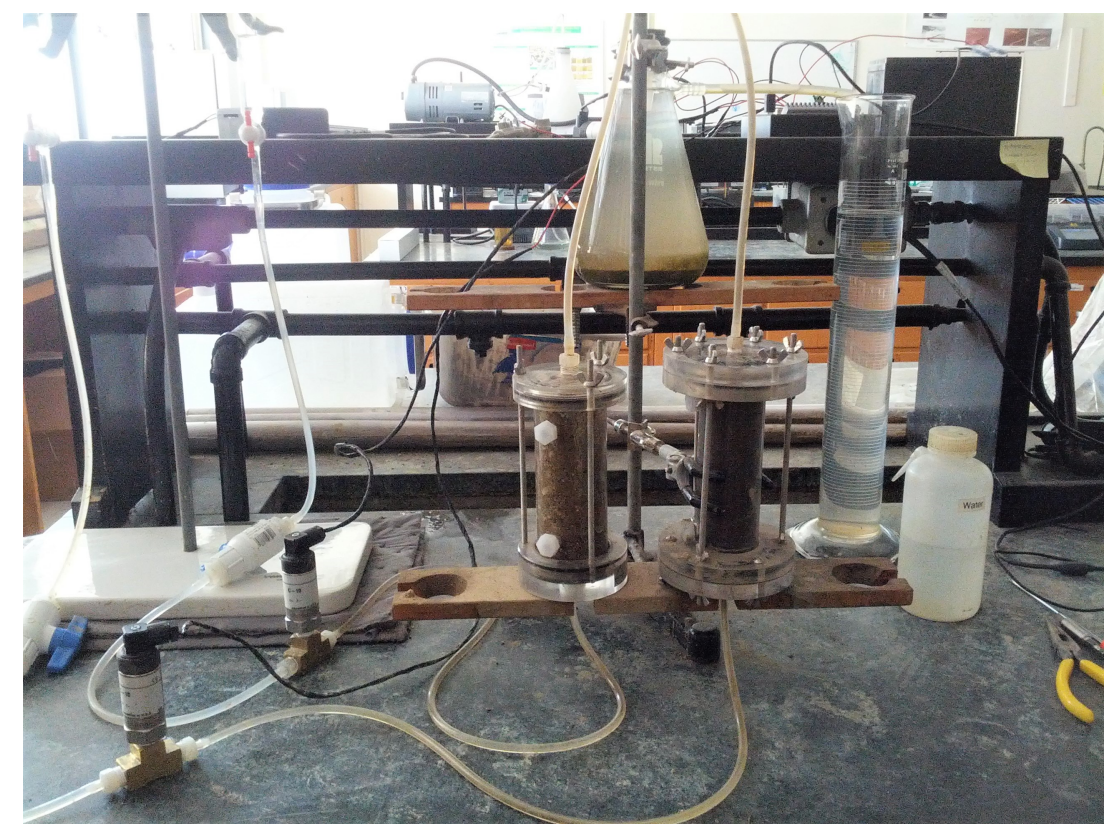

Figure 4.29: Falling-head permeameter setup.

After each test, data were downloaded from the data logger to a computer as a text file and imported into Microsoft Excel for data processing. The natural log of 


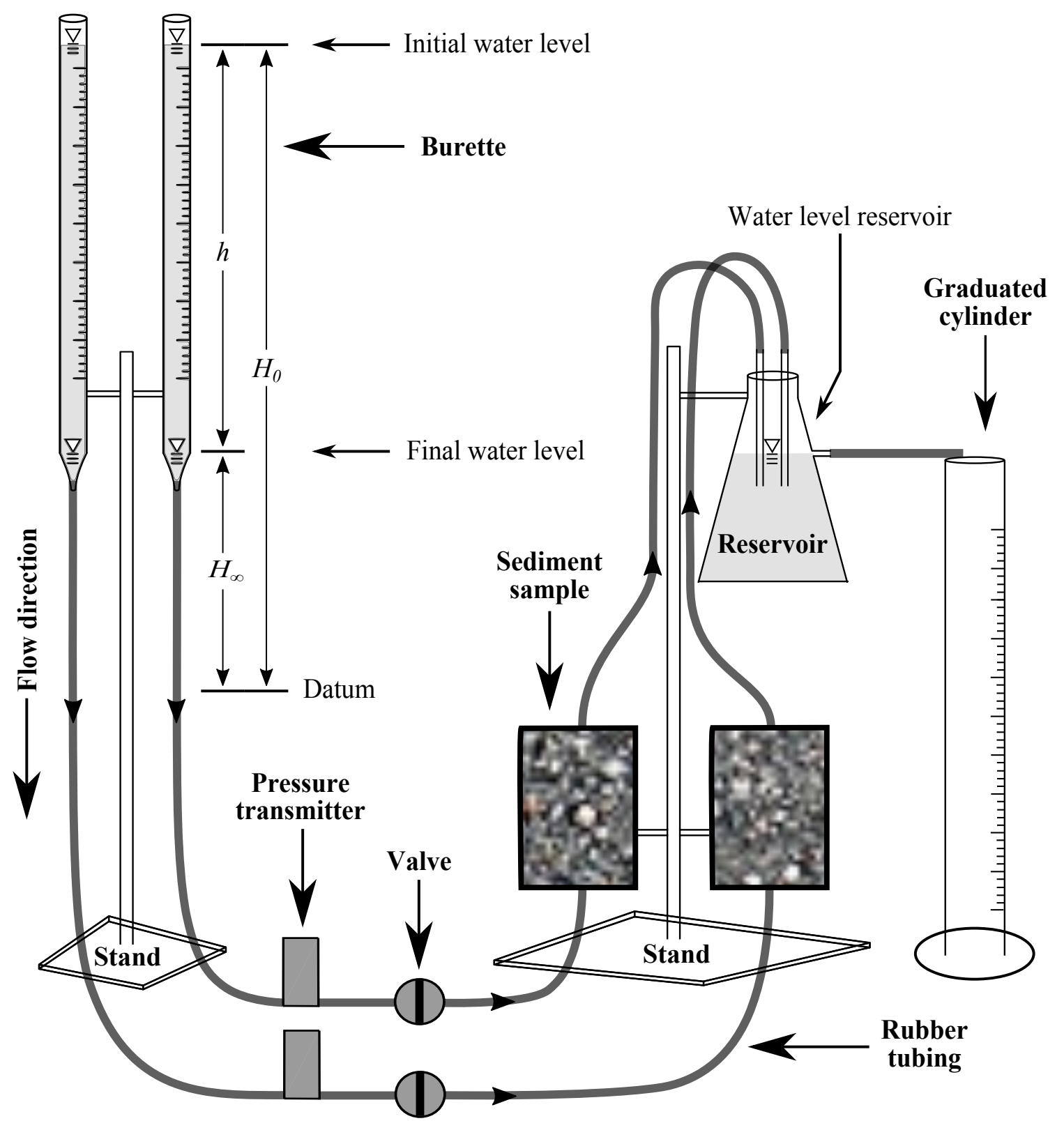

Figure 4.30: Schematic of falling-head permeameter setup. 
the hydraulic head divided by the initial head was plotted against time in minutes $\left(\ln \left[h(t) / h_{0}\right]\right.$ vs $\left.t\right)$, and a straight-line, passing through the origin $(0,0)$, was obtained (Figure 4.31). The hydraulic conductivity, $K$, of the sediment was determined using the slope of the line, $-1 / \tau_{0}$, and equation 4.4. Typical values of saturated hydraulic conductivity for unconsolidated geologic materials of different texture are listed in Table 4.4. Table 4.5 is a summary of saturated hydraulic conductivity values for sediments from EB-1 -4 determined using the falling-head permeameter method (see Appendix F for individual flow test data). Figure 4.32 provides a graphical representation of saturated hydraulic conductivity values for sediments from EB-1.

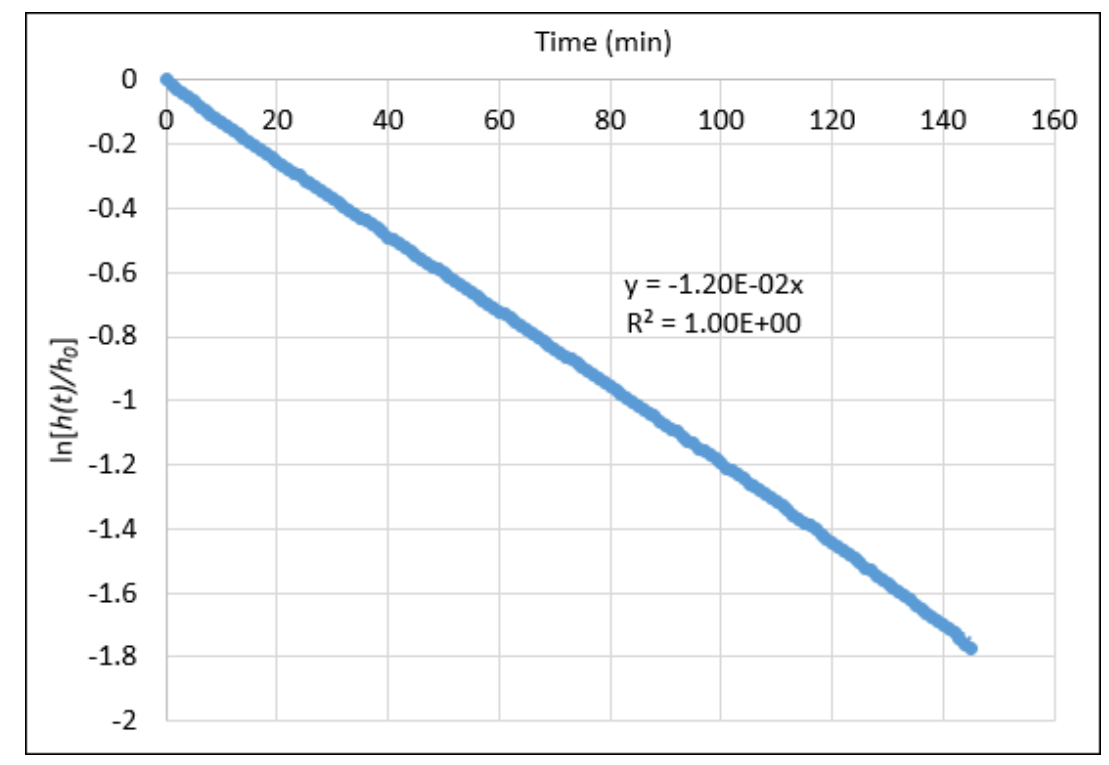

Figure 4.31: Plot of flow test data with linear fit for a single experimental run on sediments from 12-14 foot interval of EB-1.

Flow tests were performed on all sediments collected from EB-1 -4. For EB$5-8$, simply the range in saturated hydraulic conductivity of sediments from each borehole was determined by performing flow tests on individual fine- and coarsegrained sediment samples. The hydraulic conductivity of sediments from EB-5 ranged from $2.82 \times 10^{-7} \mathrm{~m} / \mathrm{s}(36-38 \mathrm{ft})$ to $4.44 \times 10^{-5} \mathrm{~m} / \mathrm{s}(32-34 \mathrm{ft})$, sediments from EB-6 
Table 4.4: Typical values of saturated hydraulic conductivity $(K)$ for unconsolidated geologic materials of different texture (adapted from Hillel, 2003).

\begin{tabular}{ccc}
\hline Material Texture & $K(\mathrm{~m} / \mathrm{s})$ & Particle Diameter $(\mathrm{mm})$ \\
\hline Clay & $10^{-10}-10^{-8}$ & $<0.002$ \\
Silt & $10^{-8}-10^{-6}$ & $0.002-0.05$ \\
Sand & $10^{-5}-10^{-3}$ & $0.05-2$ \\
Gravel & $10^{-2}-10^{-1}$ & $>2$ \\
\hline
\end{tabular}

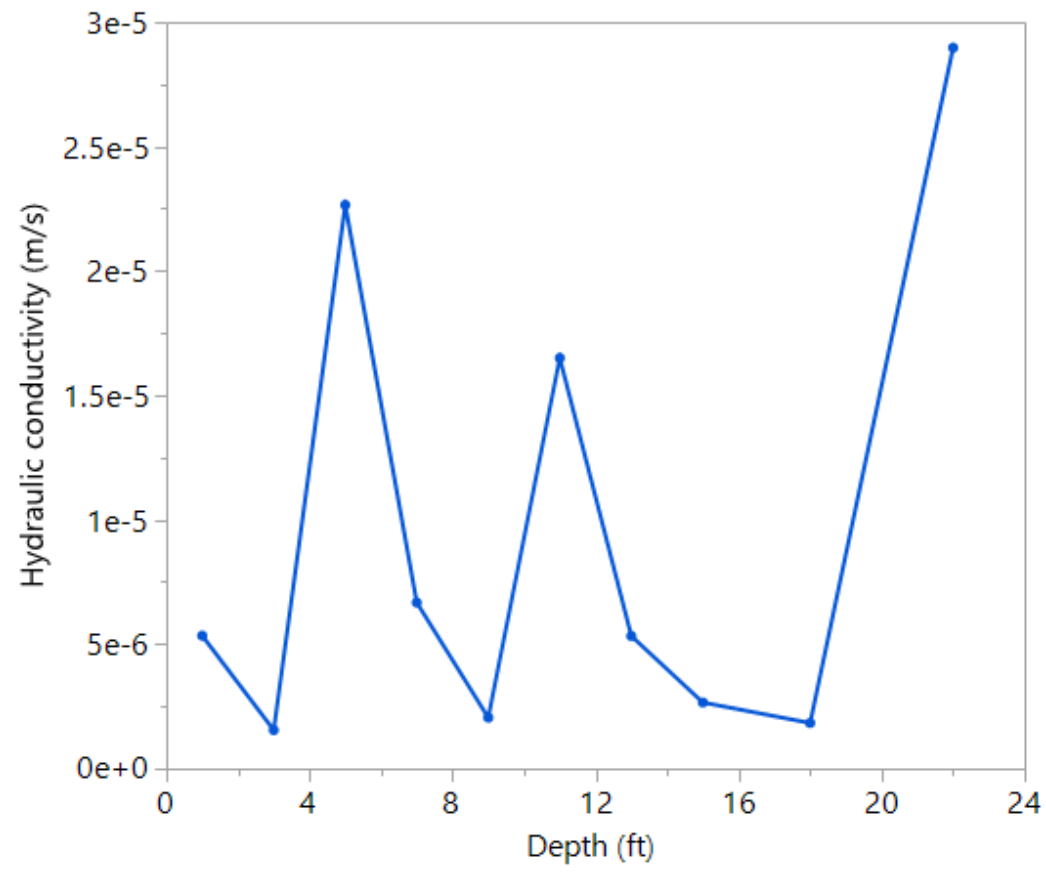

Figure 4.32: Saturated hydraulic conductivity $(K)$ in $\mathrm{m} / \mathrm{s}$ at depth $(\mathrm{ft})$ for sediments from EB-1 determined using falling-head method. 
Table 4.5: Summary of saturated hydraulic conductivity $(K)$ values for sediments from EB-1 -4 determined using falling-head permeameter method.

\begin{tabular}{|c|c|c|}
\hline Depth Range (ft) & Layer & $K(\mathrm{~m} / \mathrm{s})$ \\
\hline \multicolumn{3}{|l|}{ EB-1 } \\
\hline $0-2$ & 1 & $5.35 \times 10^{-6}$ \\
\hline $2-4$ & 1 & $1.55 \times 10^{-6}$ \\
\hline $4-6$ & 1 & $2.27 \times 10^{-5}$ \\
\hline $6-8$ & 1 & $6.68 \times 10^{-6}$ \\
\hline $8-10$ & 1 & $2.05 \times 10^{-6}$ \\
\hline $10-12$ & 1 & $1.65 \times 10^{-5}$ \\
\hline $12-14$ & 1 & $5.33 \times 10^{-6}$ \\
\hline $14-16$ & 1 & $2.66 \times 10^{-6}$ \\
\hline $16-20$ & 2 & $1.84 \times 10^{-6}$ \\
\hline $20-24$ & 3 & $2.90 \times 10^{-5}$ \\
\hline \multicolumn{3}{|l|}{ EB-2 } \\
\hline $0-6$ & 1 & $1.74 \times 10^{-6}$ \\
\hline $6-12$ & 1 & $7.19 \times 10^{-6}$ \\
\hline $20-22$ & 1 & $7.83 \times 10^{-6}$ \\
\hline $22-24$ & 2 & $2.62 \times 10^{-7}$ \\
\hline $24-26$ & 2 & $1.72 \times 10^{-6}$ \\
\hline $26-28$ & 2 & $2.03 \times 10^{-6}$ \\
\hline $28-30$ & 2 & $7.17 \times 10^{-7}$ \\
\hline $30-32$ & 2 & $1.24 \times 10^{-6}$ \\
\hline$\sim 32$ & 3 & $2.22 \times 10^{-5}$ \\
\hline \multicolumn{3}{|l|}{ EB-3 } \\
\hline $12-14$ & 1 & $6.70 \times 10^{-6}$ \\
\hline $14-16$ & 2 & $1.86 \times 10^{-6}$ \\
\hline $16-18$ & 2 & $3.46 \times 10^{-6}$ \\
\hline $18-20$ & 3 & $3.95 \times 10^{-5}$ \\
\hline $20-24$ & 3 & $6.29 \times 10^{-6}$ \\
\hline \multicolumn{3}{|l|}{ EB-4 } \\
\hline $0-2$ & 1 & $1.53 \times 10^{-6}$ \\
\hline $2-4$ & 1 & $3.03 \times 10^{-6}$ \\
\hline $4-6$ & 1 & $6.84 \times 10^{-6}$ \\
\hline $6-8$ & 1 & $4.21 \times 10^{-6}$ \\
\hline $8-12$ & 1 & $2.49 \times 10^{-6}$ \\
\hline $16-18$ & 2 & $3.21 \times 10^{-7}$ \\
\hline $18-20$ & 3 & $7.25 \times 10^{-6}$ \\
\hline $20-24$ & 3 & $5.38 \times 10^{-6}$ \\
\hline
\end{tabular}


ranged from $9.99 \times 10^{-7} \mathrm{~m} / \mathrm{s}(10-12 \mathrm{ft})$ to $8.27 \times 10^{-5} \mathrm{~m} / \mathrm{s}(8-10 \mathrm{ft})$, sediments from

EB-7 ranged from exceedingly low (not measurable) to $6.78 \times 10^{-5} \mathrm{~m} / \mathrm{s}(18-20 \mathrm{ft})$, and sediments from EB-8 ranged from $\leq 5.74 \times 10^{-8} \mathrm{~m} / \mathrm{s}(18-20 \mathrm{ft})$ to $5.98 \times 10^{-6}$ m/s (32-34 ft). Both EB-7 and EB-8 contained very low-permeability sediments that acted as plugs when packed into the flow cells essentially preventing discharge of water through the sample. In this case, the falling-head method proved inadequate and values of saturated hydraulic conductivity were not obtained. In all boreholes (EB-1 -8), saturated hydraulic conductivity values varied by an order of magnitude or more.

\subsubsection{Particle Size Analysis}

Measurement of the particle size distribution of unconsolidated geologic materials is a common procedure performed to obtain the relative proportions (percentages) by dry mass of sand, silt, and clay (some common particle size classification schemes are compared in Figure 4.33), but also provides a measure of material physical properties that can be used to estimate hydraulic conductivity. Particle size analysis is the determination of the particle size distribution of the inorganic component (mineral fraction) of unconsolidated geologic materials by laboratory methods. Analyses of the size and distribution of particles in the geologic material collected from the exploratory boreholes were carried out through sedimentation (hydrometer) and dry sieving, and, for each sample, a particle size cumulative distribution function (CDF) was plotted from which the particle size parameters needed to calculate hydraulic conductivity were determined. Figure 4.34 shows typical particle size distribution curves for various types of unconsolidated geologic materials.

Twenty-nine 300 g air-dry sediment samples were extracted from EB-1 -4. Samples were carefully selected by visually inspecting the sediment cores and extracting a representative sample from each distinct lithologic unit (identified by physical and 


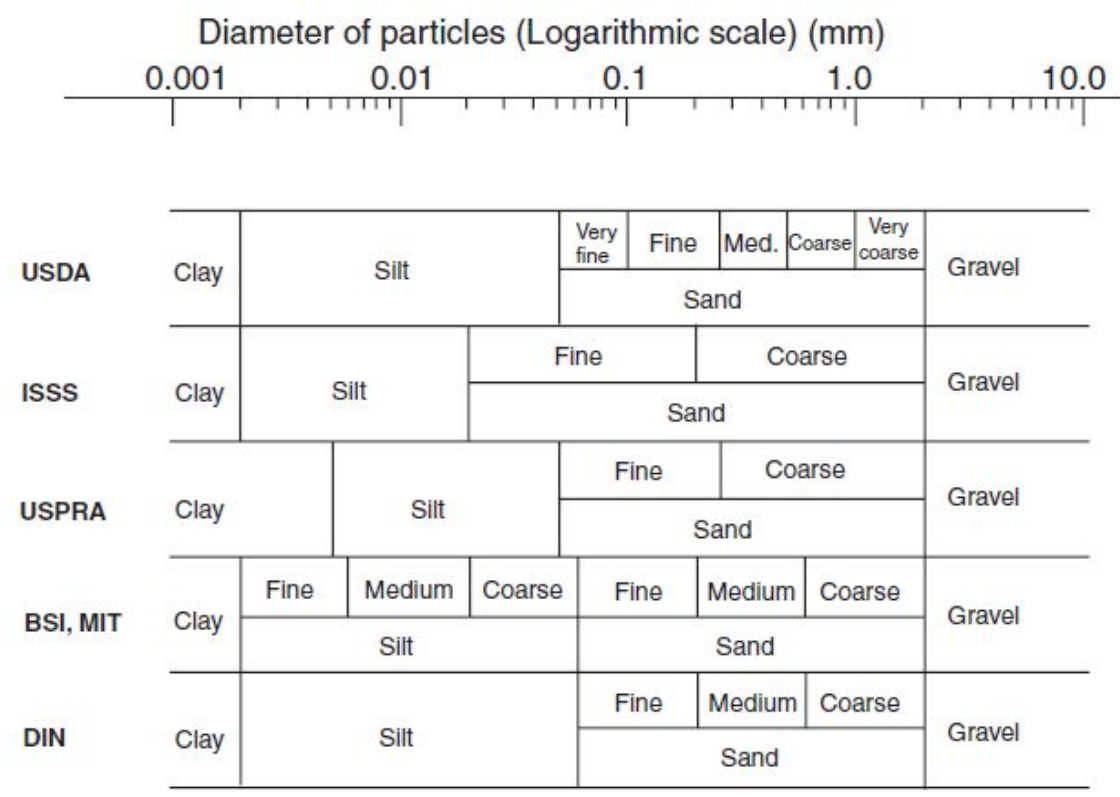

Figure 4.33: Common conventional schemes for the classification of inorganic solid particle fractions of unconsolidated geologic materials on the basis of particle diameter ranges (excerpted from Hillel, 2003).

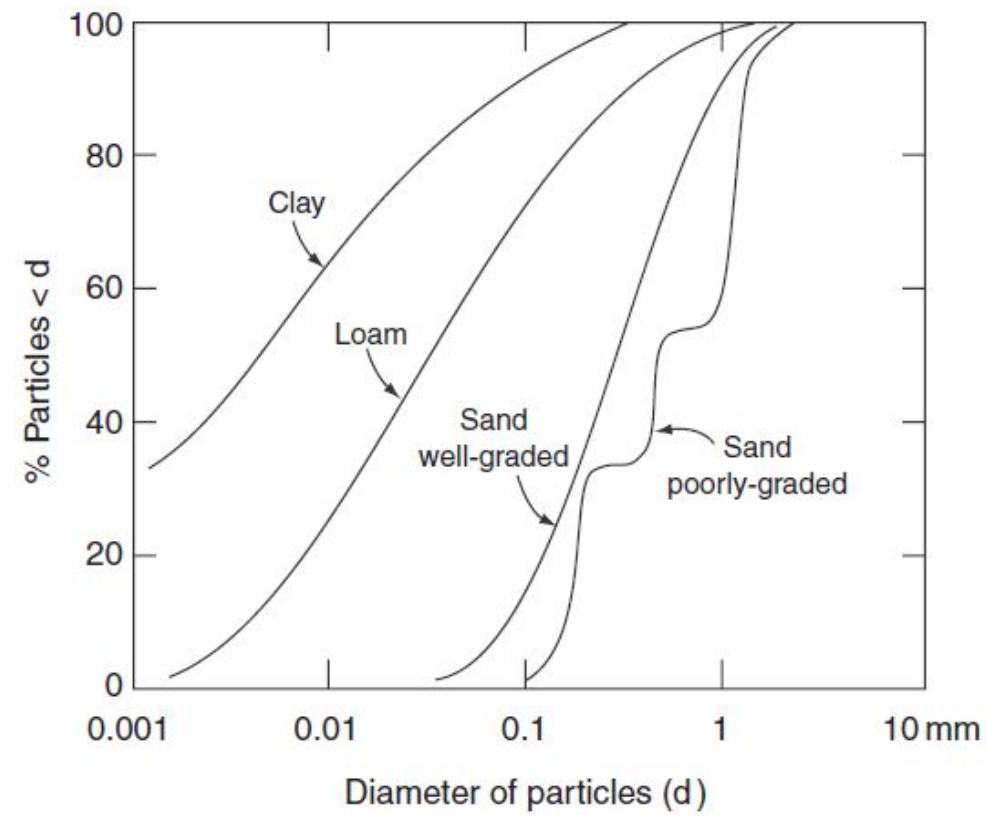

Figure 4.34: Schematic of typical particle size distribution curves for various types of unconsolidated geologic materials (excerpted from Hillel, 2003). 
textural characteristics). Samples were sieved separately through a No. $10(d \leq 2$ $\mathrm{mm}$ ) sieve to remove rock fragments. Subsamples (50 g air-dry) were transferred to $250 \mathrm{~mL}$ beakers and soaked overnight in $100 \mathrm{~mL}$ of a dispersing solution (5\% Sodium Hexametaphosphate $\left.\left(\mathrm{Na}\left(\mathrm{PO}_{3}\right)_{6}\right)\right)$. Additionally, $20 \mathrm{~g}$ air-dry subsamples were placed in a drying oven at $105^{\circ} \mathrm{C}$ for 24 hours to determine the moisture content $\left(\theta_{g}\right)$ of each $50 \mathrm{~g}$ sample. The soaked $50 \mathrm{~g}$ subsamples were quantitatively transferred into separate dispersing cups and mechanically dispersed for 30 seconds. The thoroughly dispersed contents were quantitatively transferred to separate sedimentation cylinders and deionized water was used to bring the volume of each suspension to exactly the $1130 \mathrm{~mL}$ mark with the hydrometer submerged. A blank was prepared by mixing $100 \mathrm{~mL}$ of Sodium Hexametaphosphate with $880 \mathrm{~mL}$ of deionized water. Hydrometer readings were started by thoroughly mixing the suspension in each cylinder for 30 seconds with a plunger. Upon plunger removal, a timer was started and an American Society for Testing Materials (ASTM) 152H hydrometer was carefully inserted into the suspension. Hydrometer readings were recorded at 40 seconds (repeated in triplicate), and at 2 and 7 hours. The plunger and hydrometer were rinsed and dried between uses. The temperature $\left({ }^{\circ} \mathrm{C}\right)$ of the blank and each suspension were recorded at the beginning of every set of readings. All cylinders were covered with a watch glass between hydrometer readings to minimize evaporation. When all hydrometer readings were completed, each sample was dry sieved to further separate the sand fraction into coarse, medium, and fine fractions. The contents of each sedimentation cylinder were quantitatively transferred to a No. $270(\sim 50 \mu \mathrm{m})$ sieve and thoroughly washed with tap water to discard all fines (silts and clays). The remaining sand particles were quantitatively transferred to an evaporating dish and placed in a drying oven at 105 ${ }^{\circ} \mathrm{C}$ for 24 hours. Once oven-dried, each sand sample was sieved for at least 5 minutes by hand using a stack of graded sieves $(1 \mathrm{~mm}, 0.5 \mathrm{~mm}, 0.25 \mathrm{~mm}, 0.1 \mathrm{~mm}$, and pan 
$(0.05<d \leq 0.1 \mathrm{~mm}))$ with the coarsest at the top.

Cumulative particle size distribution curves were generated using standard ASTM methods (ASTM-D6913/D6913M-17, 2017; ASTM-D7928-17, 2017). HydrogeoSieveXL software, an Excel-based spreadsheet program that calculates hydraulic conductivity and other material parameters from particle size distribution curves, was also used to generate particle size distribution curves and estimates of hydraulic conductivity for comparison purposes (Devlin, 2015). Cumulative distribution curves were created using the logarithm to the base $10\left(\log _{10}\right)$ scale for the particle diameter (x-axis), and a linear scale for the mass fractions (y-axis). Figures 4.35, 4.36, and 4.37 provide examples of the particle size distribution curves of the upper unconfined aquifer, aquitard, and lower semi-confined aquifer sediments, respectively (see Appendix G for particle size distribution curves for sediment samples from different depth ranges and boreholes). It should be noted that the silty sand aquitard sediments from the 16-20 foot interval of EB-1 are comparatively more permeable $\left(K=1.84 \times 10^{-6}\right.$ $\mathrm{m} / \mathrm{s}$ as measured by permeameter tests), and thus have a different distribution, than aquitard sediments from many of the other boreholes. Similarly, the sediments from the 20-24 foot interval of EB-1 are considered representative of the lower semi-confined aquifer (sand and gravel low in fines) even though subsurface investigations and well completion reports suggest that the lower semi-confined aquifer is located at depths $\geq 30$ feet.

Visual analysis of the cumulative particle size distributions reveals that the distributions of several samples (e.g., EB-1 16-20 feet (Figure 4.36)) add to more than, or, in some cases, less than 100 percent. Although this is partially attributable to measurement error, it is believed that the abundance of micaceous minerals in the sediments analyzed affected the reliability of the particle size analysis methods used. During the laboratory particle size analysis it was observed that the micas would get 


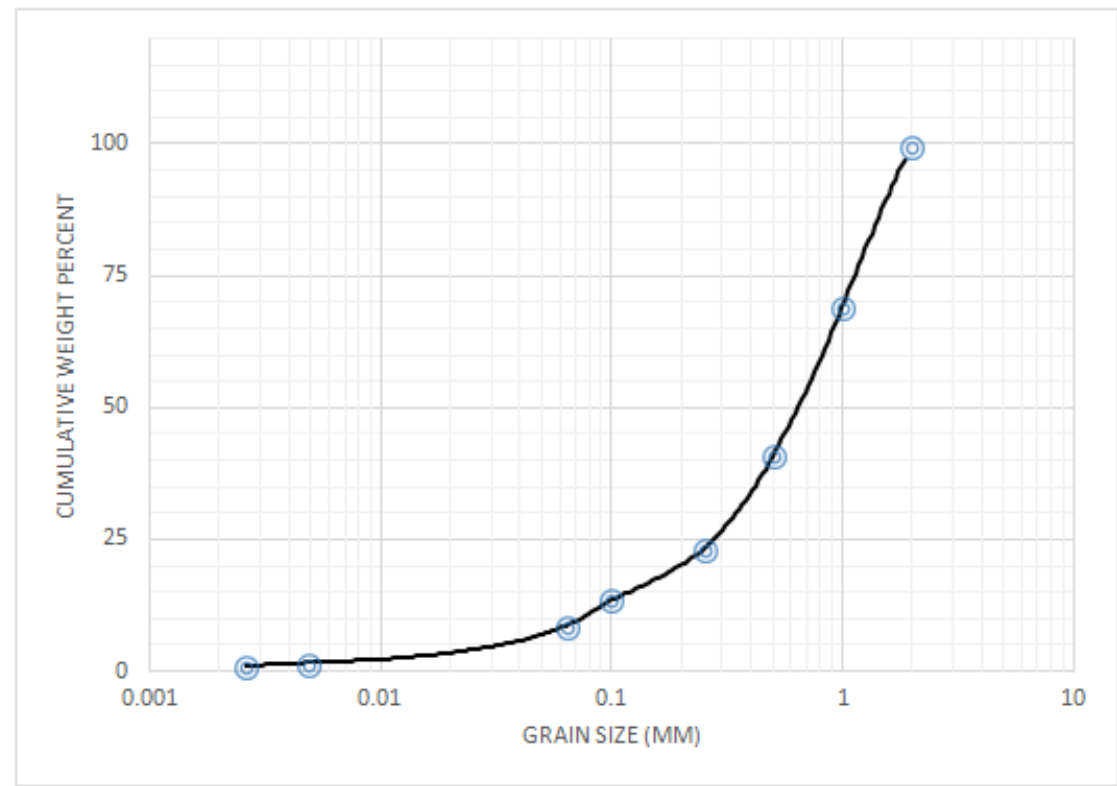

Figure 4.35: Particle size distribution for sediments from the 4-8 foot interval (surficial aquifer) of EB-1.

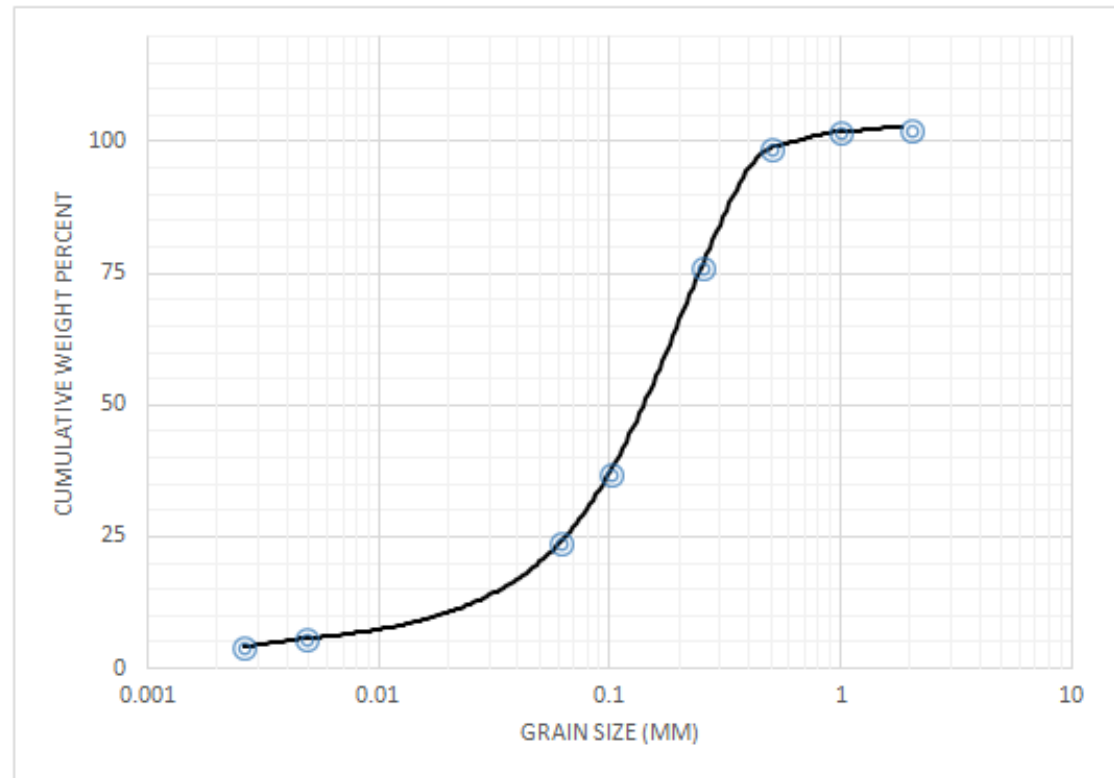

Figure 4.36: Particle size distribution for sediments from the 16-20 foot interval (semipervious layer) of EB-1. 


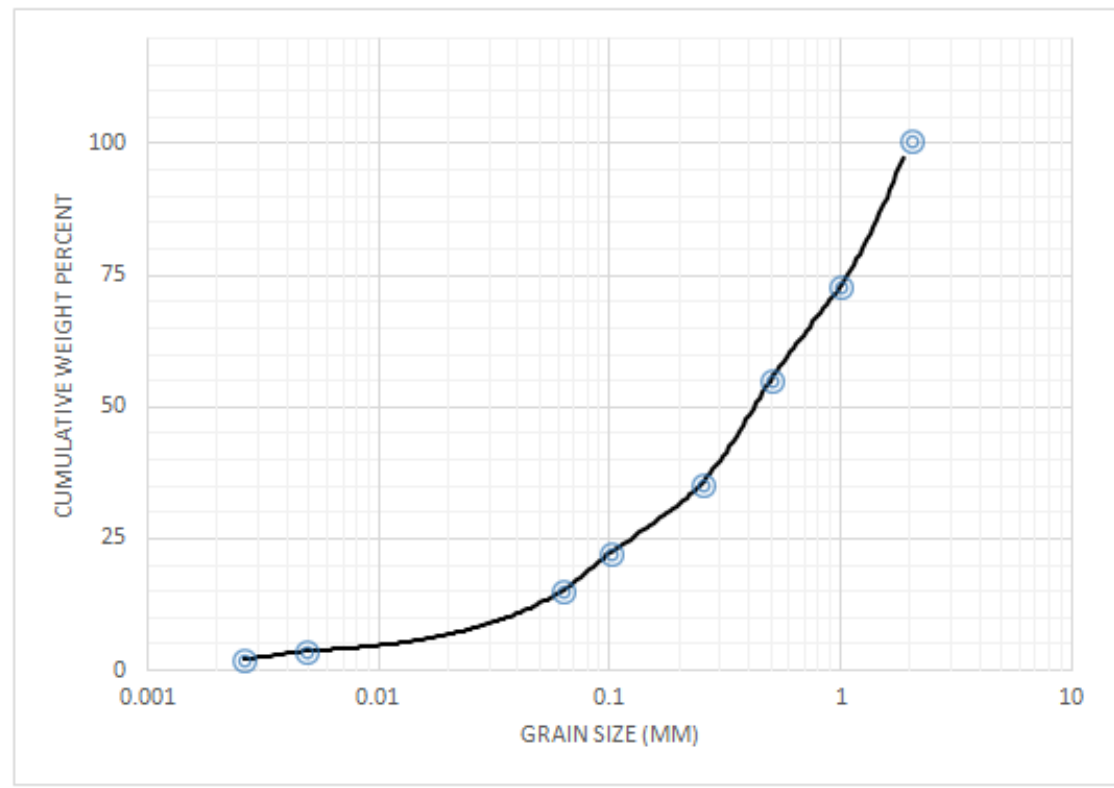

Figure 4.37: Particle size distribution for sediments from the 20-24 foot interval (deep aquifer) of EB-1.

trapped on the No. 270 sieve and were thus included in the sand fraction. Furthermore, micas are often irregular in shape (platelike) and are considered a "heavy" mineral (defined as those having a density exceeding $2900 \mathrm{~kg} / \mathrm{m}^{3}$ ) (Hillel, 2003)). These two mineral characteristics undermine the simplifying assumptions of Stokes' Law which the hydrometer method is based on, and likely affected the results of the particle size analysis. The particle size distribution curves also expose that a sedimentation time of 7 hours was insufficient for allowing the entire clay fraction (smallest settled diameter for all samples was $\sim 2.5 \mu \mathrm{m})$ to settle out at the temperatures observed $\left(17-21.5^{\circ} \mathrm{C}\right)$. Moreover, despite the preventative measures taken to reduce significant temperature fluctuations, changes of up to $4{ }^{\circ} \mathrm{C}$ were observed during the sedimentation process which can affect sedimentation rate.

The hydraulic conductivity and porosity of geologic materials is largely dependent on the size of sediment particles and the percentage of various sediment fractions. Particle size parameters, such as percent sand, silt, and clay, $d_{10}, d_{50}, d_{60}, C_{u}, n$, 
determined from the particle size distribution curves are summarized in Table 4.6. The $d_{10}, d_{50}$, and $d_{60}$ correspond to the particle diameter at $10 \%, 50 \%$, and $60 \%$ by weight, respectively. The coefficient of uniformity, $C_{u}$, is a measure of the particle size range and is the ratio of $d_{60}$ by $d_{10}\left(C_{u}=d_{60} / d_{10}\right)$. Porosity, $n$, values were calculated using the equation (Milan et al., 1992)

$$
n=0.255\left(1+0.83^{C_{u}}\right)
$$

where $C_{u}$ is the coefficient of uniformity.

A wide variation in particle size distributions of the alluvial sediments were observed. Effective grain sizes $\left(d_{10}\right)$ ranged from 0.001 to $0.098 \mathrm{~mm}$, median grain sizes $\left(d_{50}\right)$ were found to vary between 0.024 and $0.824 \mathrm{~mm}$ (silt to sand size particles), and $d_{60}$ values ranged between 0.033 to $0.999 \mathrm{~mm}$. Similarly, coefficient of uniformity $\left(C_{u}\right)$ values were found to vary between 4.1 and 99.22 for an average $C_{u}$ of 22.8. All of the sediment samples (with the exception of EB-2 $\sim 32)$ are poorly sorted $\left(C_{u}>4\right)$. Lastly, calculated values of porosity $(n)$ ranged from 0.26 to 0.37 for an average $n$ of 0.27 .

The spatial variability of hydraulic conductivity in the alluvial aquifer system was determined using empirical methods based on sediment particle size parameters. A large number of empirical formulas relating the hydraulic conductivity of a material to standard particle size parameters have been developed, two of the most commonly used being the Hazen and Kozeny-Carman equations (Bradbury and Muldoon, 1990; Rosas et al., 2014; Sahu and Saha, 2016). The Hazen (1892) method for estimating hydraulic conductivity is given by the equation (Hazen, 1892)

$$
K=C_{H} \frac{g}{v}[1+10(n-0.26)] d_{10}^{2},
$$


Table 4.6: Summary of results of the particle size analysis for sediments from EB-1 -4. The particle size parameters included in the table were determined from individual particle size distribution curves. The $d_{10}, d_{50}$, and $d_{60}$ values are in $\mathrm{mm}$.

\begin{tabular}{|c|c|c|c|c|c|c|c|c|}
\hline Depth Range (ft) & \%Sand & \%Silt & \%Clay & $d_{10}$ & $d_{50}$ & $d_{60}$ & $C_{u}$ & $n$ \\
\hline \multicolumn{9}{|l|}{ EB-1 } \\
\hline $0-4$ & 67.68 & 26.14 & 6.18 & 0.010 & 0.104 & 0.149 & 15.56 & 0.27 \\
\hline $4-8$ & 91.31 & 7.68 & 1.01 & 0.073 & 0.661 & 0.838 & 11.41 & 0.29 \\
\hline $8-12$ & 85.40 & 12.58 & 2.03 & 0.040 & 0.535 & 0.752 & 18.63 & 0.26 \\
\hline $12-14$ & 66.99 & 27.85 & 5.16 & 0.009 & 0.087 & 0.111 & 11.74 & 0.28 \\
\hline $14-16$ & 81.16 & 15.80 & 3.04 & 0.029 & 0.341 & 0.450 & 15.73 & 0.27 \\
\hline $16-20$ & 76.07 & 19.87 & 4.06 & 0.018 & 0.149 & 0.187 & 10.38 & 0.29 \\
\hline 20-24 & 84.77 & 13.20 & 2.03 & 0.036 & 0.434 & 0.635 & 17.43 & 0.26 \\
\hline \multicolumn{9}{|l|}{ EB-2 } \\
\hline $0-4$ & 72.97 & 23.37 & 3.66 & 0.017 & 0.164 & 0.222 & 13.15 & 0.28 \\
\hline $4-12$ & 85.84 & 13.55 & 0.61 & 0.043 & 0.436 & 0.571 & 13.38 & 0.28 \\
\hline 20-21 & 67.85 & 25.43 & 6.71 & 0.004 & 0.156 & 0.253 & 56.54 & 0.26 \\
\hline $21-23$ & 87.92 & 12.08 & 0.00 & 0.055 & 0.649 & 0.834 & 15.21 & 0.27 \\
\hline $23-24$ & 26.11 & 58.82 & 15.07 & 0.002 & 0.030 & 0.039 & 23.61 & 0.26 \\
\hline $24-28$ & 19.78 & 60.99 & 19.23 & 0.001 & 0.024 & 0.033 & 25.64 & 0.26 \\
\hline $28-30$ & 44.52 & 42.58 & 12.90 & 0.002 & 0.048 & 0.064 & 32.91 & 0.26 \\
\hline $30-32$ & 61.70 & 32.60 & 5.70 & 0.005 & 0.077 & 0.094 & 20.72 & 0.26 \\
\hline$\sim 32$ & 90.47 & 8.52 & 1.01 & 0.066 & 0.223 & 0.269 & 4.10 & 0.37 \\
\hline \multicolumn{9}{|l|}{ EB-3 } \\
\hline 12-14 & 94.15 & 3.83 & 2.02 & 0.098 & 0.536 & 0.728 & 7.43 & 0.32 \\
\hline $14-16$ & 51.51 & 38.26 & 10.23 & 0.002 & 0.060 & 0.082 & 32.91 & 0.26 \\
\hline 16-19 & 62.56 & 29.30 & 8.14 & 0.005 & 0.081 & 0.099 & 21.68 & 0.26 \\
\hline 19-20 & 90.76 & 6.22 & 3.01 & 0.070 & 0.758 & 0.998 & 14.28 & 0.27 \\
\hline 20-24 & 83.47 & 10.48 & 6.05 & 0.027 & 0.597 & 0.876 & 32.95 & 0.26 \\
\hline \multicolumn{9}{|l|}{ EB-4 } \\
\hline $0-2$ & 67.23 & 23.61 & 9.16 & 0.004 & 0.112 & 0.173 & 39.78 & 0.26 \\
\hline $2-4$ & 86.46 & 9.50 & 4.04 & 0.043 & 0.401 & 0.515 & 11.86 & 0.28 \\
\hline $4-8$ & 87.08 & 8.88 & 4.04 & 0.046 & 0.377 & 0.485 & 10.55 & 0.29 \\
\hline $8-12$ & 83.01 & 10.92 & 6.07 & 0.022 & 0.493 & 0.696 & 31.92 & 0.26 \\
\hline 16-19 & 40.78 & 44.88 & 14.34 & 0.002 & 0.043 & 0.056 & 31.97 & 0.26 \\
\hline 19-20 & 93.19 & 4.81 & 2.00 & 0.094 & 0.824 & 0.999 & 10.63 & 0.29 \\
\hline 20-22 & 67.32 & 22.59 & 10.09 & 0.003 & 0.160 & 0.249 & 99.22 & 0.26 \\
\hline $22-24$ & 89.75 & 8.24 & 2.01 & 0.062 & 0.443 & 0.604 & 9.77 & 0.30 \\
\hline
\end{tabular}


where $C_{H}$ is the Hazen coefficient $\left(6 \times 10^{-4}\right), g$ is acceleration due to gravity, $v$ is kinematic viscosity of water, $n$ is porosity, and $d_{10}$ is the effective grain size. The Hazen equation is suitable for sediments with a coefficient of uniformity less than five $\left(C_{u}<5\right)$ and effective grain size between $0.1 \mathrm{~mm}$ and $3 \mathrm{~mm}\left(0.1 \mathrm{~mm}<d_{10}<3 \mathrm{~mm}\right)$. The Kozeny-Carman method, initially developed by Kozeny (1927) and later modified by Carman (1956), which is appropriate for sediments with effective grain size of 3 $\mathrm{mm}$ or less $\left(d_{10} \leq 3 \mathrm{~mm}\right)$ and for textures excluding clay, is given by the equation (Carman, 1956; Kozeny, 1927)

$$
K=C_{K} \frac{g}{v} \frac{n^{3}}{(1-n)^{2}} d_{10}^{2},
$$

where $C_{K}$ is the Kozeny-Carman coefficient $\left(8.3 \times 10^{-3}\right)$. A value of $1.0034 \times 10^{-6}$ $\mathrm{m} / \mathrm{s}^{2}$ was used for the kinematic viscosity of water at a temperature of $20^{\circ} \mathrm{C}$. Table 4.7 is a summary of hydraulic conductivity values for sediments from EB-1 -4 estimated using the empirical methods of Hazen and Kozeny-Carman.

Similar to the wide variation in particle size distributions observed, the hydraulic conductivity values of sediments from each borehole, estimated using the empirical equations of Hazen and Kozeny-Carman, varied by several orders of magnitude from $4.07 \times 10^{-9} \mathrm{~m} / \mathrm{s}$ to $8.94 \times 10^{-5} \mathrm{~m} / \mathrm{s}$. For individual sediment samples, both methods predicted similar $K$ values with no more than an order of magnitude difference.

\subsection{Analysis of Pumping Tests}

\subsubsection{Estimation of Aquifer Hydraulic Properties}

Pumping test drawdown data measured in the Pump House, VFD, and Queseria wells were analyzed to estimate the hydraulic properties of the aquifer. Hydraulic properties, including transmissivity and storativity, were estimated by fitting the Theis 
Table 4.7: Summary of hydraulic conductivity $(K)$ values in $\mathrm{m} / \mathrm{s}$ for sediments from EB-1 -4 estimated using the empirical methods of Hazen and Kozeny-Carman.

\begin{tabular}{|c|c|c|c|}
\hline Depth Range (ft) & Layer & Hazen & Kozeny-Carman \\
\hline \multicolumn{4}{|l|}{ EB-1 } \\
\hline $0-4$ & 1 & $5.89 \times 10^{-7}$ & $2.72 \times 10^{-7}$ \\
\hline $4-8$ & 1 & $3.97 \times 10^{-5}$ & $1.99 \times 10^{-5}$ \\
\hline $8-12$ & 1 & $9.83 \times 10^{-6}$ & $4.42 \times 10^{-6}$ \\
\hline $12-14$ & 1 & $6.43 \times 10^{-7}$ & $3.20 \times 10^{-7}$ \\
\hline $14-16$ & 1 & $5.22 \times 10^{-6}$ & $2.41 \times 10^{-6}$ \\
\hline $16-20$ & 2 & $2.52 \times 10^{-6}$ & $1.31 \times 10^{-6}$ \\
\hline $20-24$ & 3 & $8.16 \times 10^{-6}$ & $3.70 \times 10^{-6}$ \\
\hline \multicolumn{4}{|l|}{ EB-2 } \\
\hline $0-4$ & 1 & $1.95 \times 10^{-6}$ & $9.38 \times 10^{-7}$ \\
\hline $4-12$ & 1 & $1.24 \times 10^{-5}$ & $5.92 \times 10^{-6}$ \\
\hline $20-21$ & 1 & $1.12 \times 10^{-7}$ & $4.86 \times 10^{-8}$ \\
\hline $21-23$ & 1 & $1.94 \times 10^{-5}$ & $8.99 \times 10^{-6}$ \\
\hline $23-24$ & 2 & $1.56 \times 10^{-8}$ & $6.88 \times 10^{-9}$ \\
\hline $24-28$ & 2 & $9.28 \times 10^{-9}$ & $4.07 \times 10^{-9}$ \\
\hline $28-30$ & 2 & $2.10 \times 10^{-8}$ & $9.16 \times 10^{-9}$ \\
\hline $30-32$ & 2 & $1.20 \times 10^{-7}$ & $5.35 \times 10^{-8}$ \\
\hline$\sim 32$ & 3 & $5.40 \times 10^{-5}$ & $4.66 \times 10^{-5}$ \\
\hline \multicolumn{4}{|l|}{ EB-3 } \\
\hline $12-14$ & 1 & $8.94 \times 10^{-5}$ & $5.44 \times 10^{-5}$ \\
\hline $14-16$ & 2 & $3.44 \times 10^{-8}$ & $1.50 \times 10^{-8}$ \\
\hline $16-19$ & 2 & $1.21 \times 10^{-7}$ & $5.36 \times 10^{-8}$ \\
\hline $19-20$ & 3 & $3.23 \times 10^{-5}$ & $1.52 \times 10^{-5}$ \\
\hline $20-24$ & 3 & $3.96 \times 10^{-6}$ & $1.73 \times 10^{-6}$ \\
\hline \multicolumn{4}{|l|}{ EB-4 } \\
\hline $0-2$ & 1 & $1.06 \times 10^{-7}$ & $4.62 \times 10^{-8}$ \\
\hline $2-4$ & 1 & $1.36 \times 10^{-5}$ & $6.75 \times 10^{-6}$ \\
\hline $4-8$ & 1 & $1.62 \times 10^{-5}$ & $8.38 \times 10^{-6}$ \\
\hline $8-12$ & 1 & $2.66 \times 10^{-6}$ & $1.16 \times 10^{-6}$ \\
\hline $16-19$ & 2 & $1.71 \times 10^{-8}$ & $7.47 \times 10^{-9}$ \\
\hline $19-20$ & 3 & $6.75 \times 10^{-5}$ & $3.48 \times 10^{-5}$ \\
\hline $20-22$ & 3 & $3.52 \times 10^{-8}$ & $1.53 \times 10^{-8}$ \\
\hline $22-24$ & 3 & $3.06 \times 10^{-5}$ & $1.63 \times 10^{-5}$ \\
\hline
\end{tabular}


(1935), Cooper and Jacob (1946), and Hantush and Jacob (1955) analytical models to time-drawdown data (curve matching) in AQTESOLV (commercially available and industry standard software developed by HydroSOLVE, Inc. for the analysis of pumping tests). Aquifer and aquitard thicknesses were entered based on information from well completion reports and findings from exploratory borehole drilling operations. The thickness of the aquifer $(b)$ was $24.38 \mathrm{~m}(80 \mathrm{ft})$ and the thickness of the aquitard $\left(b^{\prime}\right)$ was $4.27 \mathrm{~m}$ (14 ft). Well construction and pumping details, such as well configuration, radius, pumping rates, and observation data, were entered using information from well completion reports and flow rate and drawdown data measured during the pumping tests. The Queseria, Pump House, and VFD wells were entered as fully penetrating wells.

The Theis (1935) solution for transient flow to a well in a homogeneous, isotropic and nonleaky confined aquifer of infinite radial extent is given by the equation (Theis, 1935)

$$
s=\frac{Q}{4 \pi T} \int_{u}^{\infty} \frac{e^{-y}}{y} d y,
$$

where $s$ is drawdown, $Q$ is pumping rate, $T$ is transmissivity, $y$ is a dummy variable of integration, and $u$ is the Boltzmann similarity transform,

$$
u=\frac{r^{2} S}{4 T t},
$$

where $r$ is radial distance from pumping well to observation well, $S$ is storativity, and $t$ is elapsed time since start of pumping. Analysis with the Theis (1935) solution in AQTESOLV is performed by matching the Theis curve to drawdown data plotted as a function of time on log-log axes (Figures 4.38, 4.39, and 4.40).

The Cooper and Jacob (1946) approximation for the determination of hydraulic 


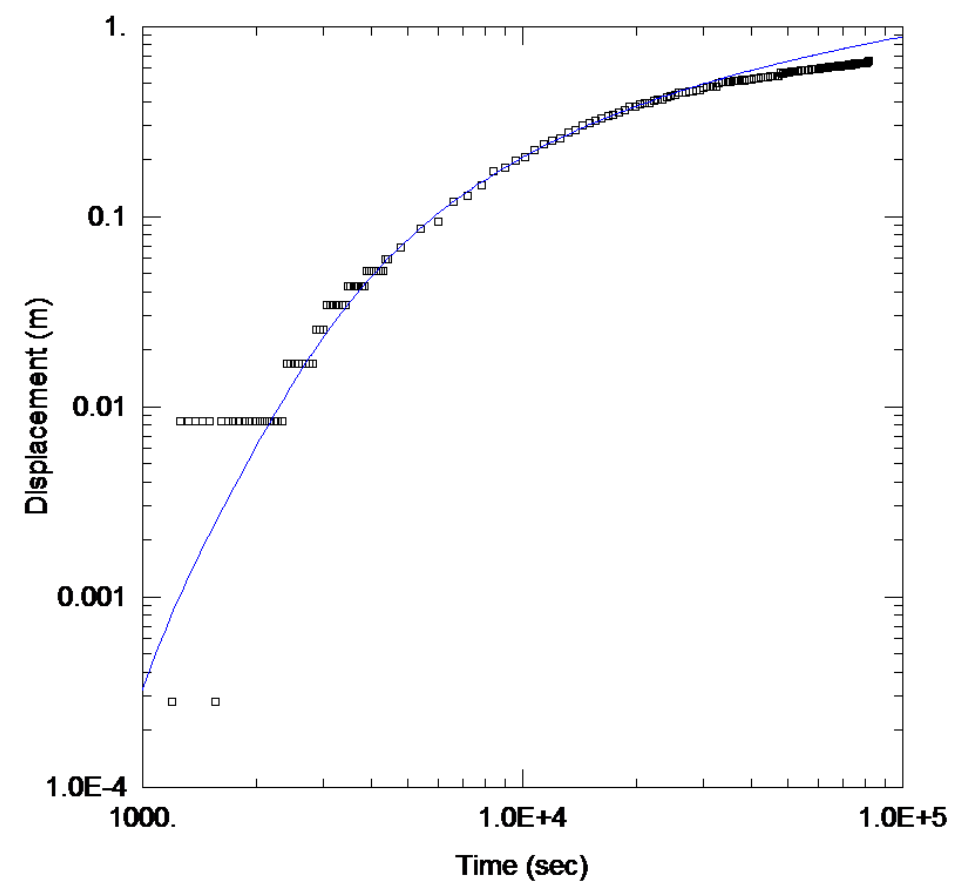

\section{Obs. Wells}

$\square$ Pump House

Aquifer Model

Confined

Solution

Theis

Parameters

$\mathrm{T} \quad=0.003932 \mathrm{~m}^{2} / \mathrm{sec}$

$\mathrm{S} \quad \mathbf{0 . 0 0 1 0 6 4}$

$\mathbf{K z} / \mathbf{K r}=1$.

b $\quad=24.38 \mathrm{~m}$

Figure 4.38: Estimation of aquifer properties by matching the Theis (1935) curve to time-drawdown data collected in Pump House Well during VFD Well pumping test.

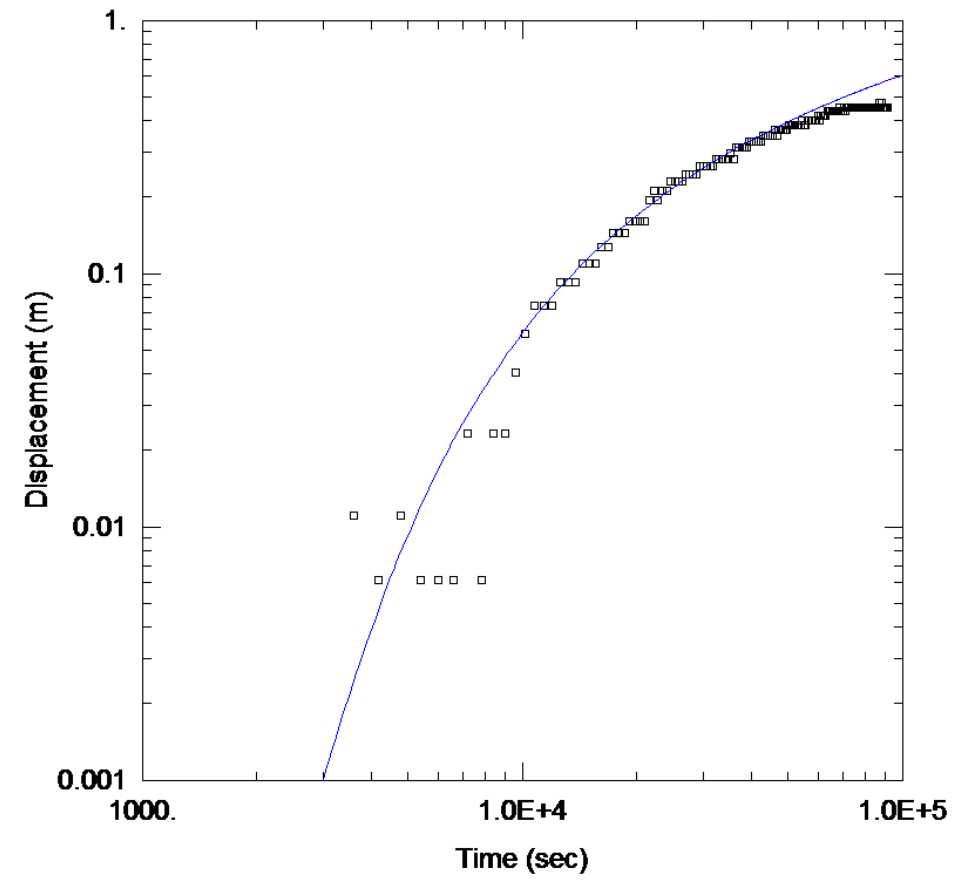

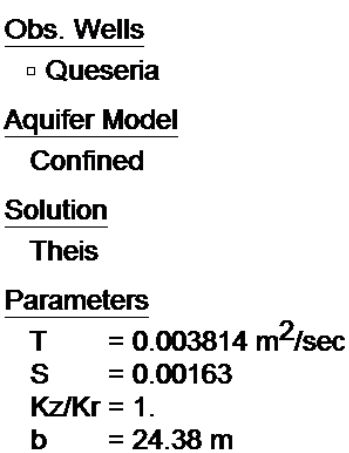

b $\quad=24.38 \mathrm{~m}$

Figure 4.39: Estimation of aquifer properties by matching the Theis (1935) curve to time-drawdown data collected in Queseria Well during VFD Well pumping test. 


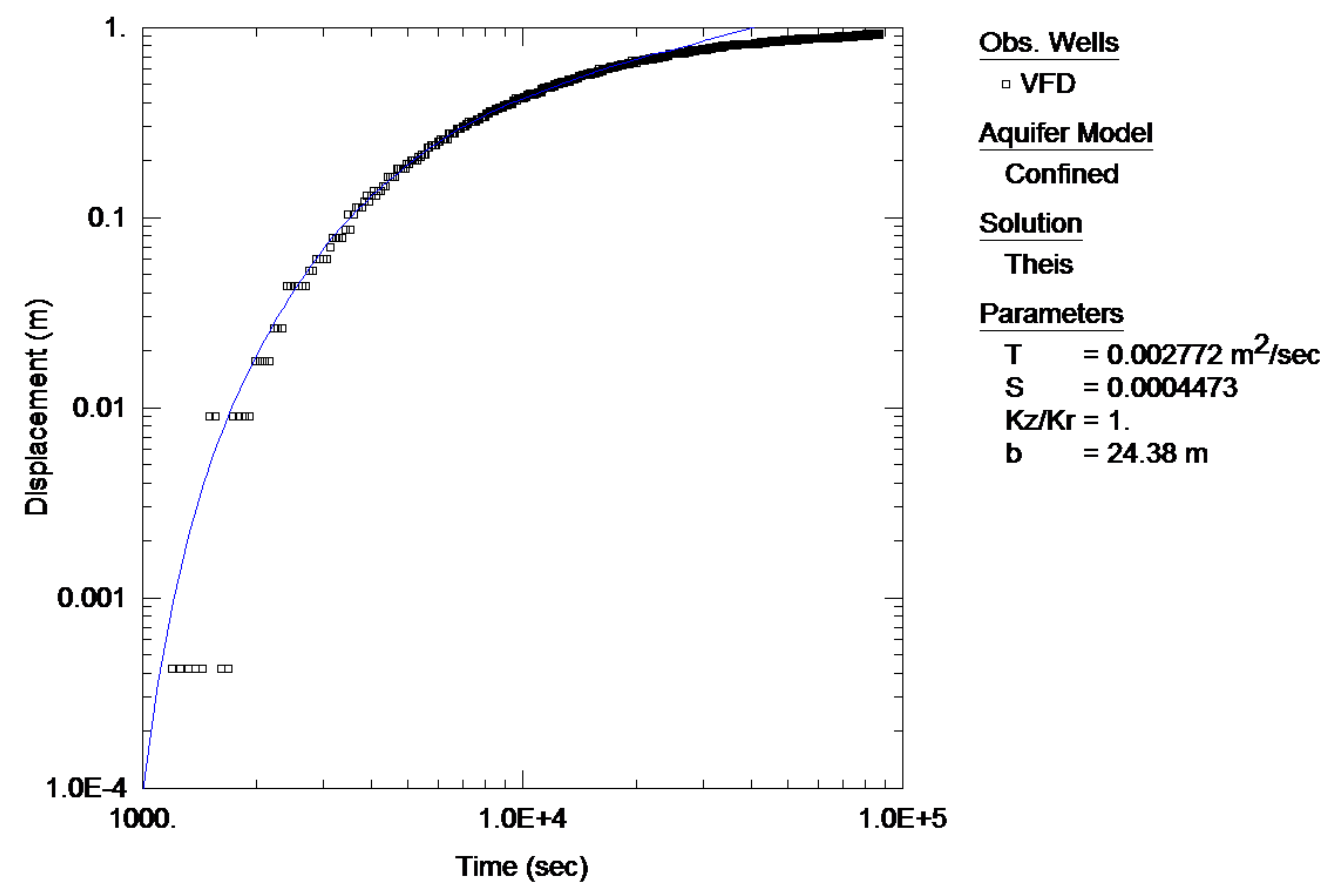

Figure 4.40: Estimation of aquifer properties by matching the Theis (1935) curve to time-drawdown data collected in VFD Well during Pump House Well pumping test.

properties of nonleaky confined aquifers, which is derived from the Theis (1935) solution for conditions where $u \leq 0.05$, is given by the linear equation (Cooper and Jacob, 1946)

$$
s=\frac{Q}{4 \pi T}\left[-0.5772-\ln \left(\frac{r^{2} S}{4 T t}\right)\right] .
$$

Analysis with the Cooper and Jacob (1946) approximation in AQTESOLV is performed by plotting drawdown as a function of log time on semi-logarithmic axes and drawing a straight line, with slope $Q / 4 \pi T$ and $S$ estimated from the time intercept, through the data (Figures 4.41, 4.42, and 4.43).

Curve-matching the Theis (1935) and Cooper and Jacob (1946) solutions to time-drawdown data recorded in individual observation wells during the pumping tests produced comparable estimates of aquifer transmissivity $(T)$ and storativity $(S)$ 


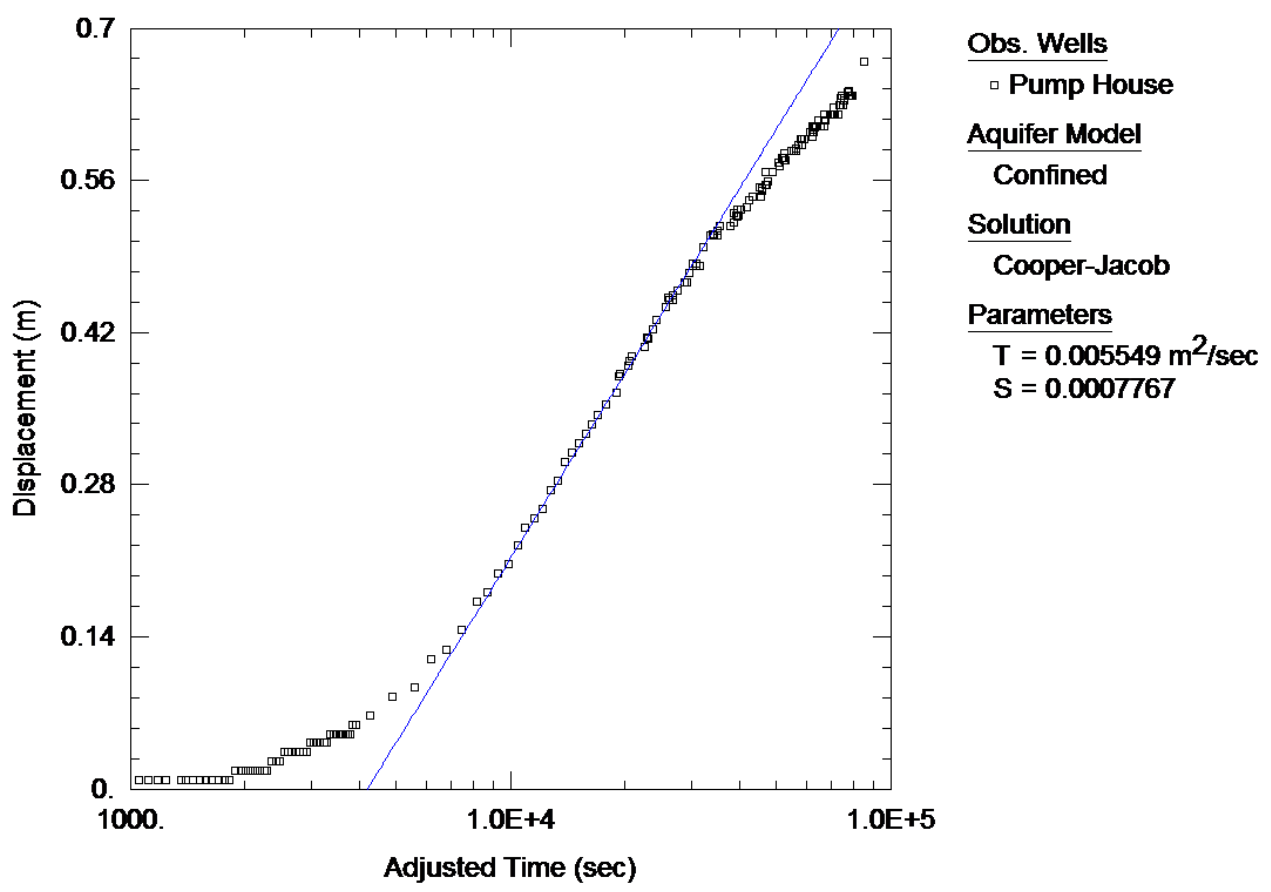

Figure 4.41: Estimation of aquifer properties by matching the Cooper and Jacob (1946) straight-line solution to time-drawdown data collected in Pump House Well during VFD Well pumping test.

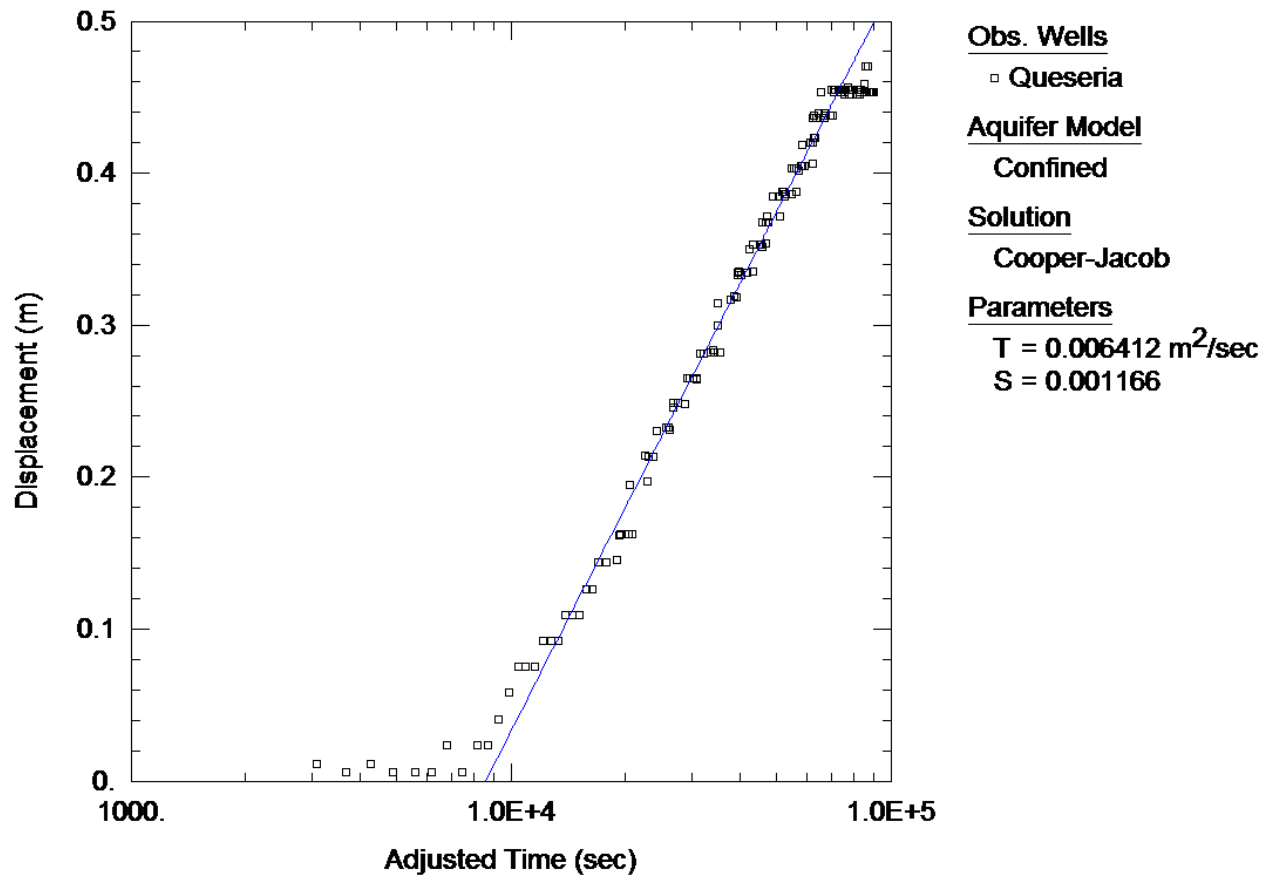

Figure 4.42: Estimation of aquifer properties by matching the Cooper and Jacob (1946) straight-line solution to time-drawdown data collected in Queseria Well during VFD Well pumping test. 


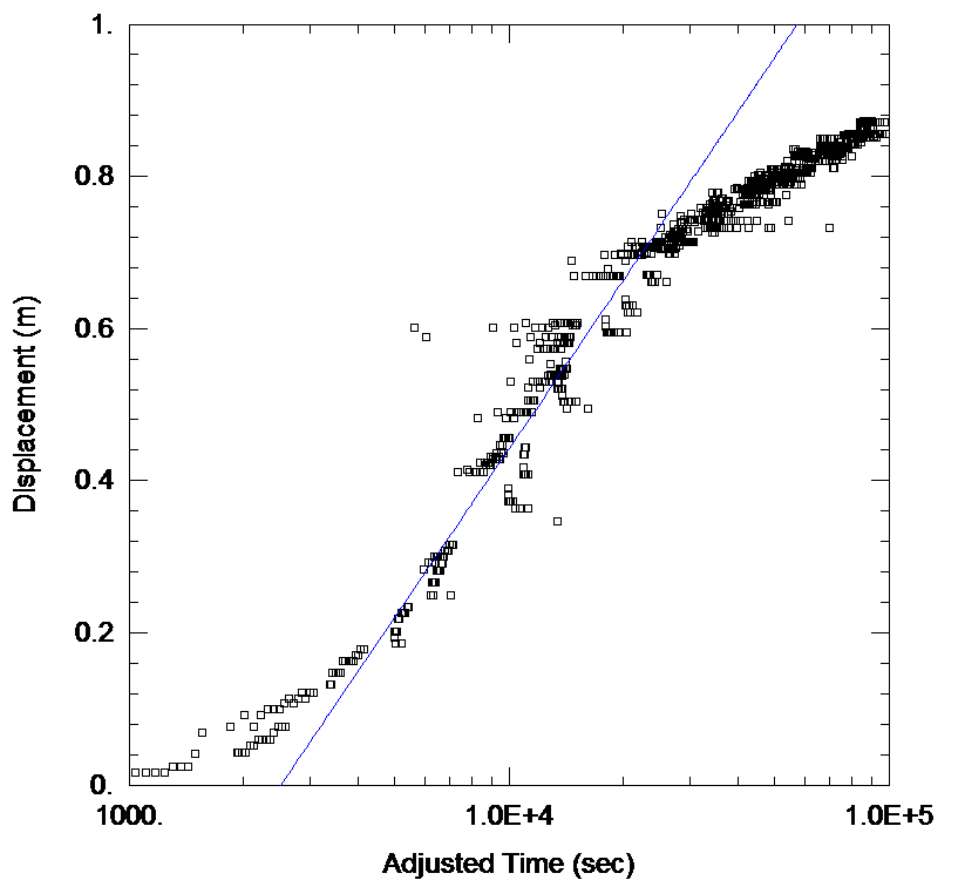

Obs. Wells

$\square$ VFD

Aquifer Model

Confined

Solution

Cooper-Jacob

Parameters

$\mathrm{T}=0.003772 \mathrm{~m}^{2} / \mathrm{sec}$

$S=0.0003148$

Figure 4.43: Estimation of aquifer properties by matching the Cooper and Jacob (1946) straight-line solution to time-drawdown data collected in VFD Well during Pump House Well pumping test.

(Figures 4.38-4.43). Values of transmissivity ranged from $2.77 \times 10^{-3} \mathrm{~m}^{2} / \mathrm{s}$ (Figure 4.40 ) to $6.41 \times 10^{-3} \mathrm{~m}^{2} / \mathrm{s}$ (Figure 4.42 ). Similarly, values of storativity ranged from $3.15 \times 10^{-4}$ (Figure 4.43$)$ to $1.63 \times 10^{-3}$ (Figure 4.39$)$. These parameter estimates were used to calculate aquifer hydraulic conductivity $(K)$ and specific storage $\left(S_{s}\right)$ by dividing by total aquifer thickness. Table 4.8 provides a summary of the hydraulic parameter estimates produced by curve-matching the Theis (1935) and Cooper and Jacob (1946) solutions to time-drawdown data in AQTESOLV.

Although the hydraulic parameter estimates produced using the Theis (1935) and Cooper and Jacob (1946) solutions are reasonable based on the sediments collected during exploratory borehole drilling operations, it is realized that both solutions deviate from the drawdown data at late time (around 6-8 hours after pumping started), which may affect the reliability of the estimates. The deviation of the Theis (1935) and 
Table 4.8: Summary of hydraulic parameter estimates produced by curve-matching the Theis (1935) and Cooper and Jacob (1946) solutions to time-drawdown data in AQTESOLV.

\begin{tabular}{ccccc}
\hline Figure & $T\left(\mathrm{~m}^{2} / \mathrm{s}\right)$ & $K(\mathrm{~m} / \mathrm{s})$ & $S$ & $S_{s}\left(\mathrm{~m}^{-1}\right)$ \\
\hline 4.38 & $3.93 \times 10^{-3}$ & $1.61 \times 10^{-4}$ & $1.06 \times 10^{-3}$ & $4.40 \times 10^{-5}$ \\
4.39 & $3.81 \times 10^{-3}$ & $1.56 \times 10^{-4}$ & $1.63 \times 10^{-3}$ & $6.70 \times 10^{-5}$ \\
4.40 & $2.77 \times 10^{-3}$ & $1.14 \times 10^{-4}$ & $4.47 \times 10^{-4}$ & $1.80 \times 10^{-5}$ \\
4.41 & $5.55 \times 10^{-3}$ & $2.28 \times 10^{-4}$ & $7.77 \times 10^{-4}$ & $3.20 \times 10^{-5}$ \\
4.42 & $6.41 \times 10^{-3}$ & $2.63 \times 10^{-4}$ & $1.17 \times 10^{-3}$ & $4.80 \times 10^{-5}$ \\
4.43 & $3.77 \times 10^{-3}$ & $1.55 \times 10^{-4}$ & $3.15 \times 10^{-4}$ & $1.30 \times 10^{-5}$ \\
\hline Average & $4.37 \times 10^{-3}$ & $1.80 \times 10^{-4}$ & $9.00 \times 10^{-4}$ & $3.70 \times 10^{-5}$ \\
\hline
\end{tabular}

Cooper and Jacob (1946) solutions from the drawdown data at late time suggests vertical leakage (possibly from the top unconfined aquifer and aquitard, or through bedrock) contributes to the recharge of the pumped aquifer. Therefore, the Hantush and Jacob (1955) solution for leaky confined aquifers was used to achieve a better model fit to data and to produce improved hydraulic parameter estimates.

The Hantush and Jacob (1955) solution for flow to a well in a homogeneous, isotropic and leaky confined aquifer of infinite radial extent is given by the equations (Hantush and Jacob, 1955)

$$
\begin{gathered}
s=\frac{Q}{4 \pi T} \int_{u}^{\infty} \frac{e^{-y-r^{2} / 4 B^{2} y}}{y} d y \\
u=\frac{r^{2} S}{4 T t}, \\
B=\sqrt{\frac{T b^{\prime}}{K^{\prime}}}
\end{gathered}
$$

where $b^{\prime}$ is aquitard thickness and $K^{\prime}$ is vertical hydraulic conductivity of the aquitard. The solution assumes no storage in incompressible leaky aquitard(s). It is realized 
that most aquitards have significant storage capacity, but in this case, based on the great variability in aquitard thickness and spatial extent observed, it is assumed the aquitard is incompressible (more complex models of Malama et al. $(2007,2008)$ that account for aquitard storage exist for flow in leaky aquifer systems, which remove the need to make the simplifying assumptions adopted by the classical leakage theory of Hantush and Jacob (1955)). Analysis with the Hantush and Jacob (1955) solution in AQTESOLV is performed by matching the modified well function to drawdown data plotted as a function of time on log-log and semi-log axes.

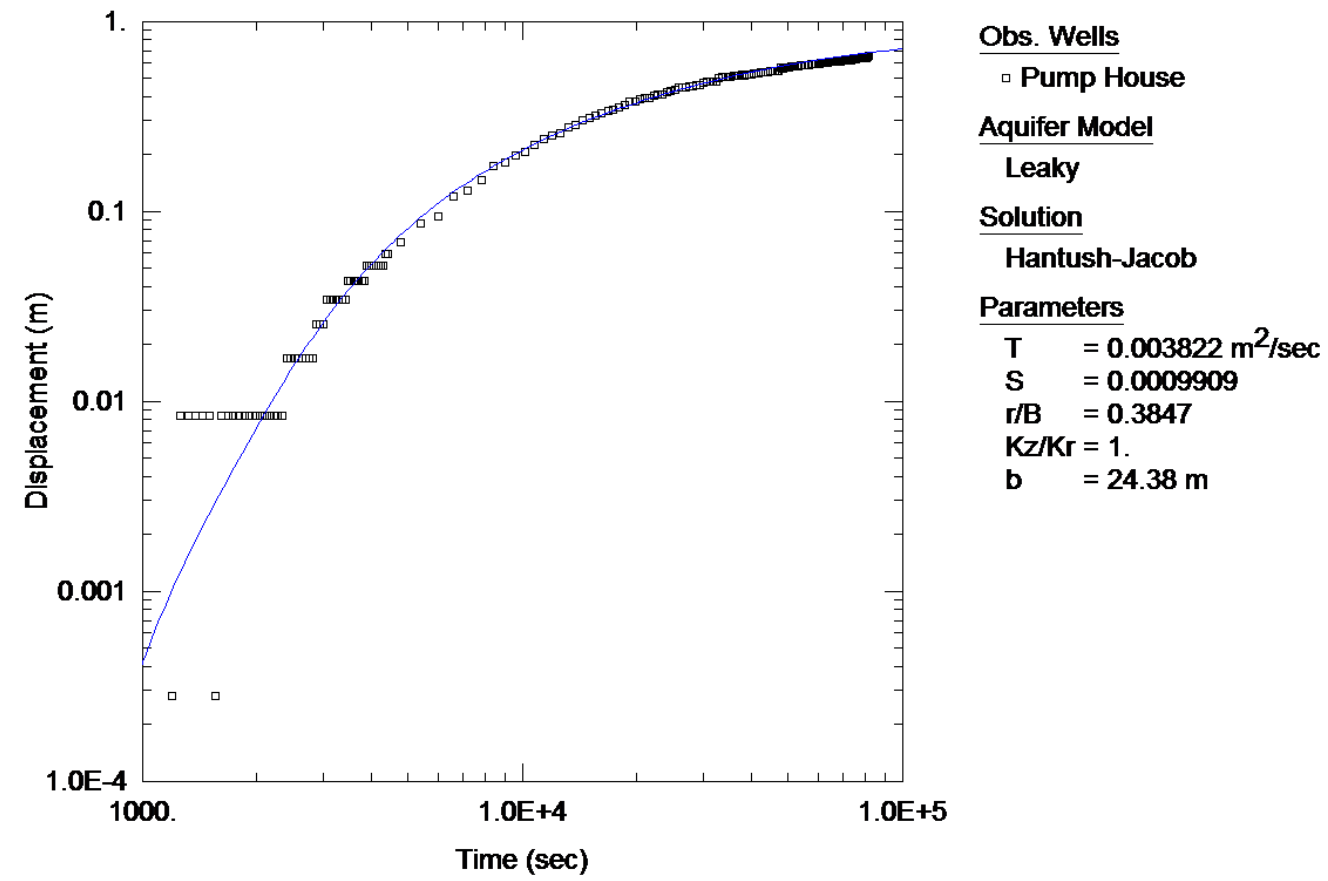

Figure 4.44: Estimation of aquifer properties by matching the Hantush and Jacob (1955) curve to time-drawdown data (log-log axes) collected in Pump House Well during VFD Well pumping test.

Figures 4.44-4.49 show results of fitting the Hantush and Jacob (1955) leaky confined aquifer model to the time-drawdown data. A significant improvement in model fit at late-time is observed when compared to the Theis (1935) and Cooper and Jacob (1946) curve-matching plots (Figures 4.38-4.43). Values of transmissivity ranged 


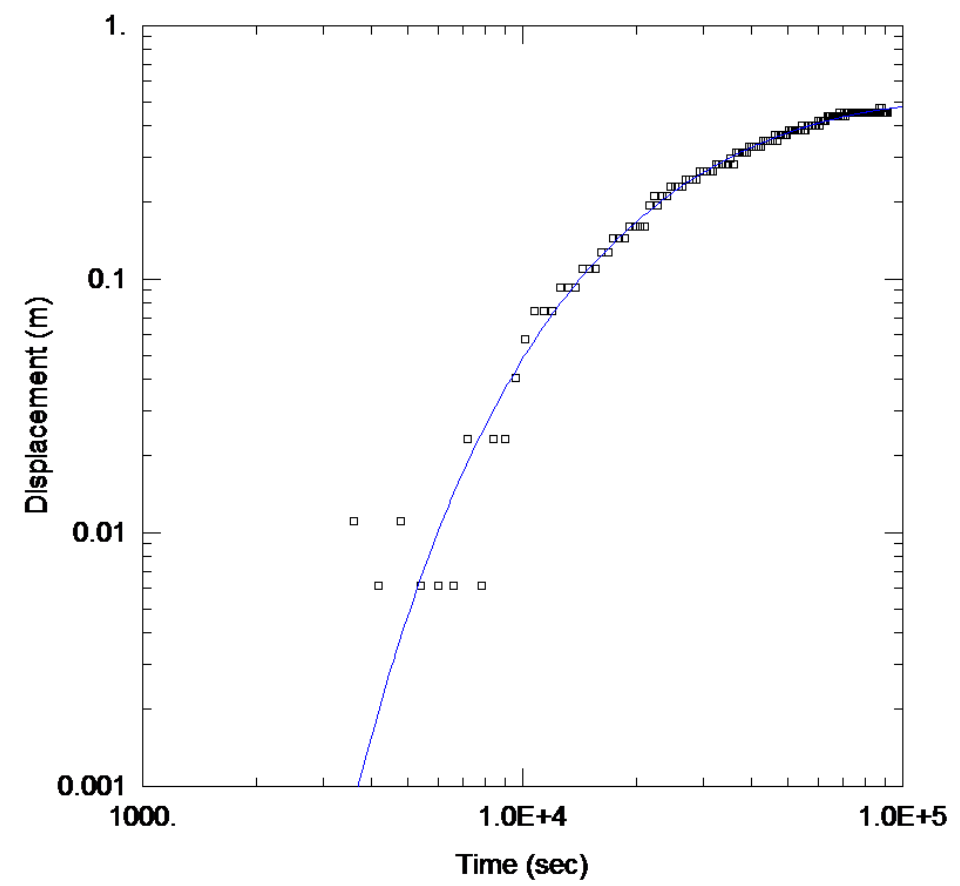

Obs. Wells

$\square$ Queseria

Aquifer Model

Leaky

Solution

Hantush-Jacob

Parameters

$\mathrm{T} \quad=0.001904 \mathrm{~m}^{2} / \mathrm{sec}$

$\mathrm{S} \quad \mathbf{0 . 0 0 1 1 5 5}$

$\mathrm{r} / \mathrm{B} \quad=1.111$

$\mathrm{K} z / \mathbf{K r}=1$

b $\quad=24.38 \mathrm{~m}$

Figure 4.45: Estimation of aquifer properties by matching the Hantush and Jacob (1955) curve to time-drawdown data (log-log axes) collected in Queseria Well during VFD Well pumping test.

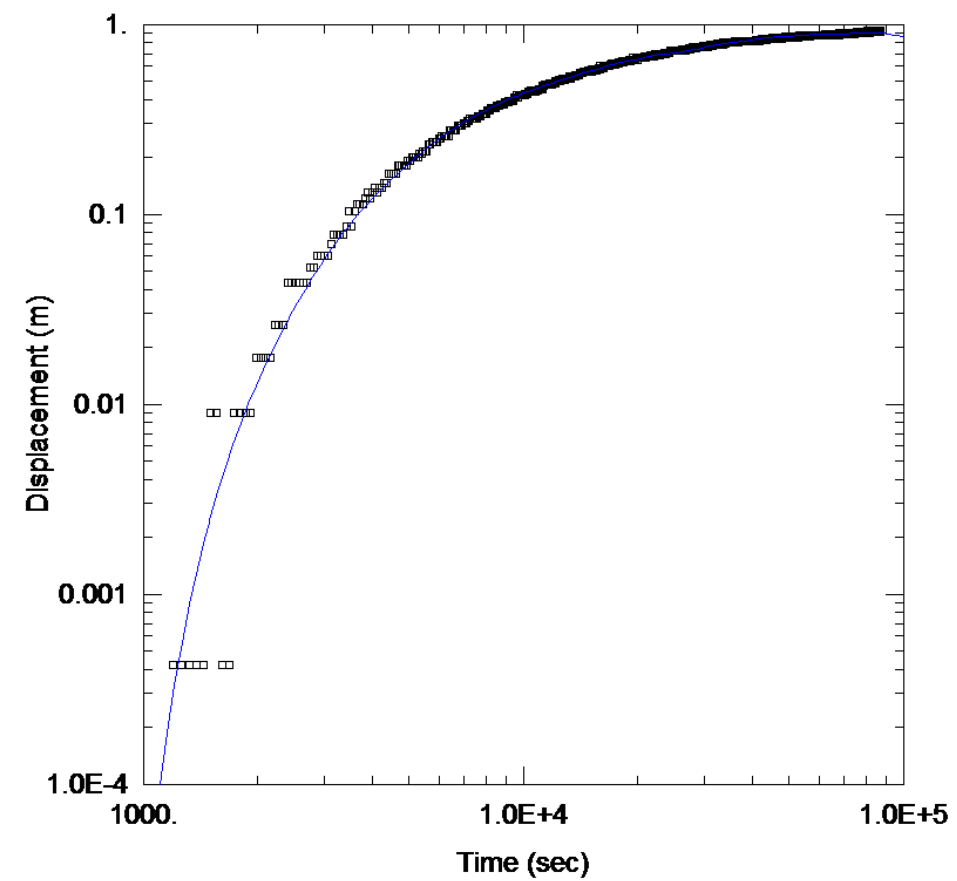

Figure 4.46: Estimation of aquifer properties by matching the Hantush and Jacob (1955) curve to time-drawdown data (log-log axes) collected in VFD Well during Pump House Well pumping test. 


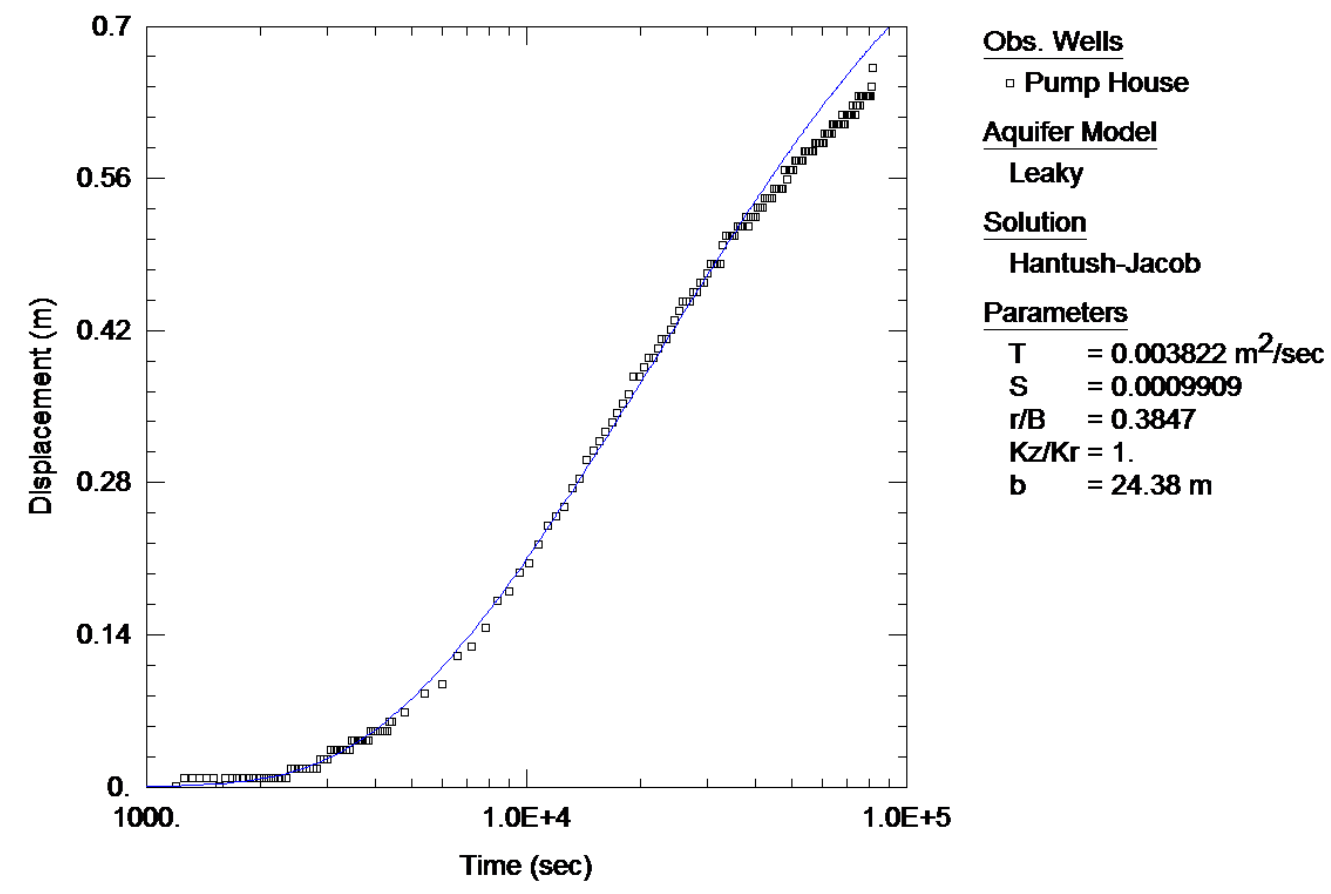

Figure 4.47: Estimation of aquifer properties by matching the Hantush and Jacob (1955) curve to time-drawdown data (semi-log axes) collected in Pump House Well during VFD Well pumping test.

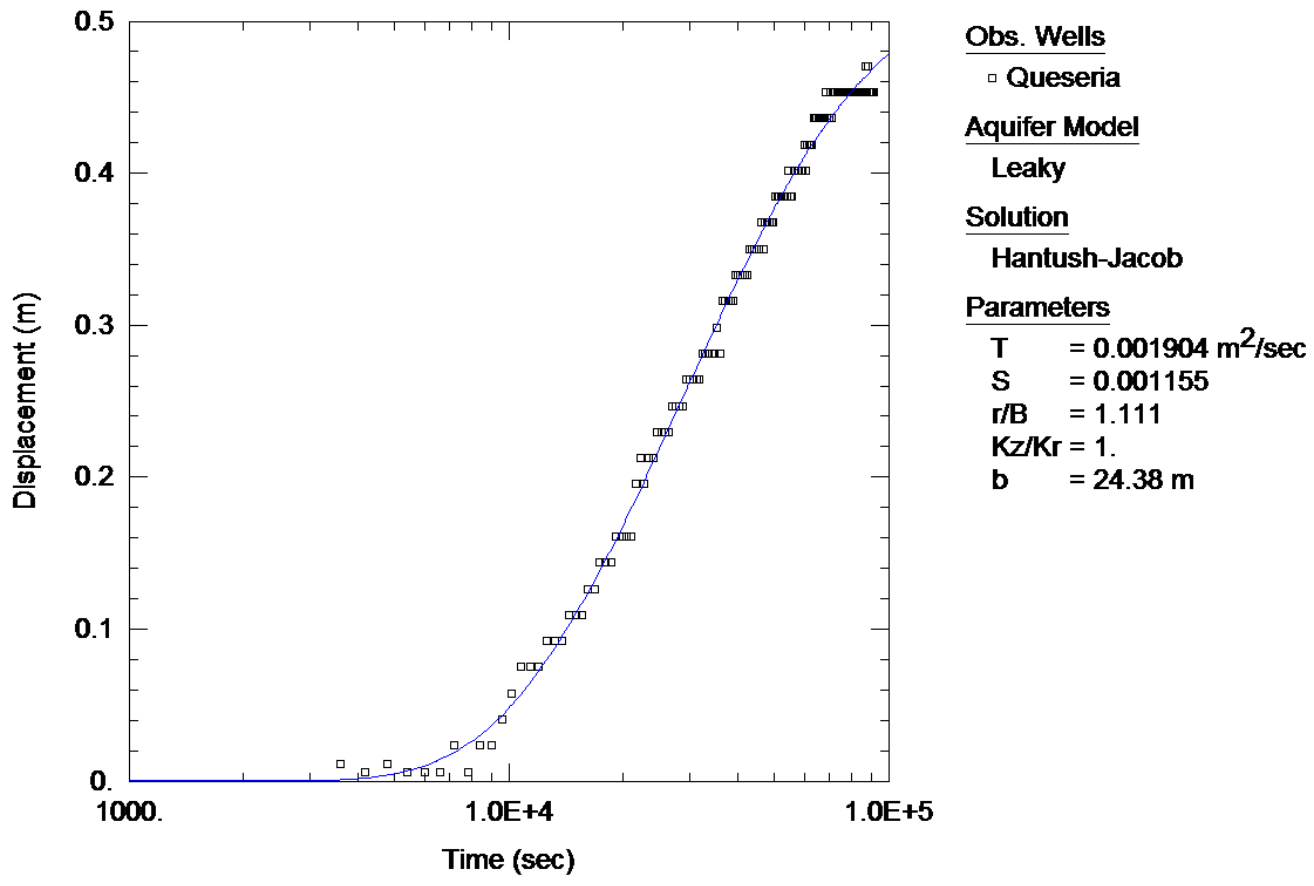

Figure 4.48: Estimation of aquifer properties by matching the Hantush and Jacob (1955) curve to time-drawdown data (semi-log axes) collected in Queseria Well during VFD Well pumping test. 

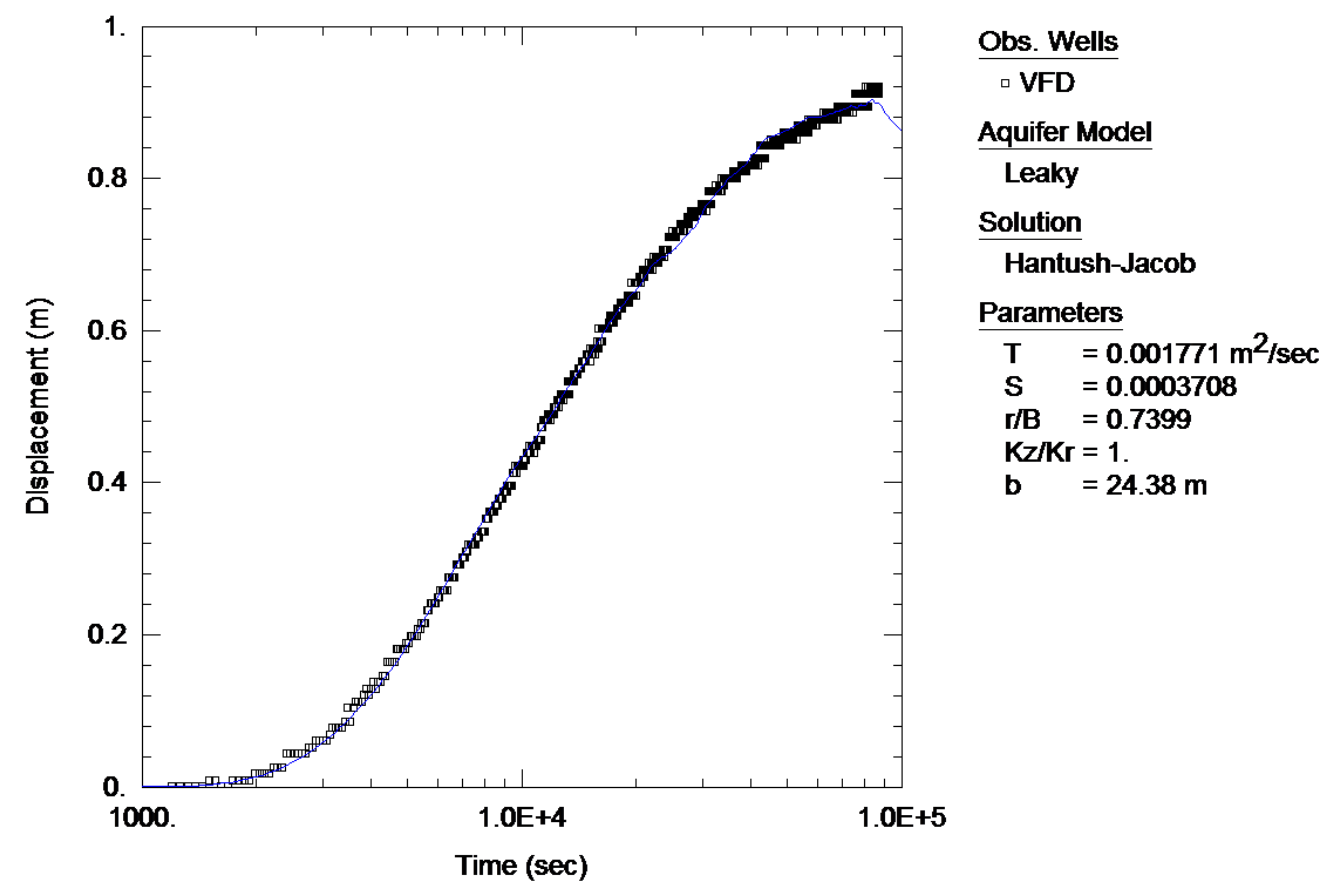

Figure 4.49: Estimation of aquifer properties by matching the Hantush and Jacob (1955) curve to time-drawdown data (semi-log axes) collected in VFD Well during Pump House Well pumping test.

from $1.77 \times 10^{-3} \mathrm{~m}^{2} / \mathrm{s}$ (Figure 4.46 ) to $3.82 \times 10^{-3} \mathrm{~m}^{2} / \mathrm{s}$ (Figure 4.44 ). Similarly, values of storativity ranged from $3.71 \times 10^{-4}$ (Figure 4.46) to $1.16 \times 10^{-3}$ (Figure 4.45). Additionally, the hydraulic conductivity of the aquitard $\left(K^{\prime}\right)$ was calculated using equation 4.14. Values of $K^{\prime}$ ranged from $3.57 \times 10^{-8} \mathrm{~m} / \mathrm{s}$ to $9.47 \times 10^{-8} \mathrm{~m} / \mathrm{s}$. Table 4.9 provides a summary of the hydraulic parameter estimates produced by curve-matching the Hantush and Jacob (1955) solution to time-drawdown data in AQTESOLV.

Table 4.9: Summary of hydraulic parameter estimates produced by curve-matching the Hantush and Jacob (1955) solution to time-drawdown data in AQTESOLV.

\begin{tabular}{cccccc}
\hline Figure & $T\left(\mathrm{~m}^{2} / \mathrm{s}\right)$ & $K(\mathrm{~m} / \mathrm{s})$ & $K^{\prime}(\mathrm{m} / \mathrm{s})$ & $S$ & $S_{s}\left(\mathrm{~m}^{-1}\right)$ \\
\hline 4.44 & $3.82 \times 10^{-3}$ & $1.57 \times 10^{-4}$ & $3.57 \times 10^{-8}$ & $9.91 \times 10^{-4}$ & $4.06 \times 10^{-5}$ \\
4.45 & $1.90 \times 10^{-3}$ & $7.80 \times 10^{-5}$ & $9.47 \times 10^{-8}$ & $1.16 \times 10^{-3}$ & $4.70 \times 10^{-5}$ \\
4.46 & $1.77 \times 10^{-3}$ & $7.30 \times 10^{-5}$ & $6.12 \times 10^{-8}$ & $3.71 \times 10^{-4}$ & $1.50 \times 10^{-5}$ \\
\hline Average & $2.50 \times 10^{-3}$ & $1.03 \times 10^{-4}$ & $6.39 \times 10^{-8}$ & $8.39 \times 10^{-4}$ & $3.42 \times 10^{-5}$ \\
\hline
\end{tabular}




\subsubsection{Calculation of Streamflow Depletion}

The Hantush (1965) equation of groundwater flow to a gravity well penetrating a water-table aquifer near a stream with a semipervious bed was applied to the semi-confined case (value of aquifer storativity substituted for specific yield) and used to quantify the effects of groundwater pumping on lower Scotts Creek stream flows. Aquifer and aquitard hydraulic properties determined by field and laboratory methods were used to solve the equation. The rate of stream depletion is given by the equation (Hantush, 1965)

$$
Q_{r}=Q\left\{\operatorname{erfc}(U)-\exp \left[-u^{2}+(U+w)^{2}\right] \operatorname{erfc}(U+w)\right\},
$$

where $Q$ is the constant discharge of the well, erfc is the complimentary error function, $U=x_{o} /(4 \alpha t)^{1 / 2}$ (where $x_{o}$ is the effective distance from the well to the stream bank, $t$ is time since pumping began, and $\alpha=K b / S_{y}$ (hydraulic diffusivity), where $K$ is the hydraulic conductivity of the aquifer, $b$ is the weighted mean of the depth of saturation,

and $S_{y}$ is the specific yield of the aquifer), and $w=(\alpha t)^{1 / 2} / a\left(a=K /\left(K^{\prime} / b^{\prime}\right)\right.$ (where $K^{\prime}$ and $b^{\prime}$ are the hydraulic conductivity and thickness of the semipervious layer of the stream bed, respectively). The equation assumes that the semipervious layer has insignificant storage.

Two scenarios were examined, the first (scenario 1) using averaged hydraulic conductivity and thickness values for the aquitard, the second (scenario 2) using hydraulic conductivity and thickness values for the aquitard that are exclusively representative of the low-permeability material (silt and clay lenses) having the greatest influence on groundwater flow and neglecting the thin permeable zones within the aquitard. The scenario 1 values used to calculate the rate of stream depletion were the following: $x_{o}=50 \mathrm{~m}, K=1.03 \times 10^{-4} \mathrm{~m} / \mathrm{s}, b=30 \mathrm{~m}, S_{y}=8.39 \times 10^{-4}$, 
$K^{\prime}=4.00 \times 10^{-7} \mathrm{~m} / \mathrm{s}$, and $b^{\prime}=5 \mathrm{~m}$. The scenario 2 values used were the same as for scenario 1, except the hydraulic conductivity and thickness of the aquitard were adjusted to $6.00 \times 10^{-8} \mathrm{~m} / \mathrm{s}$ and $2 \mathrm{~m}$, respectively. The rate of stream depletion was calculated at various times since pumping began (2 to 24 hours) and at different well discharge rates (100 to $300 \mathrm{gpm}$ ) for the two scenarios. Figures 4.50 and 4.51 provide graphical summaries of the estimated rates of stream depletion for the scenarios described (see Appendix $\mathrm{H}$ for calculated values in tabular form). Additionally, Table 4.10 provides a summary of the ratio of the rate of stream depletion to the well discharge rate $\left(Q_{r} / Q\right)$ at various times since pumping began for the two scenarios.

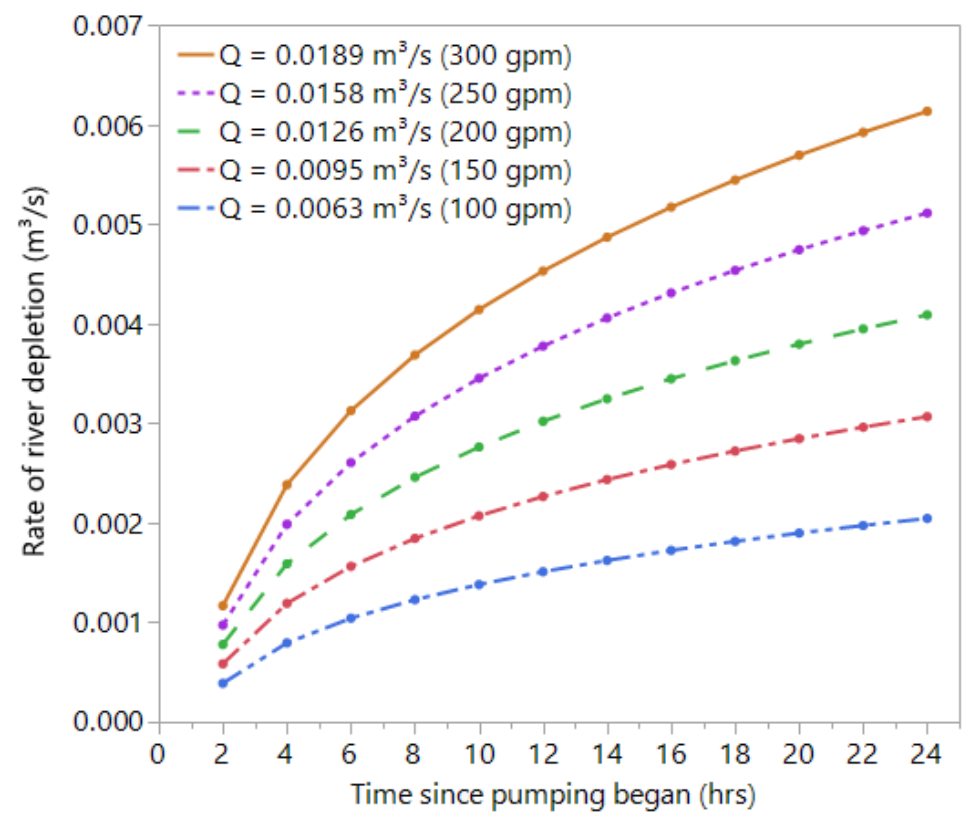

Figure 4.50: Scenario 1 estimated rates of stream depletion $\left(Q_{r}\right)$ at various times since pumping began $(t)$ and at different well discharge rates $(Q)$ obtained using the Hantush (1965) solution for flow to wells near streams with semipervious beds.

The calculations suggest that under normal pumping conditions ( 8 hours of pumping at a well discharge rate of $200 \mathrm{gpm}$ ) the rate of streamflow depletion is $2.46 \times 10^{-3}$ $\mathrm{m}^{3} / \mathrm{s}\left(8.68 \times 10^{-2} \mathrm{cfs}\right)$ or $19 \%$ of the pumping rate for scenario 1 and $9.62 \times 10^{-4} \mathrm{~m}^{3} / \mathrm{s}$ $\left(3.40 \times 10^{-2} \mathrm{cfs}\right)$ or $8 \%$ of the pumping rate for scenario 2 . That is, Scotts Creek stream 


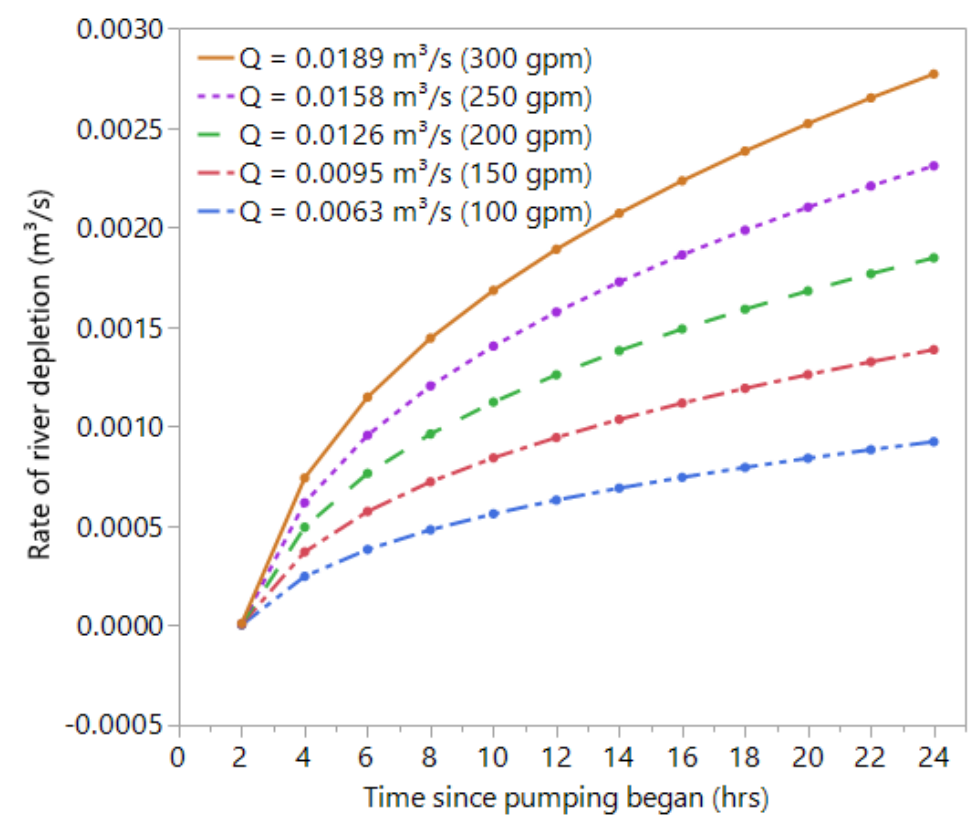

Figure 4.51: Scenario 2 estimated rates of stream depletion $\left(Q_{r}\right)$ at various times since pumping began $(t)$ and at different well discharge rates $(Q)$ obtained using the Hantush (1965) solution for flow to wells near streams with semipervious beds.

Table 4.10: Estimated rate of stream depletion expressed as a fraction of the well discharge rate $\left(Q_{r} / Q\right)$ at various times $(t)$ since pumping began for scenarios 1 and 2 .

\begin{tabular}{ccc}
\hline Time (hrs) & Scenario 1 & Scenario 2 \\
\hline 2 & 0.06 & 0.00 \\
4 & 0.13 & 0.04 \\
6 & 0.17 & 0.06 \\
8 & 0.19 & 0.08 \\
10 & 0.22 & 0.09 \\
12 & 0.24 & 0.10 \\
14 & 0.26 & 0.11 \\
16 & 0.27 & 0.12 \\
18 & 0.29 & 0.13 \\
20 & 0.30 & 0.13 \\
22 & 0.31 & 0.14 \\
24 & 0.32 & 0.15 \\
\hline
\end{tabular}


flows during the summer low-flow period would increase by $8.68 \times 10^{-2}$ cfs (scenario 1) or $3.40 \times 10^{-2}$ cfs (scenario 2) if there were no groundwater pumping. Based on the attenuated and delayed response to pumping observed in the upper unconfined aquifer (piezometers) and in Scotts Creek (instream piezometers) during the 24-hour pumping tests, it may be concluded that the scenario 1 calculated rate of stream depletion is an overestimate. There are several reasons for this including the fact that the solution does not account for storage in either the aquitard or the upper unconfined aquifer, and that by using average values of $K^{\prime}, b^{\prime}$, and $\alpha$, the complexity and variability of the subsurface are oversimplified. The low-permeability silt and clay materials $\left(K \leq 10^{-8}\right.$ $\mathrm{m} / \mathrm{s}$ ) have a strong influence on groundwater movement. Regardless, the calculations provide estimates of the upper and lower bounds of the rate of stream depletion at various times since pumping began and at different well discharge rates. To accompany the stream depletion rate estimates, a simple calculation of the maximum volume of groundwater that can be abstracted before significant leakage occurs is performed.

Detailed analysis of drawdown data from pumping tests suggest that leakage (possibly from the top unconfined aquifer and aquitard, or through bedrock), apparent in time-drawdown data recorded in observation wells several hundred meters from the pumping well, starts to occur after $\sim 6$ hours of continuous groundwater withdrawal when the average well flow rate is $260 \mathrm{gpm}$. Therefore, an estimate of the maximum volume of groundwater that can be abstracted before significant leakage occurs is 94,000 gallons (0.3 AF) per day. The calculated rate of stream depletion for the aforementioned pumping duration and well flow rate (scenario 2) is approximately $9.56 \times 10^{-4} \mathrm{~m}^{3} / \mathrm{s}$ or $3.37 \times 10^{-2} \mathrm{cfs}$. At present, pumping schedules during the driest summer months often exceed 94,000 gallons a day. Average flow rates are approximately $200 \mathrm{gpm}$ and pumping duration is around 4-10 hours for a total volume of 48,000-120,000 gallons of groundwater abstracted daily, respectively. Thus, it is 
recommended that the calculated rates of streamflow depletion be used in conjunction with the estimated volume to adjust pumping schedules to avoid causing adverse impacts to the lower Scotts Creek aquatic ecosystem.

\subsection{Groundwater Flow Modeling}

A three-dimensional (3D) finite-difference numerical groundwater flow model (MODFLOW 2000) was used to investigate the stream-aquifer relationship on lower Scotts Creek. The governing partial-differential equation of groundwater flow used in MODFLOW is (McDonald and Harbaugh, 1988)

$$
\frac{\partial}{\partial x}\left(K_{x x} \frac{\partial h}{\partial x}\right)+\frac{\partial}{\partial y}\left(K_{y y} \frac{\partial h}{\partial y}\right)+\frac{\partial}{\partial z}\left(K_{z z} \frac{\partial h}{\partial z}\right)+W=S_{s} \frac{\partial h}{\partial t}
$$

where $K_{x x}, K_{y y}$, and $K_{z z}$ are values of hydraulic conductivity along the $x, y$, and $z$ coordinate axes, which are assumed to be parallel to the major axes of hydraulic conductivity, $h$ is the potentiometric head, $W$ is a volumetric flux per unit volume representing sources and/or sinks of water, with $W<0.0$ for flow out of the groundwater system, and $W>0.0$ for flow in, $S_{s}$ is the specific storage of the porous material, and $t$ is time.

Boundary and initial conditions of the MODFLOW model used in the present study are shown in Figure 4.52. Boundary conditions not shown in Figure 4.52 include the lower boundary (bottom boundary), which was specified as a no-flow boundary, and the upper boundary (top boundary), which was specified as a free-surface boundary (water table). Appropriate boundary conditions were specified based on the current conceptualization of the groundwater flow system on lower Scotts Creek. Figure 4.53 is a schematic of the conceptual model of lower Scotts Creek used in the present study. The schematic shows a three layer system including an upper unconfined aquifer, an 
aquitard, and a lower semi-confined aquifer. The stream is hydraulically connected to the upper unconfined aquifer, but is separated from the lower semi-confined aquifer the irrigation wells are completed in by the aquitard. Initial conditions, representative of steady state conditions at time zero, were specified using measured field data and by running a transient simulation with no groundwater pumping.

The general-head boundary is a head-dependent flux boundary and is simulated according to the equation (McDonald and Harbaugh, 1988)

$$
Q_{b i, j, k}=C_{b i, j, k}\left(h_{b i, j, k}-h_{i, j, k}\right),
$$

where $Q_{b i, j, k}$ is the flow into the cell $i, j, k$ from the source, $C_{b i, j, k}$ is the hydraulic conductance between the external source and the cell $i, j, k(L W K / D)$, where $L$ multiplied by $W$ is the surface area of the grid cell face exchanging flow with the external source/sink, $K$ is the average hydraulic conductivity of the aquifer material separating the external source/sink from the model grid, and $D$ is the distance from the external source/sink to the model grid (Figure 4.54), $h_{b i, j, k}$ is the head assigned to the external source, and $h_{i, j, k}$ is the head in cell $i, j, k$.

The river boundary is also a head-dependent flux boundary and is simulated according to the equation set (McDonald and Harbaugh, 1988)

$$
\begin{gathered}
Q_{R}=C_{R}\left(H_{R}-h_{i, j, k}\right), \text { when } h_{i, j, k}>R_{B}, \text { and, } \\
Q_{R}=C_{R}\left(H_{R}-R_{B}\right), \text { when } h_{i, j, k} \leq R_{B},
\end{gathered}
$$

where $Q_{R}$ is the flow between the stream and the aquifer, $C_{R}$ is the hydraulic conductance of the stream-aquifer interconnection $(K L W / M)$, where $K$ is the hydraulic conductivity of the streambed material, $L$ is the length of the stream as it crosses the node, $W$ is the stream width, and $M$ is the thickness of the streambed layer (Figure 4.55), $H_{R}$ is the head in the stream, $h_{i, j, k}$ is the head at the node in the cell underlying 
the stream reach, and $R_{B}$ is the elevation at the bottom of the streambed layer. The following sections describe the specifics of the MODFLOW model's construction and calibration.

\subsubsection{Model Construction}

The Groundwater Modeling System (GMS) 10.2.4, a commercially available comprehensive graphical user environment for performing groundwater simulations, was used to create a conceptual model of lower Scotts Creek using GIS, field, and laboratory data.

Environmental Systems Research Institute (ESRI) ArcMap 10.4 was used to create GIS data including the model boundary and locations of wells, piezometers, and exploratory boreholes. All GIS data were assigned the NAD 1983 California State Plane Zone III FIPS 0403 (meters) projected coordinate system. GIS data were imported into GMS and converted to feature objects. In GMS, feature objects were used to build coverages (group of feature objects) including a sources and sinks coverage and a coverage for each alluvial layer. All coverage data were entered in units of meters and days.

The sources and sinks coverage included the irrigation wells and the boundary conditions of the model. The screened interval of each well was specified using information obtained from well completion reports. The Archibald Well screened interval was from 4 to $-23.5 \mathrm{~m}$, the Pump House Well screened interval was from -11 to $-25.3 \mathrm{~m}$, the VFD Well screened interval was from -9.8 to $-28 \mathrm{~m}$, and the Queseria Well screened interval was from 0.5 to $-27.5 \mathrm{~m}$. The grid around all four wells was refined and set to a base size of $15 \mathrm{~m}$, a bias of 1.1, and a maximum size of $120 \mathrm{~m}$.

Three alluvial layer coverages were created, each representing one hydrostratigraphic unit. The elevation of the top of layer 1 (upper unconfined aquifer) was 


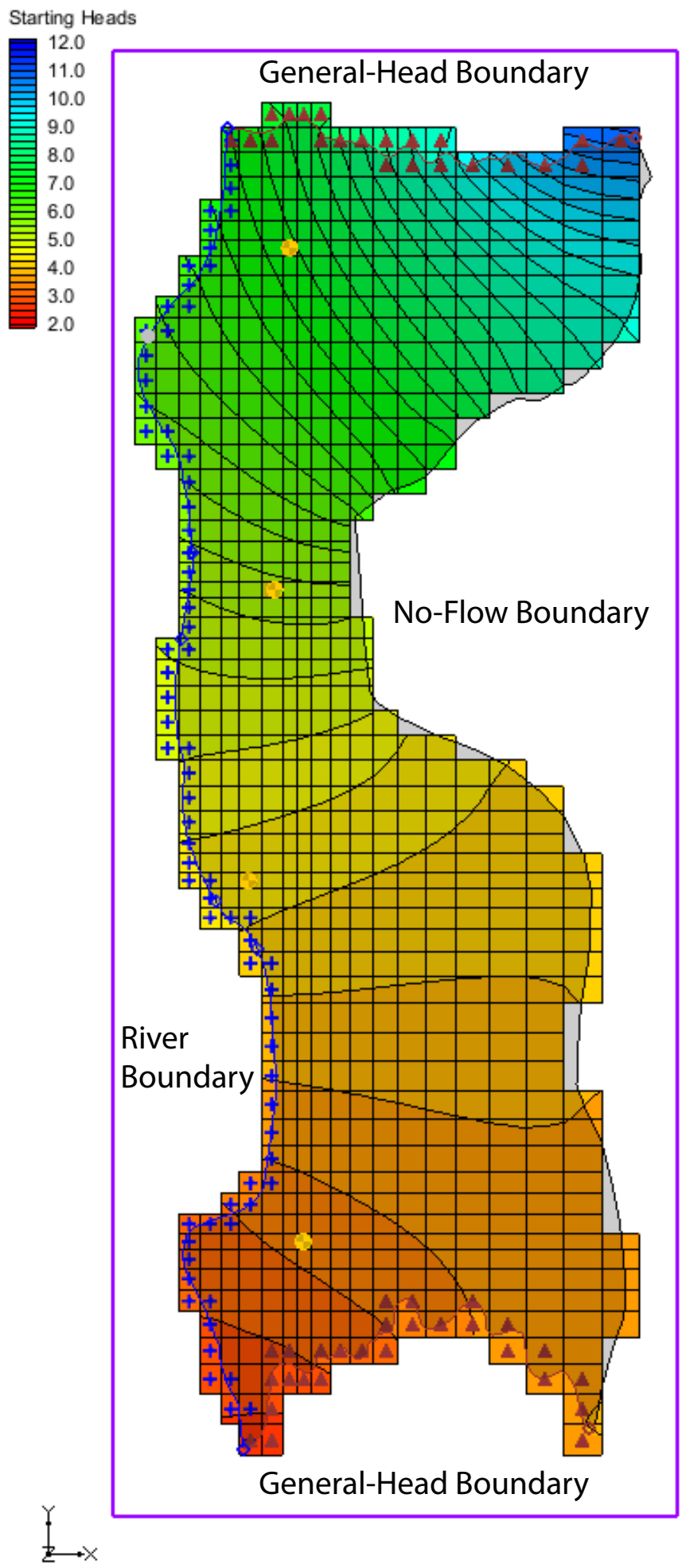

Figure 4.52: Plan view of the three-dimensional (3D) finite-difference groundwater flow model (MODFLOW 2000) grid of lower Scotts Creek showing the boundary and initial conditions (starting head contours $(\mathrm{m})$ ) of the model. 


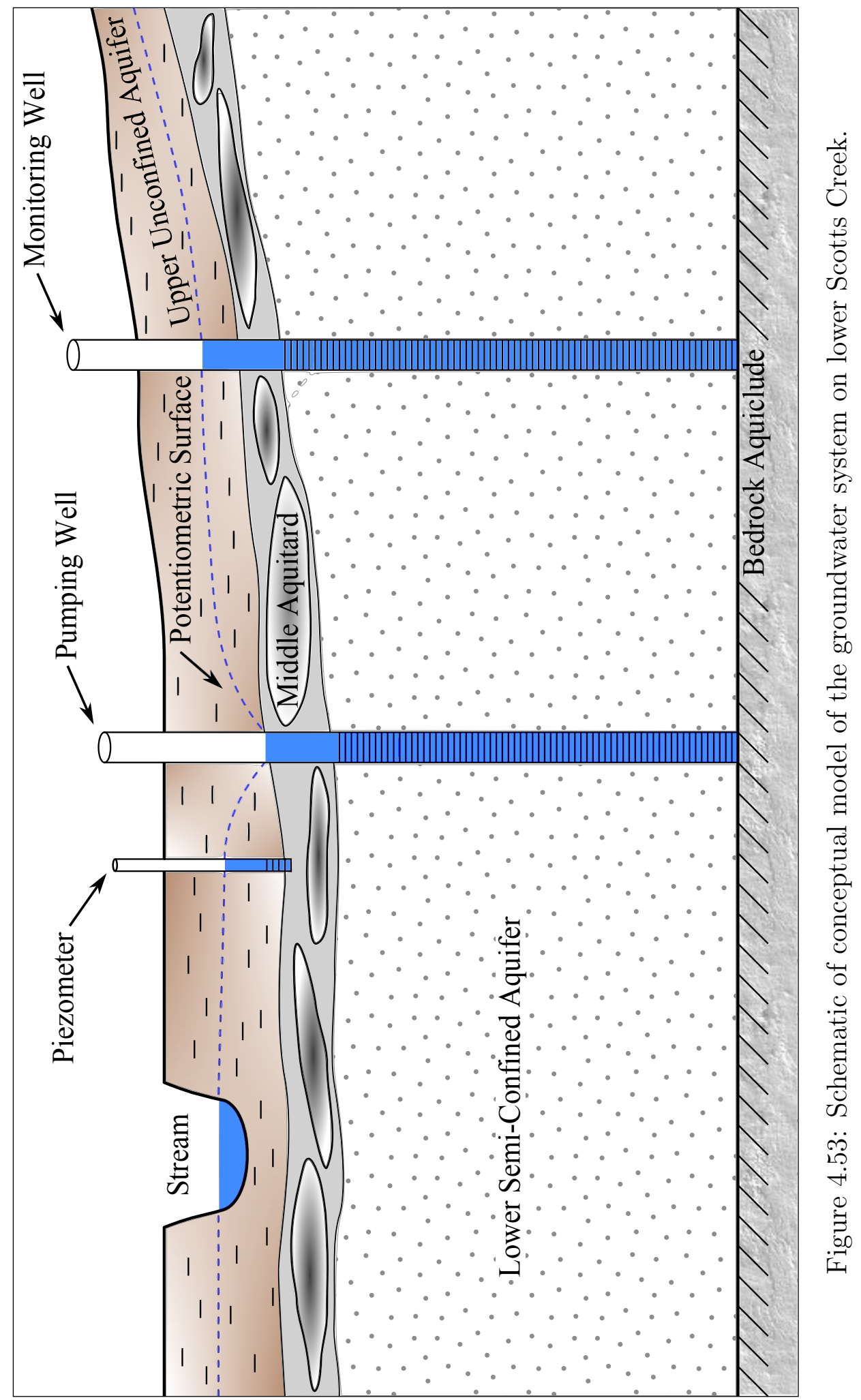




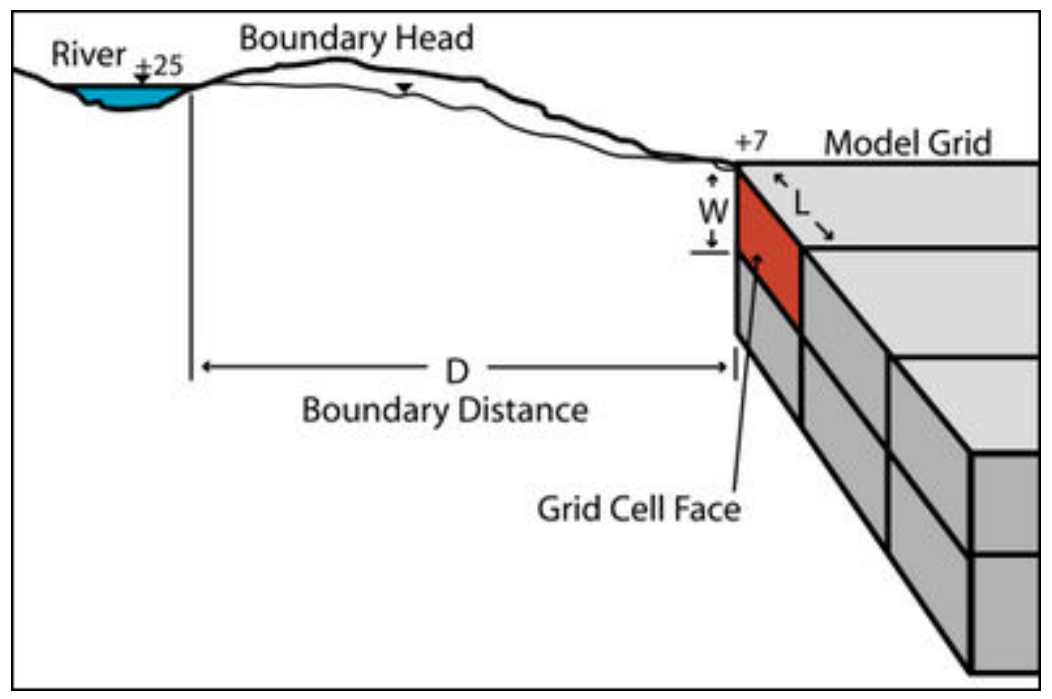

Figure 4.54: Schematic of general-head boundary (excerpted from the online usersupported help database for XMS software).

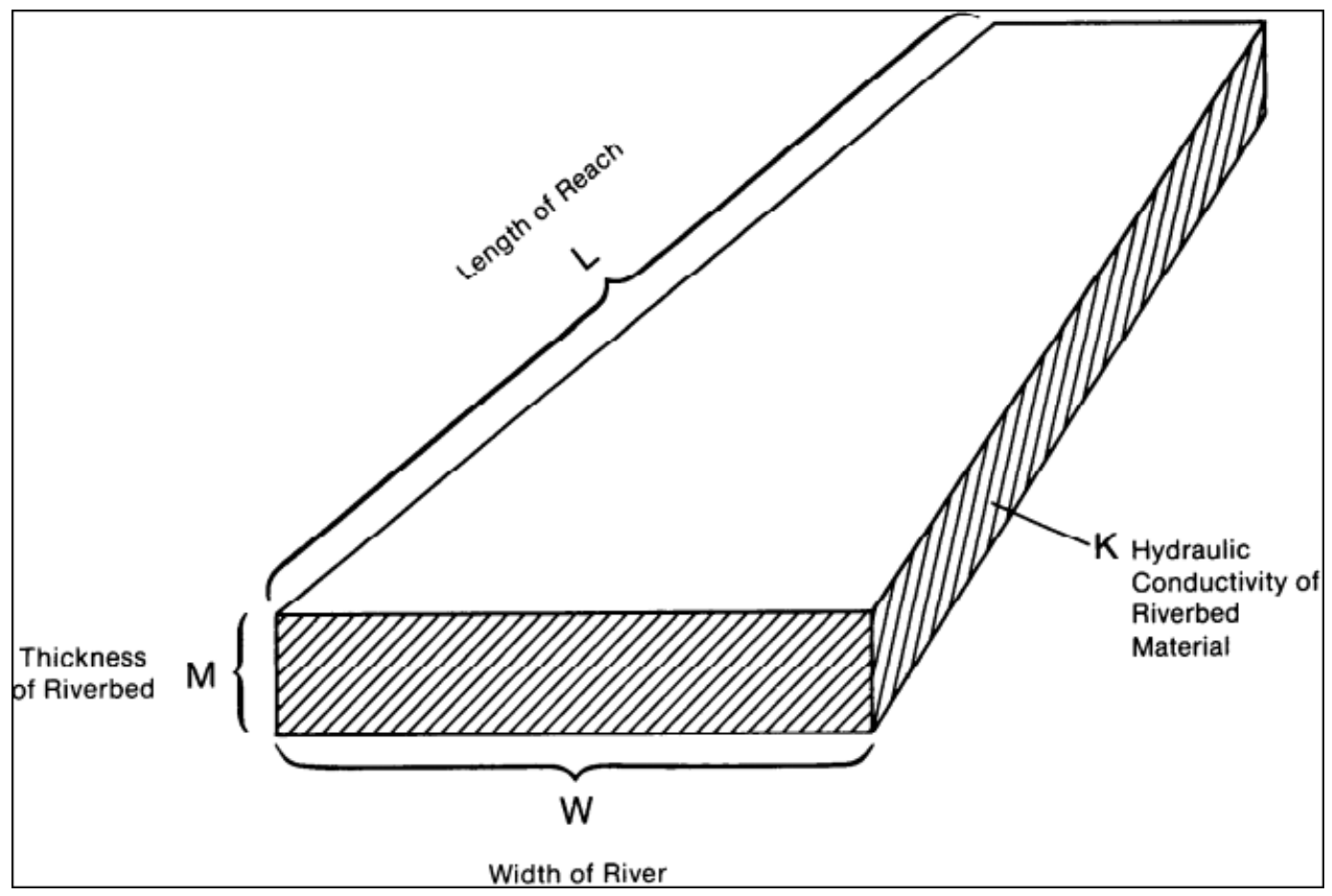

Figure 4.55: Schematic of river boundary streambed conductance components for an individual cell (excerpted from McDonald and Harbaugh, 1988). 
interpolated from a 1.5 meter digital elevation model (DEM) of the Scotts Creek watershed. The elevation of the bottom of layer 1, and the top and bottom elevations of layers 2 (aquitard) and 3 (lower semi-confined aquifer), were interpolated from exploratory borehole data and information from well completion reports that were entered into GMS as 2D scatter points. Similarly, hydraulic conductivities of layers 1 and 2 were interpolated from laboratory permeameter test data. The hydraulic conductivity and specific storage of layer 3 were set at constant values of $9.16 \mathrm{~m} / \mathrm{d}$ and $3.5 \times 10^{-5} \mathrm{~m}^{-1}$, respectively, average values from pumping test curve-matching analyses. The specific storage of layer 2 was set at a constant value of $3.5 \times 10^{-4} \mathrm{~m}^{-1}$ (one order of magnitude greater than layer 3) and the specific yield of layer 1 was set at a constant value of 0.3. All three layers were isotropic. Starting heads were interpolated from measured water table elevation data recorded in August 2017 (see Appendix I for 2D scatter data). The interpolation scheme used throughout was the inverse distance weighted (IDW) method using the constant nodal function (Shepard's method) method which is given by the equation

$$
F(x, y)=\sum_{i=1}^{n} w_{i} f_{i}
$$

where $n$ is the number of points used to interpolate, $f_{i}$ are the dataset values at the points, and $w_{i}$ are the weight functions assigned at each point calculated according to equation

$$
w_{i}=\frac{r^{-p}}{\sum_{j=1}^{n} h_{j}^{-p}}
$$

where $p$ is an arbitrary positive real number called the weighting exponent (default value of 2). The interpolated surface is a weighted average of the point data influenced 
most by measured values closest to the prediction location and less by more distant points. The constant nodal function form of the IDW method was used because of its simplicity, while still retaining all the functionality needed for the application.

The model boundary was split into four distinct arcs and each was assigned a boundary condition. The northernmost arc (Archibald Creek) was defined as a general head boundary, the easternmost arc (Swanton Road) was defined as a no-flow boundary, the southernmost arc (Queseria Creek) was defined as a general head boundary, and the westernmost arc (Scotts Creek) was modeled as a river boundary. All of the boundaries (except the no-flow boundary) were assigned a conductance of $0.34 \mathrm{~m}^{2} / \mathrm{d}$. Additionally, head-stage was defined at the upstream and downstream nodes of each general head boundary arc, and head-stage and bottom elevation were defined at six locations (upstream, downstream, and the four instream piezometer locations) along the river boundary using observed instream piezometer data. Table 4.11 provides a summary of the head-stage and bottom elevation of individual nodes along each boundary arc.

Table 4.11: Head-stage and bottom elevation in meters of nodes along the boundaries of the MODFLOW model. Dash (-) indicates data are not applicable.

\begin{tabular}{lcc}
\hline Node ID & Head-Stage $(\mathrm{m})$ & Bottom Elevation $(\mathrm{m})$ \\
\hline Archibald Upstream & 12.0 & - \\
Archibald Downstream & 6.8 & - \\
Queseria Upstream & 4.0 & - \\
Queseria Downstream & 2.3 & - \\
Scotts Upstream & 6.8 & 6.2 \\
Scotts PH-up & 5.4 & 4.8 \\
Scotts PH-down & 4.9 & 4.3 \\
Scotts VFD-up & 4.4 & 3.8 \\
Scotts VFD-down & 4.1 & 3.5 \\
Scotts Downstream & 2.3 & 1.7 \\
\hline
\end{tabular}

After the conceptual model was constructed, a rectangular 3D grid comprising 
62 columns, 22 rows, and 3 layers oriented in a north-south direction was created. The grid generated included 4,092 cells. The active zones of the model were defined by activating cells in the coverages. The active grid included 2,398 cells. The 3D grid model was converted to a MODFLOW 2000 numerical model. The MODFLOW global options were inspected to ensure that the conceptual model data were assigned to the appropriate cells. Starting heads representative of steady state conditions were generated by running a transient simulation with 75 stress periods (75 days) and no groundwater pumping. The model generated heads for the $75^{\text {th }}$ time step were set as the starting heads for all subsequent transient simulations.

\subsubsection{Model Calibration}

Model calibration was carried out manually by trial and error adjustment of parameters. First, 24-hour pumping test flow rate data were imported for an individual well (Pump House and VFD wells) and a transient simulation with 10 stress periods (1 day) was performed. Upon successful completion of a MODFLOW simulation, model generated drawdown values for layer 3 at observation wells (Figure 4.56) at each of the 10 stress periods were compared to measured values recorded during field pumping tests. Model parameters (i.e., boundary conductance, hydraulic conductivity, and specific storage) were then adjusted accordingly in sequential model runs until simulated and measured drawdown curves converged. Figure 4.57 shows drawdown data measured in the Pump House Well (observation well) during the VFD Well pumping test plotted against uncalibrated and calibrated model generated drawdown values for the different time steps. Similarly, Figure 4.58 shows drawdown data measured in the VFD Well (observation well) during the Pump House Well pumping test plotted against uncalibrated and calibrated model generated drawdown values for the different time steps. These two figures show the range in success of calibration, 
Figure 4.57 showing an outstanding model fit and, conversely, Figure 4.58 showing a marginal improvement in model fit to field conditions with calibration (see Appendix I for drawdown curve comparison figures). There are several reasons for the poor performance of the model at predicting drawdown in the VFD Well, the primary reason being that the model was calibrated manually as opposed to using the automated calibration utility, Parameter ESTimation (PEST) (not included with GMS license). It is extremely difficult to achieve perfect model calibration manually due to the multitude of possibilities the modeler must consider. Adjusting a parameter may improve model fit for a single well and simultaneously worsen calibration elsewhere. Other possible reasons for the poor performance of the model at predicting drawdown in the VFD Well is that layer 3 (pumped aquifer) was modeled as a homogeneous unit assigned a single hydraulic conductivity value (heterogeneity of aquifer not accounted for), and that GMS MODFLOW does not account for the effects of wellbore storage on the response to groundwater pumping observed in an individual cell containing an observation well. Nevertheless, the calibrated model produced drawdown curves within an acceptable range for three out of the four observation wells which indicates that the model is reliable and can be used for preliminary evaluations of stream-aquifer connectivity. Furthermore, the model can inform future research by providing a starting point for numerical simulations that more accurately portray the natural complexity of the lower Scotts Creek aquifer system. 


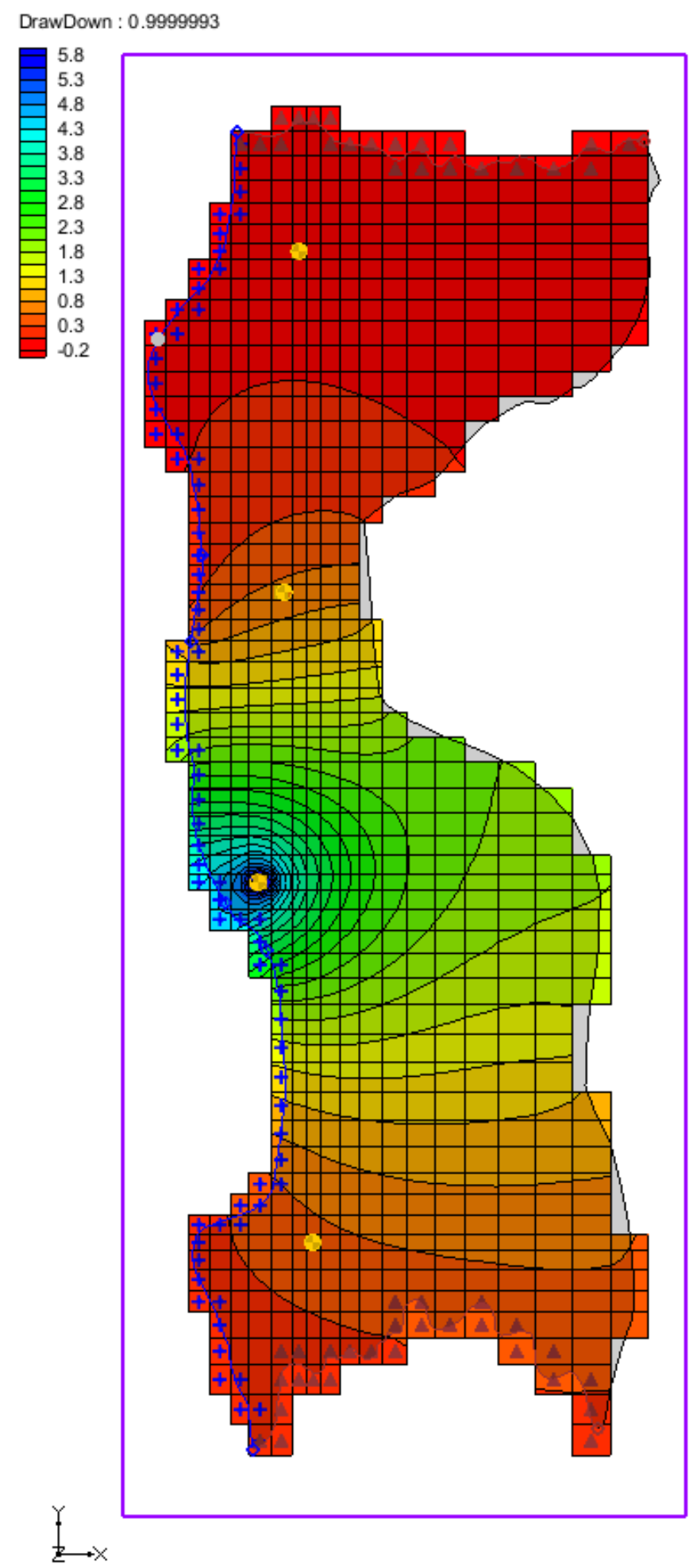

Figure 4.56: Plan view of the calibrated MODFLOW model showing layer 3 drawdown contours (m) for the last time step (time step 10) when the VFD Well is pumped. 


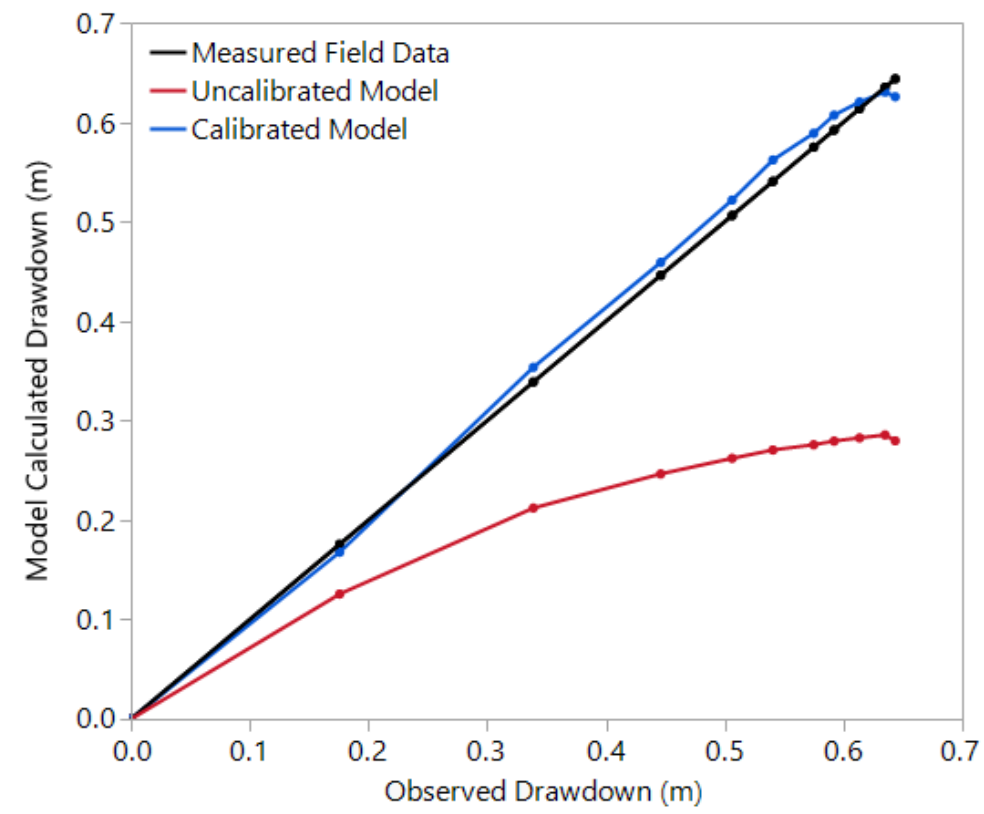

Figure 4.57: Drawdown data measured in the Pump House Well (observation well) during the VFD Well pumping test plotted against uncalibrated and calibrated model generated drawdown values.

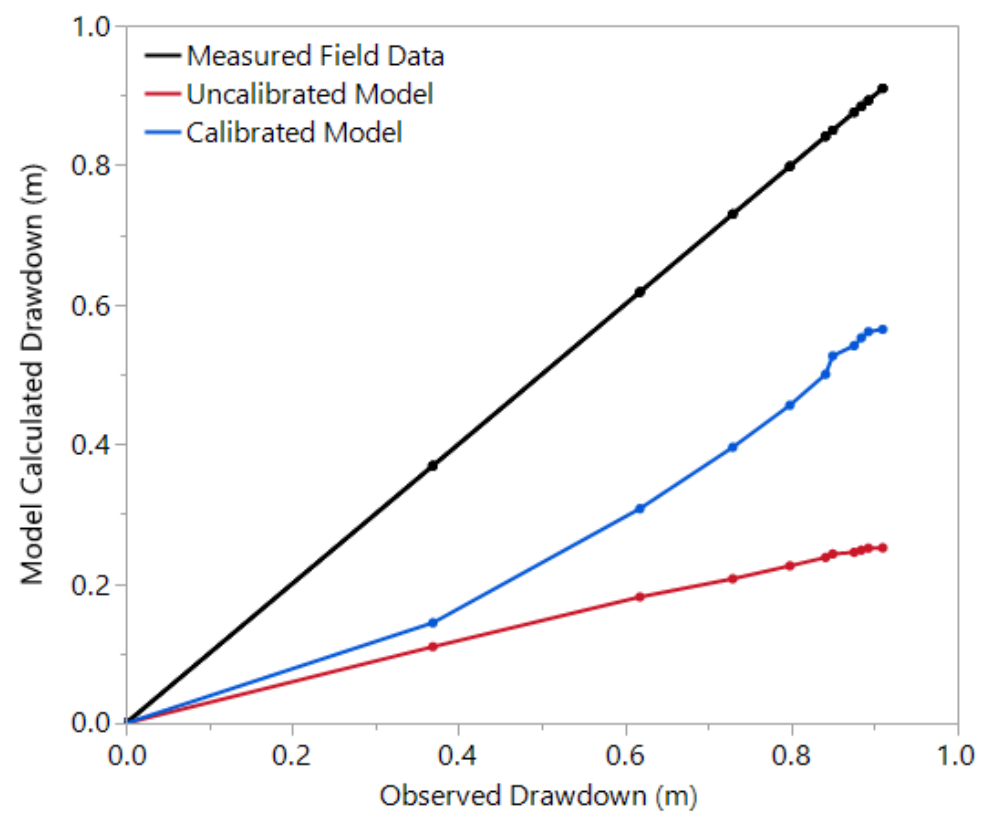

Figure 4.58: Drawdown data measured in the VFD Well (observation well) during the Pump House Well pumping test plotted against uncalibrated and calibrated model generated drawdown values. 


\section{CHAPTER 5: RESULTS AND DISCUSSION}

Integrating the various types of field and laboratory data obtained in this study provides improved understanding of the geologic heterogeneity, groundwater flow dynamics, and stream-aquifer exchange processes on lower Scotts Creek. Additionally, the use of multiple techniques allows for an assessment of method applicability and for constraining estimates of water fluxes between the stream and the aquifer. The purpose of this chapter is to summarize the findings of field and laboratory experiments discussed previously, and to conduct an in-depth analysis of data that can be used to develop sustainable groundwater management practices. First, a summary of aquifer characteristics is given. Results of numerical simulation of groundwater flow to irrigation wells are then presented and comparisons made between analytical and numerical stream depletion estimates. Lastly, long-term water-level data are examined to assess groundwater level dynamics not captured by other methods.

\subsection{Aquifer Characterization}

\subsubsection{Geometry and Lithology}

The lower Scotts Creek subsurface is a heterogeneous and stratigraphically complex deposit of unconsolidated alluvial material. It can be stratigraphically partitioned into three major layers - thin upper unconfined aquifer, middle semi-confining unit or aquitard, and lower semi-confined aquifer. However, all three layers are highly variable in thickness and extent. 
Well completion reports indicate the entire alluvial deposit ranges from 105 to 108 feet in thickness. The basement of the aquifer is interpreted to be Santa Cruz Mudstone bedrock (Taskey, 2017). The depth to bedrock is largely uniform across the study area. It is unknown if the bedrock is fractured, in which case it could be an important source of aquifer recharge.

On the basis of exploratory boreholes and geophysical surveys conducted during this study, the upper unconfined aquifer is very thin, and ranges from 14 to 24 feet in thickness. It is predominately composed of brown to reddish-brown silty sand and gravel with interbedded, generally discontinuous, silt and clay lenses.

The middle semi-confining layer ranges from 4 to 24 feet in thickness and is generally a heterogeneous unit composed of dark gray to black fine-grained silt and clay layered with thin permeable zones of sand. The fine silt and clay sediments form laterally extensive low-permeability zones near the stream channel, especially near the VFD Well. East of the stream channel, and also north of the Pump House Well, the fine sediments appear to be discontinuous.

The lower semi-confined aquifer ranges from 58 to 92 feet in thickness and is composed of gray sand and gravel low in silt and clay. This layer is substantially more homogeneous than the upper aquifer and aquitard, but exploratory borehole drilling operations were unsuccessful at retrieving truly representative samples of the lower aquifer material (drilling depth limited to 40 feet) so extrapolations of available data were made. On the basis of well completion reports (reports No. 67476 and 67477), the lower semi-confined aquifer is composed of material ranging from sand to 1.25-inch gravel. 


\subsubsection{Hydraulic Properties}

The hydraulic properties of the lower Scotts Creek aquifer were determined using both field and laboratory methods including constant rate pumping tests with multiple observation wells, laboratory falling-head permeameter tests, and estimates based on sediment particle size distributions.

Transmissivity $(T)$ and storativity $(S)$ are commonly used to characterize the hydraulic properties of an aquifer. These parameters were estimated by curve-matching the Hantush and Jacob (1955) solution to time-drawdown data recorded in observation wells during the two 24-hour pumping tests. Transmissivity and storativity values for the lower semi-confined aquifer (layer 3) ranged from $1.77 \times 10^{-3} \mathrm{~m}^{2} / \mathrm{s}$ to $3.82 \times 10^{-3}$ $\mathrm{m}^{2} / \mathrm{s}$ and $3.71 \times 10^{-4}$ to $1.16 \times 10^{-3}$, respectively, for an average transmissivity value of $2.50 \times 10^{-3} \mathrm{~m}^{2} / \mathrm{s}$ and an average storativity value of $8.39 \times 10^{-4}$. In confined aquifers values of storativity typically range between $5 \times 10^{-3}$ to $5 \times 10^{-5}$, and in an unconfined aquifer, specific yields commonly range between 0.01-0.30 (Barlow and Leake, 2012; Heath, 1983). All of the observation wells yielded storage terms within the range for a confined aquifer. Values of hydraulic conductivity $(K)$ and specific storage $\left(S_{s}\right)$ for the lower semi-confined aquifer (layer 3) were determined by dividing the transmissivity and storativity values by total aquifer thickness $(b=24.38 \mathrm{~m}(80 \mathrm{ft}))$. The average $K$

and $S_{s}$ values are $1.03 \times 10^{-4} \mathrm{~m} / \mathrm{s}$ and $3.42 \times 10^{-5} \mathrm{~m}^{-1}$, respectively. Additionally, the average hydraulic conductivity value for the aquitard $\left(K^{\prime}\right)$ is $6.39 \times 10^{-8} \mathrm{~m} / \mathrm{s}$.

The hydraulic conductivity values obtained for each alluvial layer (i.e., upper unconfined aquifer, aquitard, and lower semi-confined aquifer) are summarized by method in Table 5.1. The $K$ values estimated by laboratory methods presented in Table 5.1 are harmonic averages of data (by alluvial layer) from several boreholes. The variability observed in the hydraulic conductivity values obtained by laboratory 
methods for the alluvial sediments is consistent with the variability observed in the exploratory borehole logs and particle size analysis results. The sampled upper unconfined aquifer and lower semi-confined aquifer material generally contained a greater percentage of large particles than the sampled aquitard material. Furthermore, these results indicate that the aquitard material is significantly less conductive $(\geq 100$ times as estimated by laboratory tests and $\geq 1000$ times as estimated by pumping tests) than the upper and lower aquifer material.

Table 5.1: Comparison of hydraulic conductivity $(K)$ values in $\mathrm{m} / \mathrm{s}$ for each alluvial layer estimated using sediment particle size distributions, falling-head permeameter tests, and constant rate pumping tests. Dash $(-)$ indicates data are not available.

\begin{tabular}{lcccc}
\hline Alluvial Layer & Hazen & Kozeny-Carman & Permeameter & Pumping \\
\hline Upper Aquifer & $2.32 \times 10^{-5}$ & $1.40 \times 10^{-5}$ & $3.98 \times 10^{-6}$ & - \\
Aquitard & $6.54 \times 10^{-7}$ & $3.38 \times 10^{-7}$ & $9.37 \times 10^{-7}$ & $6.39 \times 10^{-8}$ \\
Lower Aquifer & $1.68 \times 10^{-5}$ & $1.31 \times 10^{-5}$ & $2.33 \times 10^{-5}$ & $1.03 \times 10^{-4}$ \\
\hline
\end{tabular}

The empirical equations of Hazen and Kozeny-Carman yielded similar hydraulic conductivity values as those obtained using the falling-head permeameter method, with the exception of the upper aquifer $K$ values which have a range of about one order of magnitude. Overall, the Hazen method produced better estimates of hydraulic conductivity (values closest to those estimated by permeameter tests), but if the application limits of the equations in calculating hydraulic conductivity are considered, only the empirical equation of Kozeny-Carman is applicable to the sediments analyzed. All of the sediment samples, with the exception of EB- $2 \sim 32 \mathrm{ft}$, are poorly sorted with $C_{u}>5$. Nevertheless, both empirical equations produced reasonable estimates of $K$ that provide data for depth ranges (smaller intervals) and for low-permeability sediments not measured by the falling-head permeameter method. Furthermore, differences between values obtained by the two laboratory methods can be attributed to several factors such as the exclusion of particles $>2 \mathrm{~mm}$ from the particle size 
analysis and observed sediment grain-size limitations of the falling-head permeameter method. One of the initial steps of the particle size analysis performed was to sieve the sediment samples to remove particles $>2 \mathrm{~mm}$, however these particles were included in samples packed into the flow cells. Alternatively, when sediments containing high percentages of fine-grained silt and clay particles were packed into the flow cells preferential flows paths would develop and the sample would have to be repacked before accurate measurements could be made. Even when repacked, measurements made using a permeameter, particularly poorly sorted samples that contain high mud percentages, have some error based on limitations of the method and the skill of the operator (Bradbury and Muldoon, 1990; Rosas et al., 2014).

Comparison of the laboratory estimated hydraulic conductivity values to the average value obtained by field pumping tests reveals that the laboratory methods significantly underestimate the conductivity of the aquifer. The differences in scale between field and laboratory methods, pumping tests are large scale tests (hundreds to thousands of cubic meters) where as permeameter tests and particle-size estimates are small scale $\left(<1 \mathrm{~m}^{3}\right)$, is likely accountable for a large part of the discrepancy. The larger scale field tests include geologic features such as joints, fractures, interbeds, and macropores, features that small laboratory samples cannot contain. Furthermore, sample bias and sample disturbance can occur during sediment sample collection. Lastly, directionality is a critical consideration in anisotropic materials. That is, sediment core sampling is usually vertical, but groundwater flow to pumping wells is mostly horizontal (Bradbury and Muldoon, 1990; Sahu and Saha, 2016). 


\subsection{Quantification of Stream-Aquifer Connectivity}

\subsubsection{Groundwater Flow Modeling}

A 3D finite-difference (MODFLOW 2000) groundwater flow model of lower Scotts Creek was constructed in GMS and transient simulations were performed. Manual model calibration was carried out based on the available data. Numerical simulation of groundwater flow indicated that: 1) values of hydraulic conductivity for the aquitard determined by permeameter tests are higher than the "true" values, 2) the lower semi-confined aquifer (pumped aquifer) is heterogeneous, 3) a significant amount of infiltration and aquifer recharge occurs across the Archibald Creek general head boundary arc, and 4) pumping-induced river leakage (flow into the aquifer) is greater when simulating groundwater withdrawal from the Pump House Well than the VFD Well.

The final values for calibration parameters were the following: hydraulic conductivity values of layer 2 were scaled using a multiplier value of 0.2 , hydraulic conductivity of layer 3 was $8.5 \mathrm{~m} / \mathrm{d}$, specific storage of layer 2 was $4 \times 10^{-4} \mathrm{~m}^{-1}$, and the specific storage of layer 3 was $4 \times 10^{-5} \mathrm{~m}^{-1}$. The hydraulic conductivity values and specific yield of layer 1 were not adjusted (no change). The conductances for the general head and river boundary conditions were the following: Archibald Creek general head boundary arc was $5.0 \mathrm{~m}^{2} / \mathrm{d}$, Queseria Creek general head boundary arc was $1.0 \mathrm{~m}^{2} / \mathrm{d}$, Scotts Creek river boundary arc from the Scotts Downstream node to the Scotts VFD-down node was $1.0 \mathrm{~m}^{2} / \mathrm{d}$, arc from the Scotts VFD-down node to the Scotts VFD-up node was $0.01 \mathrm{~m}^{2} / \mathrm{d}$, arc from the Scotts VFD-up node to the Scotts PH-down node was $0.01 \mathrm{~m}^{2} / \mathrm{d}$, arc from the Scotts PH-down node to the Scotts PH-up node was $7.0 \mathrm{~m}^{2} / \mathrm{d}$, and arc from the Scotts PH-up node to the Scotts Upstream node of river boundary arc was $7.0 \mathrm{~m}^{2} / \mathrm{d}$. As evidenced by the final values, the properties 
of model layers 2 (aquitard) and 3 (lower semi-confined aquifer) are the dominant variables. The final hydraulic conductivity values for the aquitard are significantly lower than those initially assigned to the layer indicating that the $K$-values determined by permeameter tests are higher than the "true" values. This finding is supported by PSA and pumping tests results which showed that aquitard sediments have low $K$-values $\left(10^{-7}-10^{-9} \mathrm{~m} / \mathrm{s}\right)$.

Flow budget data for all grid cells for the final time step (time step 10) were analyzed following each simulation and are summarized in Table 5.2. From the data it is evident that for both simulations the majority of flow into the model (aquifer recharge) occurs across the head dependent boundaries, the Archibald Creek general head boundary specifically. Similarly, river leakage accounts for a significant amount of aquifer recharge, but also for flow out of the model.

Table 5.2: Flow budget data in $\mathrm{m}^{3} / \mathrm{d}$ for all grid cells for time step 10 summarized by simulation.

\begin{tabular}{lrc}
\hline Sources/Sinks & Flow In & Flow Out \\
\hline Storage & 389.1 & -54.9 \\
Pump House Well & 0.0 & $-1,387.3$ \\
River Leakage & 541.3 & -321.5 \\
Head Dep Bounds & 960.3 & -127.0 \\
\hline Storage & 628.4 & -94.1 \\
VFD Well & 0.0 & $-1,383.1$ \\
River Leakage & 357.5 & -423.4 \\
Head Dep Bounds & 992.5 & -77.9 \\
\hline
\end{tabular}

Flow budget plots of river leakage over time for the entire model domain were examined to evaluate simulated impact of groundwater abstraction on the river boundary. Figures 5.1 and 5.2 are the flow budget versus time plots of river leakage for simulation of groundwater withdrawal from the Pump House Well and VFD Well, respectively. The "leakage in" curve is pumping-induced flow from the river that is 
recharging the aquifer where as the "leakage out" curve is groundwater that is leaving the aquifer through the river boundary. Figure 5.1 indicates that pumping-induced late-time river leakage into the aquifer $\left(541.3 \mathrm{~m}^{3} / \mathrm{d}\right)$ greatly exceeds leakage out of the aquifer $\left(-321.5 \mathrm{~m}^{3} / \mathrm{d}\right)$ when groundwater withdrawal from the Pump House Well is simulated. Initially, there is net groundwater flow from the aquifer to the river. However, as pumping continues, net flow to the river decreases and leakage into the aquifer (streamflow depletion) increases. In comparison, Figure 5.2 shows that river leakage out of the aquifer $\left(-423.4 \mathrm{~m}^{3} / \mathrm{d}\right)$ exceeds leakage into the aquifer $\left(357.5 \mathrm{~m}^{3} / \mathrm{d}\right)$ when groundwater withdrawal from the VFD Well is simulated. These findings are supported by drawdown data recorded during the field pumping tests which showed that groundwater withdrawal from the Pump House Well has a greater effect on water levels in the upper unconfined aquifer and stream than does pumping the VFD Well. Additionally, simulation of groundwater withdrawal from the Pump House Well produced a net river leakage (streamflow depletion) of $219.8 \mathrm{~m}^{3} / \mathrm{d}$ (difference between leakage in and out), which is approximately $16 \%$ of the pumping rate $\left(-1,387.3 \mathrm{~m}^{3} / \mathrm{d}\right)$. This model estimated rate of stream depletion, expressed as a fraction of the well pumping rate, is very similar to the scenario 2 calculated estimate of $15 \%$ obtained using the Hantush (1965) model. 


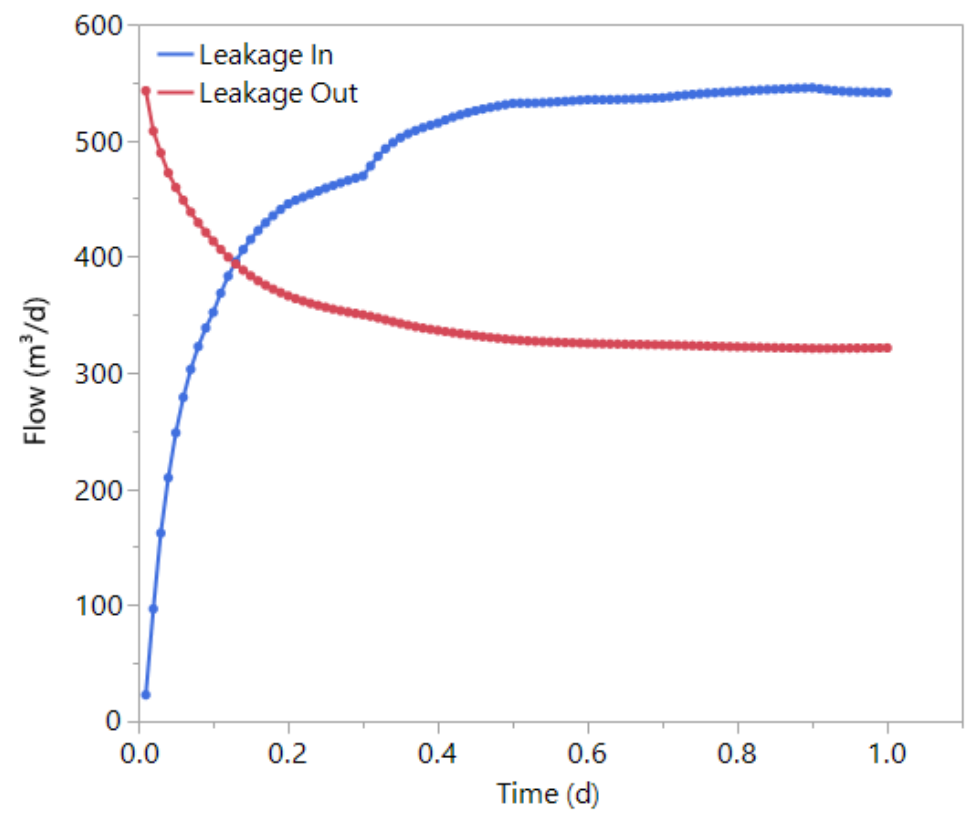

Figure 5.1: Plot showing flow $\left(\mathrm{m}^{3} / \mathrm{d}\right)$ vs. time $(\mathrm{d})$ of river leakage for simulation of groundwater withdrawal from the Pump House Well.

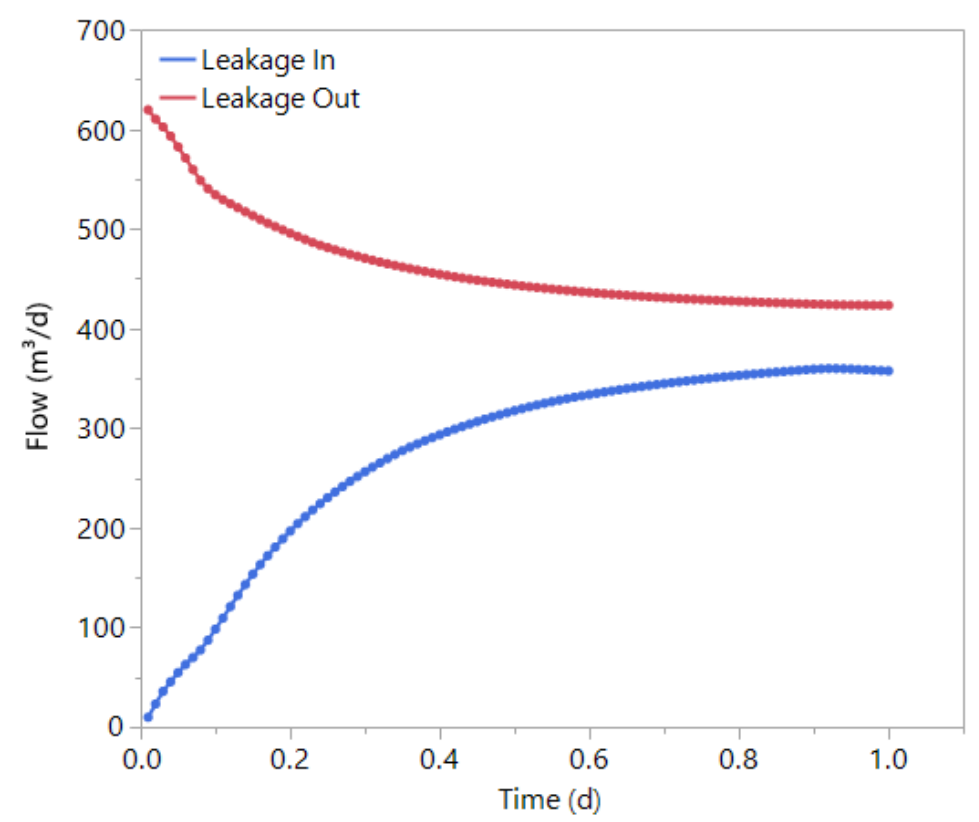

Figure 5.2: Plot showing flow $\left(\mathrm{m}^{3} / \mathrm{d}\right)$ vs. time $(\mathrm{d})$ of river leakage for simulation of groundwater withdrawal from the VFD Well. 


\subsubsection{Long-term Groundwater Monitoring}

Groundwater systems are dynamic and change continuously in response to shortand long-term fluctuations in precipitation, phreatophytic consumption, irrigation return flow, and groundwater pumping. Various other natural factors that affect groundwater levels, but usually to a lesser degree, include barometric pressure effects, Earth tides, and seismic events. Water levels in many aquifers follow a natural cyclic pattern of seasonal fluctuation, increasing during the winter and spring when precipitation and recharge are greatest, then steadily decreasing during the summer and fall as recharge dwindles and evapotranspiration peaks. Superimposed on cyclic seasonal water-level fluctuations are the effects of human activities (Taylor and Alley, 2001).

Water levels in piezometers and irrigation wells on lower Scotts Creek were monitored at 5-15 minute intervals over an 18 month period from June 2016 to November 2017. The long-term data recorded exhibit several phenomena, including the effects of groundwater pumping and phreatophytic consumption responsible for seasonal water-level decline, and infiltration of precipitation and subsurface recharge responsible for the seasonal recovery of the water table. These trends are illustrated in Figures 5.3 and 5.4, which show long-term water-level fluctuations in a piezometer (PHP-1) and an irrigation well (Pump House Well), respectively. The data show small scale water-level fluctuations recorded during the summer of 2016 followed by a sudden increase $(\sim 1.5 \mathrm{~m})$ in groundwater levels winter 2016-2017, which is then followed by receding levels again in summer 2017. The significant changes in head observed in Figure 5.4 are pumping events. From the last rainfall event in April 2017 to the end of the dry season in November 2017, a drop in head of approximately $0.6 \mathrm{~m}$ was measured in piezometers and irrigation wells on lower Scotts Creek. 


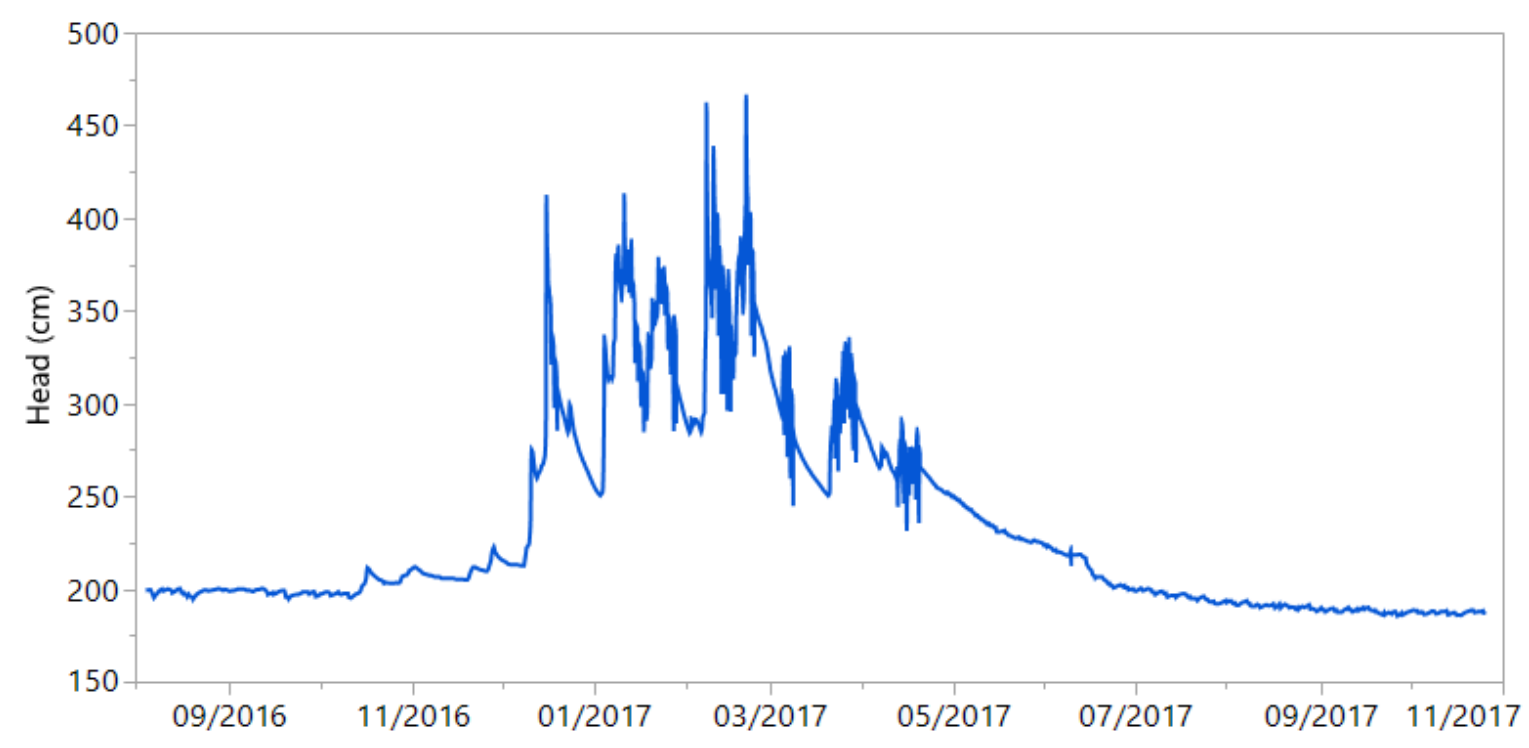

Figure 5.3: Head (cm) in PHP-1 July 2016 to November 2017.

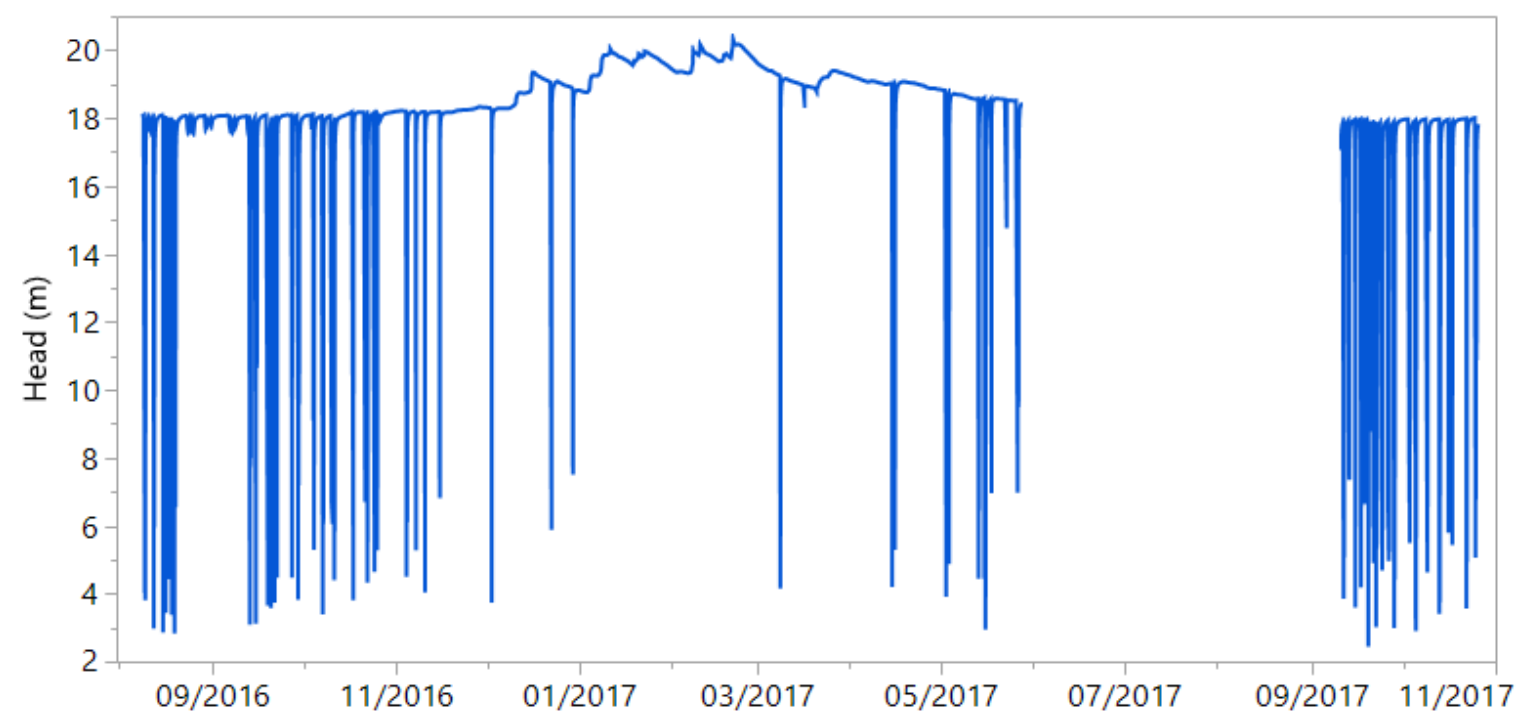

Figure 5.4: Head (m) in the Pump House Well August 2016 to November 2017. 
Placing the data on one graph with a common scale allows for comparisons to be made between the timing and magnitude of observed fluctuations (see Figure 5.5). The data were recorded at the same frequency and are anchored using an October 1, 2016 reference water-level. The piezometer and well are approximately 18 meters apart; however, PHP-1 is completed in the upper unconfined aquifer, while the Pump House Well is completed in the lower semi-confined aquifer. As seen in Figure 5.5, the timing of response to individual precipitation events vary, the well showing a 10-16 hour delayed response. Additionally, the amplitude of fluctuations differ by $0.5-1 \mathrm{~m}$. Water levels fluctuate significantly in PHP-1 in response to individual precipitation events. Conversely, the Pump House Well exhibits a more attenuated and delayed response which is attributed to the presence of the silt and clay aquitard of low hydraulic conductivity.

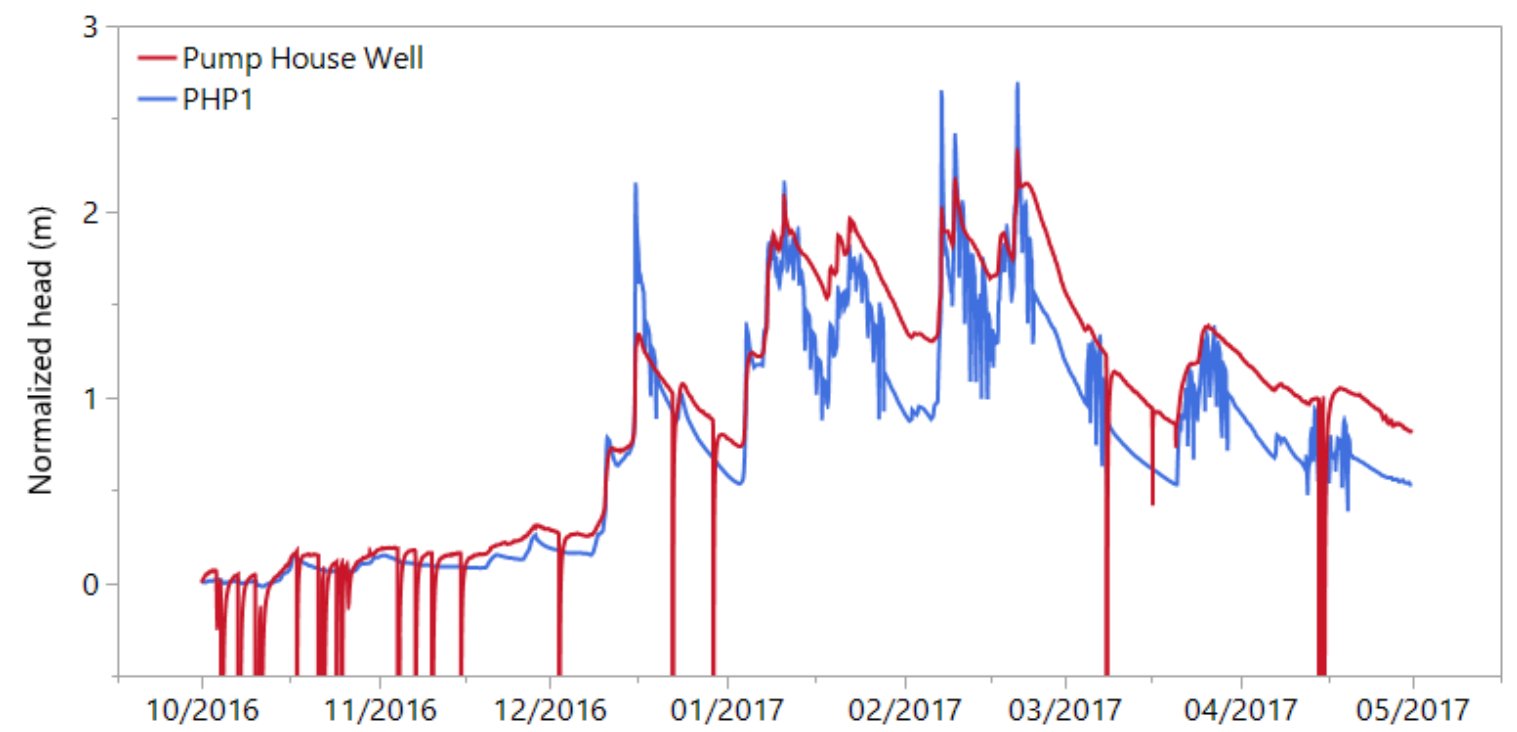

Figure 5.5: Comparison of timing and magnitude of water level fluctuations (m) in a piezometer (PHP-1) and an irrigation well (Pump House Well) over a 7 month period from October 2016 to May 2017.

A focus on PHP-1 summer 2016 and 2017 data permits identification of the dominant hydrologic stresses acting on lower Scotts Creek groundwater levels and 
the magnitude of their influence. Figure 5.6 shows water-level fluctuations in the Pump House Well and PHP-1 August-October 2016. Similarly, Figure 5.7 shows water-level fluctuations in PHP-1 June-November 2017. The 2016 and 2017 data exhibit an overall downward trend, but superimposed on the natural climatic driven fluctuations are the effects of groundwater pumping for irrigation and consumption by phreatophytes. Both groundwater hydrographs indicate that daily groundwater uptake by phreatophytes alone results in approximately $1 \mathrm{~cm}$ of water-level decline. When combined with periods of heavy groundwater pumping from the lower semiconfined aquifer, water-level fluctuations of up to $5 \mathrm{~cm}$ are observed. However, water levels rebound to near pre-pumping static levels when abstraction ceases indicating a stable groundwater supply (no significant/discernible chronic drops in groundwater levels). Additionally, given that the pumping well creates a cone of depression, the effects of pumping are greatest near the well (i.e., PHP-1) and propagate outward, and consequently drawdown is variable across the floodplain. These observations of long-term water-level trends correlate well with findings from pumping tests when flow rate data are included in the analysis. That is, for every $1 \mathrm{AF}$ of groundwater abstracted, a maximum of $\sim 5 \mathrm{~cm}$ of drawdown in the upper unconfined aquifer can be expected.

All of the groundwater level data analyzed up until this point were recorded in 2016 and 2017 and focused on daily, weekly, and monthly trends. Water levels in one well (Queseria Well) were measured at 10-15 minute intervals over a 28 month period from August 2015 to December 2017 (Figure 5.8). The data are particularly valuable for assessing the magnitude of fluctuations in water levels from year to year. Although data are missing for late 2016 and early 2017, it is clear the data follow a natural cyclic pattern of seasonal fluctuation rising by several meters during winter months, then declining during the summer and stabilizing at about the same level each fall 


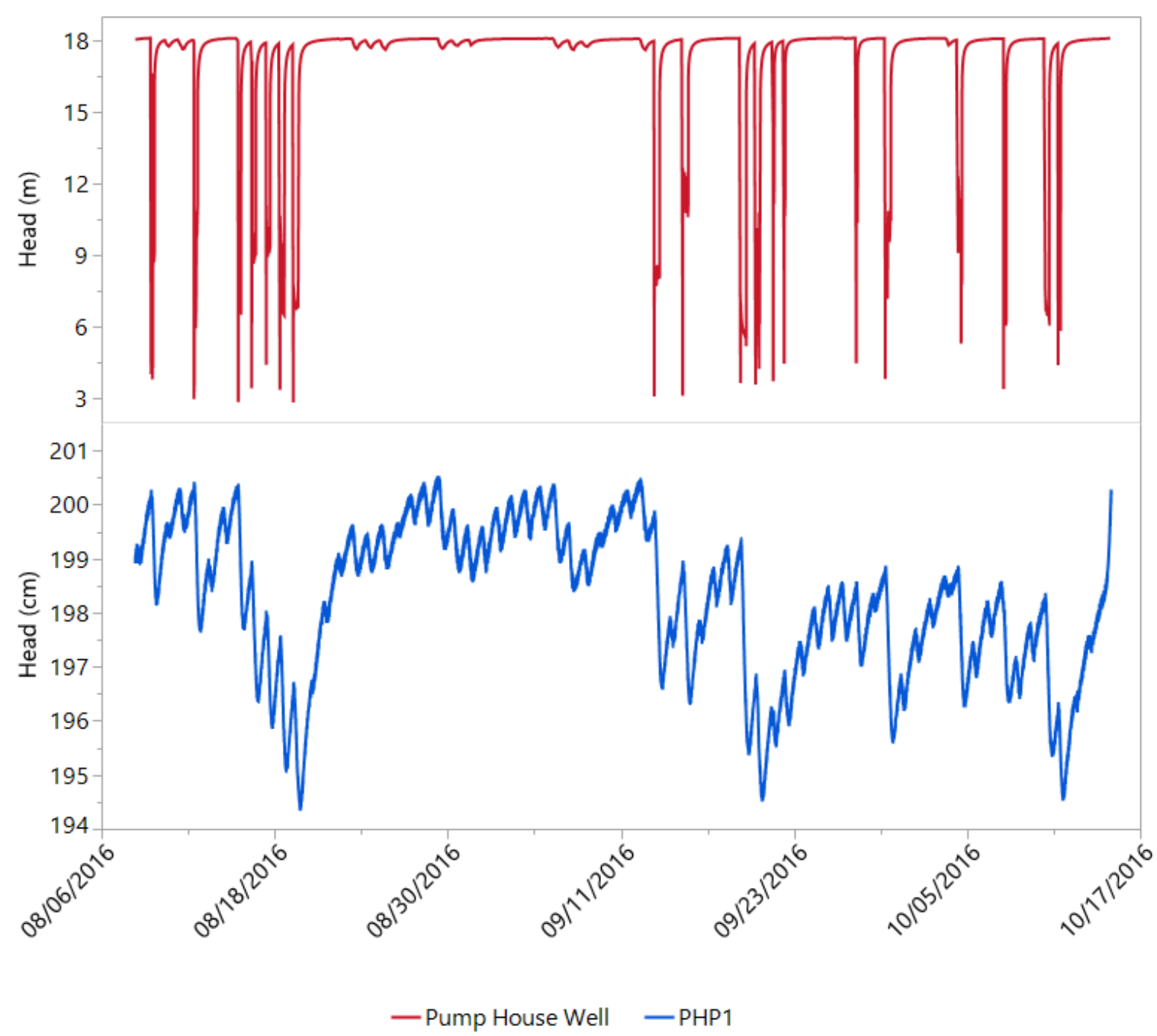

Figure 5.6: Head (m) in Pump House Well and head (cm) in PHP-1 August-October 2016. The data show pumping events in the Pump House Well and the drawdown response in PHP-1 superimposed on the diurnal fluctuations in groundwater levels in PHP-1 indicative of evapotranspiration by phreatophytes.

(within a $0.25 \mathrm{~m}$ difference). The data indicate that groundwater levels were lowest late in the summer of 2015 and highest winter 2015-2016.

As shown, long-term measurement of groundwater levels provide data for observing differences in the magnitude and timing of response within layered aquifer systems, for identifying hydrologic stresses, and for tracking fluctuations in water levels from season to season and from year to year in response to varying climatic conditions 


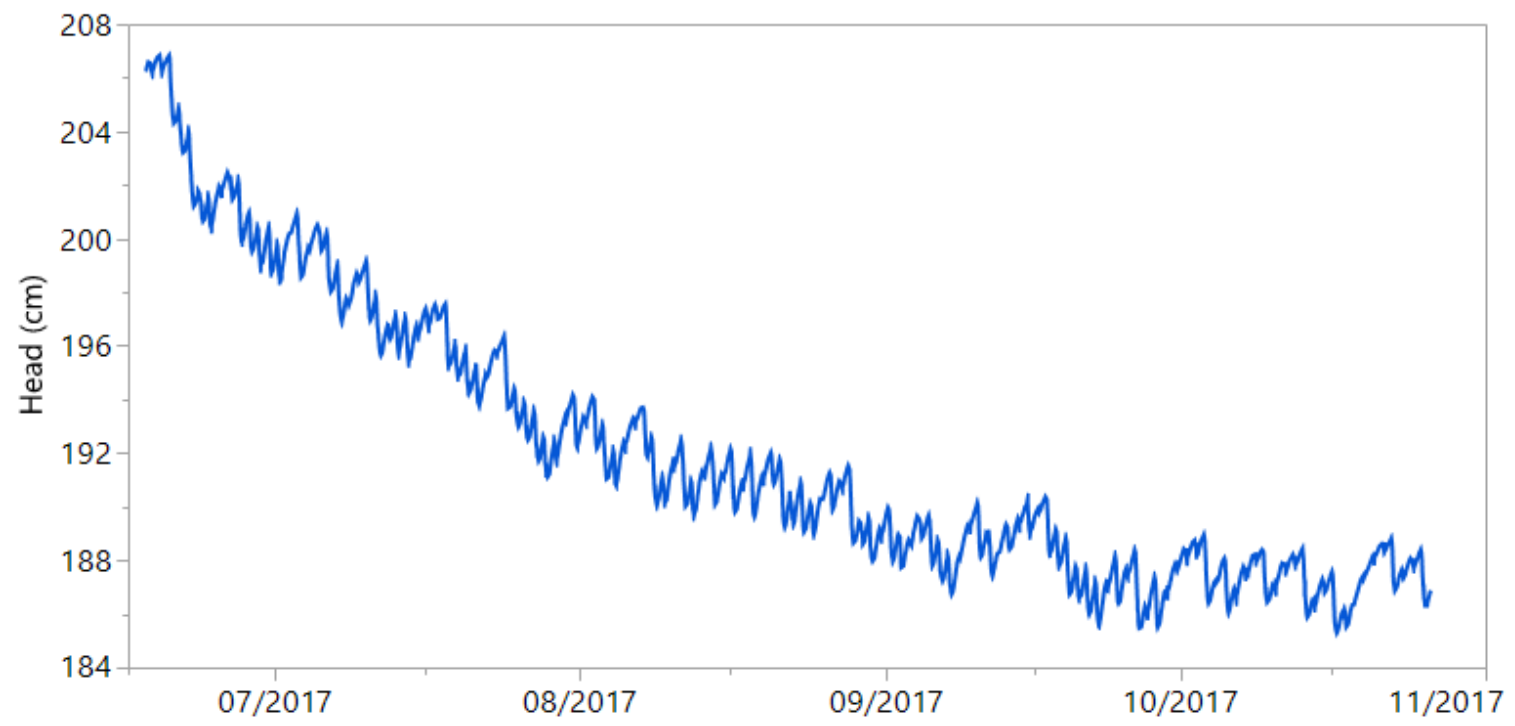

Figure 5.7: Head (cm) in PHP-1 June-November 2017. The data show fluctuations in groundwater levels as a result of phreatophytic consumption and groundwater abstraction.

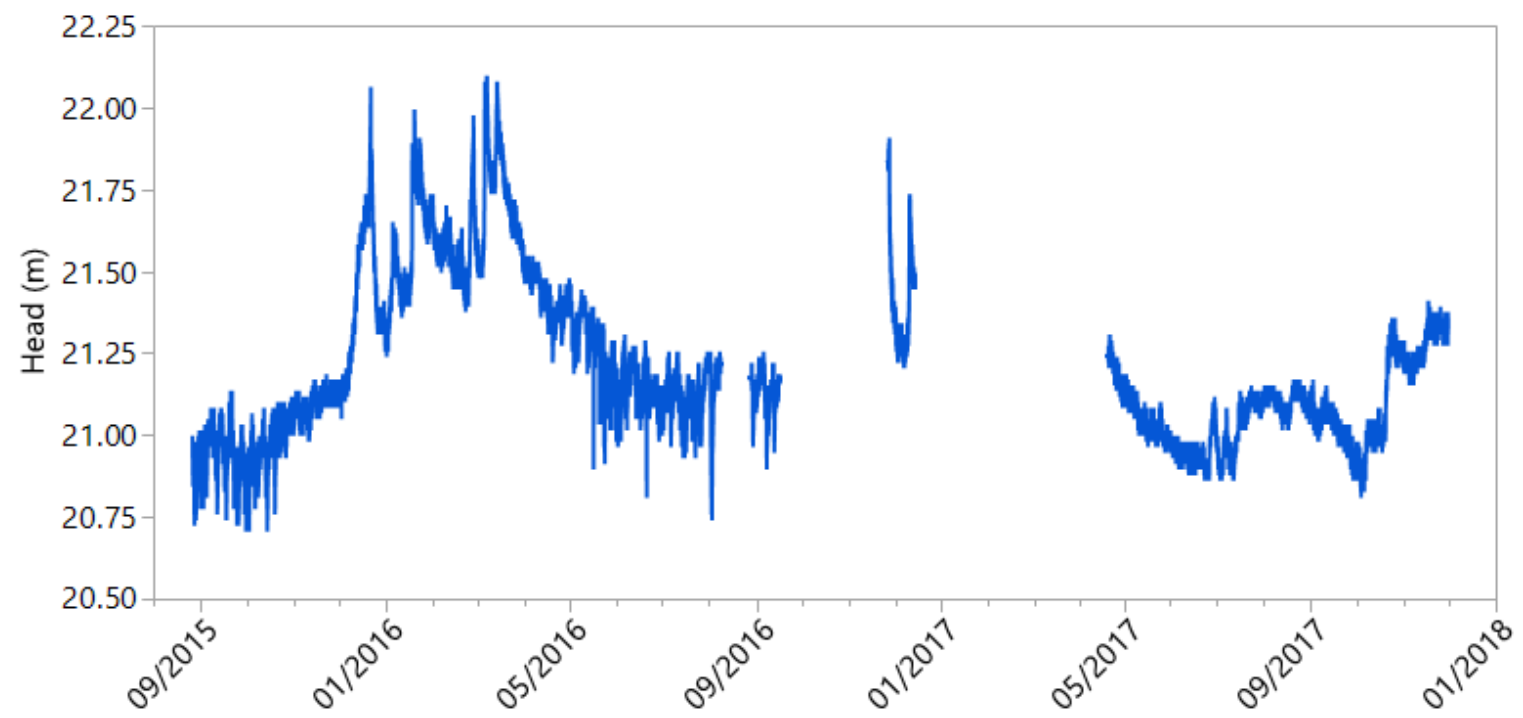

Figure 5.8: Head (m) in the Queseria Well August 2015 to December 2017.

and groundwater abstraction practices. Significant changes in water levels in aquifers caused by climatic variability and excessive groundwater pumping commonly occur over decades which highlights the value of long-term data for quantifying the effects 
of human activities on stream-aquifer interactions (Barlow and Leake, 2012; Taylor and Alley, 2001). 


\section{CHAPTER 6: CONCLUSION}

The dynamics of stream-aquifer interactions along lower Scotts Creek have been thoroughly studied, thus providing meaningful insight into the effects of groundwater abstraction from irrigation wells on Scotts Creek stream flows. This two year study integrated data from field investigations, laboratory tests of sediment samples, calculation of stream depletion rate, numerical groundwater flow modeling, and long-term groundwater monitoring to characterize the alluvial aquifer, to quantify the hydraulic connection between the stream and the aquifer, and to provide sustainable groundwater pumping recommendations. We tested the hypothesis that the stream is directly connected to the aquifer and that abstraction of groundwater from agricultural wells has a measurable impact on Scotts Creek stream flows, particularly during the summer low-flow period. Based on the data collected and analyzed, we reject the hypothesis that Scotts Creek is directly connected to the underlying alluvial aquifer and conclude that, although the rate of streamflow depletion is quantifiable, there is only a weak hydraulic connection between the stream and the aquifer. The study results to support this conclusion are summarized below.

Initial subsurface exploration using direct push methods suggested that a thin low-permeability aquitard layer of silt and clay separates surficial sediments from a deeper more permeable formation. Field tests including constant rate pumping tests, dye tracer tests, and geophysical surveys were performed, followed by laboratory analyses of sediment cores, calculation of stream depletion rate, numerical groundwater 
flow modeling, and long-term groundwater monitoring.

Drawdown data recorded in monitoring wells and piezometers during two separate 24-hour pumping tests confirmed the presence of an aquitard. An attenuated and delayed (peak drawdown occured 27-66 hours after pumping started) response to pumping was observed in all piezometers. A maximum drawdown of $5 \mathrm{~cm}$ was observed in Pump House Piezometer 1 at a distance of $18 \mathrm{~m}$ from the Pump House Well during the Pump House Well pumping test, and a small decrease in stream stage of approximately $1 \mathrm{~cm}$ was measured in instream piezometers adjacent to the Pump House Well five days cessation of the Pump House Well pumping test. However, it is uncertain whether the small decrease in stream stage was caused by groundwater pumping or if it can be attributed to natural factors given that the observed response was well within the limits of the water-level accuracy $(1-2 \mathrm{~cm})$ of the transducers used. Conversely, water levels measured in deep observation wells during the pumping tests showed a direct and unambiguous response to pumping with a maximum drawdown of $0.9 \mathrm{~m}$ measured in the VFD Well at a distance of $260 \mathrm{~m}$ from the Pump House Well during the Pump House Well pumping test.

Constant rate and slug dye injections using a dilute solution of a fluorescent dye tracer (20\% Rhodamine WT) were carried out and showed a weak hydraulic connection between the stream and pumped aquifer with insignificant change in dye concentration and calculated stream discharge observed outside the normal variation.

Electrical resistivity tomography surveys showed complex resistivity distributions (20-70 ohm-m) and revealed that the aquitard is continuous, thick, and homogeneous near the VFD Well, but that it is significantly heterogeneous and discontinuous at greater distances from the stream channel.

Soil cores were collected in the field and tested in a laboratory setting to determine variations in the particle size distribution and saturated hydraulic conductivity of 
sediments with depth. Falling-head permeameter tests and particle size analyses indicated significant variation in both the particle size distribution and saturated hydraulic conductivity of sediments from the $0-40$ foot depth range. Furthermore, the tests revealed that the aquitard material is significantly less conductive $(\geq 100$ times as estimated by laboratory tests and $\geq 1000$ times as estimated by pumping tests) than the upper and lower aquifer material.

The hydraulic properties of the aquifer were estimated by fitting the Theis (1935), Cooper and Jacob (1946), and Hantush and Jacob (1955) analytical models to timedrawdown data (curve matching) recorded in observation wells during two 24-hour pumping tests. It was found that the Theis (1935) and Cooper and Jacob (1946) solutions deviate from the drawdown data at late time suggesting vertical leakage (possibly from the top unconfined aquifer and aquitard, or through bedrock) contributes to the recharge of the pumped aquifer. Therefore, the Hantush and Jacob (1955) solution for leaky confined aquifers was used to achieve a better model fit and to produce improved hydraulic parameter estimates. The hydraulic conductivity $(K)$ and specific storage $\left(S_{s}\right)$ of the aquifer are $1.03 \times 10^{-4} \mathrm{~m} / \mathrm{s}$ and $3.42 \times 10^{-5} \mathrm{~m}^{-1}$, respectively. Additionally, the hydraulic conductivity of the aquitard $\left(K^{\prime}\right)$ is $6.39 \times 10^{-8} \mathrm{~m} / \mathrm{s}$.

The Hantush (1965) equation of groundwater flow was used to quantify the effects of groundwater pumping on lower Scotts Creek stream flows using simplified subsurface properties - averaged hydraulic conductivity and thickness values for the aquitard (scenario 1), and values for the aquitard that are exclusively representative of the low-permeability material (silt and clay lenses) having the greatest influence on groundwater flow and neglecting the thin permeable zones within the aquitard (scenario 2). The calculations suggested that under normal pumping conditions (8 hours of pumping at a well discharge rate of $200 \mathrm{gpm}$ ) the rate of streamflow depletion is $2.46 \times 10^{-3} \mathrm{~m}^{3} / \mathrm{s}\left(8.68 \times 10^{-2} \mathrm{cfs}\right)$ or $19 \%$ of the pumping rate for scenario 1 and 
$9.62 \times 10^{-4} \mathrm{~m}^{3} / \mathrm{s}\left(3.40 \times 10^{-2} \mathrm{cfs}\right)$ or $8 \%$ of the pumping rate for scenario 2 . Analysis of time-drawdown curves and associated well flow rates provided a rough estimate of 94,000 gallons or $0.3 \mathrm{AF}$ as the maximum volume of groundwater that can be abstracted daily before significant leakage occurs.

A numerical groundwater flow model (MODFLOW) was constructed in GMS, manually calibrated using data from field and laboratory tests, and transient simulations were performed. Results of numerical simulation of groundwater flow showed that: 1) values of hydraulic conductivity for the aquitard determined by permeameter tests are higher than the "true" values, 2) the lower semi-confined aquifer is heterogeneous, and 3) pumping-induced river leakage is greatest when simulating groundwater withdrawal from the Pump House Well.

Long-term groundwater monitoring data were analyzed to assess the magnitude of fluctuations in water levels from season to season and year to year. On average, groundwater levels increase by approximately 1.5 meters every winter, then slowly recede, reaching the lowest levels in the fall. The steady decrease in water levels during the summer and fall is largely attributable to climatic driven fluctuations, but consumption by phreatophytic vegetation and groundwater withdrawal for crop irrigation are also responsible for daily groundwater decline. Daily groundwater uptake by phreatophytes alone results in approximately $1 \mathrm{~cm}$ of water-level decline in the upper unconfined aquifer while groundwater pumping can cause fluctuations of up to 5 $\mathrm{cm}$ over the course of a week with the greatest impacts observed when the Pump House Well is used. However, water levels rebound to near pre-pumping static levels when abstraction ceases indicating a stable groundwater supply (no significant/discernible chronic drops in groundwater levels).

Results of this study can be viewed as good news in terms of groundwater management. The aquitard acts as a buffer between the stream and pumped aquifer. 
Effects of groundwater pumping on water levels in the upper unconfined aquifer are on the order of magnitude of a few centimeters. In general, the pumped aquifer is semi-confined. However, at the reach scale, there is spectrum of confinement; the aquifer appears to be more confined downstream of the Pump House Well and less so upstream. Although findings indicate that current groundwater abstraction practices have minimal direct impact on Scotts Creek streamflows, the pumping wells certainly capture groundwater that would otherwise discharge into the stream. During extended periods of abnormally low precipitation, this groundwater capture or depletion could exacerbate the effects of drought induced stress on the creek leading to impaired water quality and quantity. For this reason, it is important to consider the amount of capture that is acceptable when developing management strategies to conserve baseflow and avoid causing undesirable consequences.

The concept of "sustainable yield" is a way to determine appropriate withdrawals to ensure the long-term resilience of groundwater systems. The California State Groundwater Management Act (SGMA) defines sustainable yield as, "the maximum quantity of water, calculated over a base period representative of long-term conditions in the basin and including any temporary surplus, that can be withdrawn annually from a groundwater supply without causing an undesirable result". While various definitions of sustainable yield exist leaving the term open to interpretation [refer to Kalf and Woolley (2005) and Rudestam and Langridge (2014) for a thorough discussion of sustainable yield concepts and definitions], rather than attempting to apply a single definition universally, it is "better to view groundwater not as a renewable resource but as a mineral resource that can be replenished under certain circumstances and geographical locations" when developing sustainable groundwater management plans (Kalf and Woolley, 2005). Establishing a sustainable yield for the lower Scotts Creek aquifer is outside the scope of this thesis, yet the findings of this research can certainly 
inform management strategies. To start, a few results-based sustainable groundwater pumping recommendations are suggested.

Study findings indicate stronger stream-aquifer connectivity in the vicinity of the Pump House Well. It is therefore recommended that the VFD Well be used as the primary well for irrigation purposes. Additionally, current pumping schedules show residual drawdown. Restricting pumping duration to 6 hours or less and ensuring the total volume of groundwater abstracted daily does not exceed 94,000 gallons could reduce pumping-induced leakage and allow the aquifer time to recover between pumping events. To compensate for lower volumes of water, implementation of best management practices and investment in water-efficient irrigation technologies are recommended. Lastly, to ensure water security under climate uncertainty, it is recommended that water storage in the form of tanks or a reservoir with abstractions during the winter when stream flows are greatest be implemented. Limiting pumping duration, implementing best management practices in terms of water distribution efficiency, the use of stored water to supplement groundwater supplies during dry summer months, and the adoption of an adaptive and holistic management approach to account for varying climatic conditions together would minimize economic and environmental concerns surrounding groundwater use on lower Scotts Creek.

The conclusions presented herein are based on the results of a two year study. Stresses imposed by changes in climate and water resource needs should be examined with rigorous science to determine appropriate management strategies. Future research should focus on: 1) improvement of the numerical groundwater flow model so that it is more representative of the natural system and can be used to determine basin sustainable yield, 2) continued long-term measurement of groundwater levels, and 3) the completion of additional geophysical surveys and exploratory boreholes upstream of the Pump House Well and in the stream channel to further characterize the heterogeneity 
of the subsurface, in particular the spatial variability of aquitard hydraulic properties. 


\section{BIBLIOGRAPHY}

Anderson, M. P., 2005. Heat as a ground water tracer. Ground water 43 (6), 951-968.

Anderson, M. T., Woosley, L. H., 2005. Water availability for the western United States: key scientific challenges. US Department of the Interior, US Geological Survey.

ASTM-D6913/D6913M-17, 2017. Standard test methods for particle-size distribution (gradation) of soils using sieve analysis. ASTM International, West Conshohocken, PA, 2017, www.astm.org.

ASTM-D7928-17, 2017. Standard test method for particle-size distribution (gradation) of fine-grained soils using the sedimentation (hydrometer) analysis. ASTM International, West Conshohocken, PA, 2017, www.astm.org.

Barlow, P. M., Leake, S. A., 2012. Streamflow depletion by wells: Understanding and managing the effects of groundwater pumping on streamflow.

Baron, J. S., Poff, N. L., Angermeier, P. L., Dahm, C. N., Gleick, P. H., Hairston, N. G., Jackson, R. B., Johnston, C. A., Richter, B. D., Steinman, A. D., 2002. Meeting ecological and societal needs for freshwater. Ecological Applications 12 (5), 1247-1260.

Baxter, C., Hauer, F. R., Woessner, W. W., 2003. Measuring groundwater-stream water exchange: new techniques for installing minipiezometers and estimating hydraulic conductivity. Transactions of the American Fisheries Society 132 (3), 493-502.

Boulton, A. J., Findlay, S., Marmonier, P., Stanley, E. H., Valett, H. M., 1998. The functional significance of the hyporheic zone in streams and rivers. Annual Review of Ecology and Systematics, 59-81.

Boulton, N. S., 1963. Analysis of data from non-equilibrium pumping tests allowing for delayed yield from storage. Proceedings of the Institution of Civil Engineers 26 (3), 469-482.

Bradbury, K. R., Muldoon, M. A., 1990. Hydraulic conductivity determinations in unlithified glacial and fluvial materials. In: Ground water and vadose zone monitoring. ASTM International. 
Bredehoeft, J., 2011. Hydrologic trade-offs in conjunctive use management. Ground water 49 (4), 468-475.

Bredehoeft, J., Kendy, E., 2008. Strategies for offsetting seasonal impacts of pumping on a nearby stream. Ground water 46 (1), 23-29.

Brodie, R., Sundaram, B., Tottenham, R., Hostetler, S., Ransley, T., 2007. An overview of tools for assessing groundwater-surface water connectivity. Bureau of Rural Sciences, Canberra, Australia, 131.

Brunke, M., Gonser, T., 1997. The ecological significance of exchange processes between rivers and groundwater. Freshwater biology 37 (1), 1-33.

Brunner, P., Cook, P. G., Simmons, C. T., 2011. Disconnected surface water and groundwater: from theory to practice. Ground Water 49 (4), 460-467.

Brunner, P., Simmons, C. T., Cook, P. G., Therrien, R., 2010. Modeling surface water-groundwater interaction with modflow: Some considerations. Ground water 48 (2), 174-180.

Butler, J. J., Zhan, X., Zlotnik, V. A., 2007. Pumping-induced drawdown and stream depletion in a leaky aquifer system. Ground Water 45 (2), 178-186.

Butler, J. J., Zlotnik, V. A., Tsou, M.-S., 2001. Drawdown and stream depletion produced by pumping in the vicinity of a partially penetrating stream. Ground Water 39 (5), 651-659.

Cardiff, M., Barrash, W., Thoma, M., Malama, B., 2011. Information content of slug tests for estimating hydraulic properties in realistic, high-conductivity aquifer scenarios. Journal of Hydrology 403 (1-2), 66-82.

Carman, P. C., 1956. Flow of gases through porous media. Academic press.

CDFG, 2012. Draft instream flow recommendations: Scott creek, santa cruz county. California Department of Fish and Game.

Chen, X., Shu, L., 2002. Stream-aquifer interactions: Evaluation of depletion volume and residual effects from ground water pumping. Ground Water 40 (3), 284-290.

Cook, O. B., 2016. Lower scotts creek floodplain and habitat enhancement project. Master's thesis.

Cooper, H. H., Jacob, C. E., 1946. A generalized graphical method for evaluating formation constants and summarizing well-field history. Eos, Transactions American Geophysical Union 27 (4), 526-534. 
Deitch, M. J., Dolman, B., 2017. Restoring summer base flow under a decentralized water management regime: Constraints, opportunities, and outcomes in mediterraneanclimate california. Water 9 (1), 29.

Devlin, J. F., 2015. Hydrogeosievexl: an excel-based tool to estimate hydraulic conductivity from grain-size analysis. Hydrogeology Journal 23 (4), 837-844.

Domenico, P., Mifflin, M., 1965. Water from low-permeability sediments and land subsidence. Water Resources Research 1 (4), 563-576.

Faust, C. R., Mercer, J. W., et al., 1980. Ground-water modelling: numerical models. Ground Water 18 (4), 395-409.

Fleckenstein, J., Anderson, M., Fogg, G., Mount, J., 2004. Managing surface watergroundwater to restore fall flows in the cosumnes river. Journal of Water Resources Planning and Management 130 (4), 301-310.

Fleckenstein, J. H., Niswonger, R. G., Fogg, G. E., 2006. River-aquifer interactions, geologic heterogeneity, and low-flow management. Ground water 44 (6), 837-852.

Foster, S., Allen, D., 2015. Groundwater-surface water interactions in a mountainto-coast watershed: Effects of climate change and human stressors. Advances in Meteorology 2015.

Fox, G., 2004. Evaluating stream depletion analytical solutions using field data from a stream/aquifer analysis test. J. Am. Water Resour. As.(JAWRA) 40 (3), 755-763.

Freeze, R. A., Cherry, J. A., 1979. Groundwater, 604 pp.

Glover, R. E., Balmer, G. G., 1954. River depletion resulting from pumping a well near a river. Eos, Transactions American Geophysical Union 35 (3), 468-470.

Goebel, M., Pidlisecky, A., Knight, R., 2017. Resistivity imaging reveals complex pattern of saltwater intrusion along monterey coast. Journal of Hydrology.

Goldman, M., Kafri, U., 2006. Hydrogeophysical applications in coastal aquifers. In: Applied hydrogeophysics. Springer, pp. 233-254.

Gribovszki, Z., Szilágyi, J., Kalicz, P., 2010. Diurnal fluctuations in shallow groundwater levels and streamflow rates and their interpretation-a review. Journal of Hydrology 385 (1), 371-383.

Hancock, P. J., 2002. Human impacts on the stream-groundwater exchange zone. Environmental Management 29 (6), 763-781.

Hantush, M. S., 1965. Wells near streams with semipervious beds. Journal of Geophysical Research 70 (12), 2829-2838. 
Hantush, M. S., Jacob, C. E., 1955. Non-steady radial flow in an infinite leaky aquifer. Eos, Transactions American Geophysical Union 36 (1), 95-100.

Harbaugh, A. W., 2005. MODFLOW-2005, the US Geological Survey modular groundwater model: the ground-water flow process. US Department of the Interior, US Geological Survey Reston, VA, USA.

Hayashi, M., Rosenberry, D. O., 2002. Effects of ground water exchange on the hydrology and ecology of surface water. Ground water 40 (3), 309-316.

Hazen, A., 1892. Physical properties of sands and gravels with reference to use in filtration. Report to Massachusetts State Board of Health.

Heath, R. C., 1983. Basic ground-water hydrology. Vol. 2220. US Geological Survey.

Hillel, D., 2003. Introduction to environmental soil physics. Academic press.

Hunt, B., 1999. Unsteady stream depletion from ground water pumping. Ground water 37 (1), 98-102.

Hunt, B., 2003. Field-data analysis for stream depletion. Journal of Hydrologic Engineering 8 (4), 222-225.

Hunt, B., 2009. Stream depletion in a two-layer leaky aquifer system. Journal of Hydrologic Engineering 14 (9), 895-903.

Hunt, B., 2012. Review of stream depletion solutions, behavior, and calculations. Journal of Hydrologic Engineering 19 (1), 167-178.

Hunt, B., Weir, J., Clausen, B., 2001. A stream depletion field experiment. Ground Water 39 (2), 283-289.

Jenkins, C., 1968. Techniques for computing rate and volume of stream depletion by wells. Ground Water 6 (2), 37-46.

Kalbus, E., Reinstorf, F., Schirmer, M., 2006. Measuring methods for groundwater, surface water and their interactions: a review. Hydrology and Earth System Sciences Discussions 3 (4), 1809-1850.

Kalf, F. R., Woolley, D. R., 2005. Applicability and methodology of determining sustainable yield in groundwater systems. Hydrogeology Journal 13 (1), 295-312.

Kilpatrick, F. A., Cobb, E. D., 1985. Measurement of discharge using tracers.

Kløve, B., Ala-Aho, P., Bertrand, G., Gurdak, J. J., Kupfersberger, H., Kværner, J., Muotka, T., Mykrä, H., Preda, E., Rossi, P., et al., 2014. Climate change impacts on groundwater and dependent ecosystems. Journal of Hydrology 518, 250-266. 
Kollet, S. J., Zlotnik, V. A., 2003. Stream depletion predictions using pumping test data from a heterogeneous stream-aquifer system (a case study from the great plains, usa). Journal of Hydrology 281 (1), 96-114.

Kondolf, G., Maloney, L., Williams, J., 1987. Effects of bank storage and well pumping on base flow, carmel river, monterey county, california. Journal of Hydrology 91 (3), $351-369$.

Kozeny, J., 1927. Uber kapillare leitung der wasser in boden. Royal Academy of Science, Vienna, Proc. Class I 136, 271-306.

Lamontagne, S., Taylor, A., Cook, P., Crosbie, R., Brownbill, R., Williams, R., Brunner, P., 2014. Field assessment of surface water-groundwater connectivity in a semi-arid river basin (murray-darling, australia). Hydrological Processes 28 (4), 1561-1572.

Lough, H. K., Hunt, B., 2006. Pumping test evaluation of stream depletion parameters. Ground water 44 (4), 540-546.

Malama, B., Kuhlman, K. L., Barrash, W., 2007. Semi-analytical solution for flow in leaky unconfined aquifer-aquitard systems. Journal of hydrology 346 (1-2), 59-68.

Malama, B., Kuhlman, K. L., Barrash, W., 2008. Semi-analytical solution for flow in a leaky unconfined aquifer toward a partially penetrating pumping well. Journal of hydrology 356 (1-2), 234-244.

Malama, B., Kuhlman, K. L., Barrash, W., Cardiff, M., Thoma, M., 2011. Modeling slug tests in unconfined aquifers taking into account water table kinematics, wellbore skin and inertial effects. Journal of Hydrology 408 (1-2), 113-126.

Marston, D., 1992. June-july 1992 stream survey report of lower scott creek, santa cruz county. Calif. Dept. of Fish and Game Report.

McDonald, M. G., Harbaugh, A. W., 1988. A modular three-dimensional finitedifference ground-water flow model. Vol. 6. US Geological Survey Reston, VA.

McGlochlin, L. M., 1984. Aquifer-stream interaction in the lower carmel valley, monterey county, california. Master's thesis.

Menció, A., Galán, M., Boix, D., Mas-Pla, J., 2014. Analysis of stream-aquifer relationships: A comparison between mass balance and darcy's law approaches. Journal of Hydrology 517, 157-172.

Milan, V., Andjelko, S., et al., 1992. Determination of hydraulic conductivity of porous media from grain-size composition. No. $551.49 \mathrm{~V} 986$. 
Mishra, P. K., Neuman, S. P., 2010. Improved forward and inverse analyses of saturatedunsaturated flow toward a well in a compressible unconfined aquifer. Water Resources Research 46 (7).

Neuman, S. P., 1972. Theory of flow in unconfined aquifers considering delayed response of the water table. Water Resources Research 8 (4), 1031-1045.

Neuman, S. P., Witherspoon, P. A., 1972. Field determination of the hydraulic properties of leaky multiple aquifer systems. Water Resources Research 8 (5), 1284-1298.

Nyholm, T., Christensen, S., Rasmussen, K. R., 2002. Flow depletion in a small stream caused by ground water abstraction from wells. Ground Water 40 (4), 425-437.

Nyholm, T., Rasmussen, K. R., Christensen, S., 2003. Estimation of stream flow depletion and uncertainty from discharge measurements in a small alluvial stream. Journal of Hydrology 274 (1), 129-144.

Palacky, G., 1988. Resistivity characteristics of geologic targets. SEG 1, 53-129.

Poulsen, S. E., Christensen, S., Rasmussen, K. R., 2011. The interaction between the unsaturated zone, aquifer, and stream during a period of groundwater withdrawal. Journal of hydrology 396 (1), 49-60.

Rodríguez, L. B., Cello, P. A., Vionnet, C. A., 2006. Modeling stream-aquifer interactions in a shallow aquifer, choele choel island, patagonia, argentina. Hydrogeology Journal 14 (4), 591-602.

Ronayne, M. J., Roudebush, J. A., Stednick, J. D., 2017. Analysis of managed aquifer recharge for retiming streamflow in an alluvial river. Journal of Hydrology 544, $373-382$.

Rosas, J., Lopez, O., Missimer, T. M., Coulibaly, K. M., Dehwah, A. H., Sesler, K., Lujan, L. R., Mantilla, D., 2014. Determination of hydraulic conductivity from grain-size distribution for different depositional environments. Groundwater 52 (3), 399-413.

Rosenberry, D. O., LaBaugh, J. W., 2008. Field techniques for estimating water fluxes between surface water and ground water. Tech. rep., Geological Survey (US).

Rudestam, K., Langridge, R., 2014. Sustainable yield in theory and practice: Bridging scientific and mainstream vernacular. Groundwater 52 (S1), 90-99.

Rugel, K., Jackson, C. R., Romeis, J. J., Golladay, S. W., Hicks, D. W., Dowd, J. F., 2012. Effects of irrigation withdrawals on streamflows in a karst environment: lower flint river basin, georgia, usa. Hydrological Processes 26 (4), 523-534. 
Sahu, S., Saha, D., 2016. Empirical methods and estimation of hydraulic conductivity of fluvial aquifers. Environmental \& Engineering Geoscience 22 (4), 319-340.

Smith, J. J., 1994. Abundance of coho and steelhead in redwood creek in 1994. Available from San Jose State Univ., Department of Biological Sciences, San Jose, CA 95192.

Snider, B., Urquhart, K., Marston, D., 1995. The relationship between instream flow and coho salmon and steelhead habitat availability in scott creek, santa cruz county. California. CDFG. ESD. Stream flow and habitat evaluation program.

Somers, L. D., Gordon, R. P., McKenzie, J. M., Lautz, L. K., Wigmore, O., Glose, A. M., Glas, R., Aubry-Wake, C., Mark, B., Baraer, M., et al., 2016. Quantifying groundwater-surface water interactions in a proglacial valley, cordillera blanca, peru. Hydrological Processes.

Sophocleous, M., 2002. Interactions between groundwater and surface water: the state of the science. Hydrogeology journal 10 (1), 52-67.

Su, G. W., Jasperse, J., Seymour, D., Constantz, J., 2004. Estimation of hydraulic conductivity in an alluvial system using temperatures. Ground Water 42 (6/7), 890.

Su, G. W., Jasperse, J., Seymour, D., Constantz, J., Zhou, Q., 2007. Analysis of pumping-induced unsaturated regions beneath a perennial river. Water Resources Research 43 (8).

Taskey, R., 2017. Discussion of scotts creek watershed geology and soils. Personal communication.

Taylor, C. J., Alley, W. M., 2001. Ground-water-level monitoring and the importance of long-term water-level data. Vol. 1217. Geological Survey (USGS).

Theis, C., 1941. The effect of a well on the flow of a nearby stream. Eos, Transactions American Geophysical Union 22 (3), 734-738.

Theis, C. V., 1935. The relation between the lowering of the piezometric surface and the rate and duration of discharge of a well using ground-water storage. Eos, Transactions American Geophysical Union 16 (2), 519-524.

Weber, K. A., Perry, R. G., 2006. Groundwater abstraction impacts on spring flow and base flow in the hillsborough river basin, florida, usa. Hydrogeology Journal 14 (7), 1252-1264.

West, J., 2014. Traversing swanton road. https://arboretum.ucsc.edu/pdfs/traversingswanton.pdf. 
Woessner, W. W., 2000. Stream and fluvial plain ground water interactions: rescaling hydrogeologic thought. Ground Water 38 (3), 423-429.

Zektser, S., Loáiciga, H. A., Wolf, J., 2005. Environmental impacts of groundwater overdraft: selected case studies in the southwestern united states. Environmental Geology 47 (3), 396-404.

Zlotnik, V. A., 2004. A concept of maximum stream depletion rate for leaky aquifers in alluvial valleys. Water Resources Research 40 (6).

Zlotnik, V. A., Huang, H., 1999. Effect of shallow penetration and streambed sediments on aquifer response to stream stage fluctuations (analytical model). Ground Water 37 (4), 599-605. 
APPENDIX A: WELL COMPLETION REPORTS 


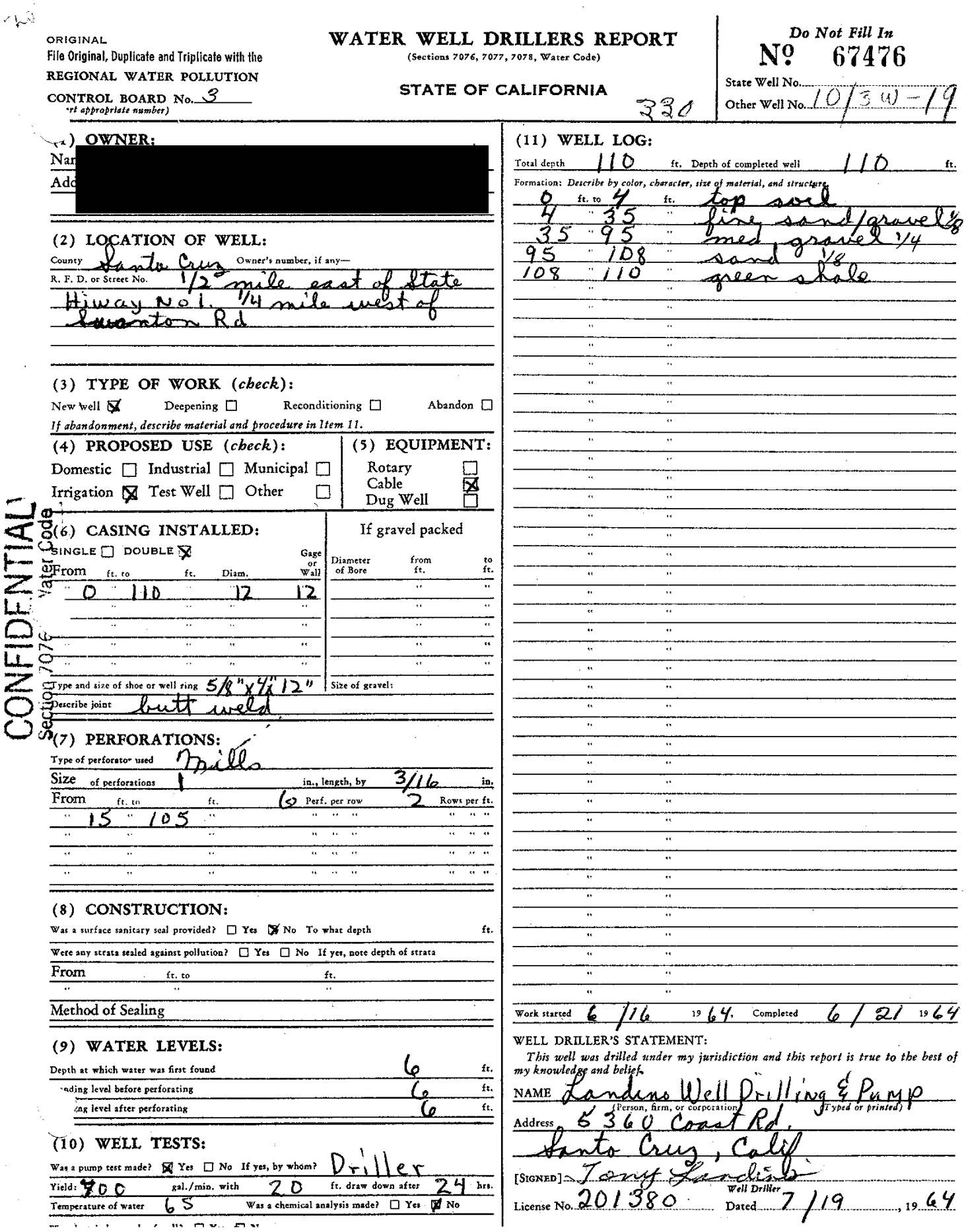

Figure A.1: Archibald Well drillers report (No. 67476). 


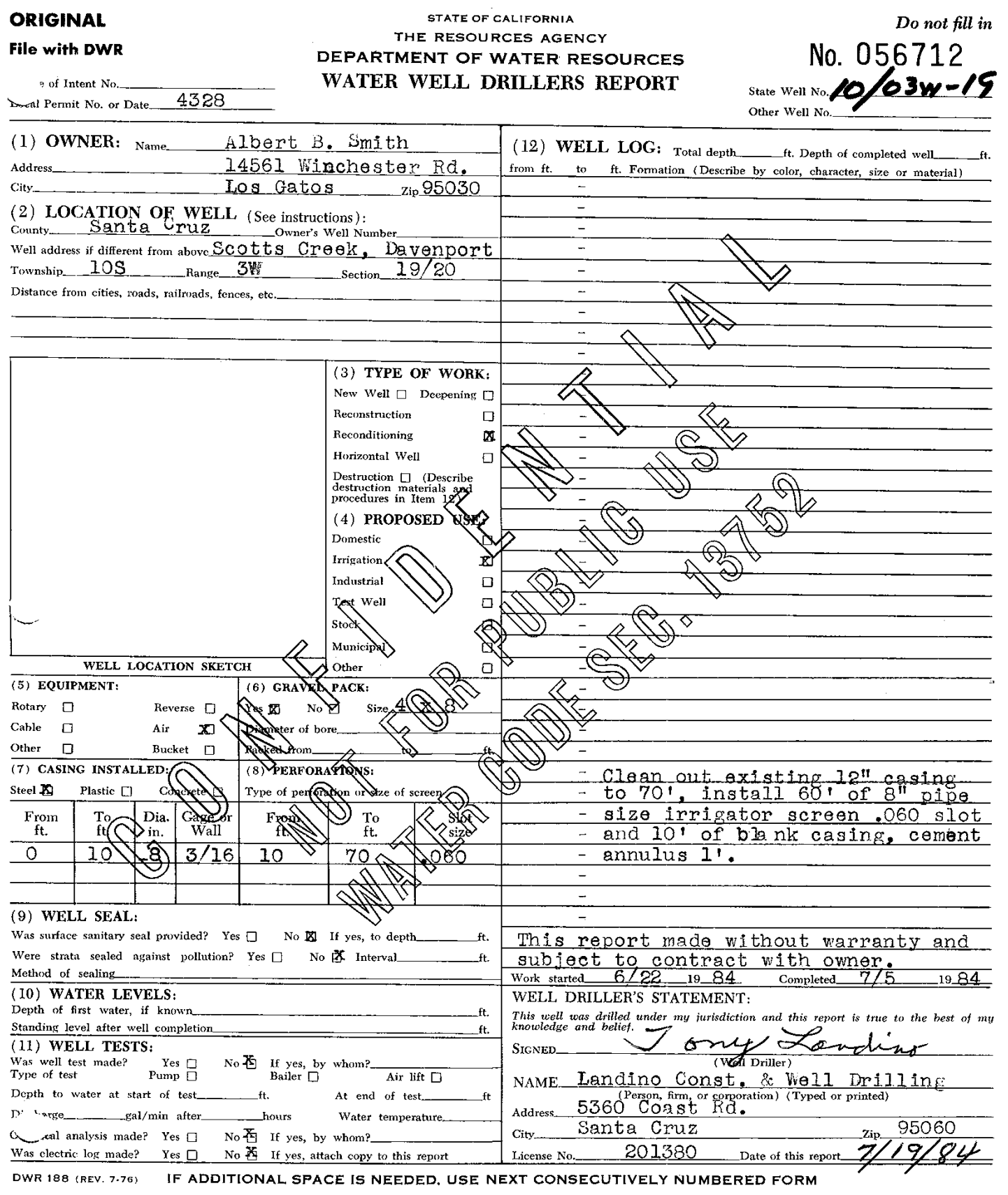

Figure A.2: Archibald Well (cleaning) drillers report (No. 056712). 
Wi ORIGINAL

File Original, Duplicafe and Triplicate with the REGIONAL WATER POLEUTION

CONTROL BOARD No. 3 "rt appropriate number)

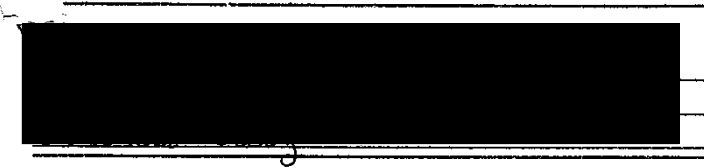

(2) LOCATION OF WELL:

County Saucta Cruz. Owner's number, if any-

R. F. D. or Stres No. 3 mule NW of Davemperstand

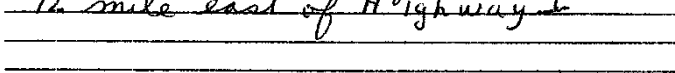

(3) TYPE OF WORK (cbeck):

New wrell $\mathbb{\text { Deepening }} \square \quad$ Recondisioning $\square \quad$ Abandon $\square$ If abandonment, describe material and procedure in Item 11 .

(4) PROPOSED USE (check):

Domestic $\square$ Industrial $\square$

Irrigation $\square$ Test Well $\square$ Other

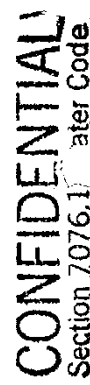

(6) CASING INSTALLED:

Single $\square$ double $\nabla$

From

$\frac{\text { ft. to }}{0.110}$

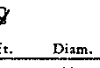

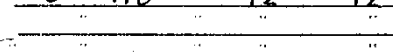

-

Type and size of shoe or well ting $5 / 4 \times 6 \times 12$

\section{§(7) PERFORATIONS:}

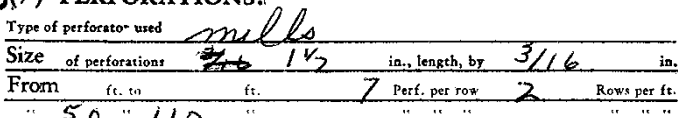

\begin{tabular}{|c|c|c|c|c|c|c|c|}
\hline From & ft. to & ft. & Petri & per & & Row & per $\mathrm{ft}$. \\
\hline$\because 50$ & 1110 & $"$ & " & $"$ & $"$ & $"$ & \\
\hline$\pi$ & ". & ". & " & " & " & $"$ & \\
\hline$"$ & it & $\because$ & $"$ & & " & $"$ & \\
\hline
\end{tabular}

\section{(8) CONSTRUCTION:}

Was a surfaces sanitazy seal provided? $\square$ Yes No To what depth

Were any strata sealed against pollution? $\square$ Yes $\square$ No If yes, note depth of strata

From

$$
\text { xt. to }
$$
ft.

Method of Sealing

(9) WATER LEVELS:

Depth st which water was first found

ling level before perforating

$f^{\prime}$ ing level after perforating

(10) WELL, TESTS:

Was a pump test made? [O Yes $\square$ No If yes, by whom? Driller Yield: 600 gal./min. with 30 ft. draw down after Temperature of water $63^{\circ} F$ Was a chemical analysis made? Yes.

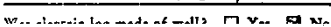

(5) EQUIPMENT: Rotary
Cable Dug Well If gravel packed 


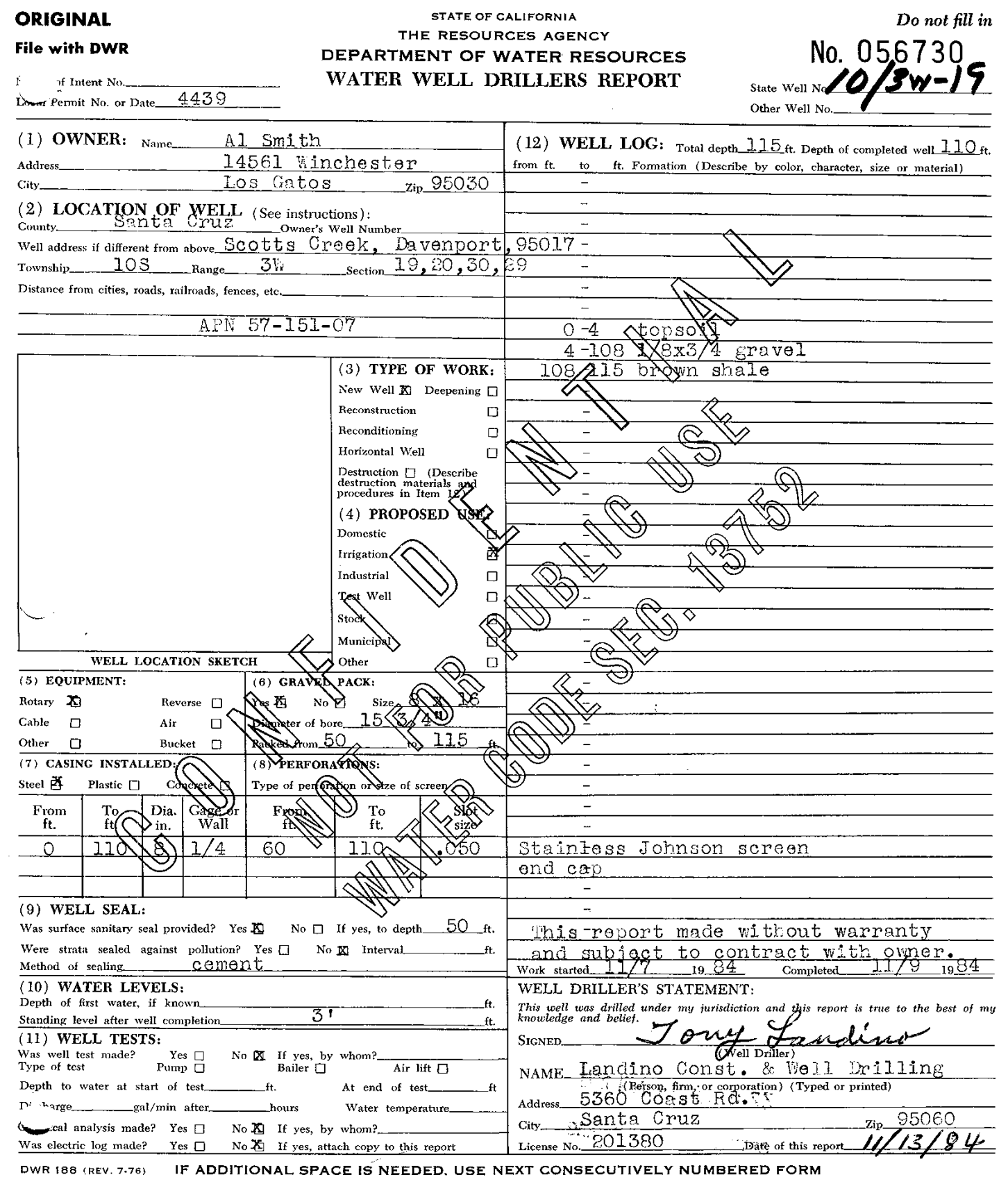

Figure A.4: Pump House Well drillers report (No. 056730). 
APPENDIX B: EXPLORATORY BOREHOLE DRILLING LOGS 


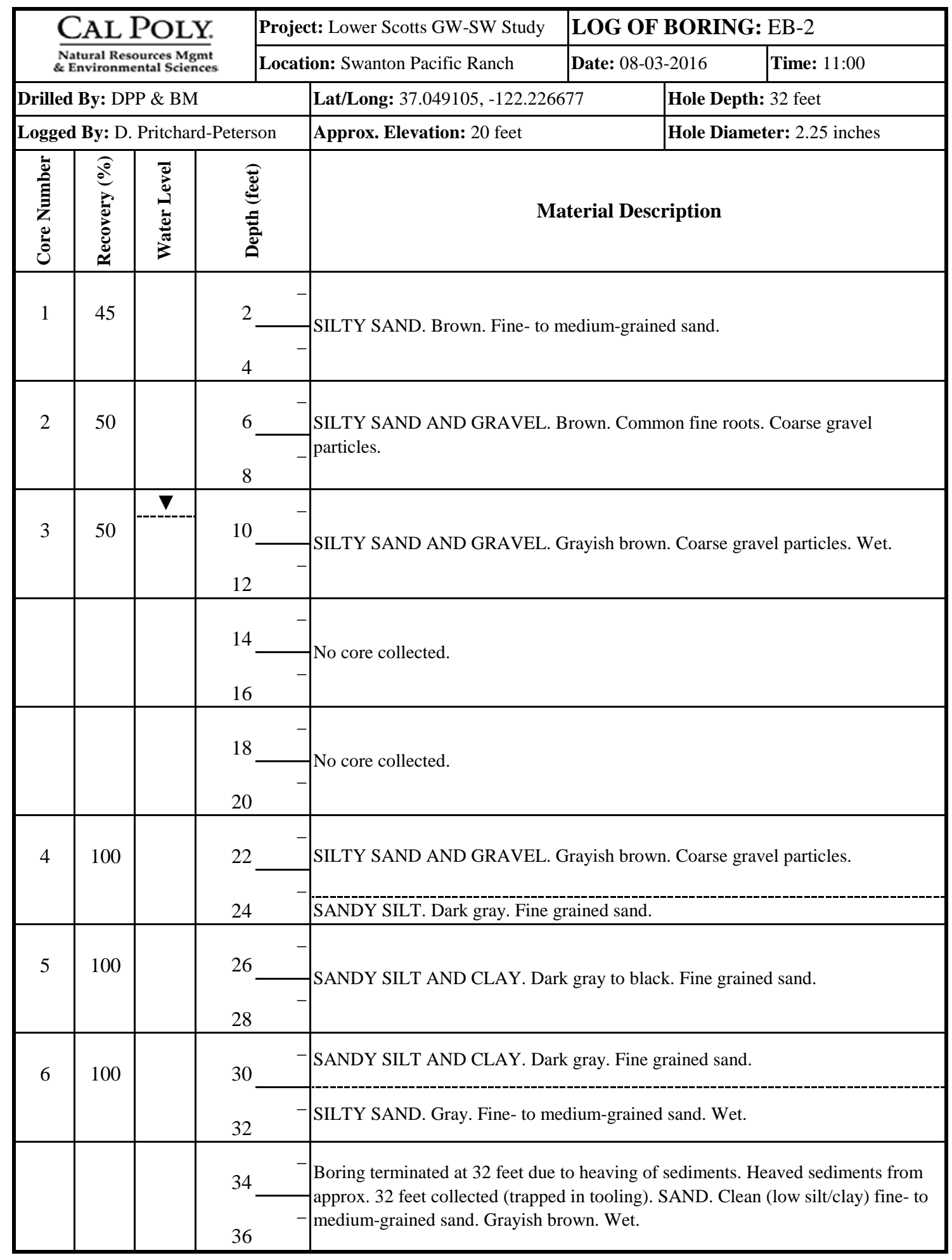

Figure B.1: Log of boring EB-2. 


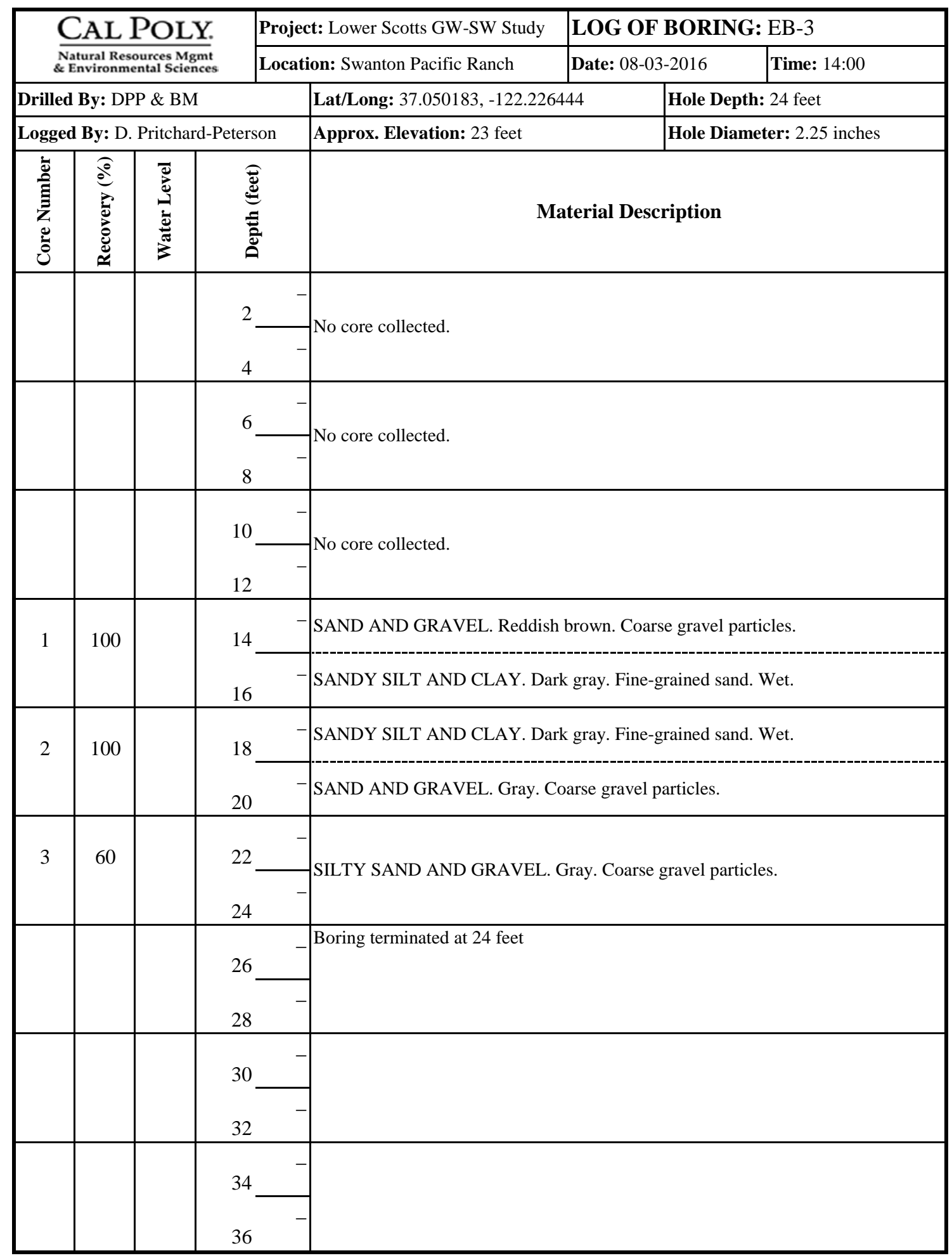

Figure B.2: Log of boring EB-3. 


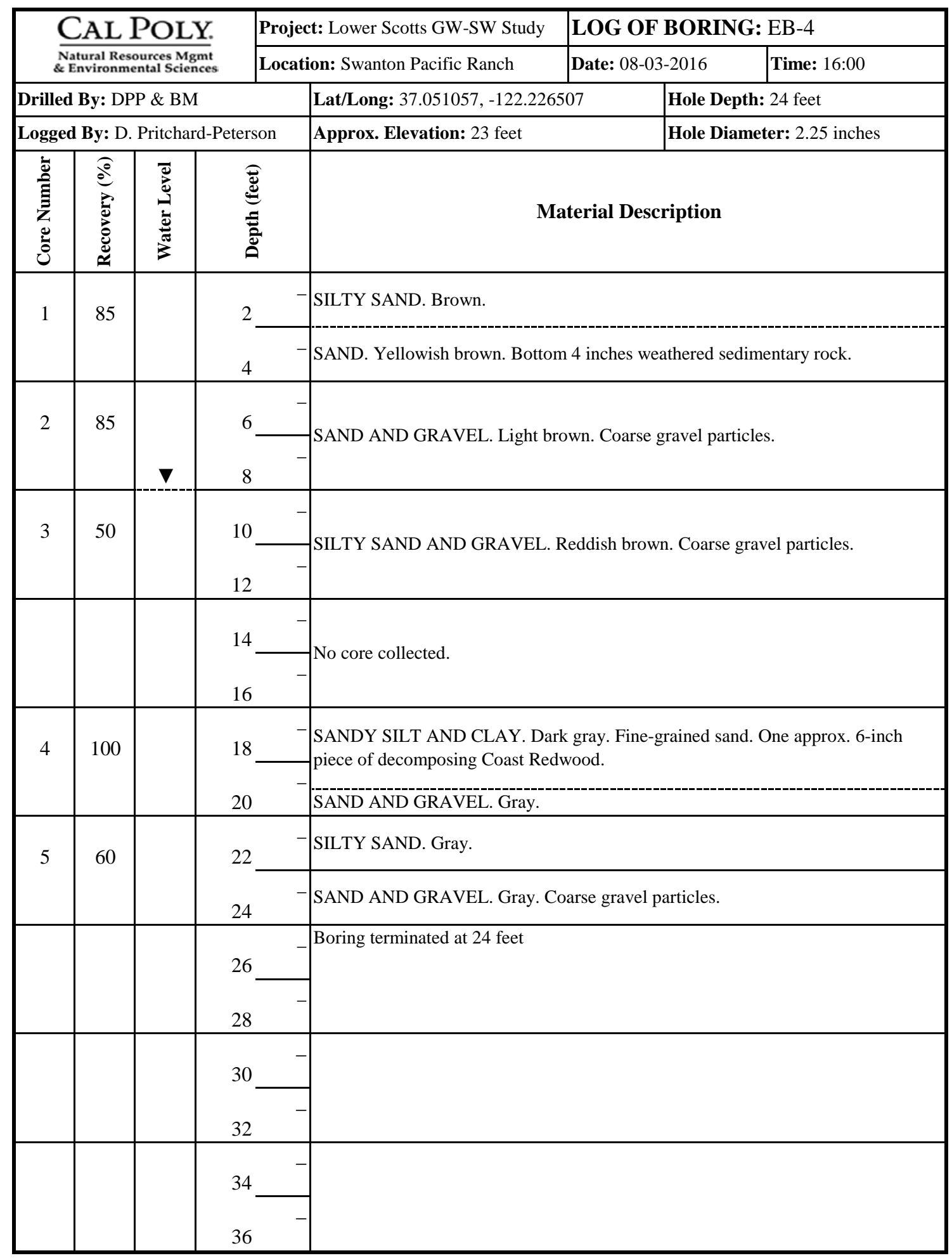

Figure B.3: Log of boring EB-4. 


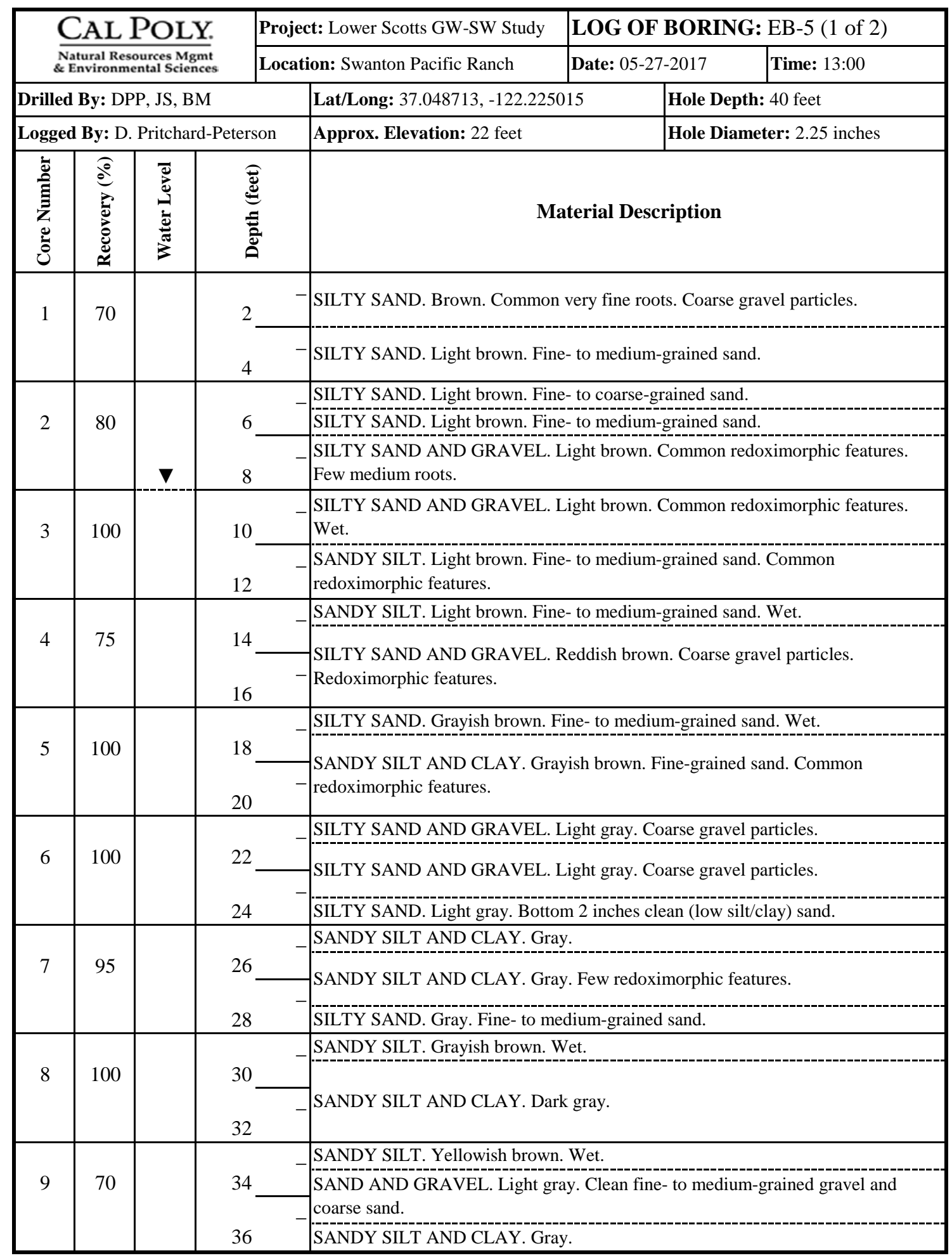

Figure B.4: Log of boring EB-5 (1 of 2). 


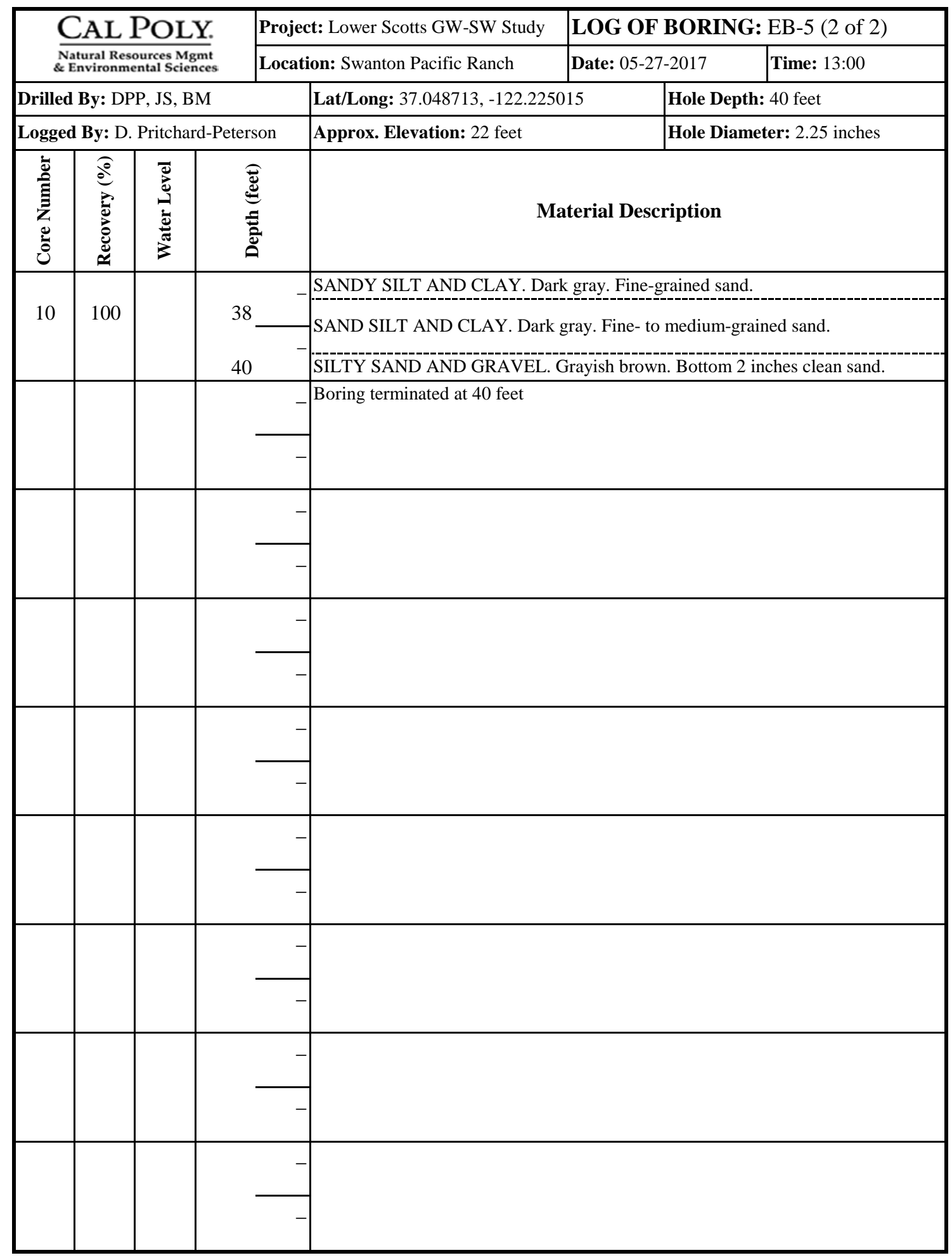

Figure B.5: Log of boring EB-5 (2 of 2). 


\begin{tabular}{|c|c|c|c|c|c|c|c|}
\hline & & & & Projec & t: Lower Scotts GW-SW Study & LOG OF BOR & EB-6 (1 of 2) \\
\hline & ivironn & & & Locatic & on: Swanton Pacific Ranch & Date: 06-20-2017 & Time: 13:00 \\
\hline Drill & By: D & \& $\mathrm{J}$ & & & Lat/Long: $37.052052,-122.225$ & Hole & 40 feet \\
\hline Logg & By: D & ritch & eterson & & Approx. Elevation: 25 feet & Hole & ter: 2.25 inches \\
\hline 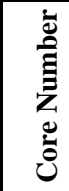 & 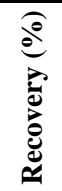 & 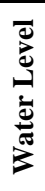 & 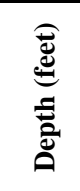 & & & terial Descriptio & \\
\hline & & & & & SILTY SAND. Brown. Few fine & oots. Coarse gravel & \\
\hline 1 & 75 & & 2 & & SILTY SAND. Dark brown. Fin & -grained sand. & \\
\hline & & & 4 & & SANDY SILT AND CLAY. Bro & & \\
\hline & & & & & SANDY SILT. Yellowish brown & & \\
\hline 2 & 60 & & 6 & & SILTY SAND AND GRAVEL. & ellowish brown. Co & avel particles. \\
\hline & & $\boldsymbol{\nabla}$ & 8 & & SILTY GRAVEL. Yellowish br & wn. & \\
\hline 3 & 100 & & 10 & - & $\begin{array}{l}\text { SAND AND GRAVEL. Reddish } \\
\text { sand. Wet. }\end{array}$ & brown. Fine- to med & ained gravel and coarse \\
\hline & & & 12 & & $\begin{array}{l}\text { SILTY SAND. Light brown. Fin } \\
\text { redoximorphic features. Bottom }\end{array}$ & $\begin{array}{l}\text { - to medium-grainec } \\
\text { inches gray sand. }\end{array}$ & Common \\
\hline 4 & 100 & & 14 & - & $\begin{array}{l}\text { SAND AND GRAVEL. Light gr } \\
\text { fine-grained gravel. }\end{array}$ & y. Clean (low silt/cl & arse-grained sand and \\
\hline & & & 16 & - & $\begin{array}{l}\text { SILTY SAND AND GRAVEL. } \\
\text { features. Bottom } 3 \text { inches weath }\end{array}$ & $\begin{array}{l}\text { ight gray to yellowi } \\
\text { ed sedimentary rock }\end{array}$ & Nn. Redoximorphic \\
\hline & & & & & SANDY SILT. Light brown. We & & \\
\hline 5 & 100 & & 18 & & SAND AND GRAVEL. Yellow & h brown. Clean fine- & dium-grained gravel. \\
\hline & & & 20 & & SILTY SAND AND GRAVEL. & ight brown. Coarse & particles \\
\hline & & & & - & SANDY SILT. Light brown. We & & \\
\hline 6 & 100 & & & & SAND AND GRAVEL. Yellow & h brown. Clean fine- & dium-grained gravel. \\
\hline & & & 24 & & SILTY SAND AND GRAVEL. & ellowish brown. Co & avel particles. \\
\hline & & & & & SANDY SILT. Light brown. We & & \\
\hline 7 & 100 & & 26 & & $\begin{array}{l}\text { SAND AND GRAVEL. Gray. C } \\
\text { sand. }\end{array}$ & ean fine- to medium- & d gravel and coarse \\
\hline & & & 28 & & SILTY SAND AND GRAVEL. & rayish brown. One & ecomposing wood. \\
\hline & & & & 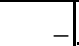 & SANDY SILT. Light brown. We & & \\
\hline 8 & 100 & & 30 & & $\begin{array}{l}\text { SAND AND GRAVEL. Gray. C } \\
\text { sand. }\end{array}$ & an fine- to medium- & d gravel and coarse \\
\hline & & & 32 & & SILTY SAND AND GRAVEL. & ray. Coarse gravel $\mathrm{p}$ & \\
\hline & & & & 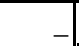 & SANDY SILT. Light brown. We & & \\
\hline 9 & 100 & & & & $\begin{array}{l}\text { SAND AND GRAVEL. Gray. C } \\
\text { sand. }\end{array}$ & ean fine- to medium- & d gravel and coarse \\
\hline & & & 36 & & SILTY SAND AND GRAVEL. & ray. Coarse gravel & \\
\hline
\end{tabular}

Figure B.6: Log of boring EB-6 (1 of 2). 


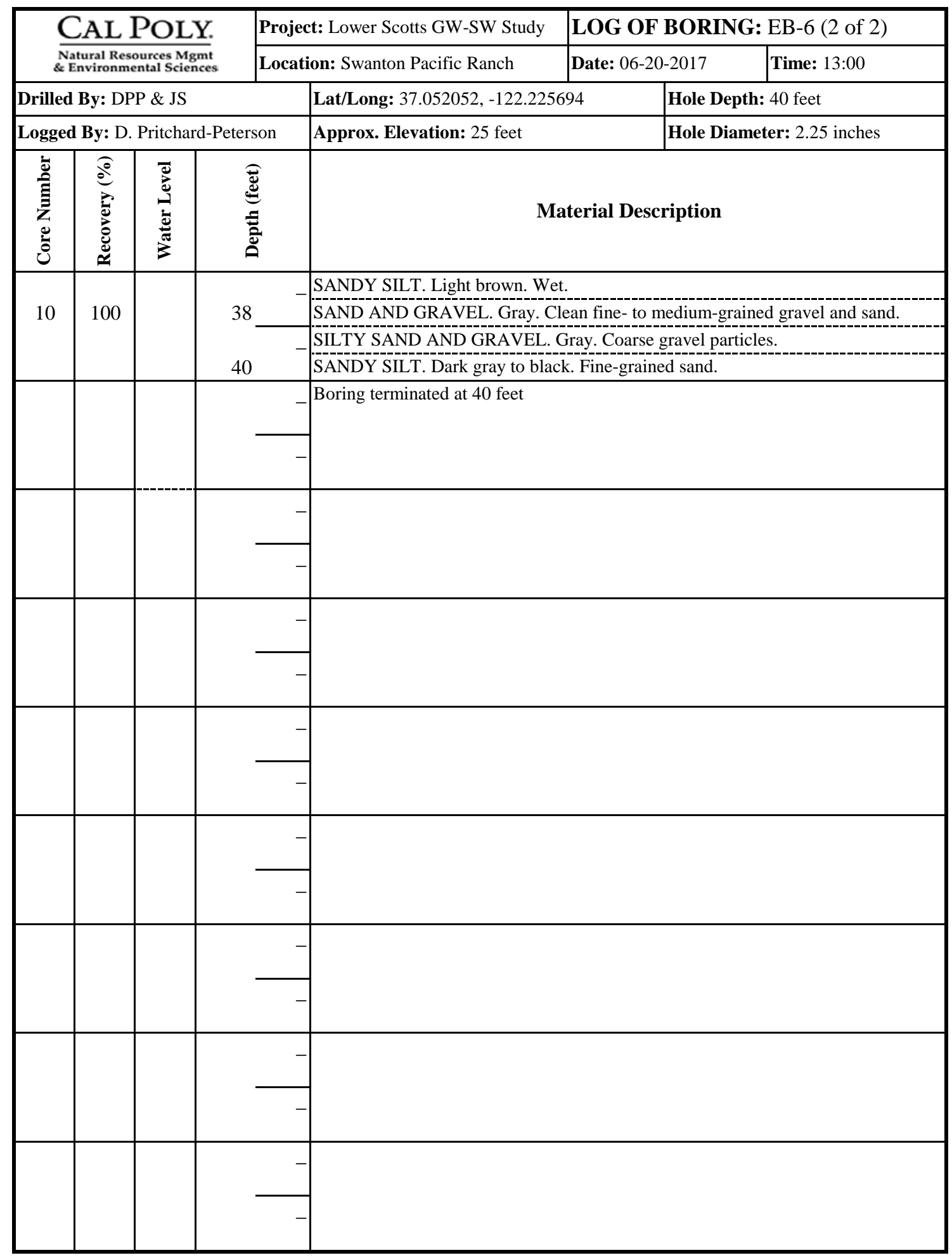

Figure B.7: Log of boring EB-6 (2 of 2). 


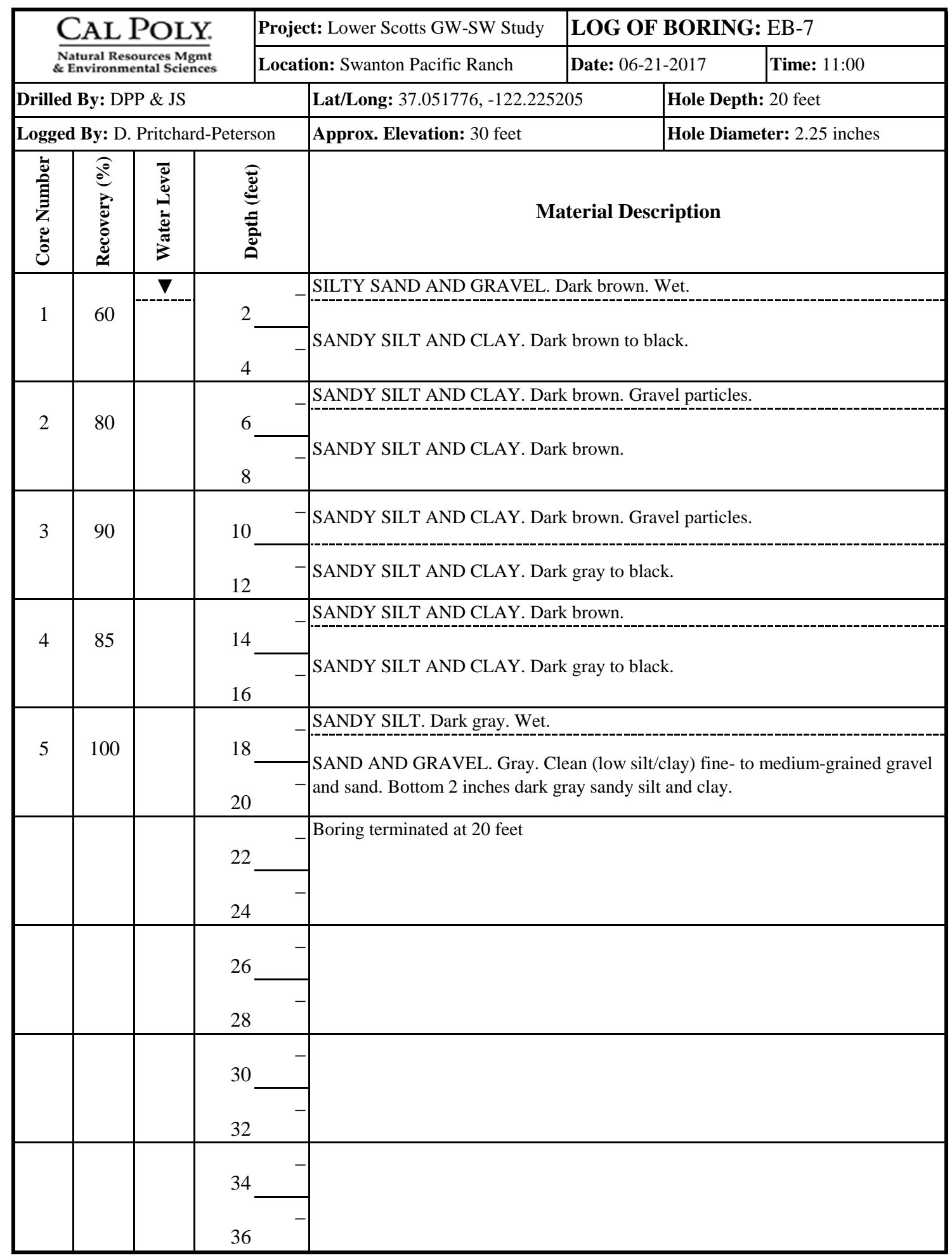

Figure B.8: Log of boring EB-7. 


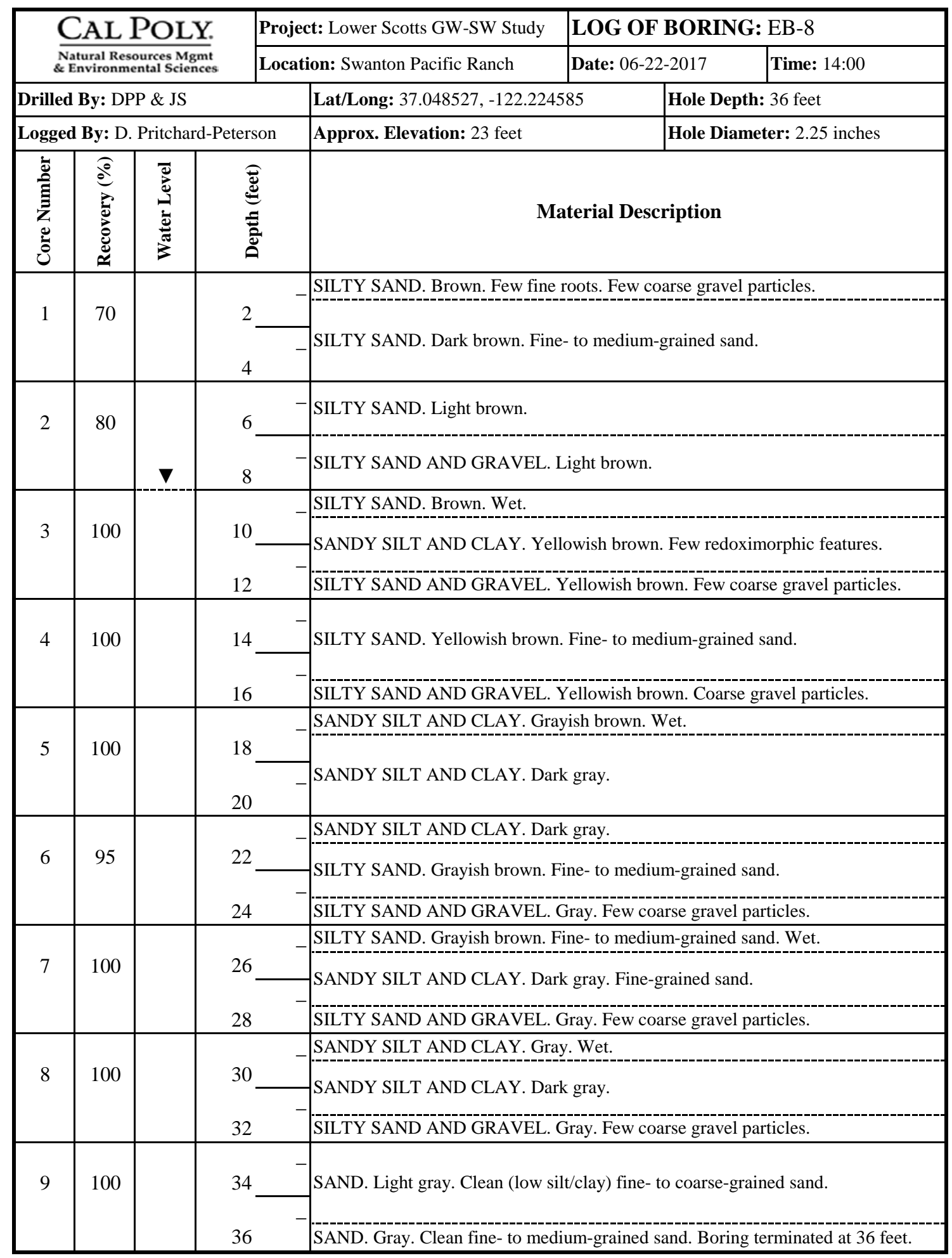

Figure B.9: Log of boring EB-8. 


\section{APPENDIX C: PIEZOMETER INSTALLATION}

Table C.1: Geographic location (latitude and longitude in decimal degrees) of each piezometer and each irrigation well.

\begin{tabular}{lc}
\hline Piezometer/Well ID & Lat/Long (decimal degrees) \\
\hline PHP-1 & $37.0508,-122.2264$ \\
PHP-2 & $37.0503,-122.2263$ \\
PHP-3 & $37.0506,-122.2264$ \\
PHP-4 & $37.0506,-122.2266$ \\
PHP-5 & $37.0512,-122.2265$ \\
VFDP-1 & $37.0485,-122.2265$ \\
VFDP-2 & $37.0484,-122.2265$ \\
VFDP-3 & $37.0483,-122.2266$ \\
VFDP-4 & $37.0492,-122.2266$ \\
JFP-1 & $37.0487,-122.2250$ \\
JFP-2 & $37.0521,-122.2257$ \\
JFP-3 & $37.0485,-122.2246$ \\
AP-1 & $37.0518,-122.2252$ \\
Arch-up & $37.0552,-122.2269$ \\
PH-up & $37.0510,-122.2270$ \\
PH-down & $37.0503,-122.2271$ \\
VFD-up & $37.0482,-122.2267$ \\
VFD-down & $37.0478,-122.2262$ \\
Archibald & $37.0534,-122.2261$ \\
Pump House & $37.0507,-122.2262$ \\
VFD & $37.0483,-122.2264$ \\
Queseria & $37.0455,-122.2258$ \\
\hline
\end{tabular}


APPENDIX D: PUMPING TESTS 
Table D.1: VFD Well pumping test flow rate (gpm) data.

\begin{tabular}{|c|c|c|c|c|c|}
\hline Date and Time & Flow & Date and Time & Flow & Date and Time & Flow \\
\hline $8 / 1 / 2016$ 15:12 & 136 & 8/1/2016 23:24 & 270 & $8 / 2 / 20167: 37$ & 271 \\
\hline $8 / 1 / 201615: 27$ & 274 & 8/1/2016 23:39 & 270 & $8 / 2 / 20167: 52$ & 268 \\
\hline $8 / 1 / 2016$ 15:42 & 272 & $8 / 1 / 201623: 55$ & 271 & 8/2/2016 8:08 & 268 \\
\hline $8 / 1 / 201615: 58$ & 273 & 8/2/2016 0:10 & 271 & $8 / 2 / 20168: 23$ & 270 \\
\hline $8 / 1 / 2016$ 16:13 & 274 & 8/2/2016 0:26 & 269 & 8/2/2016 8:38 & 270 \\
\hline $8 / 1 / 201616: 29$ & 274 & 8/2/2016 0:41 & 270 & $8 / 2 / 20168: 54$ & 269 \\
\hline $8 / 1 / 201616: 44$ & 272 & 8/2/2016 0:57 & 270 & 8/2/2016 9:09 & 271 \\
\hline $8 / 1 / 201616: 59$ & 272 & $8 / 2 / 20161: 12$ & 272 & $8 / 2 / 20169: 25$ & 269 \\
\hline $8 / 1 / 2016$ 17:14 & 271 & $8 / 2 / 20161: 28$ & 268 & 8/2/2016 9:40 & 269 \\
\hline $8 / 1 / 201617: 30$ & 270 & $8 / 2 / 20161: 43$ & 270 & 8/2/2016 9:56 & 270 \\
\hline $8 / 1 / 201617: 45$ & 270 & $8 / 2 / 20161: 58$ & 269 & 8/2/2016 10:11 & 271 \\
\hline $8 / 1 / 2016$ 18:01 & 270 & $8 / 2 / 20162: 14$ & 270 & $8 / 2 / 201610: 26$ & 270 \\
\hline $8 / 1 / 201618: 16$ & 271 & $8 / 2 / 20162: 29$ & 271 & $8 / 2 / 2016$ 10:42 & 270 \\
\hline $8 / 1 / 2016$ 18:31 & 271 & $8 / 2 / 20162: 45$ & 270 & $8 / 2 / 201610: 57$ & 270 \\
\hline $8 / 1 / 2016$ 18:47 & 271 & 8/2/2016 3:00 & 269 & $8 / 2 / 2016$ 11:12 & 271 \\
\hline 8/1/2016 19:02 & 271 & $8 / 2 / 20163: 16$ & 271 & $8 / 2 / 201611: 27$ & 270 \\
\hline $8 / 1 / 2016$ 19:17 & 271 & 8/2/2016 3:31 & 269 & $8 / 2 / 201611: 43$ & 270 \\
\hline $8 / 1 / 201619: 32$ & 271 & 8/2/2016 3:46 & 268 & $8 / 2 / 201611: 58$ & 270 \\
\hline $8 / 1 / 201619: 47$ & 271 & 8/2/2016 4:02 & 270 & $8 / 2 / 201612: 14$ & 269 \\
\hline $8 / 1 / 201620: 03$ & 270 & $8 / 2 / 20164: 17$ & 271 & $8 / 2 / 201612: 29$ & 271 \\
\hline $8 / 1 / 201620: 18$ & 268 & $8 / 2 / 20164: 33$ & 271 & $8 / 2 / 201612: 45$ & 270 \\
\hline $8 / 1 / 201620: 33$ & 270 & 8/2/2016 4:48 & 268 & $8 / 2 / 2016$ 13:00 & 270 \\
\hline 8/1/2016 20:49 & 269 & 8/2/2016 5:03 & 271 & $8 / 2 / 201613: 15$ & 270 \\
\hline $8 / 1 / 2016$ 21:04 & 272 & 8/2/2016 5:19 & 269 & $8 / 2 / 201613: 31$ & 272 \\
\hline $8 / 1 / 201621: 20$ & 269 & 8/2/2016 5:34 & 271 & $8 / 2 / 201613: 46$ & 268 \\
\hline $8 / 1 / 201621: 35$ & 270 & $8 / 2 / 20165: 49$ & 270 & $8 / 2 / 2016$ 14:01 & 270 \\
\hline $8 / 1 / 201621: 51$ & 270 & 8/2/2016 6:05 & 271 & $8 / 2 / 201614: 17$ & 270 \\
\hline $8 / 1 / 201622: 06$ & 268 & $8 / 2 / 20166: 20$ & 270 & $8 / 2 / 2016$ 14:32 & 271 \\
\hline $8 / 1 / 201622: 22$ & 269 & $8 / 2 / 20166: 35$ & 269 & $8 / 2 / 201614: 47$ & 272 \\
\hline $8 / 1 / 201622: 37$ & 269 & $8 / 2 / 20166: 51$ & 270 & $8 / 2 / 2016$ 15:02 & 271 \\
\hline $8 / 1 / 201622: 53$ & 272 & 8/2/2016 7:06 & 269 & $8 / 2 / 201615: 18$ & 163 \\
\hline 8/1/2016 23:08 & 270 & $8 / 2 / 2016 \quad 7: 21$ & 269 & & \\
\hline
\end{tabular}


Table D.2: Pump House Well pumping test flow rate (gpm) data.

\begin{tabular}{|c|c|c|c|c|c|}
\hline Date and Time & Flow & Date and Time & Flow & Date and Time & Flow \\
\hline $8 / 5 / 2016$ 14:09 & 184 & $8 / 5 / 201622: 19$ & 256 & $8 / 6 / 20166: 32$ & 255 \\
\hline $8 / 5 / 201614: 24$ & 258 & $8 / 5 / 201622: 34$ & 261 & 8/6/2016 6:48 & 263 \\
\hline $8 / 5 / 201614: 40$ & 243 & $8 / 5 / 201622: 49$ & 249 & 8/6/2016 7:03 & 251 \\
\hline $8 / 5 / 201614: 55$ & 272 & $8 / 5 / 201623: 04$ & 263 & $8 / 6 / 20167: 19$ & 264 \\
\hline $8 / 5 / 2016$ 15:11 & 267 & $8 / 5 / 201623: 20$ & 255 & $8 / 6 / 20167: 34$ & 253 \\
\hline $8 / 5 / 201615: 26$ & 256 & $8 / 5 / 201623: 35$ & 252 & $8 / 6 / 20167: 50$ & 256 \\
\hline $8 / 5 / 201615: 41$ & 249 & $8 / 5 / 201623: 50$ & 254 & 8/6/2016 8:05 & 267 \\
\hline $8 / 5 / 201615: 57$ & 255 & 8/6/2016 0:05 & 252 & 8/6/2016 8:21 & 244 \\
\hline $8 / 5 / 201616: 12$ & 233 & 8/6/2016 0:21 & 261 & 8/6/2016 8:36 & 266 \\
\hline $8 / 5 / 201616: 28$ & 228 & 8/6/2016 0:36 & 278 & $8 / 6 / 20168: 51$ & 256 \\
\hline $8 / 5 / 201616: 43$ & 246 & 8/6/2016 0:52 & 253 & 8/6/2016 9:06 & 262 \\
\hline $8 / 5 / 201616: 58$ & 254 & 8/6/2016 1:07 & 275 & 8/6/2016 9:21 & 254 \\
\hline $8 / 5 / 201617: 14$ & 234 & $8 / 6 / 20161: 23$ & 270 & 8/6/2016 9:37 & 267 \\
\hline $8 / 5 / 201617: 29$ & 253 & 8/6/2016 1:38 & 260 & 8/6/2016 9:52 & 259 \\
\hline $8 / 5 / 2016 \quad 17: 45$ & 246 & $8 / 6 / 20161: 54$ & 250 & 8/6/2016 10:07 & 252 \\
\hline $8 / 5 / 2016$ 18:00 & 249 & 8/6/2016 2:09 & 255 & $8 / 6 / 2016$ 10:23 & 249 \\
\hline $8 / 5 / 201618: 15$ & 261 & $8 / 6 / 20162: 25$ & 254 & $8 / 6 / 201610: 39$ & 251 \\
\hline $8 / 5 / 201618: 31$ & 243 & $8 / 6 / 20162: 40$ & 255 & $8 / 6 / 201610: 55$ & 280 \\
\hline $8 / 5 / 2016$ 18:46 & 236 & $8 / 6 / 20162: 56$ & 261 & $8 / 6 / 2016$ 11:10 & 251 \\
\hline 8/5/2016 19:01 & 228 & $8 / 6 / 20163: 11$ & 257 & $8 / 6 / 201611: 26$ & 251 \\
\hline $8 / 5 / 201619: 16$ & 263 & 8/6/2016 3:27 & 247 & $8 / 6 / 2016$ 11:41 & 256 \\
\hline $8 / 5 / 201619: 32$ & 277 & 8/6/2016 3:42 & 272 & $8 / 6 / 201611: 57$ & 272 \\
\hline $8 / 5 / 201619: 47$ & 220 & 8/6/2016 3:58 & 254 & $8 / 6 / 201612: 12$ & 265 \\
\hline $8 / 5 / 201620: 02$ & 215 & $8 / 6 / 20164: 13$ & 263 & $8 / 6 / 201612: 28$ & 260 \\
\hline $8 / 5 / 201620: 17$ & 240 & $8 / 6 / 20164: 29$ & 259 & $8 / 6 / 201612: 43$ & 264 \\
\hline $8 / 5 / 201620: 33$ & 237 & 8/6/2016 4:44 & 259 & $8 / 6 / 201612: 58$ & 242 \\
\hline $8 / 5 / 201620: 48$ & 259 & 8/6/2016 5:00 & 264 & $8 / 6 / 201613: 13$ & 244 \\
\hline $8 / 5 / 201621: 03$ & 241 & $8 / 6 / 20165: 15$ & 260 & $8 / 6 / 201613: 29$ & 267 \\
\hline $8 / 5 / 201621: 18$ & 251 & 8/6/2016 5:31 & 248 & $8 / 6 / 201613: 44$ & 257 \\
\hline $8 / 5 / 201621: 33$ & 243 & $8 / 6 / 20165: 46$ & 260 & $8 / 6 / 201613: 59$ & 240 \\
\hline $8 / 5 / 201621: 48$ & 299 & 8/6/2016 6:01 & 248 & & \\
\hline $8 / 5 / 201622: 04$ & 248 & $8 / 6 / 20166: 17$ & 253 & & \\
\hline
\end{tabular}




\section{APPENDIX E: DYE TRACING}

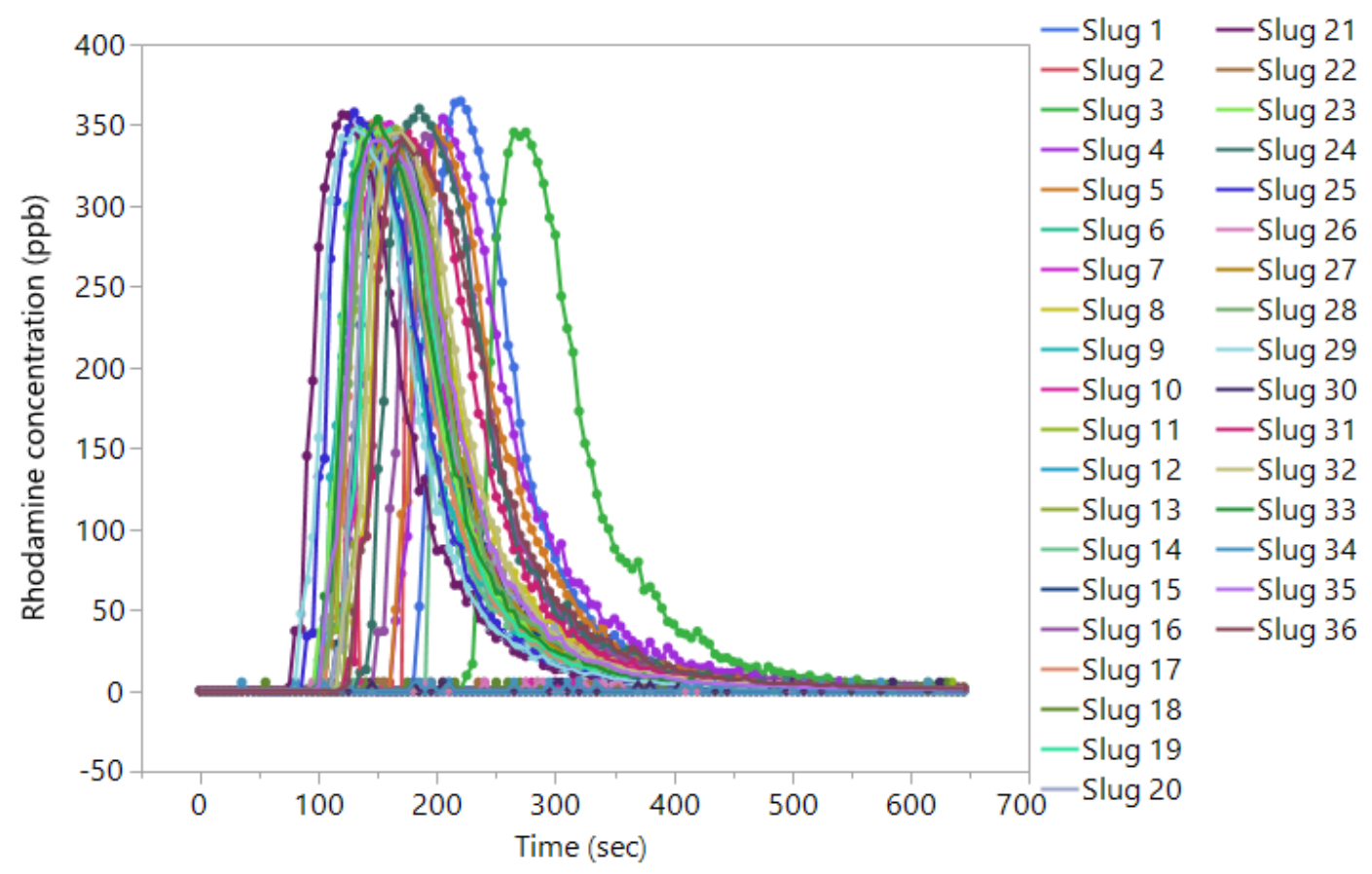

Figure E.1: Time-concentration curves for all 36 slug dye injections. Timeconcentration curves lacking bell-shaped curve are slug dye injections where low concentrations of Rhodamine dye were measured and are considered outliers. 


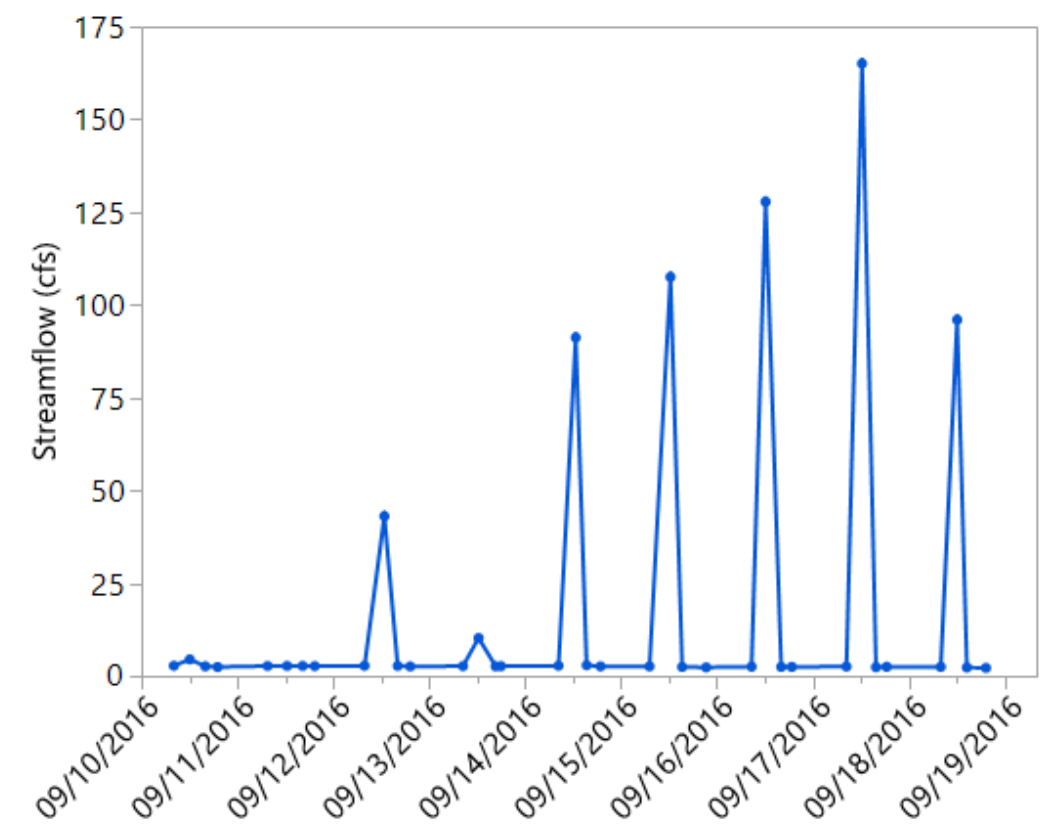

Figure E.2: Stream discharge (cfs) calculated from slug dye injection time-concentration curves. High discharge estimates correspond with slug dye injections considered outliers. 
APPENDIX F: PERMEAMETER TESTS 
Table F.1: Summary of flow test data for sediments from EB-1.

\begin{tabular}{|c|c|c|c|c|}
\hline Depth Range (ft) & File Name & $m$ & $\tau$ & $K(\mathrm{~m} / \mathrm{s})$ \\
\hline \multirow{3}{*}{$0-2$} & spreb100ft04132017 & $1.23 \times 10^{-2}$ & 81.30 & $4.77 \times 10^{-6}$ \\
\hline & spreb100ft04122017test1 & $1.50 \times 10^{-2}$ & 66.67 & $5.81 \times 10^{-6}$ \\
\hline & spreb100ft04122017test2 & $1.41 \times 10^{-2}$ & 70.92 & $5.46 \times 10^{-6}$ \\
\hline \multirow{3}{*}{$2-4$} & spreb102ft04042017 & $4.32 \times 10^{-3}$ & 231.48 & $1.67 \times 10^{-6}$ \\
\hline & spreb102ft04052017 & $4.07 \times 10^{-3}$ & 245.70 & $1.58 \times 10^{-6}$ \\
\hline & spreb102ft04062017 & $3.63 \times 10^{-3}$ & 275.48 & $1.41 \times 10^{-6}$ \\
\hline \multirow{3}{*}{$4-6$} & spreb104ft04032017 & $8.19 \times 10^{-2}$ & 12.21 & $3.17 \times 10^{-5}$ \\
\hline & spreb104ft04042017test 1 & $5.06 \times 10^{-2}$ & 19.76 & $1.96 \times 10^{-5}$ \\
\hline & spreb104ft04042017test2 & $4.29 \times 10^{-2}$ & 23.31 & $1.66 \times 10^{-5}$ \\
\hline \multirow{3}{*}{$6-8$} & spreb106ft03272017test1 & $1.54 \times 10^{-2}$ & 64.94 & $5.97 \times 10^{-6}$ \\
\hline & spreb106ft03272017test2 & $1.91 \times 10^{-2}$ & 52.36 & $7.40 \times 10^{-6}$ \\
\hline & spreb106ft03272017test3 & $1.72 \times 10^{-2}$ & 58.14 & $6.67 \times 10^{-6}$ \\
\hline \multirow{3}{*}{$8-10$} & spreb108ft03212017 & $8.20 \times 10^{-3}$ & 121.95 & $3.18 \times 10^{-6}$ \\
\hline & spreb108ft03222017 & $4.74 \times 10^{-3}$ & 210.97 & $1.84 \times 10^{-6}$ \\
\hline & spreb108ft03232017 & $2.96 \times 10^{-3}$ & 337.84 & $1.15 \times 10^{-6}$ \\
\hline \multirow{3}{*}{$10-12$} & spreb110ft04132017test1 & $4.91 \times 10^{-2}$ & 20.37 & $1.90 \times 10^{-5}$ \\
\hline & spreb110ft04132017test2 & $4.19 \times 10^{-2}$ & 23.87 & $1.62 \times 10^{-5}$ \\
\hline & spreb110ft04142017 & $3.68 \times 10^{-2}$ & 27.17 & $1.43 \times 10^{-5}$ \\
\hline \multirow{3}{*}{$12-14$} & spreb112ft06162017test1 & $1.20 \times 10^{-2}$ & 83.33 & $4.65 \times 10^{-6}$ \\
\hline & spreb112ft06162017test2 & $1.35 \times 10^{-2}$ & 74.07 & $5.23 \times 10^{-6}$ \\
\hline & spreb112ft06172017 & $1.58 \times 10^{-2}$ & 63.29 & $6.12 \times 10^{-6}$ \\
\hline \multirow{3}{*}{$14-16$} & spreb114ft02032017 & $1.01 \times 10^{-3}$ & 990.10 & $4.49 \times 10^{-6}$ \\
\hline & spreb114ft02072017 & $3.20 \times 10^{-4}$ & 3125.00 & $1.42 \times 10^{-6}$ \\
\hline & spreb114ft02122017 & $4.67 \times 10^{-4}$ & 2141.33 & $2.08 \times 10^{-6}$ \\
\hline \multirow{3}{*}{$16-20$} & spreb116ft04132017 & $5.63 \times 10^{-3}$ & 177.62 & $1.56 \times 10^{-6}$ \\
\hline & spreb116ft04142017 & $5.98 \times 10^{-3}$ & 167.22 & $1.66 \times 10^{-6}$ \\
\hline & spreb116ft04152017 & $8.24 \times 10^{-3}$ & 121.36 & $2.29 \times 10^{-6}$ \\
\hline \multirow{3}{*}{$20-24$} & spreb120ft01172017 & $7.74 \times 10^{-3}$ & 129.20 & $3.44 \times 10^{-5}$ \\
\hline & spreb120ft01182017 & $6.81 \times 10^{-3}$ & 146.84 & $3.03 \times 10^{-5}$ \\
\hline & spreb120ft01192017 & $5.01 \times 10^{-3}$ & 199.60 & $2.23 \times 10^{-5}$ \\
\hline
\end{tabular}


Table F.2: Summary of flow test data for sediments from EB-2.

\begin{tabular}{clcrc}
\hline Depth Range (ft) & \multicolumn{1}{c}{ File Name } & $m$ & $\tau$ & $K(\mathrm{~m} / \mathrm{s})$ \\
\hline \multirow{3}{*}{$0-6$} & spreb200ft06062017 & $3.58 \times 10^{-3}$ & 279.33 & $1.39 \times 10^{-6}$ \\
& spreb200ft06072017 & $3.05 \times 10^{-3}$ & 327.87 & $1.18 \times 10^{-6}$ \\
& spreb200ft06082017 & $6.86 \times 10^{-3}$ & 145.77 & $2.66 \times 10^{-6}$ \\
\hline \multirow{3}{*}{$6-12$} & spreb206ft05312017 & $3.74 \times 10^{-2}$ & 26.74 & $1.04 \times 10^{-5}$ \\
& spreb206ft06012017test1 & $2.06 \times 10^{-2}$ & 48.54 & $5.72 \times 10^{-6}$ \\
& spreb206ft06012017test2 & $1.96 \times 10^{-2}$ & 51.02 & $5.44 \times 10^{-6}$ \\
\hline \multirow{3}{*}{$20-22$} & spreb220ft04202017test1 & $2.66 \times 10^{-2}$ & 37.59 & $7.39 \times 10^{-6}$ \\
& spreb220ft04202017test2 & $2.93 \times 10^{-2}$ & 34.13 & $8.14 \times 10^{-6}$ \\
& spreb220ft04212017test1 & $2.87 \times 10^{-2}$ & 34.84 & $7.97 \times 10^{-6}$ \\
\hline \multirow{3}{*}{$22-24$} & spreb222ft05062017 & $7.89 \times 10^{-4}$ & 1267.43 & $3.06 \times 10^{-7}$ \\
& spreb222ft05092017 & $6.62 \times 10^{-4}$ & 1510.57 & $2.57 \times 10^{-7}$ \\
& spreb222ft05112017 & $5.77 \times 10^{-4}$ & 1733.10 & $2.24 \times 10^{-7}$ \\
\hline \multirow{3}{*}{$24-26$} & spreb224ft04252017 & $3.87 \times 10^{-3}$ & 258.40 & $1.50 \times 10^{-6}$ \\
& spreb224ft04262017 & $4.13 \times 10^{-3}$ & 242.13 & $1.60 \times 10^{-6}$ \\
& spreb224ft04272017 & $5.33 \times 10^{-3}$ & 187.62 & $2.07 \times 10^{-6}$ \\
\hline \multirow{3}{*}{$26-28$} & spreb226ft04202017 & $3.25 \times 10^{-3}$ & 307.69 & $1.26 \times 10^{-6}$ \\
& spreb226ft04222017 & $7.47 \times 10^{-3}$ & 133.87 & $2.89 \times 10^{-6}$ \\
& spreb226ft04242017 & $5.02 \times 10^{-3}$ & 199.20 & $1.95 \times 10^{-6}$ \\
\hline \multirow{2}{*}{$28-30$} & spreb228ft05152017 & $1.68 \times 10^{-3}$ & 595.24 & $6.51 \times 10^{-7}$ \\
& spreb228ft05172017 & $1.96 \times 10^{-3}$ & 510.20 & $7.60 \times 10^{-7}$ \\
& spreb228ft05182017 & $1.91 \times 10^{-3}$ & 523.56 & $7.40 \times 10^{-7}$ \\
\hline \multirow{3}{*}{$30-32$} & spreb230ft05222017 & $2.56 \times 10^{-3}$ & 390.63 & $9.92 \times 10^{-7}$ \\
& spreb230ft05232017 & $2.64 \times 10^{-3}$ & 378.79 & $1.02 \times 10^{-6}$ \\
& spreb230ft05262017 & $4.40 \times 10^{-3}$ & 227.27 & $1.71 \times 10^{-6}$ \\
\hline \multirow{3}{*}{$\sim 32$} & spreb232ft05302017test1 & $7.87 \times 10^{-2}$ & 12.71 & $2.19 \times 10^{-5}$ \\
& spreb232ft05302017test2 & $8.17 \times 10^{-2}$ & 12.24 & $2.27 \times 10^{-5}$ \\
& spreb232ft05312017 & $7.96 \times 10^{-2}$ & 12.56 & $2.21 \times 10^{-5}$ \\
\hline & & & & \\
\hline
\end{tabular}


Table F.3: Summary of flow test data for sediments from EB-3.

\begin{tabular}{clcrc}
\hline Depth Range (ft) & \multicolumn{1}{c}{ File Name } & $m$ & $\tau$ & $K(\mathrm{~m} / \mathrm{s})$ \\
\hline \multirow{3}{*}{$12-14$} & spreb312ft04262017test2 & $2.85 \times 10^{-2}$ & 35.09 & $7.92 \times 10^{-6}$ \\
& spreb312ft04272017test1 & $2.18 \times 10^{-2}$ & 45.87 & $6.06 \times 10^{-6}$ \\
& spreb312ft04272017test2 & $2.21 \times 10^{-2}$ & 45.25 & $6.14 \times 10^{-6}$ \\
\hline \multirow{3}{*}{$14-16$} & spreb314ft06122017 & $6.66 \times 10^{-3}$ & 150.15 & $2.58 \times 10^{-6}$ \\
& spreb314ft06132017 & $3.60 \times 10^{-3}$ & 277.78 & $1.40 \times 10^{-6}$ \\
& spreb314ft06142017 & $4.13 \times 10^{-3}$ & 242.13 & $1.60 \times 10^{-6}$ \\
\hline \multirow{3}{*}{$16-18$} & spreb316ft05032017test1 & $9.10 \times 10^{-3}$ & 109.89 & $3.53 \times 10^{-6}$ \\
& spreb316ft05032017test2 & $9.14 \times 10^{-3}$ & 109.41 & $3.54 \times 10^{-6}$ \\
& spreb316ft05042017 & $8.56 \times 10^{-3}$ & 116.82 & $3.32 \times 10^{-6}$ \\
\hline \multirow{3}{*}{$18-20$} & spreb318ft04252017test1 & $1.50 \times 10^{-1}$ & 6.67 & $4.17 \times 10^{-5}$ \\
& spreb318ft04252017test2 & $1.36 \times 10^{-1}$ & 7.35 & $3.78 \times 10^{-5}$ \\
& spreb318ft04252017test3 & $1.41 \times 10^{-1}$ & 7.09 & $3.92 \times 10^{-5}$ \\
\hline \multirow{2}{*}{$20-24$} & spreb320ft04242017test1 & $2.26 \times 10^{-2}$ & 44.25 & $6.28 \times 10^{-6}$ \\
& spreb320ft04242017test2 & $2.27 \times 10^{-2}$ & 44.05 & $6.31 \times 10^{-6}$ \\
& spreb320ft04252017 & $2.26 \times 10^{-2}$ & 44.25 & $6.28 \times 10^{-6}$ \\
\hline
\end{tabular}


Table F.4: Summary of flow test data for sediments from EB-4.

\begin{tabular}{clcrc}
\hline Depth Range (ft) & \multicolumn{1}{c}{ File Name } & $m$ & \multicolumn{1}{c}{$\tau$} & $K(\mathrm{~m} / \mathrm{s})$ \\
\hline \multirow{3}{*}{$0-2$} & spreb400ft05052017 & $6.37 \times 10^{-3}$ & 156.99 & $1.77 \times 10^{-6}$ \\
& spreb400ft05062017 & $5.66 \times 10^{-3}$ & 176.68 & $1.57 \times 10^{-6}$ \\
& spreb400ft05072017 & $4.49 \times 10^{-3}$ & 222.72 & $1.25 \times 10^{-6}$ \\
\hline \multirow{3}{*}{$2-4$} & spreb402ft05032017 & $1.57 \times 10^{-2}$ & 63.69 & $4.36 \times 10^{-6}$ \\
& spreb402ft05042017test1 & $1.01 \times 10^{-2}$ & 99.01 & $2.81 \times 10^{-6}$ \\
& spreb402ft05042017test2 & $6.90 \times 10^{-3}$ & 144.93 & $1.92 \times 10^{-6}$ \\
\hline \multirow{3}{*}{$4-6$} & spreb404ft05082017test1 & $2.25 \times 10^{-2}$ & 44.44 & $6.25 \times 10^{-6}$ \\
& spreb404ft05082017test2 & $2.34 \times 10^{-2}$ & 42.74 & $6.50 \times 10^{-6}$ \\
& spreb404ft05092017 & $2.80 \times 10^{-2}$ & 35.71 & $7.78 \times 10^{-6}$ \\
\hline \multirow{3}{*}{$6-8$} & spreb406ft05092017test1 & $1.81 \times 10^{-2}$ & 55.25 & $5.03 \times 10^{-6}$ \\
& spreb406ft05092017test2 & $1.70 \times 10^{-2}$ & 58.82 & $4.72 \times 10^{-6}$ \\
& spreb406ft05102017 & $1.04 \times 10^{-2}$ & 96.15 & $2.89 \times 10^{-6}$ \\
\hline \multirow{3}{*}{$8-12$} & spreb408ft05162017 & $8.72 \times 10^{-3}$ & 114.68 & $2.42 \times 10^{-6}$ \\
& spreb408ft05172017 & $1.25 \times 10^{-2}$ & 80.00 & $3.47 \times 10^{-6}$ \\
& spreb408ft05182017 & $5.63 \times 10^{-3}$ & 177.62 & $1.56 \times 10^{-6}$ \\
\hline \multirow{2}{*}{$16-18$} & spreb416ft05312017 & $5.83 \times 10^{-4}$ & 1715.27 & $2.26 \times 10^{-7}$ \\
& spreb416ft06022017 & $5.30 \times 10^{-4}$ & 1886.79 & $2.05 \times 10^{-7}$ \\
& spreb416ft06042017 & $1.37 \times 10^{-3}$ & 729.93 & $5.31 \times 10^{-7}$ \\
\hline \multirow{2}{*}{$18-20$} & spreb418ft05232017test1 & $2.90 \times 10^{-2}$ & 34.48 & $8.06 \times 10^{-6}$ \\
& spreb418ft05232017test2 & $2.84 \times 10^{-2}$ & 35.21 & $7.89 \times 10^{-6}$ \\
& spreb418ft05242017 & $2.09 \times 10^{-2}$ & 47.85 & $5.81 \times 10^{-6}$ \\
\hline & spreb420ft05242017 & $2.58 \times 10^{-2}$ & 38.76 & $7.17 \times 10^{-6}$ \\
& spreb420ft05252017 & $1.78 \times 10^{-2}$ & 56.18 & $4.94 \times 10^{-6}$ \\
& spreb420ft05262017 & $1.45 \times 10^{-2}$ & 68.97 & $4.03 \times 10^{-6}$ \\
\hline & & & & \\
& & &
\end{tabular}


Table F.5: Summary of flow test data for sediments from EB-5.

\begin{tabular}{cllrc}
\hline Depth Range (ft) & \multicolumn{1}{c}{ File Name } & \multicolumn{1}{c}{$m$} & $\tau$ & $K(\mathrm{~m} / \mathrm{s})$ \\
\hline \multirow{3}{*}{$14-16$} & spreb514ft07042017 & $1.44 \times 10^{-2}$ & 69.44 & $4.00 \times 10^{-6}$ \\
& spreb514ft07052017 & $2.31 \times 10^{-2}$ & 43.29 & $6.42 \times 10^{-6}$ \\
& spreb514ft07062017 & $2.30 \times 10^{-2}$ & 43.48 & $6.39 \times 10^{-6}$ \\
\hline \multirow{3}{*}{$32-34$} & spreb532ft06302017test1 & $1.53 \times 10^{-1}$ & 6.54 & $4.25 \times 10^{-5}$ \\
& spreb532ft06302017test2 & $1.67 \times 10^{-1}$ & 5.99 & $4.64 \times 10^{-5}$ \\
& spreb532ft07022017 & $1.60 \times 10^{-1}$ & 6.25 & $4.44 \times 10^{-5}$ \\
\hline \multirow{3}{*}{$36-38$} & spreb536ft06302017 & $6.36 \times 10^{-4}$ & 1572.33 & $2.46 \times 10^{-7}$ \\
& spreb536ft07042017 & $7.09 \times 10^{-4}$ & 1410.44 & $2.75 \times 10^{-7}$ \\
& spreb536ft07062017 & $8.39 \times 10^{-4}$ & 1191.90 & $3.25 \times 10^{-7}$ \\
\hline
\end{tabular}

Table F.6: Summary of flow test data for sediments from EB-6.

\begin{tabular}{clccc}
\hline Depth Range (ft) & File Name & $m$ & $\tau$ & $K(\mathrm{~m} / \mathrm{s})$ \\
\hline \multirow{3}{*}{$8-10$} & spreb608ft07162017test1 & $3.38 \times 10^{-3}$ & 295.86 & $7.86 \times 10^{-5}$ \\
& spreb608ft07162017test2 & $3.80 \times 10^{-3}$ & 263.16 & $8.84 \times 10^{-5}$ \\
& spreb608ft07162017test3 & $3.49 \times 10^{-3}$ & 286.53 & $8.11 \times 10^{-5}$ \\
\hline \multirow{3}{*}{$10-12$} & spreb610ft07162017 & $2.13 \times 10^{-3}$ & 469.48 & $5.92 \times 10^{-7}$ \\
& spreb610ft07312017 & $6.24 \times 10^{-3}$ & 160.26 & $1.73 \times 10^{-6}$ \\
& spreb610ft08012017 & $2.42 \times 10^{-3}$ & 413.22 & $6.72 \times 10^{-7}$ \\
\hline \multirow{3}{*}{$36-38$} & spreb636ft07112017 & $3.38 \times 10^{-2}$ & 29.59 & $9.39 \times 10^{-6}$ \\
& spreb636ft07122017test1 & $2.72 \times 10^{-2}$ & 36.76 & $7.56 \times 10^{-6}$ \\
& spreb636ft07122017test2 & $3.42 \times 10^{-2}$ & 29.24 & $9.50 \times 10^{-6}$ \\
\hline
\end{tabular}

Table F.7: Summary of flow test data for sediments from EB-7.

\begin{tabular}{ccccc}
\hline Depth Range (ft) & File Name & $m$ & $\tau$ & $K(\mathrm{~m} / \mathrm{s})$ \\
\hline \multirow{3}{*}{$18-20$} & spreb718ft07162017test1 & $4.07 \times 10^{-3}$ & 245.70 & $6.78 \times 10^{-5}$ \\
& spreb718ft07162017test2 & $4.01 \times 10^{-3}$ & 249.38 & $6.68 \times 10^{-5}$ \\
& spreb718ft07162017test3 & $4.12 \times 10^{-3}$ & 242.72 & $6.87 \times 10^{-5}$ \\
\hline
\end{tabular}


Table F.8: Summary of flow test data for sediments from EB-8.

\begin{tabular}{clcrc}
\hline Depth Range (ft) & \multicolumn{1}{c}{ File Name } & $m$ & $\tau$ & $K(\mathrm{~m} / \mathrm{s})$ \\
\hline $18-20$ & spreb818ft07262017 & $1.48 \times 10^{-4}$ & 6756.76 & $5.74 \times 10^{-8}$ \\
\hline \multirow{3}{*}{$32-34$} & spreb832ft07162017 & $1.53 \times 10^{-2}$ & 65.36 & $5.93 \times 10^{-6}$ \\
& spreb832ft07172017test1 & $1.46 \times 10^{-2}$ & 68.49 & $5.66 \times 10^{-6}$ \\
& spreb832ft07172017test2 & $1.64 \times 10^{-2}$ & 60.98 & $6.36 \times 10^{-6}$ \\
\hline
\end{tabular}




\section{APPENDIX G: PARTICLE SIZE ANALYSIS}

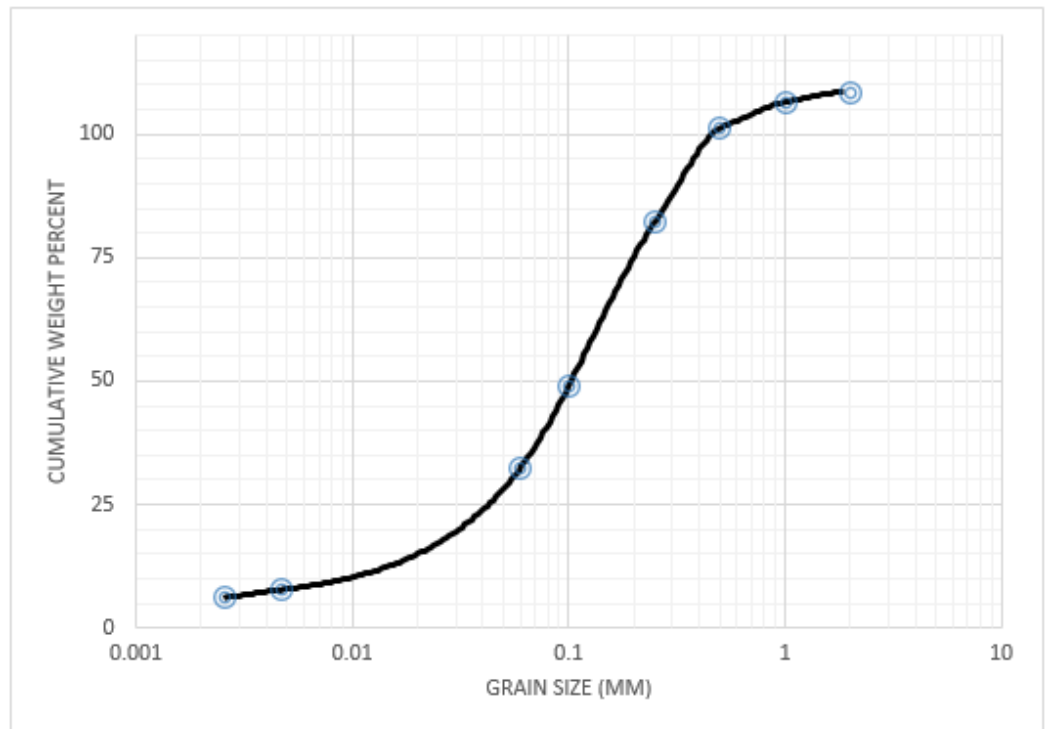

Figure G.1: Particle size distribution for sediments from 0-4 ft interval of EB-1. 


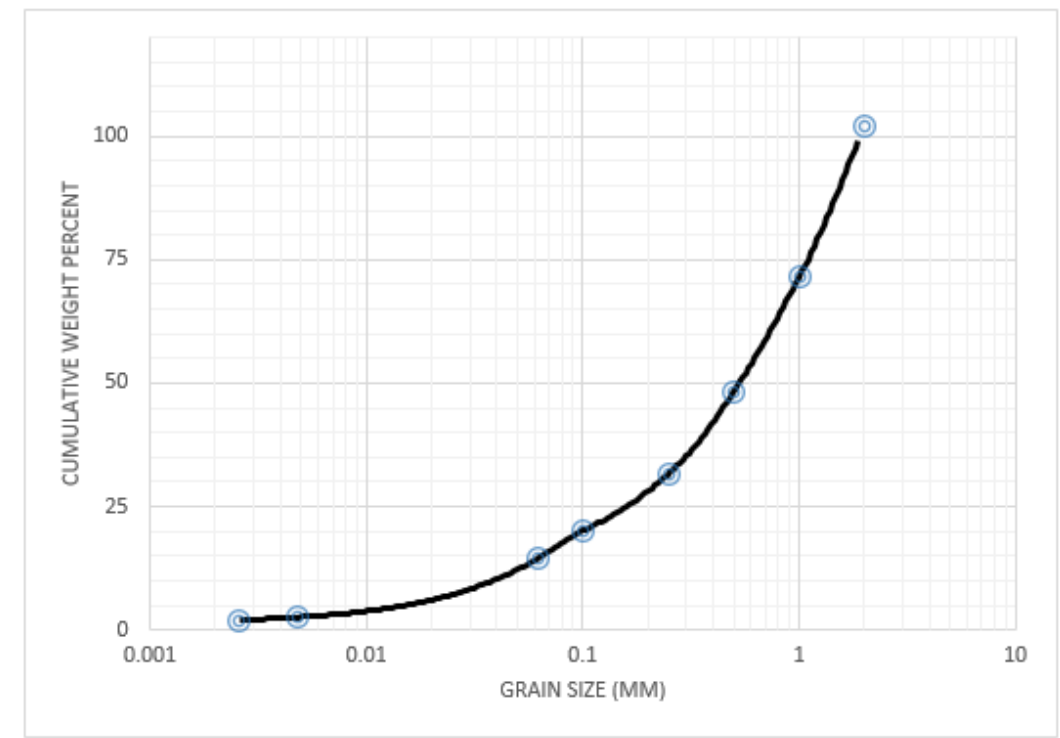

Figure G.2: Particle size distribution for sediments from 8-12 ft interval of EB-1.

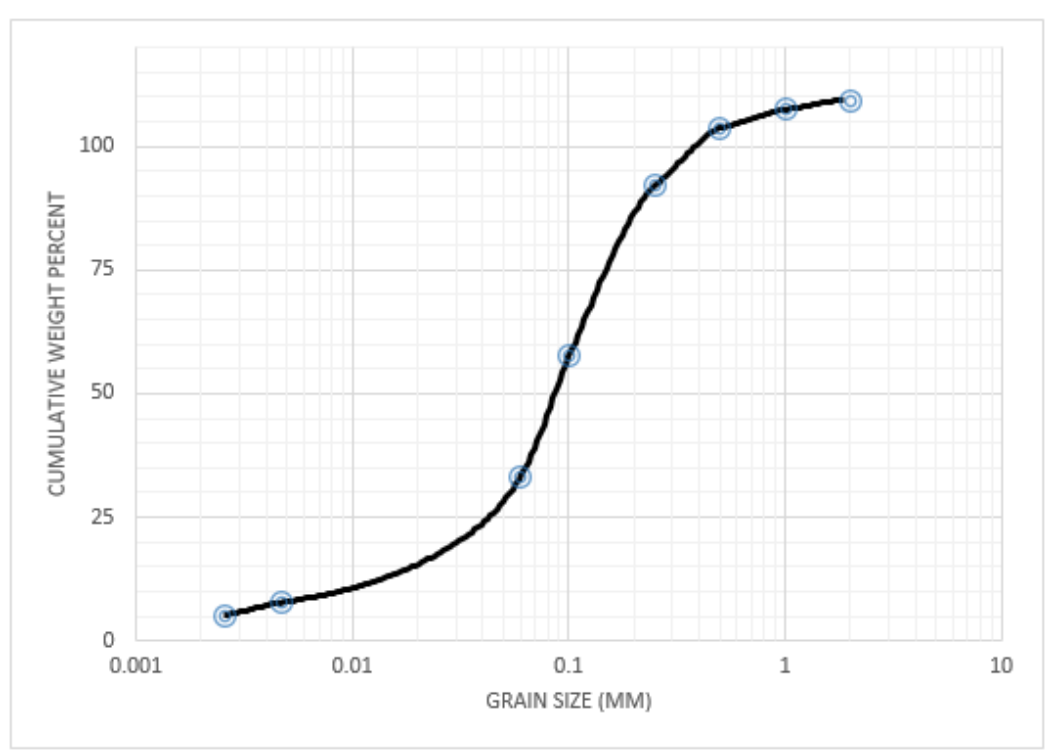

Figure G.3: Particle size distribution for sediments from 12-14 ft interval of EB-1. 


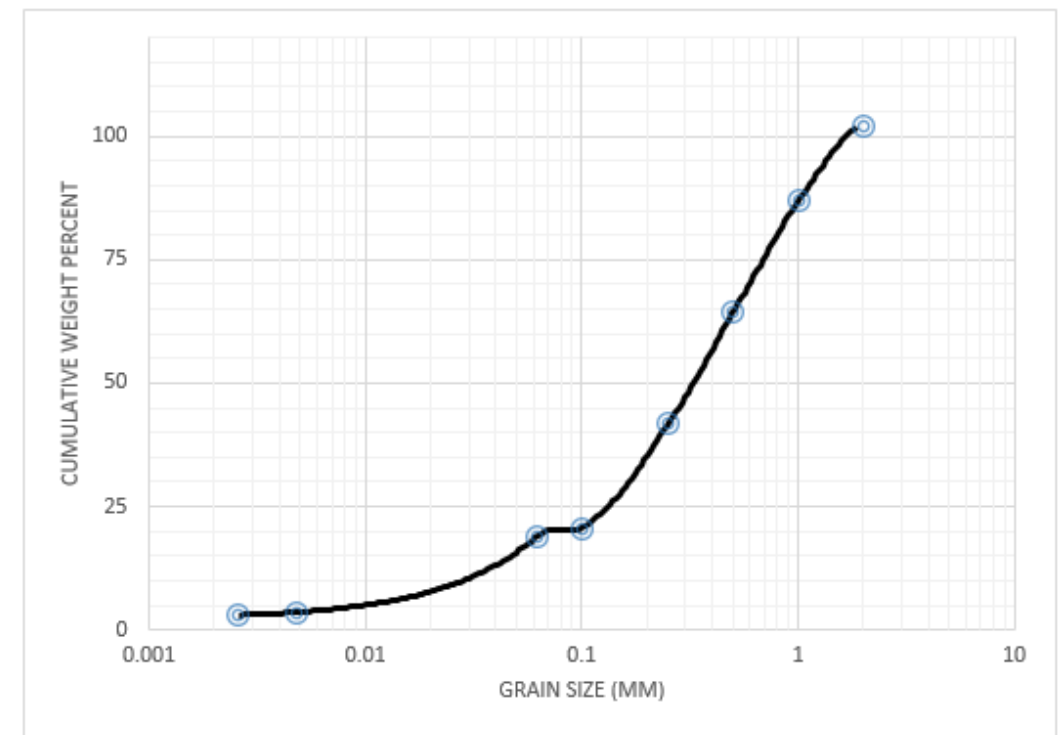

Figure G.4: Particle size distribution for sediments from 14-16 ft interval of EB-1.

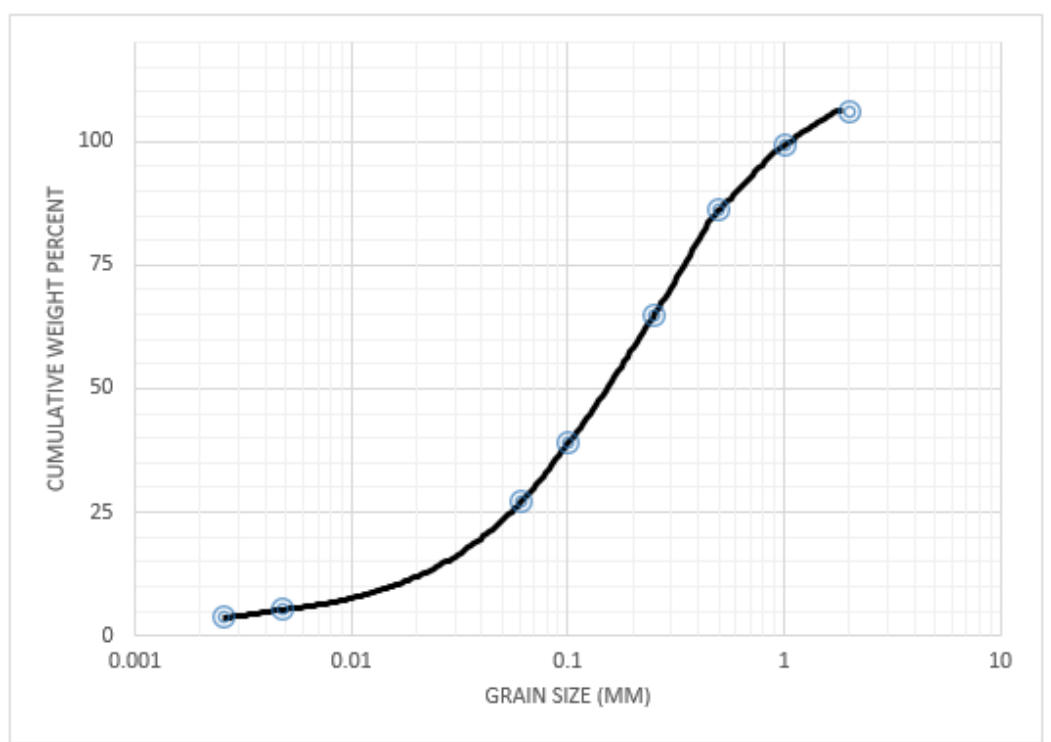

Figure G.5: Particle size distribution for sediments from 0-4 ft interval of EB-2. 


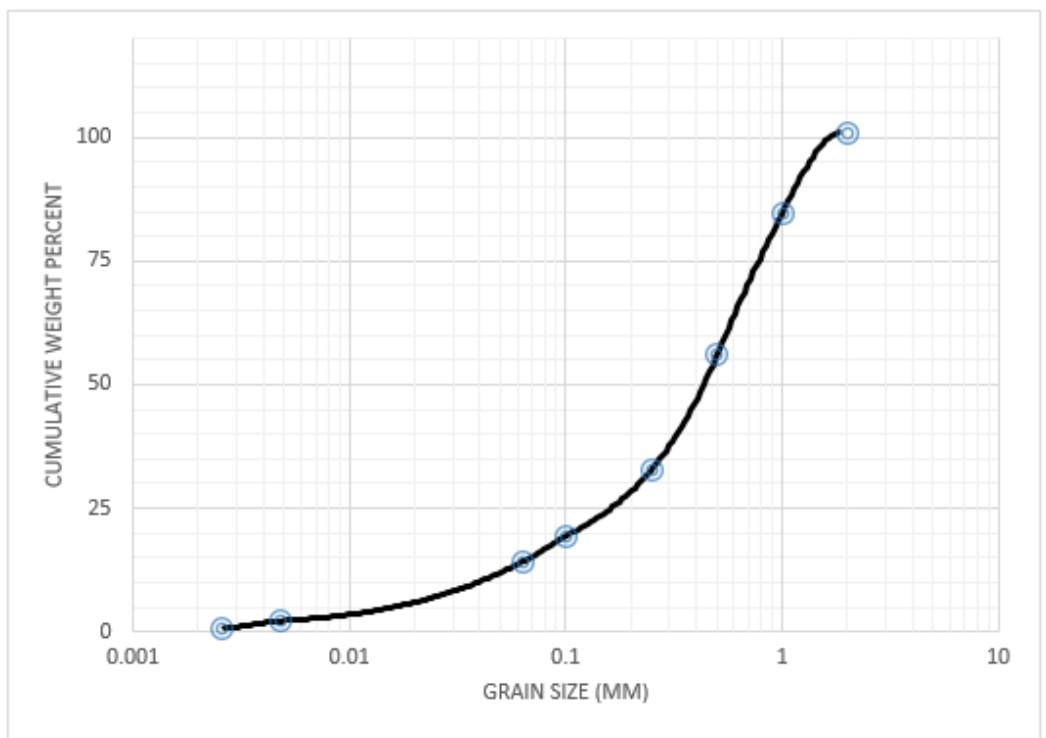

Figure G.6: Particle size distribution for sediments from 4-12 ft interval of EB-2.

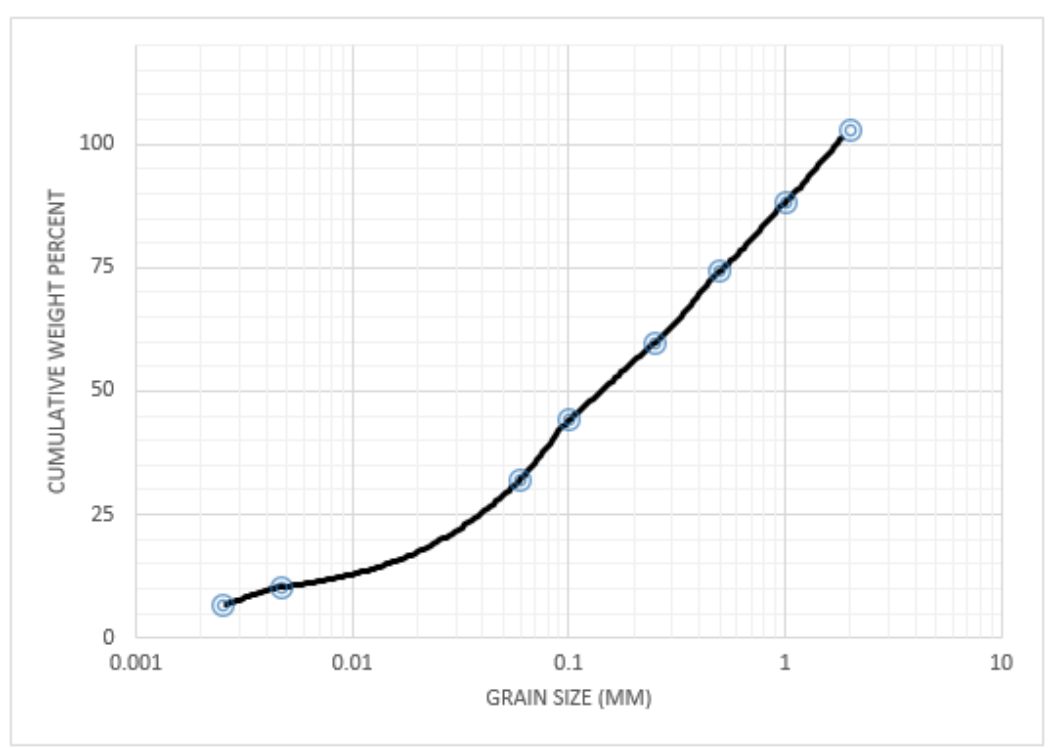

Figure G.7: Particle size distribution for sediments from 20-21 ft interval of EB-2. 


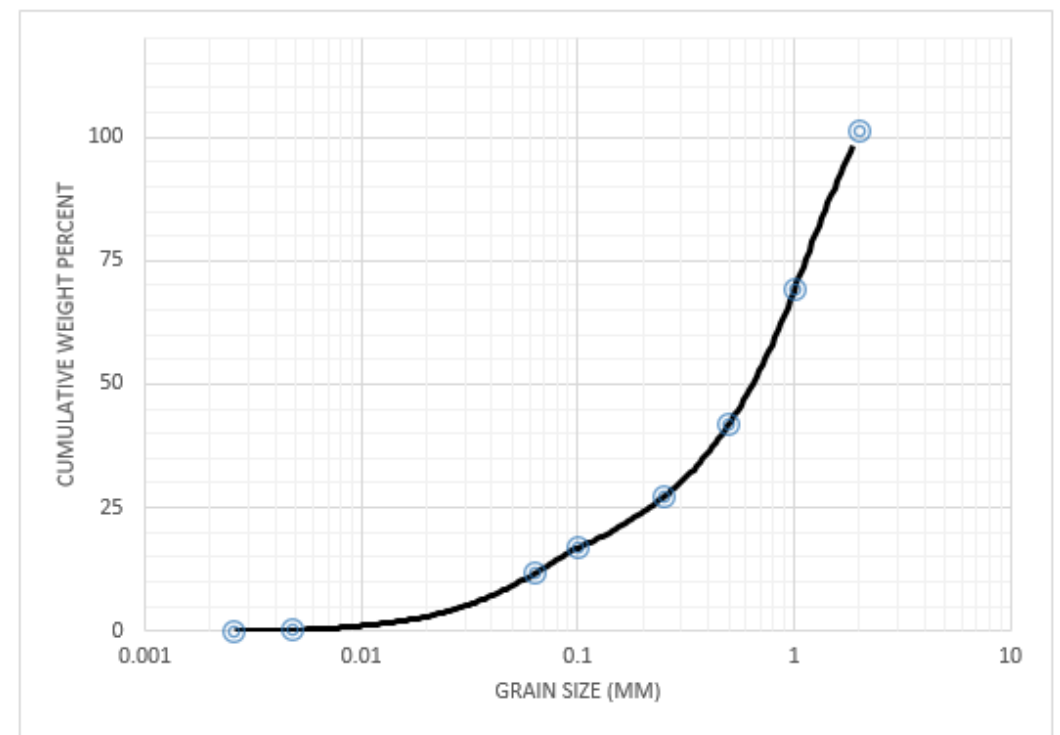

Figure G.8: Particle size distribution for sediments from 21-23 ft interval of EB-2.

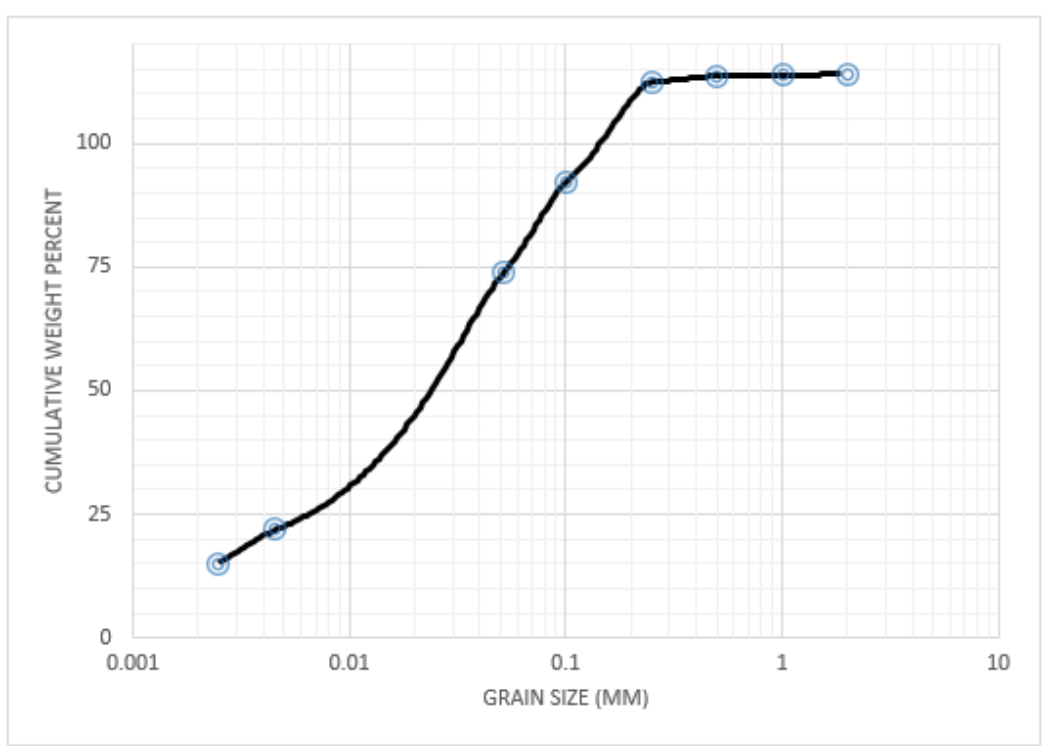

Figure G.9: Particle size distribution for sediments from 23-24 ft interval of EB-2. 


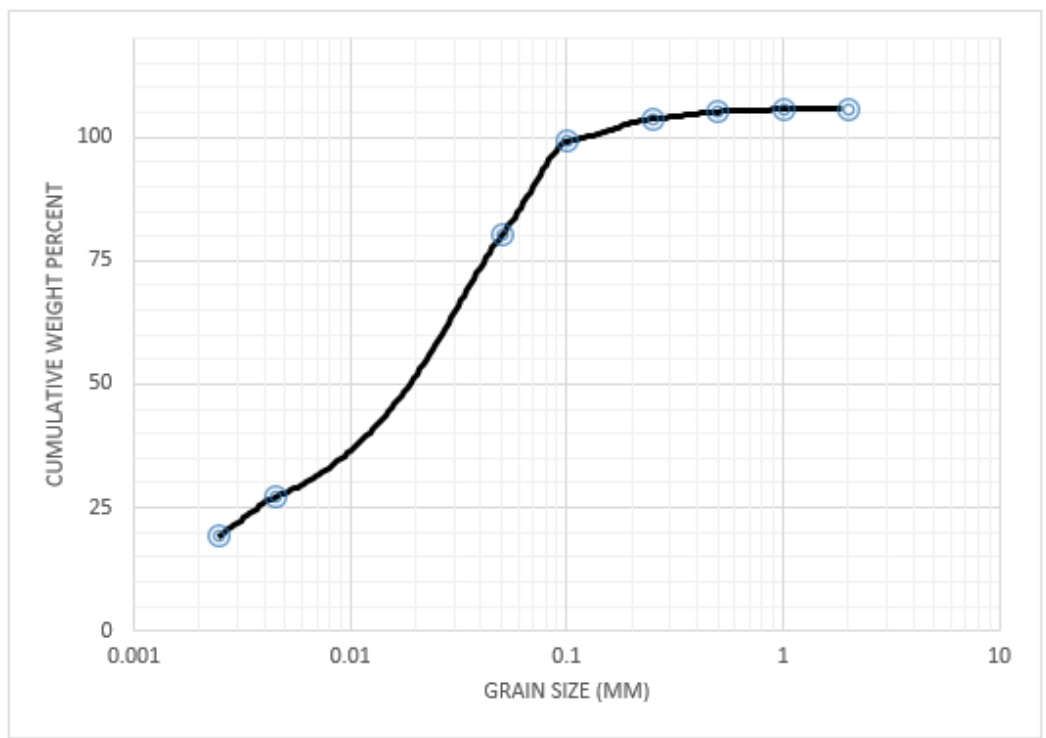

Figure G.10: Particle size distribution for sediments from 24-28 ft interval of EB-2.

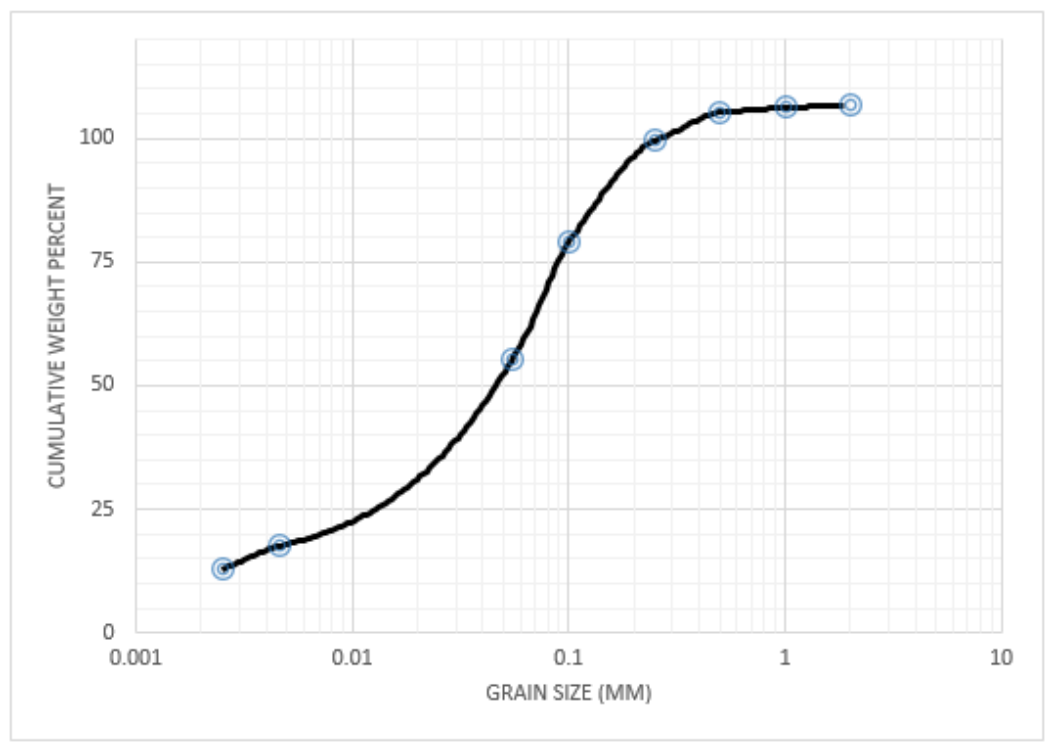

Figure G.11: Particle size distribution for sediments from 28-30 ft interval of EB-2. 


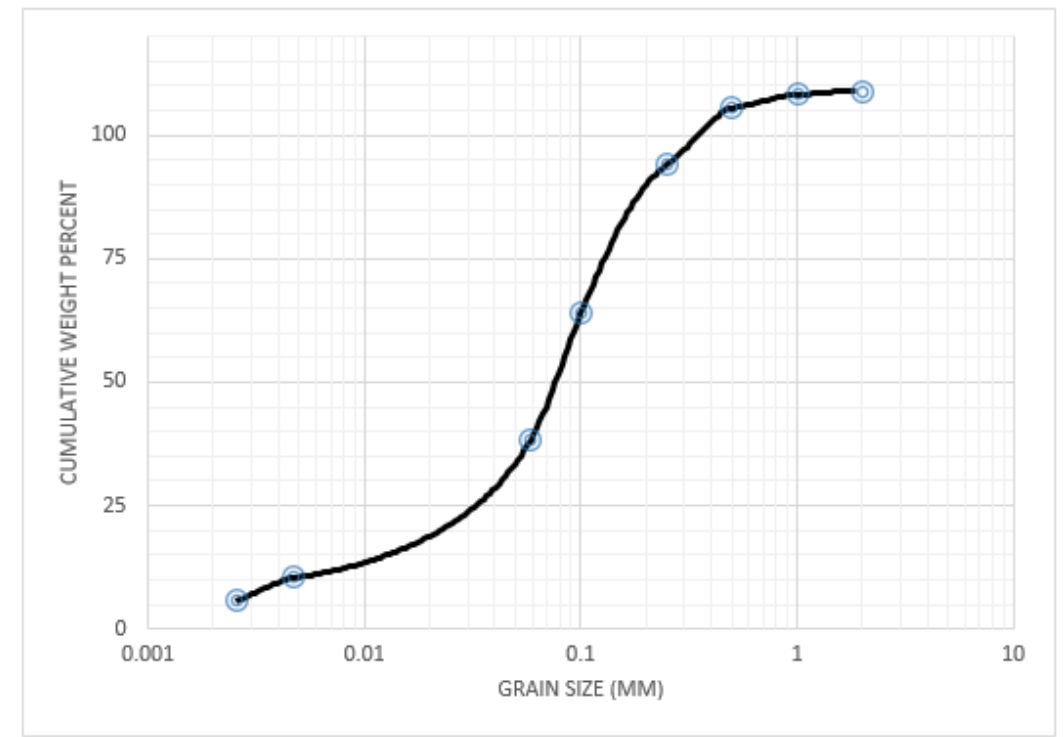

Figure G.12: Particle size distribution for sediments from 30-32 ft interval of EB-2.

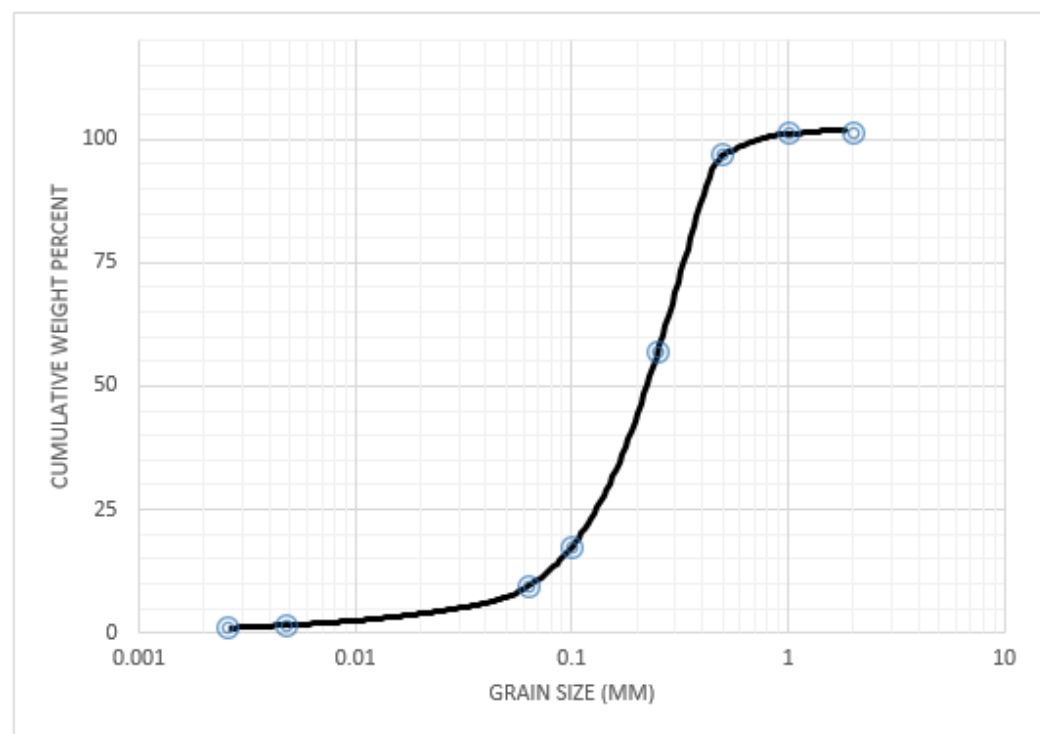

Figure G.13: Particle size distribution for heaved sediments from approx. $32 \mathrm{ft}$ of EB-2. 


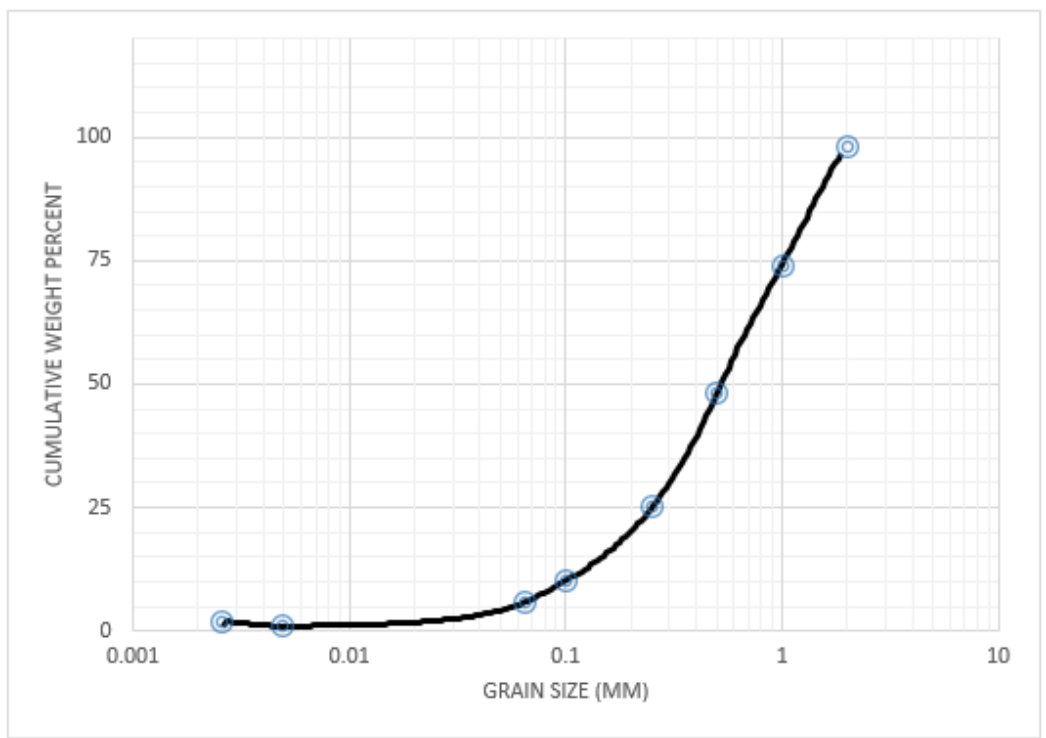

Figure G.14: Particle size distribution for sediments from 12-14 ft interval of EB-3.

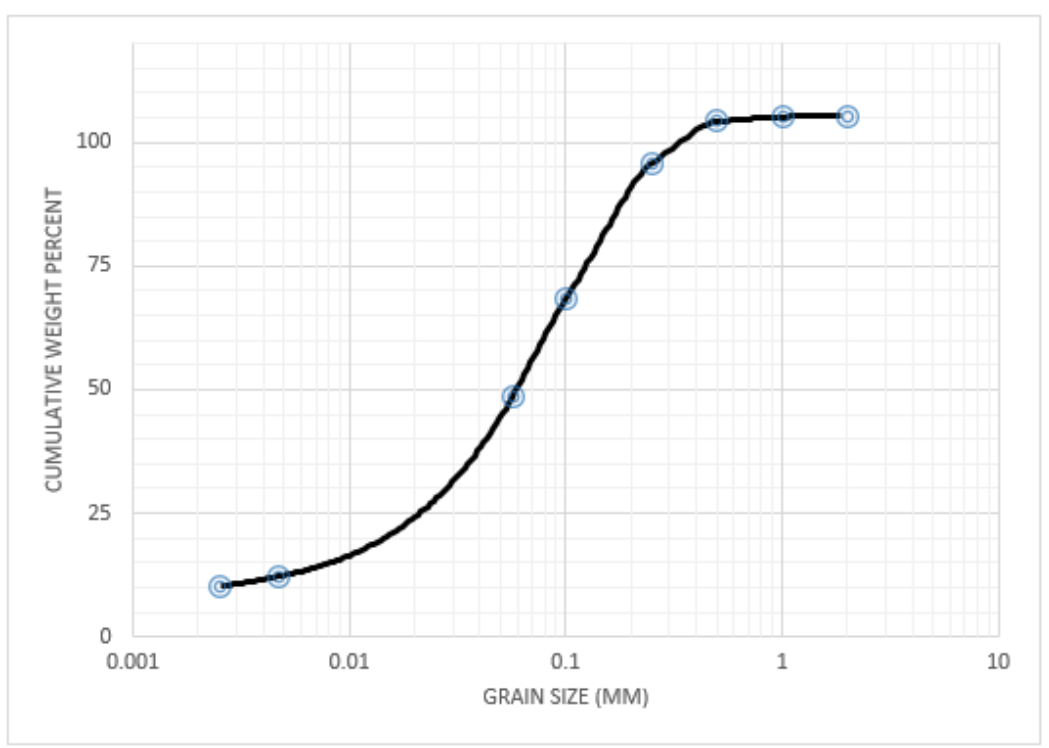

Figure G.15: Particle size distribution for sediments from 14-16 ft interval of EB-3. 


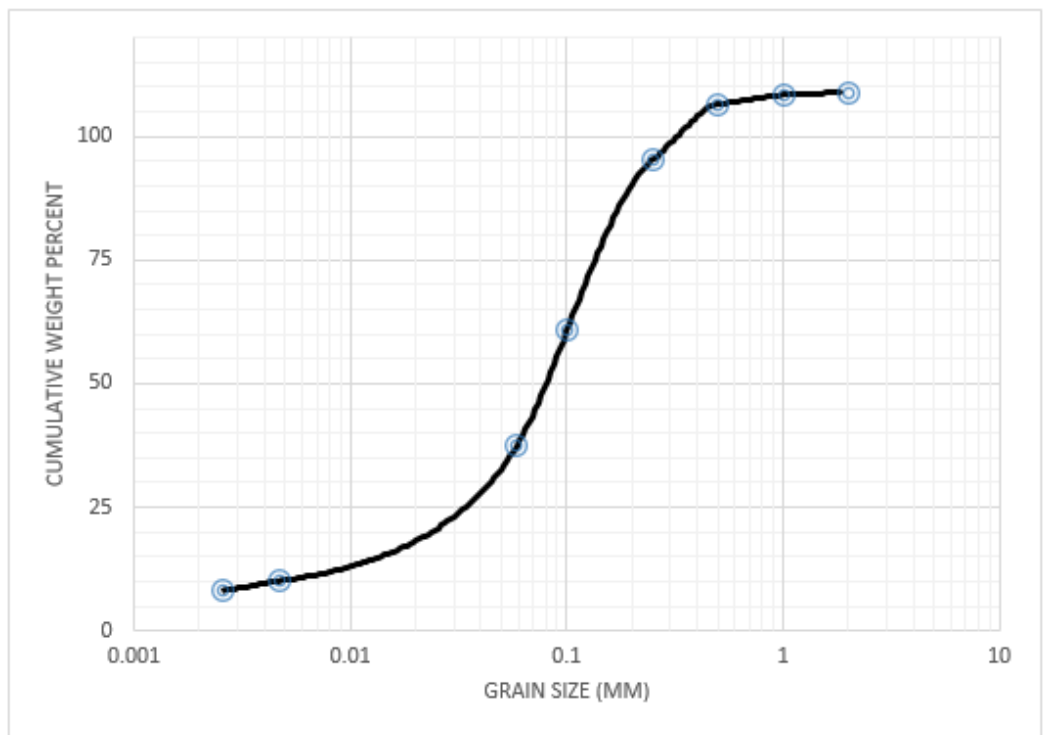

Figure G.16: Particle size distribution for sediments from 16-19 ft interval of EB-3.

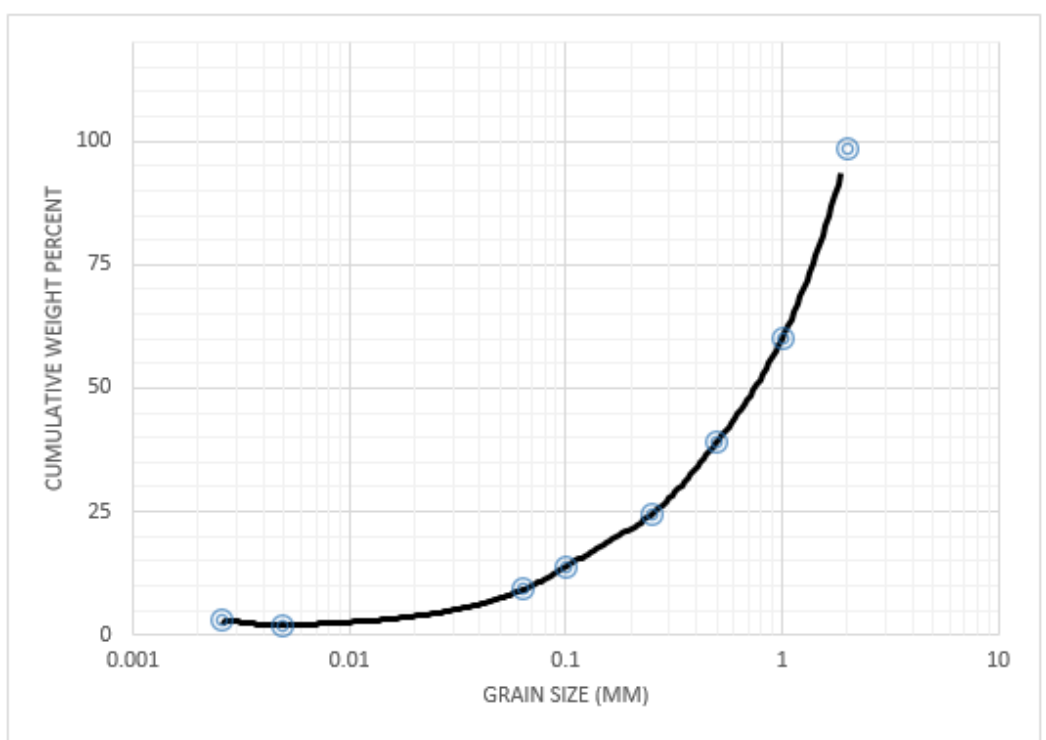

Figure G.17: Particle size distribution for sediments from 19-20 ft interval of EB-3. 


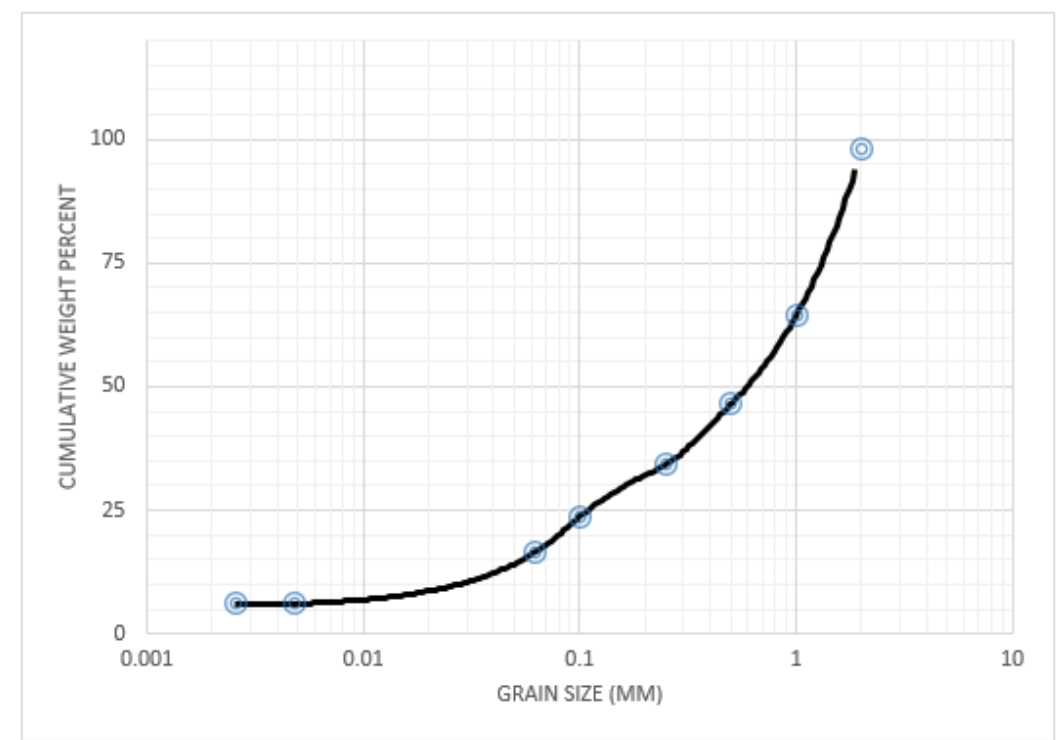

Figure G.18: Particle size distribution for sediments from 20-24 ft interval of EB-3.

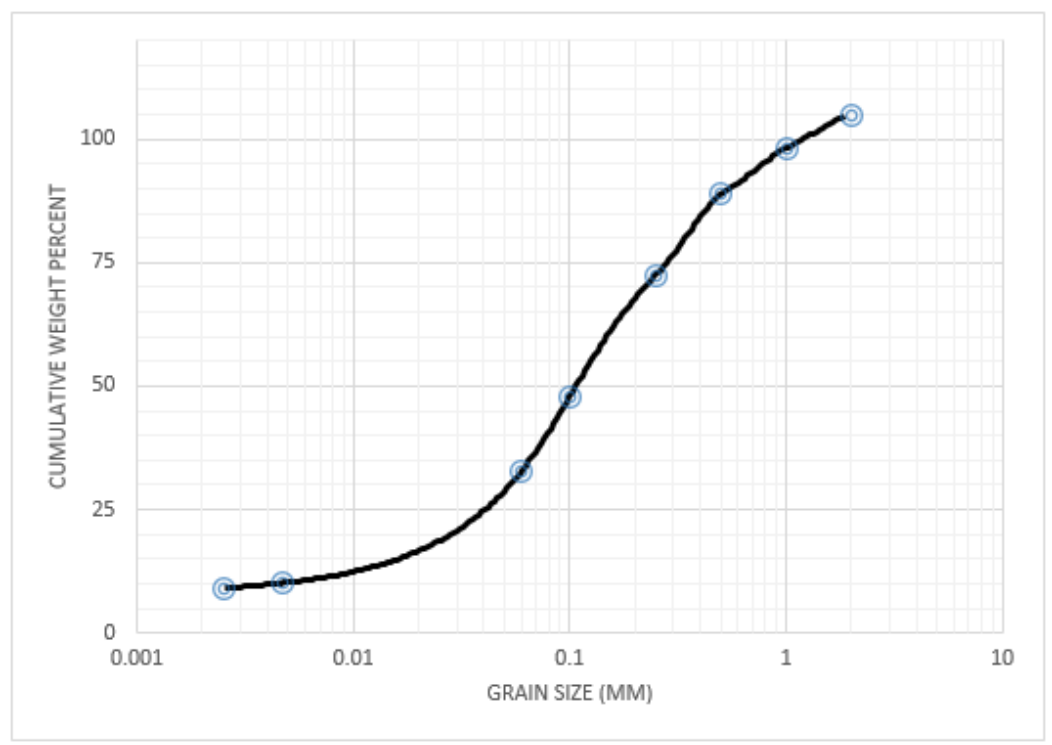

Figure G.19: Particle size distribution for sediments from 0-2 ft interval of EB-4. 


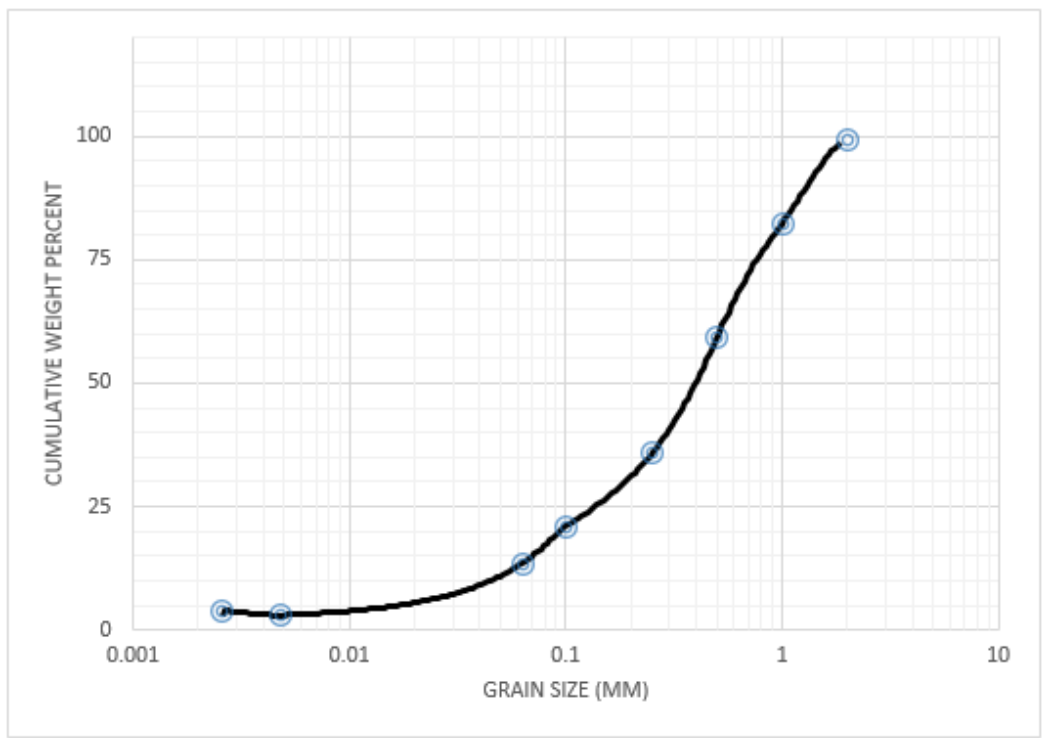

Figure G.20: Particle size distribution for sediments from 2-4 ft interval of EB-4.

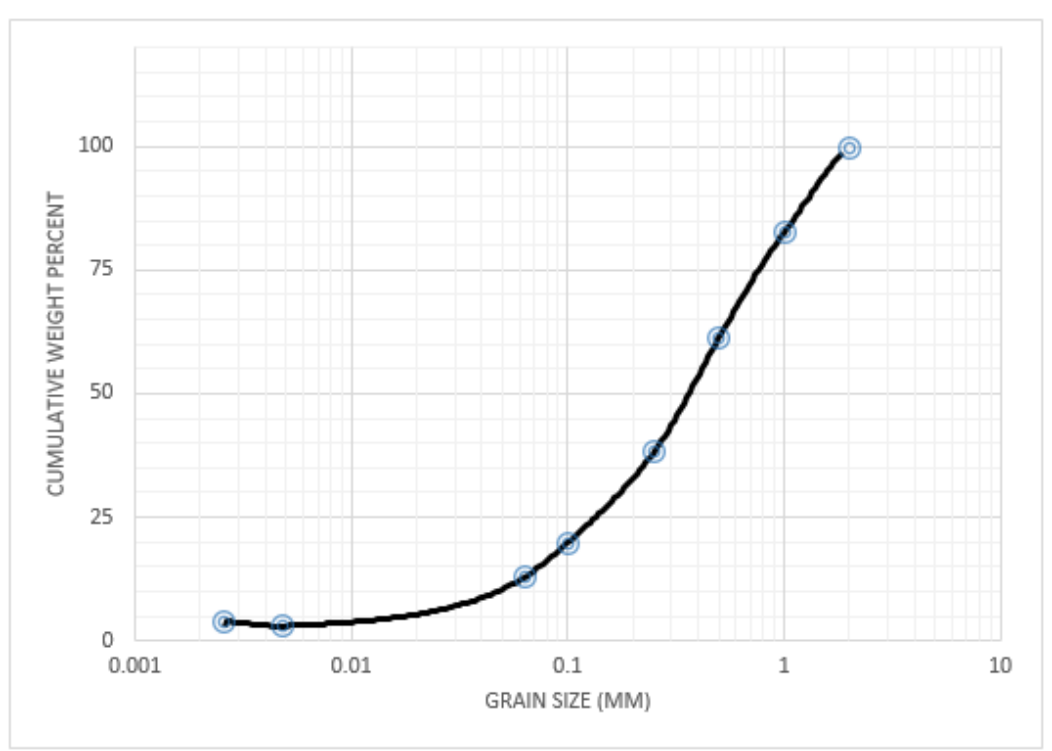

Figure G.21: Particle size distribution for sediments from 4-8 ft interval of EB-4. 


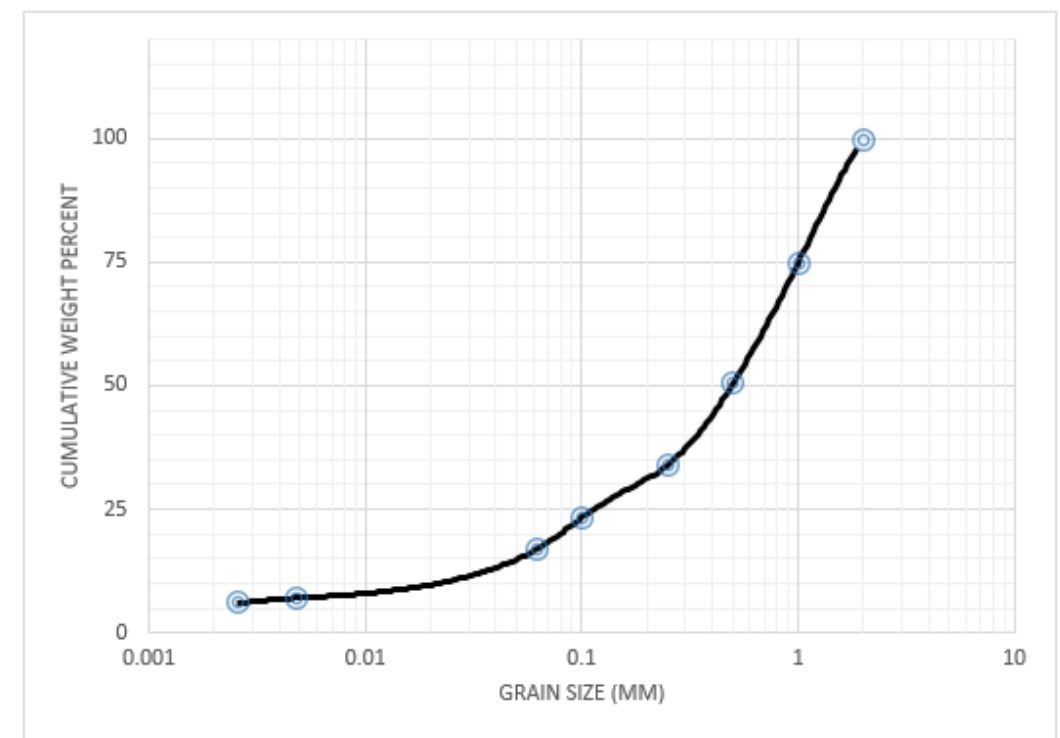

Figure G.22: Particle size distribution for sediments from 8-12 ft interval of EB-4.

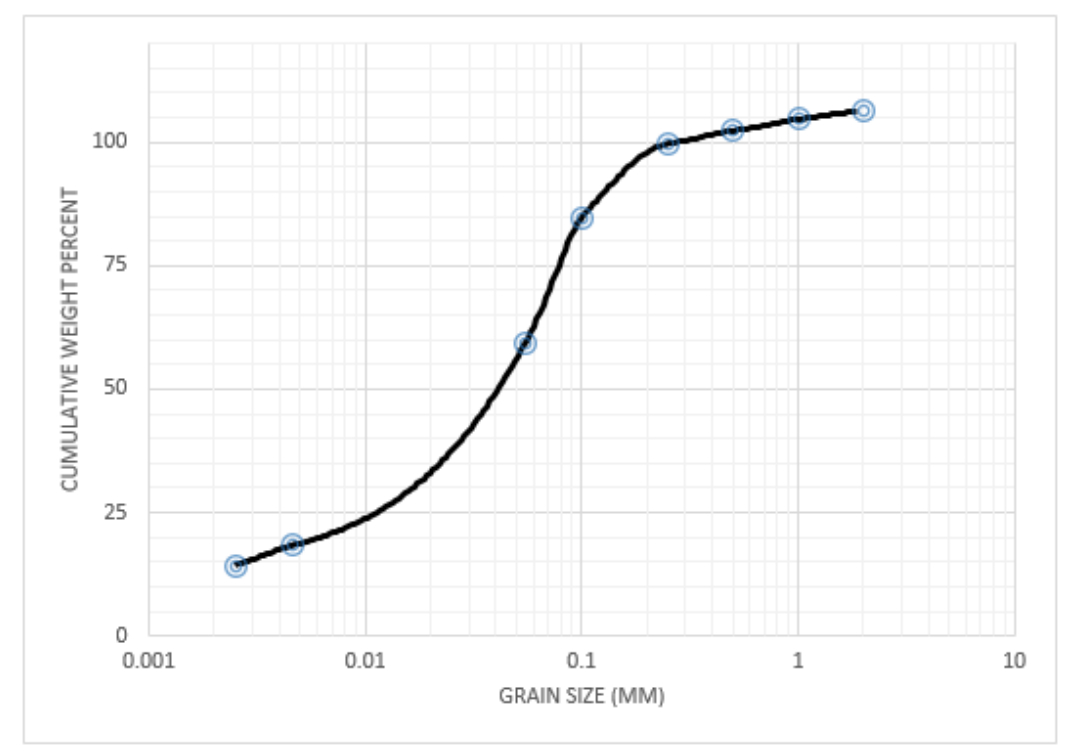

Figure G.23: Particle size distribution for sediments from 16-19 ft interval of EB-4. 


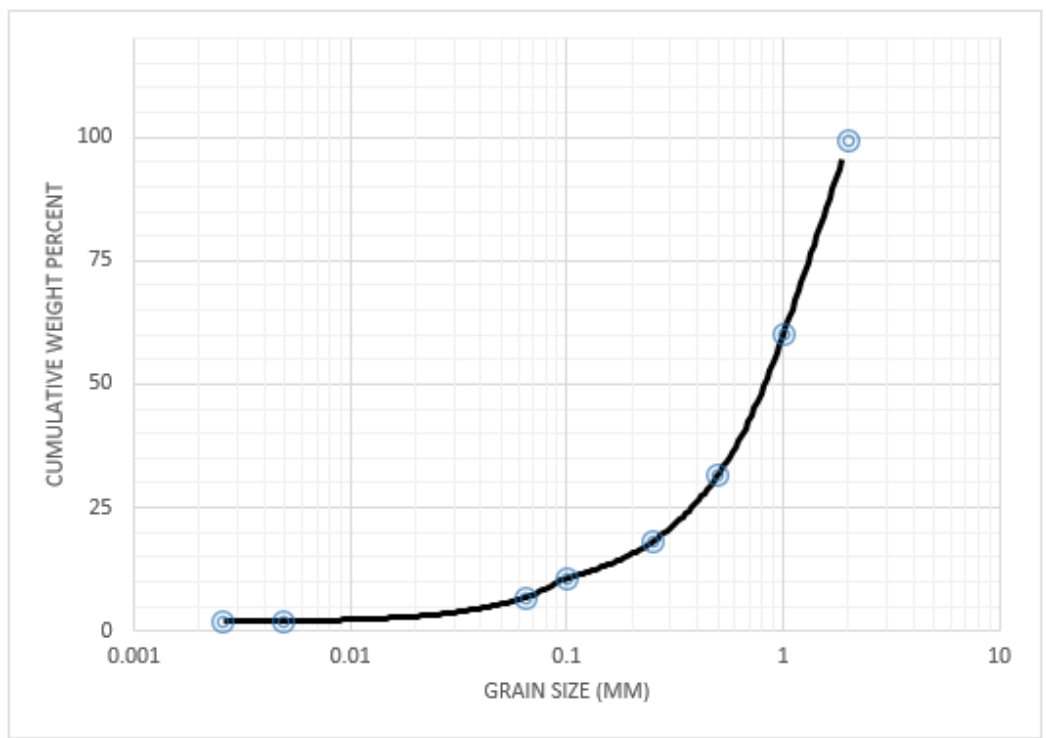

Figure G.24: Particle size distribution for sediments from 19-20 ft interval of EB-4.

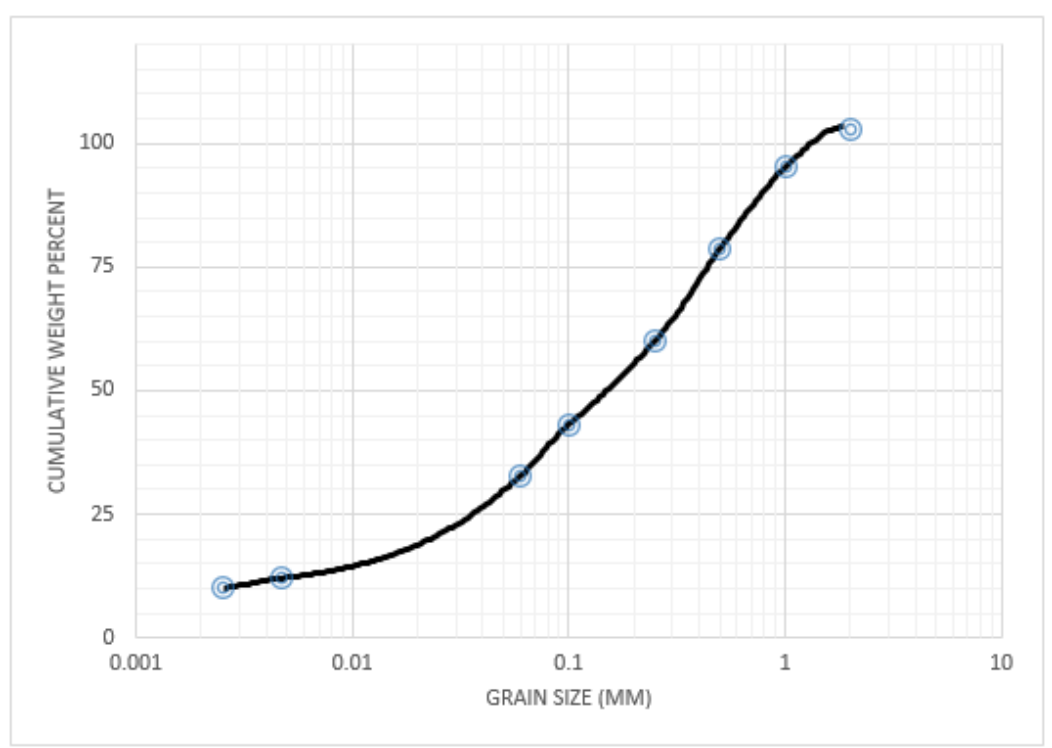

Figure G.25: Particle size distribution for sediments from 20-22 ft interval of EB-4. 


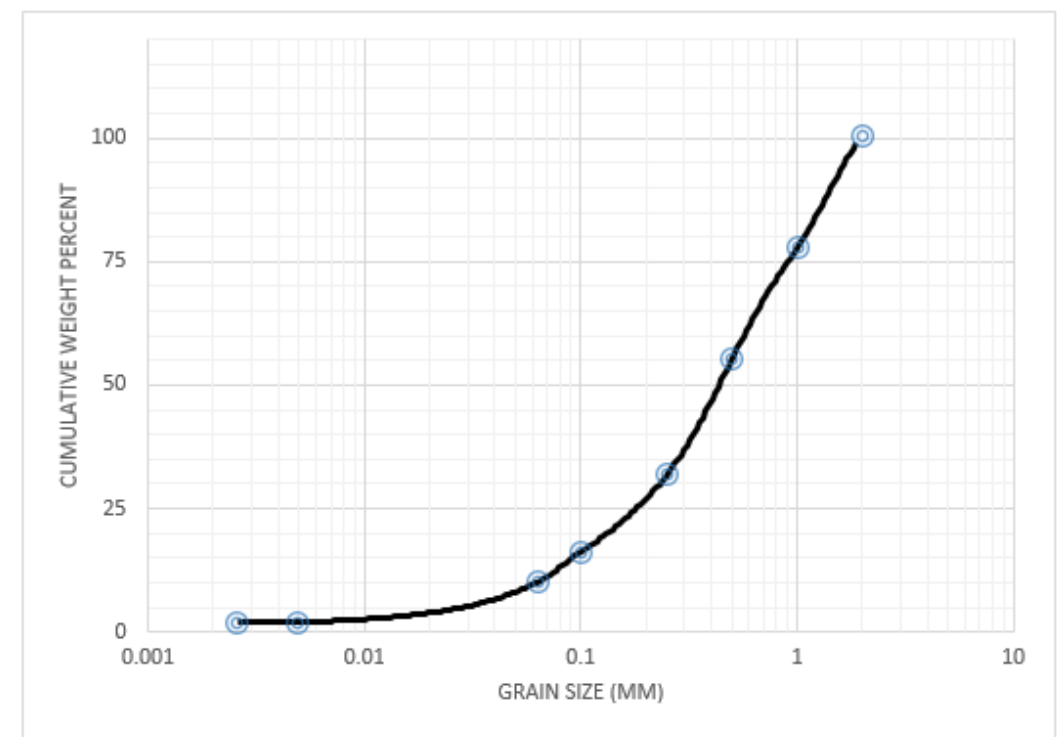

Figure G.26: Particle size distribution for sediments from 22-24 ft interval of EB-4. 


\section{APPENDIX H: CALCULATION OF STREAMFLOW DEPLETION}

Table H.1: Scenario 1 estimated rates of stream depletion $\left(Q_{r}\right)$ at various times since pumping began $(t)$ and at different well discharge rates $(Q)$ obtained using the Hantush (1965) solution for flow to wells near streams with semipervious beds.

\begin{tabular}{cccccc}
\hline Time (hrs) & \multicolumn{5}{c}{$Q_{r}\left(\mathrm{~m}^{3} / \mathrm{s}\right)$} \\
\hline & $\mathrm{Q}=100 \mathrm{gpm}$ & $\mathrm{Q}=150 \mathrm{gpm}$ & $\mathrm{Q}=200 \mathrm{gpm}$ & $\mathrm{Q}=250 \mathrm{gpm}$ & $\mathrm{Q}=300 \mathrm{gpm}$ \\
\hline 2 & $3.89 \times 10^{-4}$ & $5.84 \times 10^{-4}$ & $7.79 \times 10^{-4}$ & $9.73 \times 10^{-4}$ & $1.17 \times 10^{-3}$ \\
4 & $7.94 \times 10^{-4}$ & $1.19 \times 10^{-3}$ & $1.59 \times 10^{-3}$ & $1.98 \times 10^{-3}$ & $2.38 \times 10^{-3}$ \\
6 & $1.04 \times 10^{-3}$ & $1.56 \times 10^{-3}$ & $2.08 \times 10^{-3}$ & $2.60 \times 10^{-3}$ & $3.13 \times 10^{-3}$ \\
8 & $1.23 \times 10^{-3}$ & $1.84 \times 10^{-3}$ & $2.46 \times 10^{-3}$ & $3.07 \times 10^{-3}$ & $3.69 \times 10^{-3}$ \\
10 & $1.38 \times 10^{-3}$ & $2.07 \times 10^{-3}$ & $2.76 \times 10^{-3}$ & $3.45 \times 10^{-3}$ & $4.14 \times 10^{-3}$ \\
12 & $1.51 \times 10^{-3}$ & $2.26 \times 10^{-3}$ & $3.02 \times 10^{-3}$ & $3.77 \times 10^{-3}$ & $4.53 \times 10^{-3}$ \\
14 & $1.62 \times 10^{-3}$ & $2.43 \times 10^{-3}$ & $3.24 \times 10^{-3}$ & $4.06 \times 10^{-3}$ & $4.87 \times 10^{-3}$ \\
16 & $1.72 \times 10^{-3}$ & $2.58 \times 10^{-3}$ & $3.45 \times 10^{-3}$ & $4.31 \times 10^{-3}$ & $5.17 \times 10^{-3}$ \\
18 & $1.81 \times 10^{-3}$ & $2.72 \times 10^{-3}$ & $3.63 \times 10^{-3}$ & $4.53 \times 10^{-3}$ & $5.44 \times 10^{-3}$ \\
20 & $1.90 \times 10^{-3}$ & $2.85 \times 10^{-3}$ & $3.79 \times 10^{-3}$ & $4.74 \times 10^{-3}$ & $5.69 \times 10^{-3}$ \\
22 & $1.97 \times 10^{-3}$ & $2.96 \times 10^{-3}$ & $3.95 \times 10^{-3}$ & $4.93 \times 10^{-3}$ & $5.92 \times 10^{-3}$ \\
24 & $2.04 \times 10^{-3}$ & $3.07 \times 10^{-3}$ & $4.09 \times 10^{-3}$ & $5.11 \times 10^{-3}$ & $6.13 \times 10^{-3}$ \\
\hline
\end{tabular}


Table H.2: Scenario 2 estimated rates of stream depletion $\left(Q_{r}\right)$ at various times since pumping began $(t)$ and at different well discharge rates $(Q)$ obtained using the Hantush (1965) solution for flow to wells near streams with semipervious beds.

\begin{tabular}{cccccc}
\hline Time (hrs) & \multicolumn{5}{c}{$Q_{r}\left(\mathrm{~m}^{3} / \mathrm{s}\right)$} \\
\hline & $\mathrm{Q}=100 \mathrm{gpm}$ & $\mathrm{Q}=150 \mathrm{gpm}$ & $\mathrm{Q}=200 \mathrm{gpm}$ & $\mathrm{Q}=250 \mathrm{gpm}$ & $\mathrm{Q}=300 \mathrm{gpm}$ \\
\hline 2 & $3.72 \times 10^{-6}$ & $5.57 \times 10^{-6}$ & $7.43 \times 10^{-6}$ & $9.29 \times 10^{-6}$ & $1.11 \times 10^{-5}$ \\
4 & $2.47 \times 10^{-4}$ & $3.70 \times 10^{-4}$ & $4.94 \times 10^{-4}$ & $6.17 \times 10^{-4}$ & $7.41 \times 10^{-4}$ \\
6 & $3.82 \times 10^{-4}$ & $5.73 \times 10^{-4}$ & $7.64 \times 10^{-4}$ & $9.56 \times 10^{-4}$ & $1.15 \times 10^{-3}$ \\
8 & $4.81 \times 10^{-4}$ & $7.22 \times 10^{-4}$ & $9.62 \times 10^{-4}$ & $1.20 \times 10^{-3}$ & $1.44 \times 10^{-3}$ \\
10 & $5.61 \times 10^{-4}$ & $8.42 \times 10^{-4}$ & $1.12 \times 10^{-3}$ & $1.40 \times 10^{-3}$ & $1.68 \times 10^{-3}$ \\
12 & $6.30 \times 10^{-4}$ & $9.44 \times 10^{-4}$ & $1.26 \times 10^{-3}$ & $1.57 \times 10^{-3}$ & $1.89 \times 10^{-3}$ \\
14 & $6.90 \times 10^{-4}$ & $1.03 \times 10^{-3}$ & $1.38 \times 10^{-3}$ & $1.72 \times 10^{-3}$ & $2.07 \times 10^{-3}$ \\
16 & $7.44 \times 10^{-4}$ & $1.12 \times 10^{-3}$ & $1.49 \times 10^{-3}$ & $1.86 \times 10^{-3}$ & $2.23 \times 10^{-3}$ \\
18 & $7.94 \times 10^{-4}$ & $1.19 \times 10^{-3}$ & $1.59 \times 10^{-3}$ & $1.99 \times 10^{-3}$ & $2.38 \times 10^{-3}$ \\
20 & $8.40 \times 10^{-4}$ & $1.26 \times 10^{-3}$ & $1.68 \times 10^{-3}$ & $2.10 \times 10^{-3}$ & $2.52 \times 10^{-3}$ \\
22 & $8.83 \times 10^{-4}$ & $1.32 \times 10^{-3}$ & $1.77 \times 10^{-3}$ & $2.21 \times 10^{-3}$ & $2.65 \times 10^{-3}$ \\
24 & $9.23 \times 10^{-4}$ & $1.38 \times 10^{-3}$ & $1.85 \times 10^{-3}$ & $2.31 \times 10^{-3}$ & $2.77 \times 10^{-3}$ \\
\hline
\end{tabular}




\section{APPENDIX I: GROUNDWATER FLOW MODELING}

Table I.1: MODFLOW 2D scatter data for elevation (m) of model layers.

\begin{tabular}{|c|c|c|c|c|c|}
\hline Borehole & $\mathrm{X}$ & $\mathrm{Y}$ & bot1 & bot2 & bot3 \\
\hline EB-1 & 1846484.8974505 & 562242.88778882 & \multicolumn{3}{|c|}{$0.360343-0.858857-28.262857$} \\
\hline EB-2 & 1846412.6354671 & 562357.66068483 & \multicolumn{3}{|c|}{$-1.213414-4.261414-28.007814$} \\
\hline EB-3 & 1846435.5652811 & 562476.89329297 & 2.270769 & \multirow{2}{*}{\multicolumn{2}{|c|}{$\begin{array}{l}1.051569-26.962031 \\
1735252-26278348\end{array}$}} \\
\hline EB-4 & $1846431.7514 !$ & 562573.97578043 & 2.344852 & & \\
\hline EB-5 & 1846559.6700073 & 562311.4859959 & 1.544547 & \multicolumn{2}{|c|}{$-5.770653-27.078653$} \\
\hline EB-6 & 1846506.0627112 & 562683.03281227 & 0.599892 & \multicolumn{2}{|c|}{$0.599892-25.584908$} \\
\hline EB-7 & 1846548.9795847 & 562651.61419891 & 8.484949 & \multicolumn{2}{|c|}{$3.912949-24.710251$} \\
\hline EB-8 & 1846597.4959423 & 562290.052609 & \multicolumn{3}{|c|}{$1.797041-3.079759-26.826159$} \\
\hline
\end{tabular}

Table I.2: MODFLOW 2D scatter data for elevation (m) of water table.

\begin{tabular}{clll}
\hline Piezometer & \multicolumn{1}{c}{ X } & \multicolumn{1}{c}{$\mathrm{Y}$} & \multicolumn{1}{c}{$\mathrm{Z}$} \\
\hline PHP-3 & 1846438.4410113 & 562519.70379415 & 4.867656 \\
PHP-4 & 1846423.267731 & 562527.7844153 & 4.898136 \\
PHP-1 & 1846445.1053006 & 562542.02714898 & 5.026152 \\
PHP-5 & 1846428.3160519 & 562595.12271432 & 5.772912 \\
PHP-2 & 1846447.2244085 & 562486.76661472 & 4.803648 \\
VFDP-4 & 1846421.0236335 & 562363.30253091 & 3.883152 \\
VFDP-1 & 1846425.6926812 & 562292.20850868 & 4.029456 \\
VFDP-2 & 1846428.9456085 & 562274.29629984 & 3.965448 \\
VFDP-3 & 1846415.0956123 & 562265.70295324 & 3.93192 \\
AP-1 & 1846548.9795847 & 562651.61419891 & 7.888224 \\
JFP-1 & 1846559.6700073 & 562311.4859959 & 3.727704 \\
JFP-2 & 1846506.0627112 & 562683.03281227 & 5.696712 \\
JFP-3 & 1846597.4959423 & 562290.052609 & 4.047744 \\
\hline
\end{tabular}


Table I.3: MODFLOW 2D scatter data for hydraulic conductivity (m/d) of layer 1.

\begin{tabular}{cclc}
\hline Borehole & \multicolumn{1}{c}{ X } & \multicolumn{1}{c}{ Y } & \multicolumn{1}{c}{$K$} \\
\hline EB-1 & 1846484.8974505 & 562242.88778882 & 0.32366 \\
EB-2 & 1846412.6354671 & 562357.66068483 & 0.26680 \\
EB-3 & 1846435.5652811 & 562476.89329297 & 0.57920 \\
EB-4 & 1846431.7514925 & 562573.97578043 & 0.23867 \\
EB-5 & 1846559.6700073 & 562311.4859959 & 0.48400 \\
EB-6 & 1846506.0627112 & 562683.03281227 & 0.17058 \\
\hline
\end{tabular}

Table I.4: MODFLOW 2D scatter data for hydraulic conductivity (m/d) of layer 2.

\begin{tabular}{cclc}
\hline Borehole & \multicolumn{1}{c}{ X } & \multicolumn{1}{c}{ Y } & $K$ \\
\hline EB-1 & 1846484.8974505 & 562242.88778882 & 0.15880 \\
EB-2 & 1846412.6354671 & 562357.66068483 & 0.06092 \\
EB-3 & 1846435.5652811 & 562476.89329297 & 0.20898 \\
EB-4 & 1846431.7514925 & 562573.97578043 & 0.02771 \\
EB-5 & 1846559.6700073 & 562311.4859959 & 0.02437 \\
EB-8 & 1846597.4959423 & 562290.052609 & 0.00496 \\
\hline
\end{tabular}

\begin{tabular}{|l|l|l|}
\hline & How In & How Out \\
\hline Sources/Sinks & & \\
\hline STORAGE & 389.11743164063 & -54.93821716309 \\
\hline CONSTANT HEAD & 0.0 & 0.0 \\
\hline WELLS & 0.0 & -1.387 .342285156 \\
\hline RIVER LEAKAGE & 541.29598189198 & -321.4871800572 \\
\hline HEAD DEP BOUNDS & 960.30240442604 & -126.9389588721 \\
\hline Total Source/Sink & $\mathbf{1 . 8 9 0 . 7 1 5 8 1 7 9 5 8 6}$ & $\mathbf{- 1 . 8 9 0 . 7 0 6 6 4 1 2 4 9}$ \\
\hline Zone How & & \\
\hline FLOW RIGHT FACE & 0.0 & 0.0 \\
\hline FLOW FRONT FACE & 0.0 & 0.0 \\
\hline FLOW LOWER FACE & 0.0 & 0.0 \\
\hline FLOW LEFT FACE & 0.0 & 0.0 \\
\hline FLOW UPPER FACE & 0.0 & 0.0 \\
\hline FLOW BACK FACE & 0.0 & 0.0 \\
\hline Total Zone How & $\mathbf{0 . 0}$ & $\mathbf{0 . 0}$ \\
\hline TOTAL FLOW & $\mathbf{1 . 8 9 0 . 7 1 5 8 1 7 9 5 8 6}$ & $\mathbf{- 1 . 8 9 0 . 7 0 6 6 4 1 2 4 9}$ \\
\hline Summary & In - Out & \% difference \\
\hline Sources/Sinks & $\mathbf{0 . 0 0 9 1 7 6 7 1 0 0 3 1 2}$ & $\mathbf{0 . 0 0 0 4 8 5 3 5 7 5 6 7 4}$ \\
\hline Cell To Cell & $\mathbf{0 . 0}$ & $\mathbf{0 . 0}$ \\
\hline Total & $\mathbf{0 . 0 0 9 1 7 6 7 1 0 0 3 1 2}$ & $\mathbf{0 . 0 0 0 4 8 5 3 5 7 5 6 7 4}$ \\
\hline
\end{tabular}

Figure I.1: Flow budget data $\left(\mathrm{m}^{3} / \mathrm{d}\right)$ for simulation of groundwater withdrawal from the Pump House Well. 


\begin{tabular}{|l|l|l|}
\hline & How In & How Out \\
\hline Sources/Sinks & & \\
\hline STORAGE & 628.36396026611 & -94.09713745117 \\
\hline CONSTANT HEAD & 0.0 & 0.0 \\
\hline WELLS & 0.0 & -1.383 .128662109 \\
\hline RIVER LEAKAGE & 357.48141856608 & -423.3539431053 \\
\hline HEAD DEP BOUNDS & 992.48900902644 & -77.86821567826 \\
\hline Total Source/Sink & $\mathbf{1 . 9 7 8 . 3 3 4 3 8 7 8 5 8 6}$ & $\mathbf{- 1 . 9 7 8 . 4 4 7 9 5 8 3 4 4}$ \\
\hline Zone How & & \\
\hline FLOW RIGHT FACE & 0.0 & 0.0 \\
\hline FLOW FRONT FACE & 0.0 & 0.0 \\
\hline FLOW LOWER FACE & $\mathbf{0 . 0}$ & $\mathbf{0 . 0}$ \\
\hline FLOW LEFT FACE & 0.0 & $\mathbf{0 . 0}$ \\
\hline FLOW UPPER FACE & 0.0 & $\mathbf{0 . 0}$ \\
\hline FLOW BACK FACE & 0.0 & 0.0 \\
\hline Total Zone Fow & $\mathbf{0 . 0}$ & $\mathbf{0 . 0}$ \\
\hline TOTAL FLOW & $\mathbf{1 . 9 7 8 . 3 3 4 3 8 7 8 5 8 6}$ & $\mathbf{- 1 . 9 7 8 . 4 4 7 9 5 8 3 4 4}$ \\
\hline Summary & $\mathbf{l n}-\mathbf{O u t}$ & $\boldsymbol{\%}$ difference \\
\hline Sources/Sinks & $\mathbf{- 0 . 1 1 3 5 7 0 4 8 5 4 9 7}$ & $\mathbf{- 0 . 0 0 5 7 4 0 5 4 7 5 2 4}$ \\
\hline Cell To Cell & $\mathbf{0 . 0}$ & $\mathbf{0 . 0}$ \\
\hline Total & $\mathbf{- 0 . 1 1 3 5 7 0 4 8 5 4 9 7}$ & $\mathbf{- 0 . 0 0 5 7 4 0 5 4 7 5 2 4}$ \\
\hline
\end{tabular}

Figure I.2: Flow budget data $\left(\mathrm{m}^{3} / \mathrm{d}\right)$ for simulation of groundwater withdrawal from the VFD Well.

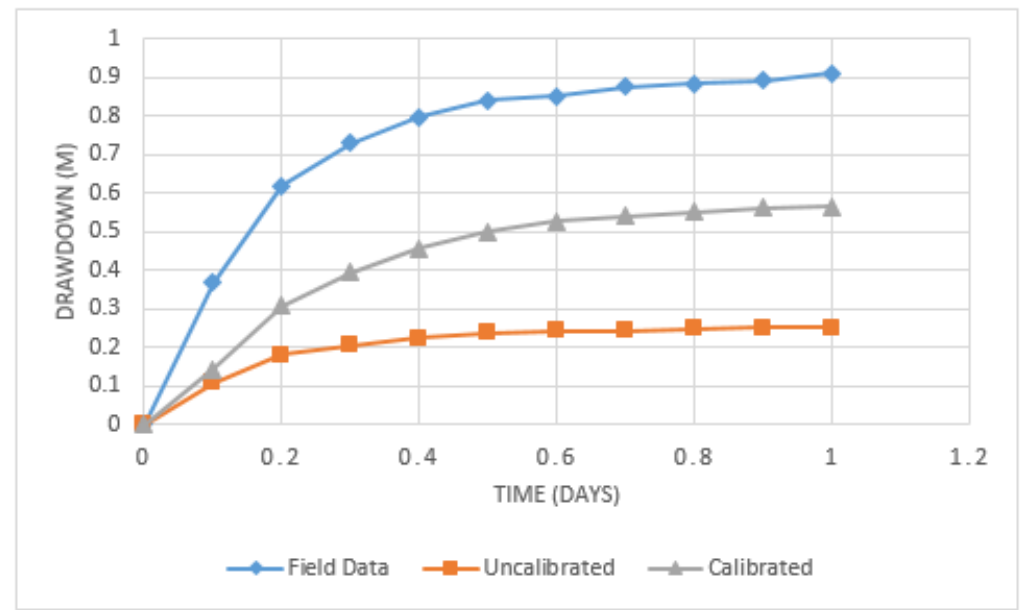

Figure I.3: Comparison of field drawdown data to uncalibrated and calibrated model generated drawdown data for the VFD Well (observation well) during the Pump House Well pumping test. 


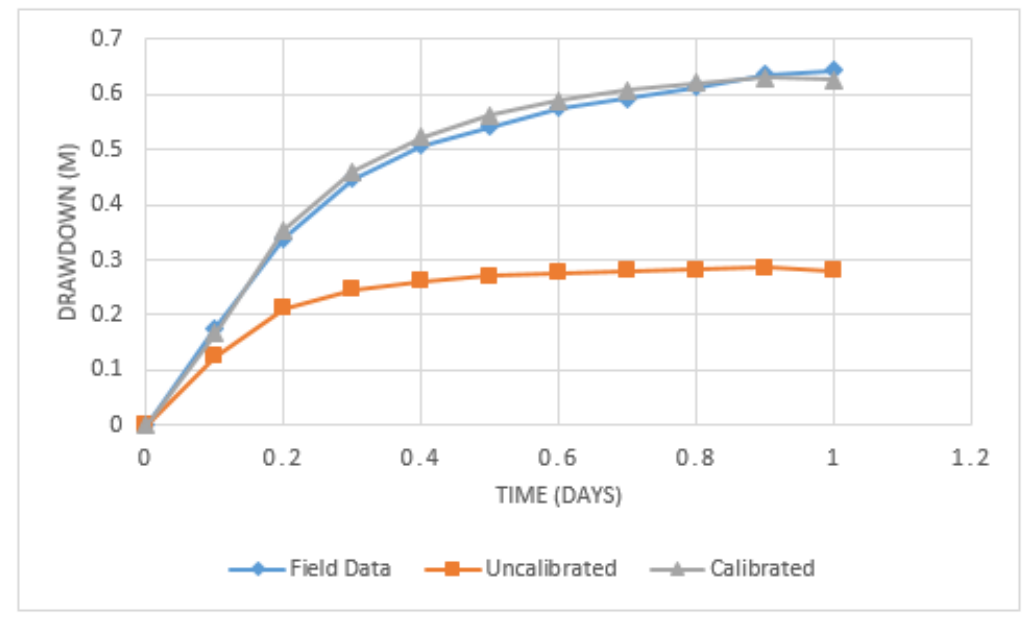

Figure I.4: Comparison of field drawdown data to uncalibrated and calibrated model generated drawdown data for the Pump House Well (observation well) during the VFD Well pumping test.

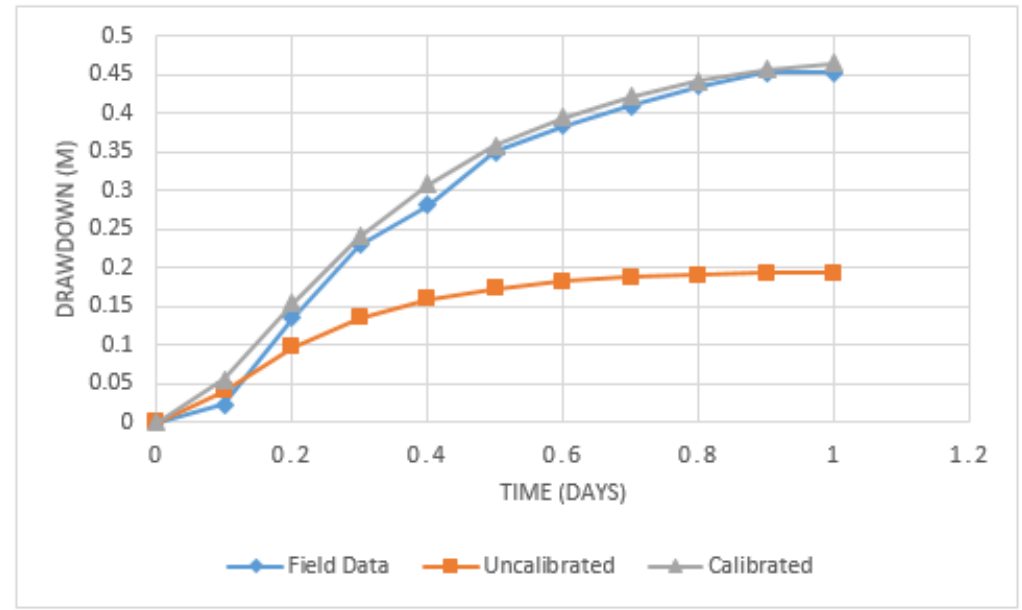

Figure I.5: Comparison of field drawdown data to uncalibrated and calibrated model generated drawdown data for the Queseria Well (observation well) during the VFD Well pumping test. 


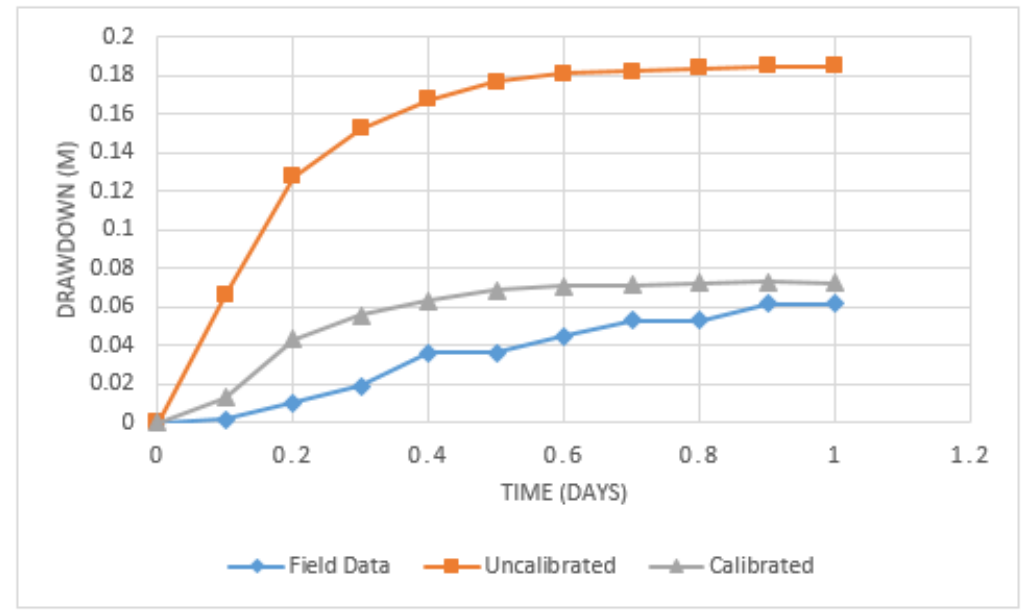

Figure I.6: Comparison of field drawdown data to uncalibrated and calibrated model generated drawdown data for the Archibald Well (observation well) during the Pump House Well pumping test. 


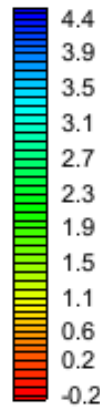
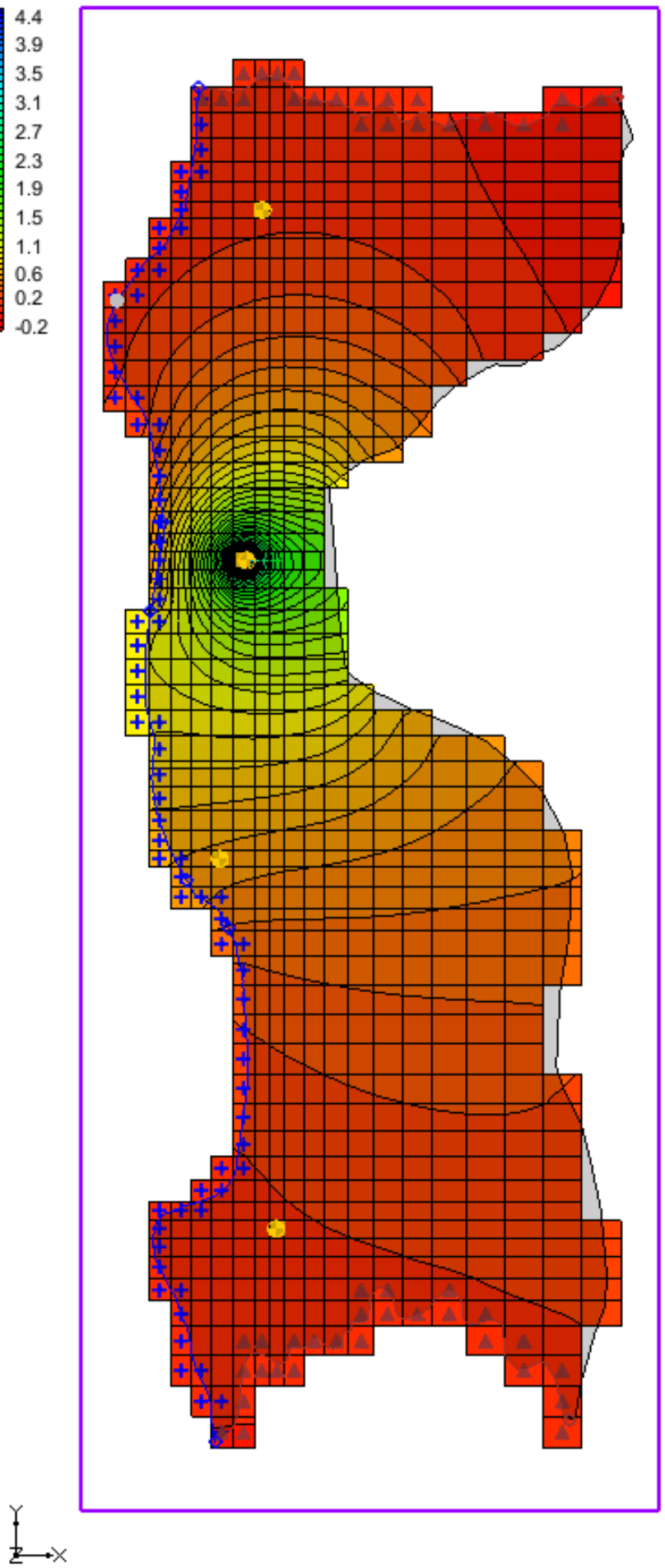

Figure I.7: Layer 3 drawdown contours (m) for the last time step when the Pump House Well is pumped. 


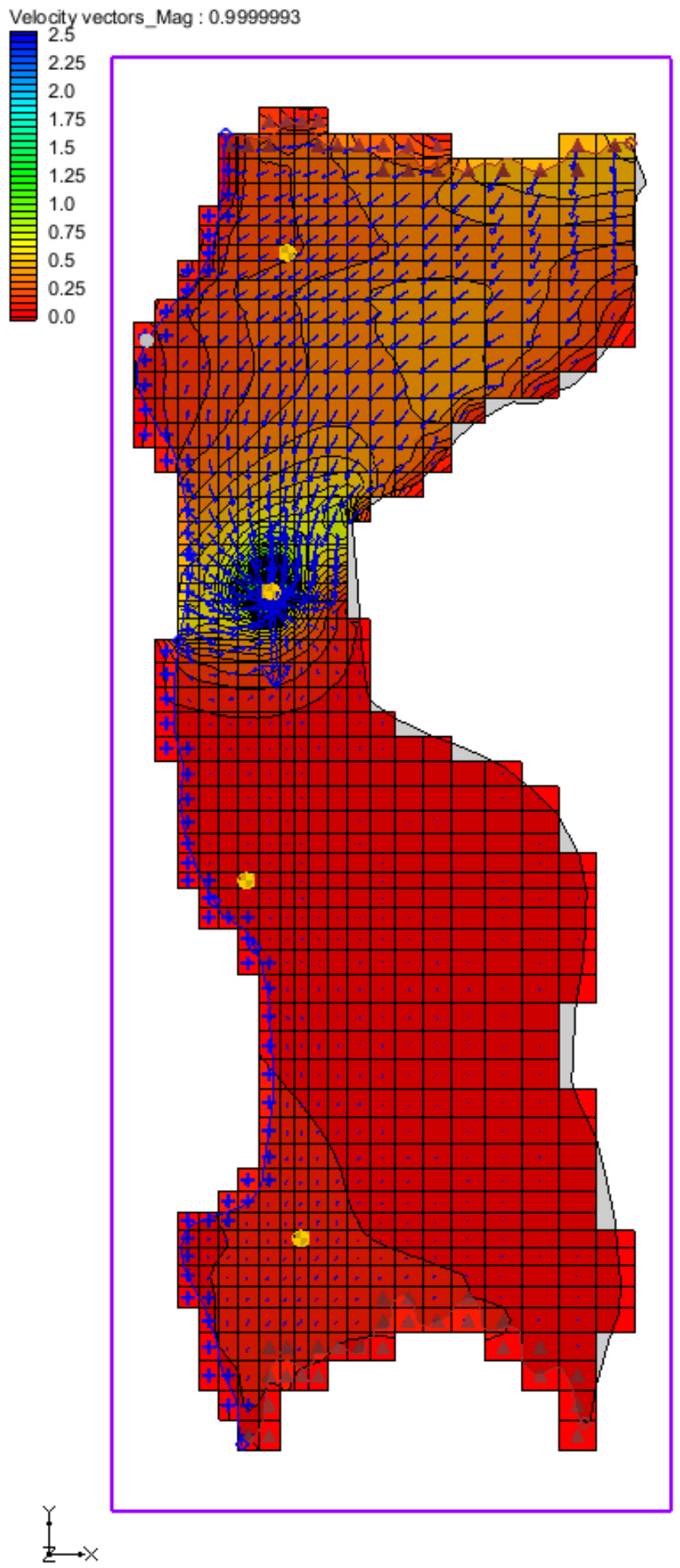

Figure I.8: Layer 3 velocity vectors for the last time step when the Pump House Well is pumped. 


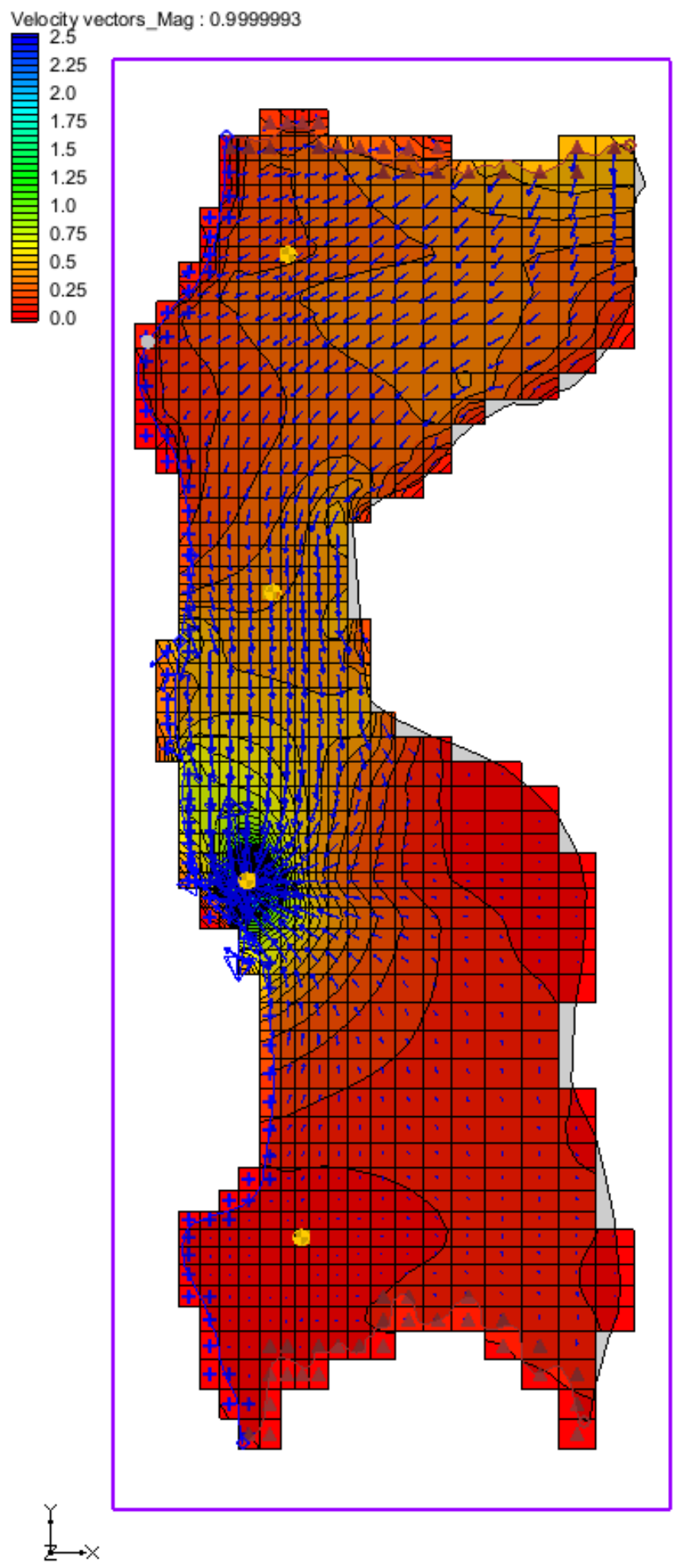

Figure I.9: Layer 3 velocity vectors for the last time step when the VFD Well is pumped. 